\title{
The influence of underwater embankment properties on breaching failures
}

\author{
Joana Silva
}

UTRECHT STUDIES IN EARTH SCIENCES

Mededelingen van de

Faculteit Geowetenschappen

Universiteit Utrecht

No. 218 
Members of the dissertation committee:

Dr. E.T. Bowman

Department of Civil and Structural Engineering, The University of Sheffield

Sheffield, UK

Prof. dr. M.G. Kleinhans

Department of Physical Geography, Utrecht University

Utrecht, The Netherlands

Prof. dr. D. Mohrig

Jackson School of Geosciences, University of Texas at Austin

Austin, Texas, USA

Prof. dr. W.S.J. Uijttewaal

Faculty of Civil Engineering and Geosciences, Delft University of Technology

Delft, The Netherlands

Dr. P.J. Vardon

Faculty of Civil Engineering and Geosciences, Delft University of Technology

Delft, The Netherlands

The research was carried out at the Sedimentology Research Group, Department of Earth Sciences, Faculty of Geoscience, Utrecht University.

ISBN 978-90-6266-582-2

Utrecht Studies in Earth Science No. 218

Photo in the cover: Partial dike collapse following a flow slide event at OudKempenshofstedepolder, 4 October 1968, photographer: C. Kotvis, ZB| Beeldbank Zeeland, record nr. 6890

Copyright (C) Joana Silva, Faculty of Geoscience, Utrecht University, 2020

All rights reserved. No part of this publication may be reproduced in any form, by print or photo print, microfilm or any other means, without written permission by the author. 


\title{
The influence of underwater embankment properties on breaching failures
}

\section{De invloed van de opbouw van onderwatertaluds op taludvervloeiing}

(met een samenvatting in het Nederlands)

\begin{abstract}
Proefschrift
ter verkrijging van de graad van doctor aan de Universiteit Utrecht op gezag van de rector magnificus, prof.dr. H.R.B.M. Kummeling, ingevolge het besluit van het college voor promoties in het openbaar te verdedigen op vrijdag 28 augustus 2020 des middags te 4.15 uur
\end{abstract}

door

Joana Rita Carvalho Henriques da Silva

geboren op 24 juni 1989

te Lissabon, Portugal 


\section{Promotor:}

Prof. dr. J.B.M. Middelburg

\section{Copromotoren:}
Dr. J.T. Eggenhuisen
Dr. J.P. Trabucho Alexandre

This study was conducted as a part of the MPM-Flow project "Understanding flow slides in flood defences".

This project was accomplished with financial support from the Netherlands Organisation for Scientific Research (NWO) (grant number 13889).

Additional support was granted by Deltares, Rijkswaterstaat, Van Oord, Boskalis, and FloodControl IJkdijk. 


\section{Table of contents}

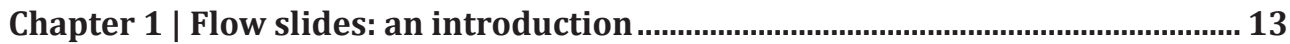

1.1 Flow slides.................................................................................................................... 14

1.2 Two types of flow slides .............................................................................................. 17

1.2.1 Liquefaction flow slides .................................................................................... 17

1.2.2 Case histories of liquefaction flow slides ..................................................... 21

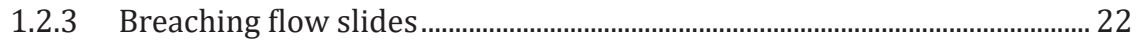

1.2.4 Case histories of breaching flow slides ........................................................ 25

1.3 Aim, approach, and objectives of this thesis............................................................... 30

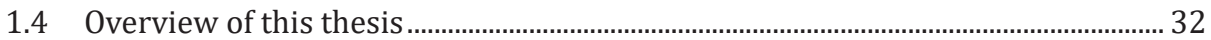

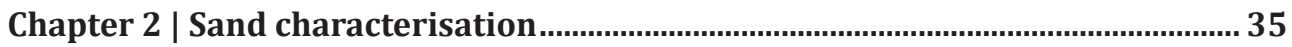

2.1 Introduction...................................................................................................................

2.2 Physical characterisation ......................................................................................... 37

2.2.1 Grain-size distribution ............................................................................... 37

2.2.2 Minimum and maximum porosity................................................................. 38

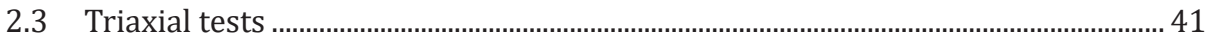

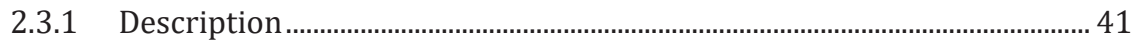

2.3.2 Procedure ................................................................................................................ 41

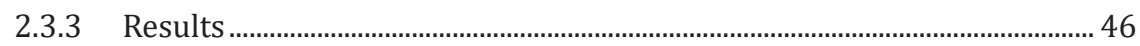

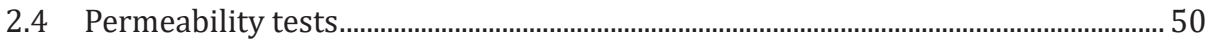

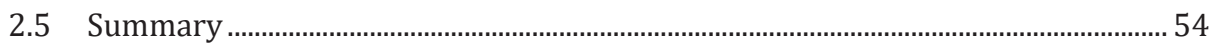

Chapter 3 | Hybrid dilative-contractive behaviour in underwater flow slides ... 57

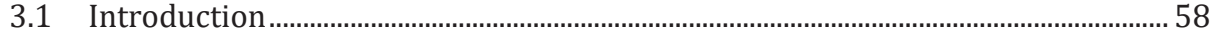

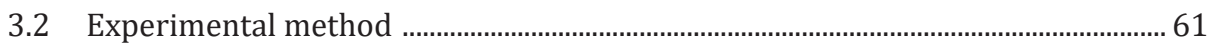

3.2.1 Experimental setup and materials.................................................................... 61

3.2.2 Data acquisition............................................................................................... 62

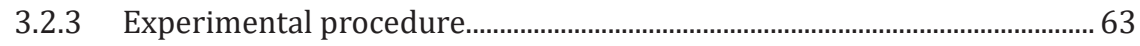

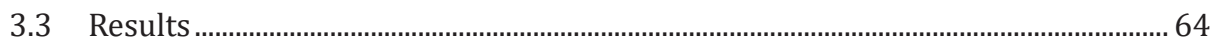

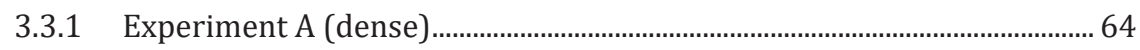

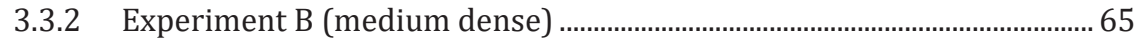

3.3.3 Experiment C (intermediate) ……………………………………………………... 66 


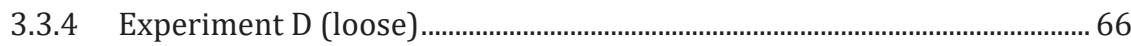

3.3.5 Summary of the results..................................................................................... 67

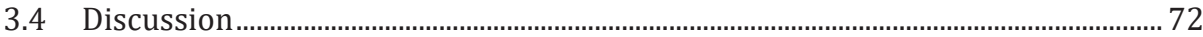

3.4.1 Influence of initial embankment porosity on breach failure evolution 72

3.4.2 The influence of intermediate and high embankment porosities on failure

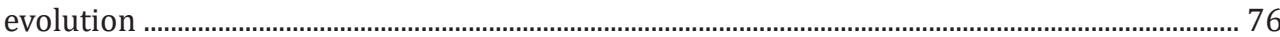

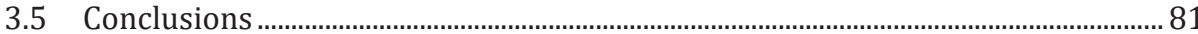

Chapter 4 | The influence of embankment heterogeneity on breaching failures 83

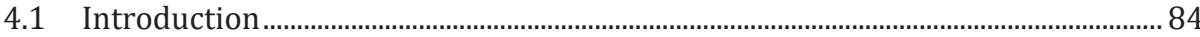

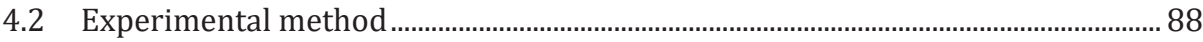

4.2.1 Experimental setup and materials ................................................................... 88

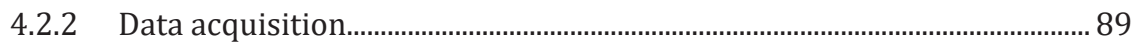

4.2.3 Experimental procedure ............................................................................. 89

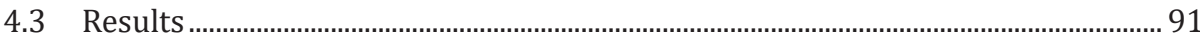

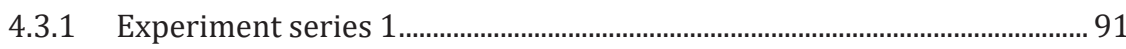

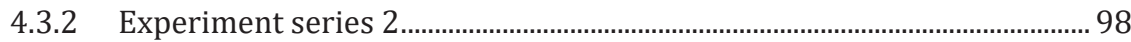

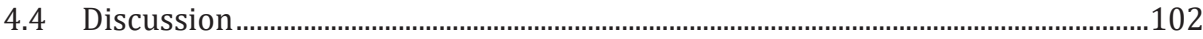

4.4.1 The effect of heterogeneity type on breach evolution (series 1)............102

4.4.2 Heterogeneities at different sand densities (series 2) ..............................103

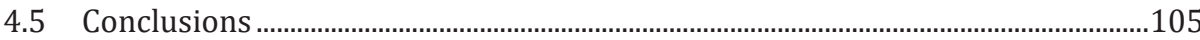

Chapter 5 | Coeval measurements of breaching failures and generated turbidity currents...............................................................................................................................................107

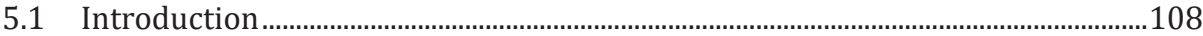

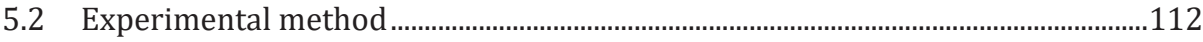

5.2.1 Experimental setup and materials ..............................................................112

5.2.2 Experimental procedure ...................................................................................113

5.2.3 UVP data acquisition and processing ..............................................................113

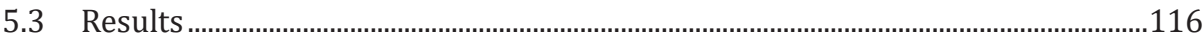

5.3.1 Erosion failure style..................................................................................... 117

5.3.2 Turbidity current velocities into the flume ...................................................119

5.3.3 Correlations between turbidity-current flow-rate, and occurrence of erosion and deposition in front of the failure .......................................................................... 120

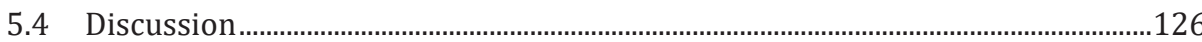

5.4.1 Correlation between breach evolution, turbidity current, erosion, and deposition 126 
5.4.2 Implications for recognising breach process influences in natural deposits 129

5.4 Conclusions 131

Chapter 6 | 3D breaching failure experiments...............................................133

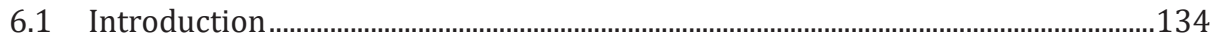

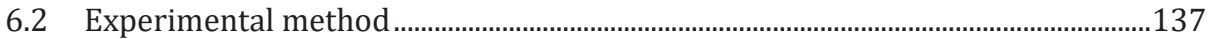

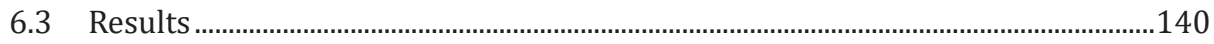

6.3.1 Pore pressure measurements ........................................................................140

6.3.2 Morphological characteristics....................................................................

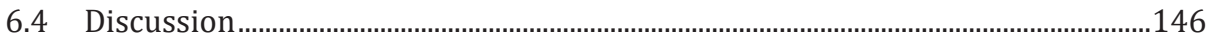

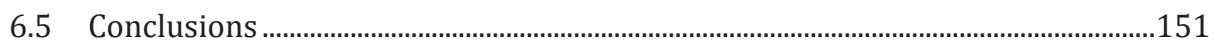

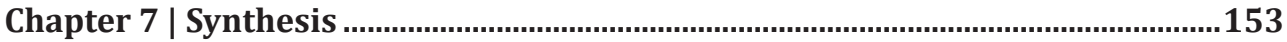

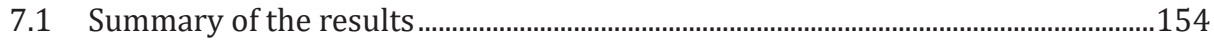

7.2 Implications of this study for the research field ........................................................156

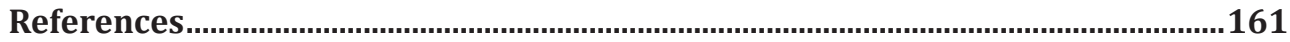

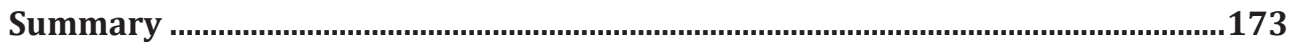

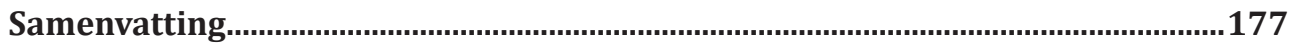

Acknowledgements........................................................................................................181

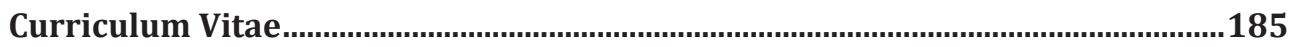

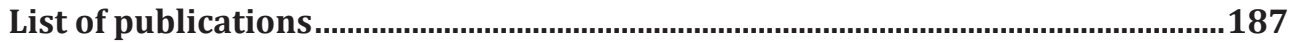





\section{List of symbols}

\begin{tabular}{|c|c|}
\hline A & Area \\
\hline $\mathrm{B}$ & Skempton's B-parameter \\
\hline $\mathrm{C}_{\mathrm{u}}$ & Coefficient of uniformity \\
\hline $\mathrm{C}_{\mathrm{c}}$ & Coefficient of curvature \\
\hline $\mathrm{CPT}$ & Cone Penetration Test \\
\hline$c$ & Cohesion of soil \\
\hline $\mathrm{D}_{\%}$ & Grain size of $\%$ percent passing (e.g., $30 \%, D_{30}$ \\
\hline $\mathrm{D}_{10}$ & Effective size \\
\hline $\mathrm{D}_{50}$ & Median grain size \\
\hline DEM & Digital Elevation Model \\
\hline$e$ & Void ratio \\
\hline$e_{\min } e_{\max }$ & Minimum, maximum void ratio \\
\hline$e_{c}$ & Critical void ratio \\
\hline$G_{s}$ & Specific gravity of solid particles \\
\hline$g$ & Acceleration of gravity \\
\hline$h$ & Pressure head \\
\hline$K$ & Hydraulic conductivity \\
\hline$k$ & Coefficient of permeability \\
\hline$L$ & Length \\
\hline$M_{s}$ & Sand mass \\
\hline MPM & Material Point Method \\
\hline$p^{\prime}$ & Mean effective stress \\
\hline$Q$ & Water discharge, average flow rate \\
\hline$q$ & Deviator stress \\
\hline$R D$ & Relative density \\
\hline$T_{\text {diss }}$ & Dissipation time \\
\hline$t_{\text {exp }}$ & Experimental time \\
\hline$t_{\text {num }}$ & Numerical time \\
\hline USCS & Unified Soil Classification System \\
\hline UVP & Ultrasonic Velocity Profiler \\
\hline$V$ & Total volume \\
\hline $\mathrm{z}$ & Depth from the ground surface \\
\hline
\end{tabular}




$\gamma_{\mathrm{sat}}$
$\gamma_{\mathrm{w}}$
$\triangle P$
$\Delta u$
$\Delta x$
$\Delta \eta$
$\Delta \sigma$
$\eta$
$\eta_{c}$
$\eta_{\min } \eta_{\max }$
$\mu$
$\rho_{s}$
$\rho_{d}$
$\rho_{f}$
$\rho_{d, \min } \rho_{d, \max }$
$\rho_{w}$
$\sigma$
$\sigma_{1^{\prime}} \sigma_{3}$
$\sigma_{c}^{\prime}$
$\tau$
$\varphi$

Saturated unit weight

Unit weight of water

Pressure difference

Change in pore pressure

Length difference

Dilatancy potential

Increment of the confining pressure

Porosity

Critical porosity

Minimum, maximum porosity

Dynamic viscosity

Density of sand

Density of soil in dry state

Density of fluid

Minimum, maximum dry density

Density of water

Normal stress

Major, minor principal stress

Confining pressures

Shear stress

Internal friction angle 
"Here comes the sun,

Here comes the sun, and I say It's all right"

The Beatles 

Chapter

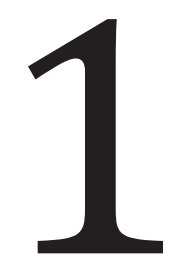

Flow slides: an introduction

"The beginning is the most important part of the work."

- Plato (428/427 BC-348/347 BC) 


\subsection{Flow slides}

In April 2017, people in a coffee shop in the town of Hong Ngu, in the Mekong Delta region of Vietnam, suddenly felt the ground beneath their feet disappear. The riverbank crumbled into the Tien River, the main branch of the Mekong River, taking with it not only the coffee shop, but also other shops, homes, and farm fields (Fig. 1.1). Fortunately, most of the residents were not at home during the event and nobody, not even the people in the coffee shop, were harmed. Afterwards, the witnesses reported that they had seen cracks along the riverbank, which were the telltale signs of the impeding collapse (Beiser, 2018).
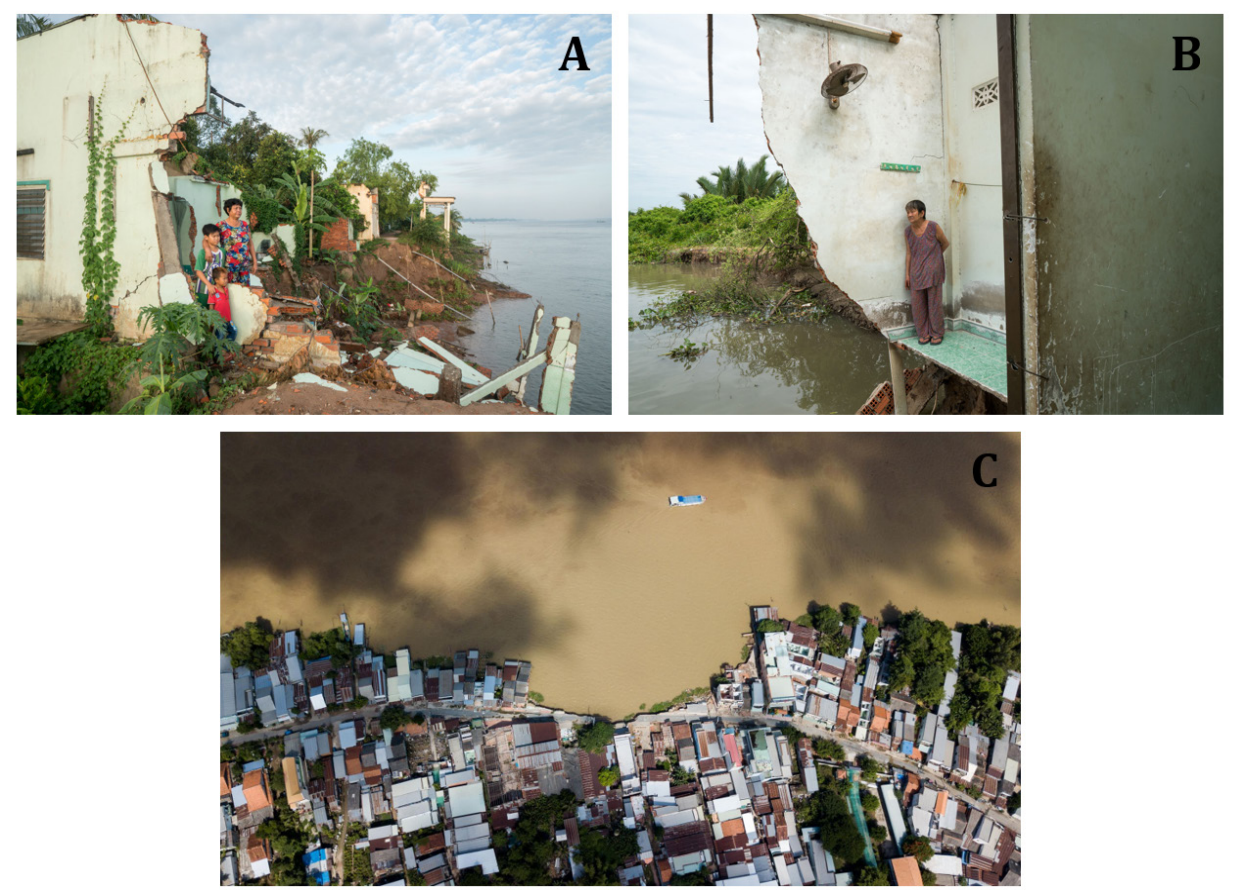

Figure 1.1: Impact of the collapse of the river banks along Mekong River, Vietnam, in different provinces: $(\boldsymbol{A})$ ruins of a home along the Tien River in Dong Thap, (B) ruins of a home in Nha Be, and (C) $0.8 \mathrm{~km}$ stretch of riverfront along the Van Nao River collapsed in An Giang (pictures copyright Sim Chi Yin / Magnum Photos, all rights reserved). 
What happened on that day in Hong Ngu in Vietnam was a classic example of a flow slide. A flow slide is a type of underwater slope failure which occurs when part of an underwater embankment fails and moves downslope (Fig. 1.2). Flow slides generally occur in fine sandy slopes along coasts, estuaries, and rivers. They start underwater and can cause a dike or beach to collapse when they reach the subaerial riverbank. A flow slide is defined as when the failing material mixes with water and is transported away from the embankment. This process can also itself cause further slope erosion. The final deposit has a very gentle run-out angle (Mastbergen et al., 2019).

Flow slides can be triggered by a variety of factors, including erosion by tidal currents, local changes in water pressure, and human interventions such as dredging or mining (Kramer, 1988; Visser, 1998; Beinssen et al., 2014). In the case of the Hong Ngu flow slide, the event was attributed mainly to excessive sand mining, which had weakened the riverbank. Sand is used to make concrete, which is the essential building material for Vietnam's fast-growing cities. Vietnam is far from being the only place where sand mining is inflicting such damage. All over the developing world, sand is being consumed in extraordinary quantities. Nearly 50 billion tons of sand and gravel are extracted annually to make all the concrete needed for skyscrapers, apartment blocks, highways, and airports (Beiser, 2018). In order to have these luxuries, deltas keep eroding, and so does the ground beneath the feet of the local population.

Flow slides pose considerable risks to flood defences and human life, particularly in densely populated coastal regions below sea-level, such as the Netherlands. Here, extensive research has been conducted on flow slides since two thirds of the country is vulnerable to flooding. More than 1000 slope failures have been documented in the Dutch province of Zeeland in the past 200 years (Wilderom, 1979; Stoutjesdijk et al., 1994). Being able to estimate the risk that flow slides pose to flood defences is vital for the safety of lowlying, densely populated coastal regions. The ability to predict flow slides is an important asset for the design of flood defence measures, their construction, maintenance, and safety assessment; even more so in view of intensifying land use and the impact of climate change on low-lying coastal areas worldwide. 


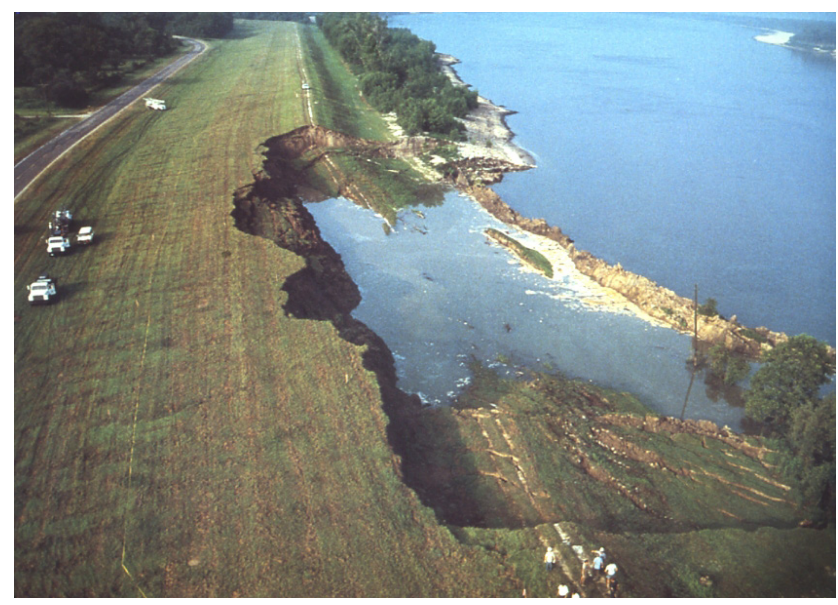

Figure 1.2: Partial dike failure into the Mississippi River due to a flow slide in 1993 (photo: U. S. Army Corps of Engineers).

Despite the case histories of known flow-slide events, like the one in Hong Ngu, the processes operating during an active flow slide are not well understood. Flow slides are difficult to observe and monitor. The events start underwater and are only noticed once the failure reaches the subaerial bank. For this reason, though the final geometries of the flow slides are well known, the trigger mechanism and the actual development of the slides over time have seldom been witnessed.

Additional reasons why flow slides are difficult to study are associated with insufficient data from soil investigation, limitations of conventional field methods, and disturbance of the soils tested in the laboratory. As a result, there is an uncertainty in soil conditions and properties. 


\subsection{Two types of flow slides}

Two different types of flow slides are distinguished in the literature, based on the geo-mechanical behaviour of a packed sand when subjected to shear force: liquefaction (Terzaghi, 1957; Lade, 1992; Hampton et al., 1996) and breaching (Van Rhee \& Bezuijen, 1998; Van den Berg et al., 2002; Eke et al., 2011). Liquefaction occurs in loose sand (Lade, 1992) at a fast rate, whereas breaching is related to densely packed sand and is referred to as a slow, gradual failure of the slope $(\sim \mathrm{mm} / \mathrm{s}$; Van den Berg et al., 2002; Eke et al., 2011; You et al., 2012, 2014a). The differences between liquefaction and breaching are caused by the undrained strength of saturated granular materials, which is governed by the packing density of the sediment particles in the embankment (Duncan et al., 2014). Despite the differences, both types of failure occur under similar environmental conditions (Van den Berg et al., 2002). The best-studied cases are associated with liquefaction, but researchers have argued more and more often that some of the presupposed case histories of liquefaction flow slides may have been cases of breaching failures instead due to their similar environmental conditions. For instance, the Mississippi bank failures were supposed to be caused by liquefaction. However, studies from Torrey et al. (1988) revealed a slow retrogressive nature of the failures where negative pore pressures developed due to dilation. Therefore, the Mississippi bank failures should be interpreted and classified as breaching failure.

\subsubsection{Liquefaction flow slides}

A liquefaction flow slide is triggered in loose sand on a subaqueous slope when that mass of sand suddenly behaves like a viscous fluid (Silvis \& Groot, 1995). Failures resulting from liquefaction tend to occur on gentle slopes, develop rapidly and the liquefied materials are displaced far from their initial location (Kramer, 1988).

Liquefaction starts when a saturated, loosely packed sand is subjected to shear. Since the initial packing is loose, there is no significant particle interlocking to overcome, and the particles tend to pack more closely as they are sheared (Fig. 1.3A). Sandy soils are relatively permeable and pore waters are quickly discharged as the grains pack more densely. However, if a sudden shearing force is applied, the water may not escape from the pores quickly enough. In this case, the pore pressure increases relative to ambient pressure with a consequential reduction of the effective stress (Fig. 1.3B). For saturated soils, effective stress is defined as the difference between the total stress minus the pore-water pressure. 
The sand deposit reduces its shear strength and, eventually, assumes the consistency of a liquid when the effective stress becomes approximately zero.

The effect of an increase in pore pressure at a certain point on a deposit can be represented in a Mohr circle diagram, which provides a representation of the stress state, and plots the combination of normal effective stress and shear stresses on each plane (Bowles, 1979; Terzaghi et al., 1996; Fig. 1.4). The stresses on all planes together form a circle. The failure envelope is given by the Mohr-Coulomb failure criterion, where $\tau$ is the shear stress, $\sigma$ 'is the normal effective stress, $c$ is the cohesion, and $\varphi^{\prime}$ is the effective angle of internal friction (Fig. 1.4). The soil properties are often denoted as $c^{\prime}$ and $\varphi^{\prime}$ in order to stress that these quantities refer to effective stresses. If the circle is completely within the envelope no failure will occur, because on all planes the shear stress remains well below the critical value. In Figure 1.4, $\sigma^{\prime}$ is the major principal effective stress acting typically in vertical direction, and $\sigma_{3}^{\prime}$ is the minor principal effective stress acting typically in horizontal direction. The black circle represents the initial state at a certain point. As pore pressure increases, the effective stresses decrease, and the Mohr circle moves to the left towards the failure envelope (Fig. 1.4). Failure will start to occur whenever Mohr's circle just touches the Mohr-Coulomb envelope (Bowles, 1979; Terzaghi et al., 1996). As a material failure begins at one place in a slope, this causes pore pressures to rise elsewhere, and more of the slope to fail. Then the whole slope may liquefy leading to a fast failure.

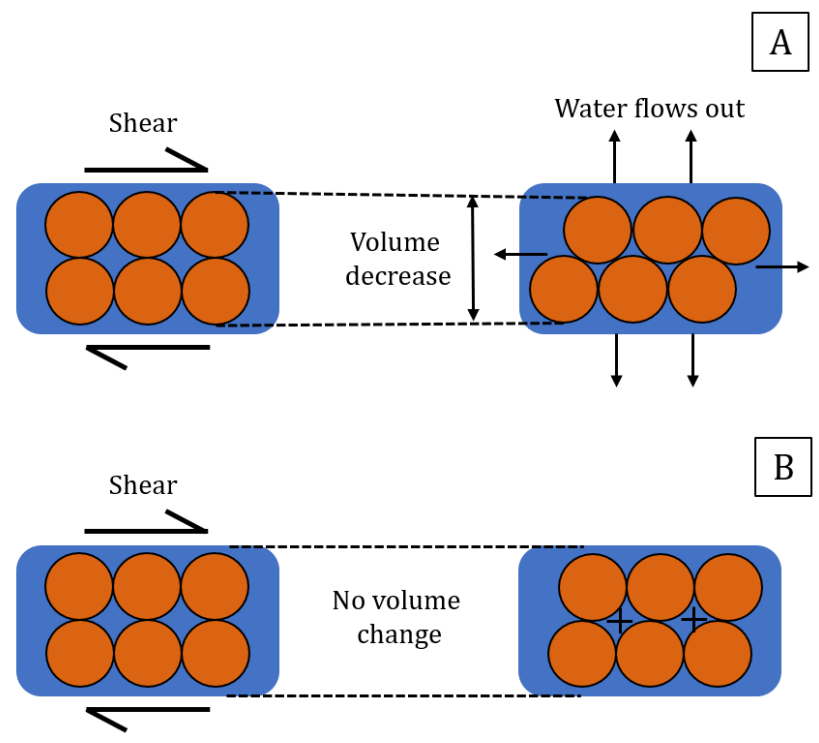

Figure 1.3: Behaviour of a loosely packed sand when sheared: (A) drained, (B) undrained response (the plus signs indicate positive excess pore-water pressure). 


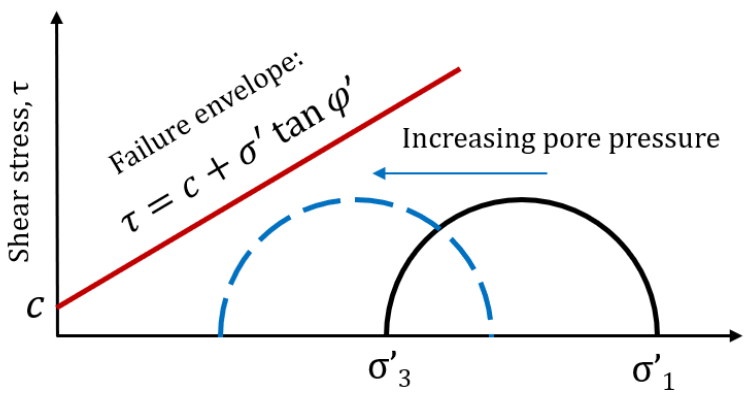

Effective stress, $\sigma^{\prime}$

Figure 1.4: Schematic evolution of Mohr circles with increasing pore pressure (black circle represents the initial state).

Another liquefaction flow slide characteristic is the abrupt increase of excess pore pressure just before the moment of failure. An example has been given by de Jager et al. (2017). The authors designed and built a liquefaction tank, $5 \times 2 \times 2 \mathrm{~m}$ (length $\times$ width $\times$ height) (Fig. 1.5A), to conduct physical scale model tests of liquefaction flow slides. They used subrounded sand with a median diameter of $125 \mu \mathrm{m}$. The tests started with a fully submerged sand bed with thickness of $50 \mathrm{~cm}$ that was fluidized before the test to create a uniform, loosely packed sand bed. The liquefaction tank was subsequently tilted uniformly to a final angle of $10^{\circ}$ with the horizontal. Figure 1.5 shows the pore pressure response at the base of the sand bed. During the tilting process, the excess pore pressure starts to increase up to $0.1 \mathrm{kPa}$. When the tank reaches an angle of approximately $6.3^{\circ}$, the excess pore pressures rise rapidly to $2.5-3.5 \mathrm{kPa}$ marking the moment of failure (Fig. 1.5B). The tilting of the tank back to its original position also yielded a liquefaction event even though to a lesser extent than the first event. 


\section{A}
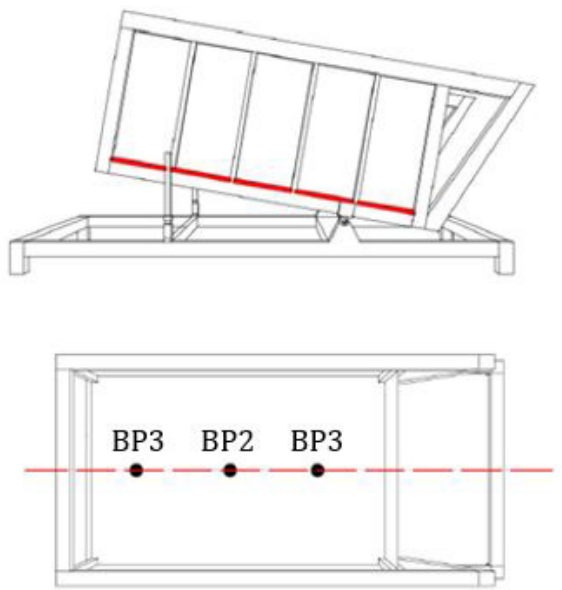

\section{B}

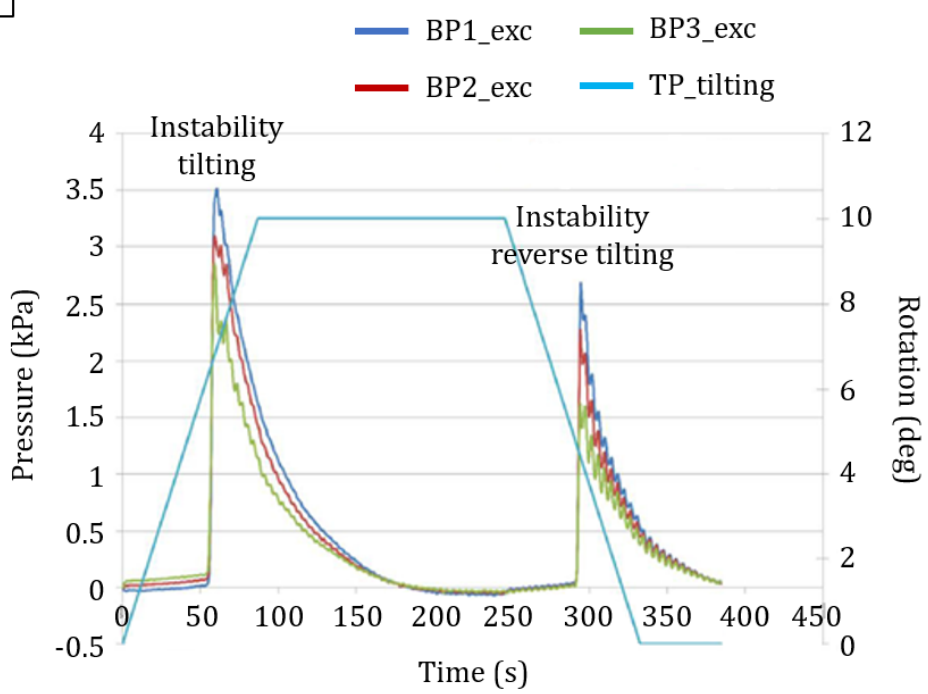

Figure 1.5: Pore-fluid pressure response measured at the bottom of the liquefaction tank: $(A)$ position of the three fluid pressure sensors at the bottom of the tank, (B) excess pore pressures and rotation of tank during tilting test (modified from de Jager et al., 2017). 


\subsubsection{Case histories of liquefaction flow slides}

\section{Fraser River Delta: case history}

A natural example of liquefaction flow slide was observed in the Fraser River Delta, on the west coast of Canada, where five liquefaction flow slides have been reported between 1970 and 1985. The post-failure collapse depressions had head scarps up to $12 \mathrm{~m}$ in height (McKenna et al., 1992) and slope angles up to $23^{\circ}$ (Christian et al., 1997b). The largest event occurred at the delta front in 1985 and resulted in the loss of more than $1 \times 10^{6} \mathrm{~m}^{3}$ of sediment and a slope retrogression of $350 \mathrm{~m}$ (McKenna et al., 1992).

The delta is in a seismically active region but no local earthquakes were reported at that time. Geotechnical site investigations carried out at Sand Heads encountered very loose layered sequences of sands and silts (Christian et al., 1997b). An investigation into the 1985 liquefaction slide evaluated the contribution of possible triggering mechanisms such as sedimentation, surface waves, and tidal drawdown on saturated sediments, and concluded that neither alone nor combined could any of these mechanisms account for the deep-seated flow failures that were observed (Chillarige et al., 1997). The observation of high concentrations of methane gas in the pore fluid of these deposits (Christian et al., 1997) prompted an examination into the effect of gas. Chillarige et al. (1997) found that gas induces desaturation of the sediment, which can induce residual pore pressures in the sediments during low tides. It was postulated that the combination of loose sediments, small amounts of gas and low tides contributes to the triggering of flow liquefaction failures in the Frasier delta.

\section{Fort Peck Dam: case history}

Starting in 1934, the Fort Peck Dam was built on the Missouri River in Montana, about $112 \mathrm{~km}$ south of the Canadian border. In 1938, a large slide occurred in the upstream shell of the dam, close to the end of construction. The failure occurred over a $500 \mathrm{~m}$ section and was preceded by bulging over at least $12 \mathrm{~h}$ prior to the failure. Just before the failure, the dam was $60 \mathrm{~m}$ high with an average slope of $1 \mathrm{~V}: 4 \mathrm{H}$.

At some time after these initial strains, a flow slide developed with very large displacements in the range $300 \mathrm{~m}$ to $450 \mathrm{~m}$ and very flat final slopes (1V:20H) (Jefferies \& Been, 2006). About $7.5 \times 10^{6} \mathrm{~m}^{3}$ of material was involved in the failure and eight men lost their lives. The post-failure appearance consisted on intact blocks in a mass of disturbed material. Figure 1.6 shows an aerial view of the failure. 


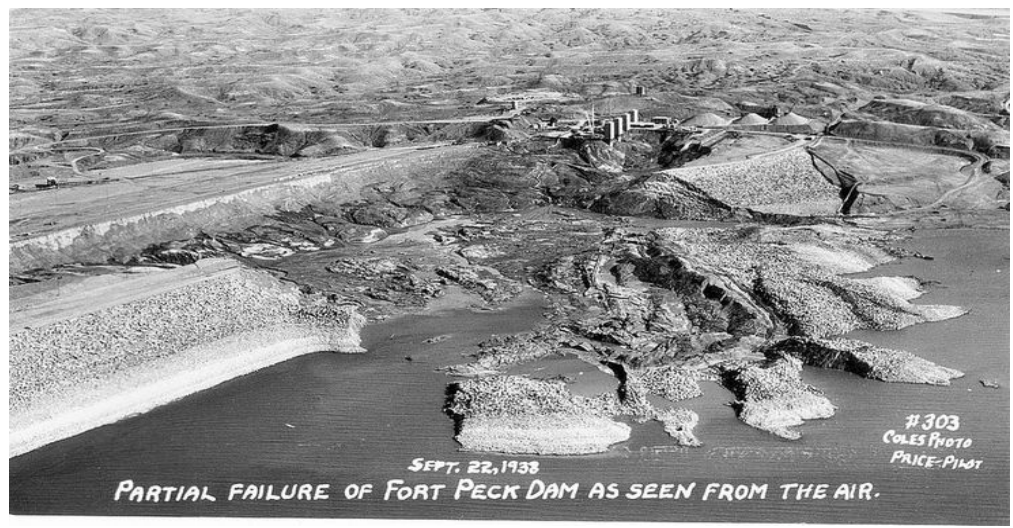

Figure 1.6: Aerial view of Fort Peck failure (photo: Valley County Historical Society).

\subsubsection{Breaching flow slides}

The term breaching is usually attributed to retrogressive erosion and to the failure that occurs due to overtopping of embankments, dams, dikes and sand barriers (Visser, 1998; Coleman et al., 2002; Stretch \& Parkinson, 2006). This thesis follows Van den Berg et al. (2002) who specifically referred to breaching as a gradual retrogressive failure of a very steep subaqueous slope, i.e., steeper than the angle of repose (Fig. 1.7A). Breaching mostly occurs in densely packed sand with a low permeability (Van Rhee \& Bezuijen, 1998; Mastbergen \& Van den Berg, 2003).

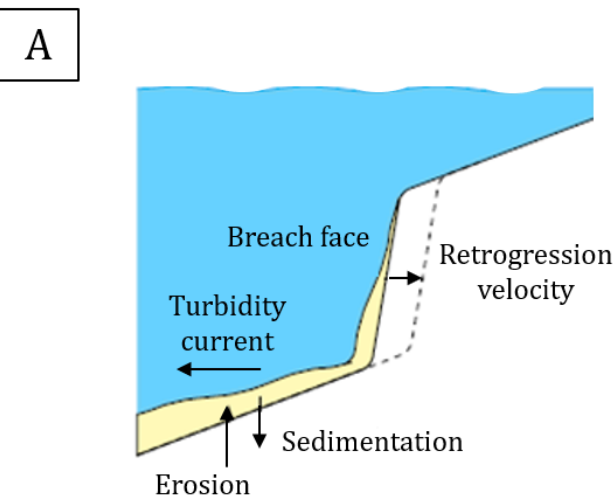




\section{B}

$\underline{\text { Stable }}$

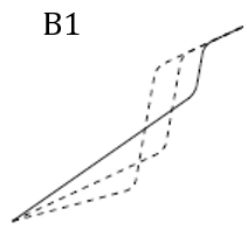

$\underline{\text { Unstable }}$

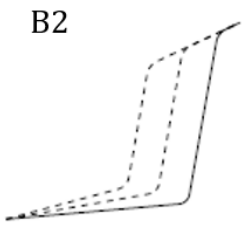

Figure 1.7: Breaching mechanism: (A) (previous page) Illustration of the breaching process; (B) difference between stable and unstable breaching: B1) in stable breaching, the breach height decreases over time, B2) in unstable breaching, the breach height increases (modified from Weij et al., 2016).

Breaching starts when a slope, steeper than the internal friction angle, is not stable and shears. Since its initial state is dense, the sand must expand so the grains can move up and over each other (Fig. 1.8A). This increase in volume as the result of shear deformation was discovered by Reynolds (1885) and it is called dilatancy.

During dilatancy, the pore volume increases, resulting in a negative pore pressure relative to hydrostatic pressure, and an increase of the effective stress (Fig. 1.8B). If we make use of the Mohr diagram, in this case the circle moves to the right, away from the failure envelope. The deposit would fail under hydrostatic pore-water pressure, but it is stabilised by the generation of negative pore pressures and consequent increase of the effective stresses (Fig. 1.9). The reduced pore-water pressure can thus temporarily keep the sand body stable. As water flows into the pores, due to the inward hydraulic gradient, sand grains are released one by one at the sand-water interface. During this grain-by-grain failure, the negative excess pore pressure is released locally, weakening the deposit near the sand-water interface and resulting in a thin surficial slide (Meijer \& Van Os, 1976; Van Rhee \& Bezuijen, 1998). Thus, this slope only fails gradually, since the negative pore pressure is released slowly by water flowing in from the ambient fluid into the failing sand body (Van Rhee \& Bezuijen, 1998; Van den Berg et al., 2002). The released sand grains mix with water, developing a turbidity current flowing over and interacting with the slope surface possibly causing extra erosion at the toe of the failure surface (Fig. 1.7A). 


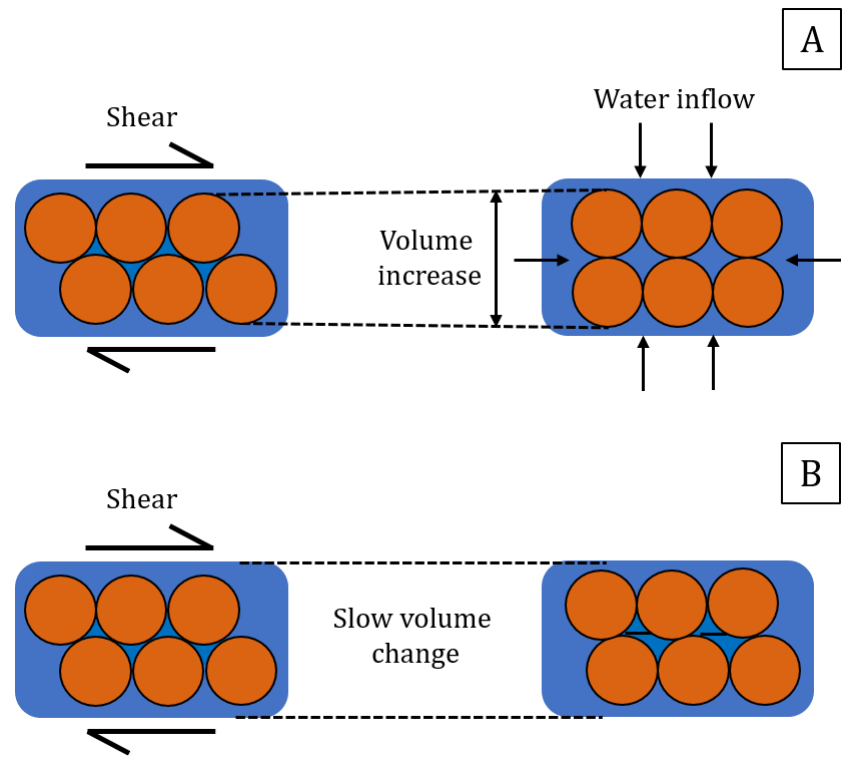

Figure 1.8: Behaviour of a densely packed sand when sheared: (A) drained, (B) partially drained response (the minus signs indicate negative excess pore-water pressure).

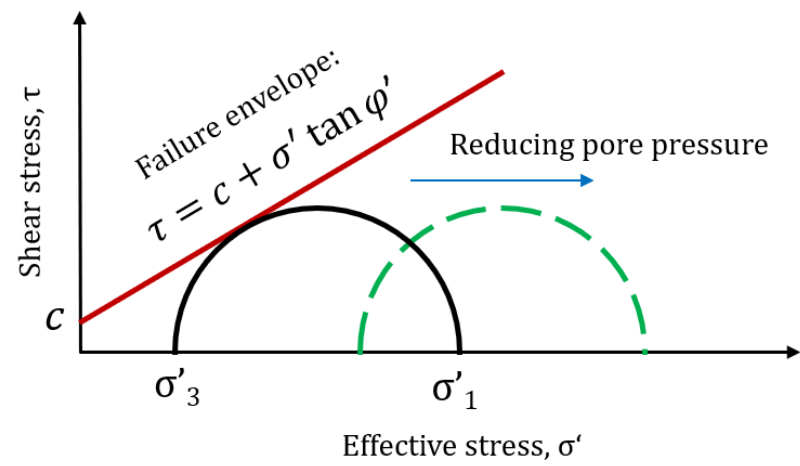

Figure 1.9: Schematic evolution of Mohr circles with reducing pore pressure (black circle represents the initial state).

Breaching can be stable or unstable, which depends mostly on the interaction between the formed turbidity current and the downstream slope (Van Rhee \& Bezuijen, 1998). During a stable breach, the height of the breach face decreases in time (Fig. 1.7B-B1), 
and at a certain time the breaching stops. Contrarily, when the breach is unstable, the breach face increases in height over time (Fig. 1.7B-B2). This is the case when the toe of the breach is eroded, by the turbidity current. The breaching then continues longer and interchanges much more sediment. Therefore, especially unstable beaching may cause a lot of damage. It is difficult to predict when the process will end; depending on the slope, this can take hours. The result can be that large sections of land have disappeared into the water.

\subsubsection{Case histories of breaching flow slides}

\section{Walsoorden, the Netherlands}

On the $22^{\text {nd }}$ of July 2014, a large flow slide occurred along the tidal flat of Walsoorden (Fig. 1.10) in the eastern part of the Western Scheldt. It was possibly initiated by low water levels in combination with large precipitation (Rijkswaterstaat 2014). During the event, $850000 \mathrm{~m}^{3}$ of sediment flowed downslope into the navigation channel, reducing the navigation depth by $7 \mathrm{~m}$. A week later, further activity was noticed on the shoreline, where gullies incised the tidal flat and slabs of sand gradually dropped into the water. The duration of the event was at least several hours, but probably lasted more than 24 hours (Van den Ham et al., 2015).

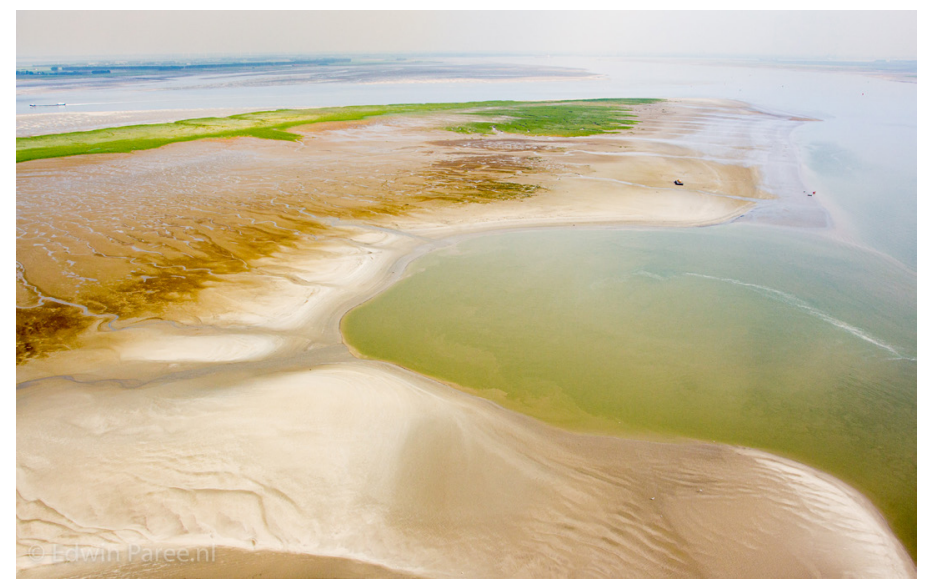

Figure 1.10: Aerial view of the tidal flat of Walsoorden after the July 2014 collapse (Photo Copyright Edwin Paree / Rijkswaterstaat). 
In order to induce and monitor a flow slide on full scale, a field test was performed in September 2014 (IJkdijk, Deltares 2016). The location for this test was the slope of Walsoorden tidal flat, where the flow slide on the $22^{\text {nd }}$ of July 2014 occurred. The flow slide was initiated by dredging, few hundred meters to the east of the previous failure, and continuously surveyed during a two-week test period starting on the $23^{\text {rd }}$ of September 2014. A soil investigation program was performed before and after the field test. Before the test, Cone Penetration Tests (CPT) and geophysical surveys (multibeam and sub-bottom profiling) were performed (Van Duinen et al., 2014). Pore-water pressure meters were installed in wells at $5 \mathrm{~m}$ depth allowing continuous monitoring during the test (Mastbergen et al., 2016). Analysis of the soil tests revealed generally uniform fine sand $\left(d_{50}=140 \mu \mathrm{m}\right.$ and $\mathrm{d}_{60} / \mathrm{d}_{10}$ about 1.5 ) with low clay content and some loosely packed sand layers at $10 \mathrm{~m}$ depth (Mastbergen et al., 2016). In addition, clay layers and organic material were found in the tidal zone.

The flow slide was initiated by oversteepening of the slope over a certain height by excavation of the slope by dredging. The aim of the dredging was the loosely packed sand layer, identified in the CPT data, in order to create a small breach or induce liquefaction. Two vessels equipped with multibeam sensors for seabed mapping jointly surveyed the area continuously, resulting in a bathymetric map about every 15 min (Mastbergen et al., 2016). A third, larger vessel served as the test control centre and moved slowly alongside the dredger. As soon as any flow slide activity was observed, the dredger was moved away from the location.

A few flow slide events were detected during the test, including a steep active breach of up to $6 \mathrm{~m}$ height and $30 \mathrm{~m}$ width (Mastbergen et al., 2019) (Fig. 1.11A). The stable breach retrogressed over a couple of hours and generated a turbidity current that ran out over about $100 \mathrm{~m}$ (Van den Ham et al., 2015). The retrogression speed of the breaches was between 10 and $20 \mathrm{~m} / \mathrm{h}$ (Mastbergen et al., 2016) (Fig. 1.11B). No measurements of the changing pore water pressures were registered, which could be an indication of liquefaction or breaching, because the sensors were not close enough to the failure. 


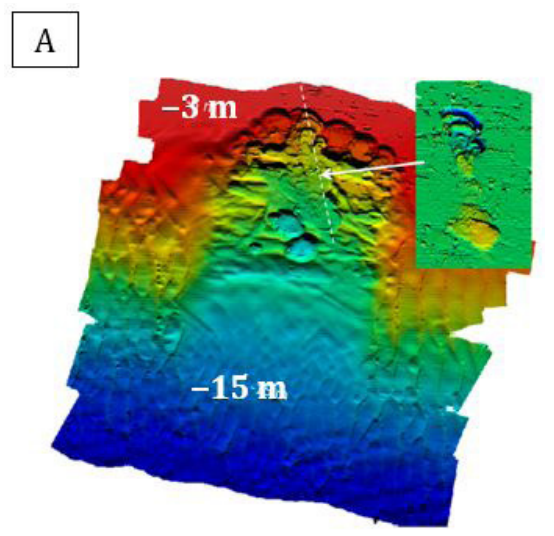

$\mathrm{B}$

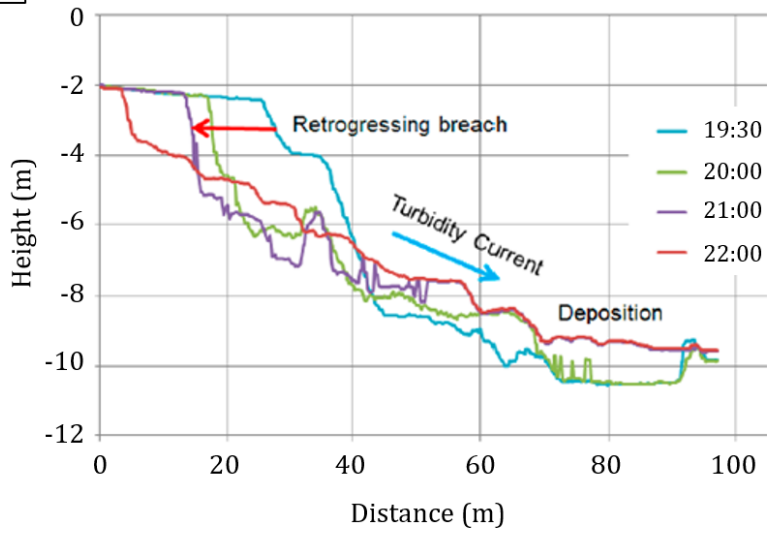

Figure 1.11: Walsoorden field test in September 2014: (A) bathymetry of dredging area $(100 \times 100 \mathrm{~m})$ with small flow slide scars (below low-water line). Inserted: differential bathymetry (blue = erosion, yellow = deposition); (B) cross-section along dashed line in (A) showing breach retrogression on October 15t, 2014 (Mastbergen et al., 2019).

\section{Amity and Inskip Point: case histories}

Field observations of breaching were reported by Beinssen et al. (2014) on the Australian coast at two locations: Amity Point and Inskip Point (Fig. 1.12). Erosion events have been observed at Amity Point for over 100 years. In 1913 a local historian Thomas Welsby wrote (Thomson, 1967): "I have known large slips at Amity carrying away tons of sand, and many a ti-tree familiar to my boating companions has toppled and fallen into the waters of the Bay". Since that time, several events have been observed. 
To better understand these events, the shoreline of the Amity Point beach was measured and video recorded almost daily from July 2011 to February 2014. During this 20-month study period, 44 breaching events emerged onto the subaerial beach. On each occasion, sand was 'raining' off the wall below the water line. Periodically, wedges of sand about 0.4 metres thick by 4 to $10 \mathrm{~m}$ wide sheared off the sand wall and sank vertically downwards. The surface area of the affected beach was measured to be between $20 \mathrm{~m}^{2}$ to almost $3000 \mathrm{~m}^{2}$. The largest observed breaching event penetrated 54 metres far into the shoreline with a width of $105 \mathrm{~m}$. The events appeared to be initiated on slopes of about $5^{\circ}$, and the maximum slopes were measured at $30^{\circ}$ to $35^{\circ}$. The speed of retrogression was always close to $0.8 \mathrm{~m} / \mathrm{min}$ on the lower beach but on at least one occasion it slowed to 0.3 $\mathrm{m} / \mathrm{min}$ on the upper beach.

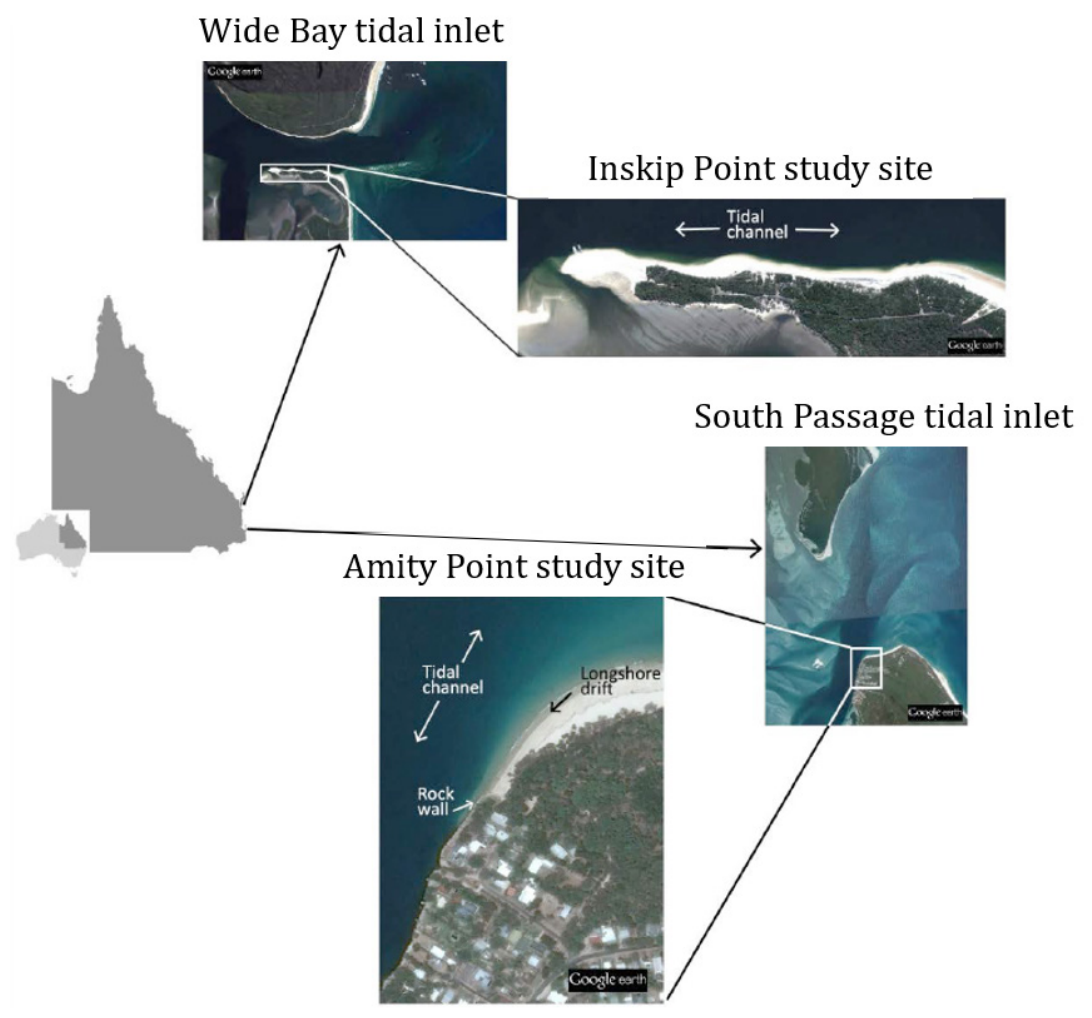

Figure 1.12: Locations of Amity Point and Inskip Point study sites from Google earth (modified from Beinssen et al., 2014). 
Another example of breaching in nature was observed at nearby Inskip Point. (Fig. 1.13) This event was only documented by phone interviews with residents who had witnessed the event, and by photos and video footage (Beinssen et al., 2014). The extension of each event was estimated to be over $150 \mathrm{~m}$ in diameter and $6 \mathrm{~m}$ depth. The failure progressed up the beach and into the vegetated area and was active for about 3 hours. One of the events had a duration of 107 minutes and eroded an area of $3000 \mathrm{~m}^{2}$. The height of the breach face was estimated by eye at between 6 and 7 metres as it arrived at the beach. The initial velocity was about $0.8 \mathrm{~m} / \mathrm{min}$. A bathymetric scan taken 14 hours after the event indicates that the triggering position was probably at 6 or 7 metres depth and 50 metres offshore. If so, the event was active and retrogressing towards the beach for about an hour before it became visible.

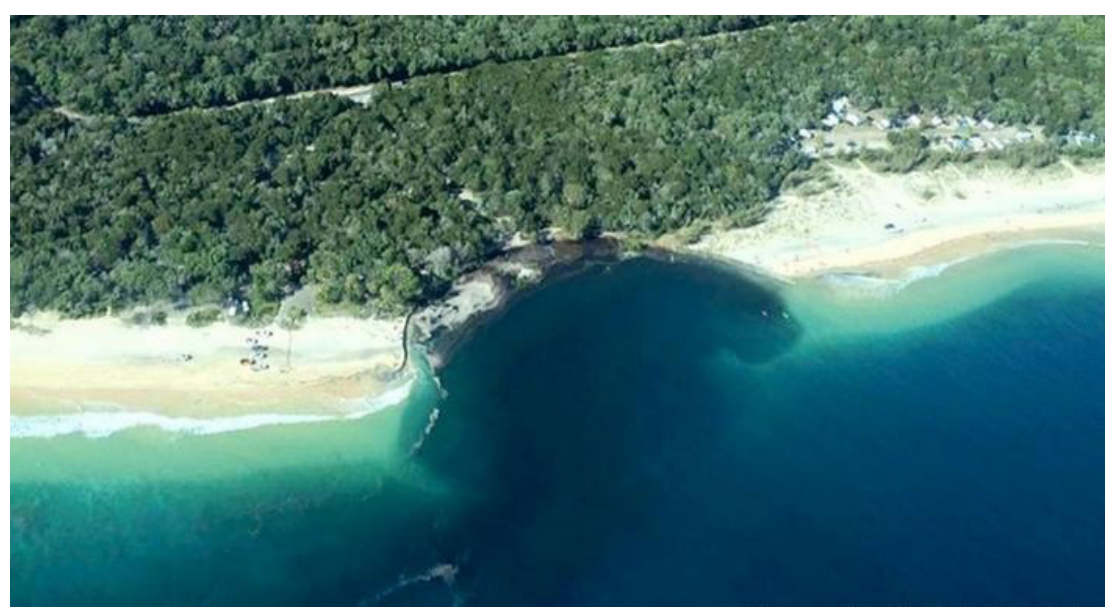

Figure 1.13: Breach failure event at Inskip Point (photo: Rainbow Beach Helicopters Australia). 


\subsection{Aim, approach, and objectives of this thesis}

\section{$\underline{\text { Aim }}$}

The aim of my research was to gain a deeper understanding of flow-slide processes, focusing on the properties of embankments and their influence on the type of failure.

\section{Research approach}

The research presented in this thesis is part of the interdisciplinary project, "MPMFlow: understanding flow slides in flood defences", which aims to develop an integrated numerical solution for the simulation of underwater flow slides, through numerical modelling with the material point method (MPM). The study of flow slides requires an integrated approach of fluid and soil mechanics as soil movements induce turbulent water motions, which in turn might erode the soil surface. A team of four PhD students worked on different work packages in order to improve the existing models. Lisa Wobbes worked on the implementation of the new model, solving mathematical issues, and improving the numerical solution (Wobbes 2019). Marco Bolognin was involved with the validation of the MPM software and a field scale flow slide test. Said Alhaddad focussed on the turbulence dynamics (soil-water interaction) and large laboratory tests. The main contribution of the research presented in this thesis is to demonstrate and quantify the processes that contribute to the phenomenon, and to gain a deeper understanding of how these processes depend on the embankment characteristics, through small scale laboratory testing.

Field experiments, large, and small laboratory experiments, and numerical modelling are complementary research approaches that each have their own strengths and weaknesses.

Field experiments have proven to be important for understanding of flow slides. Researchers go to the field to perform tests with the same conditions as previous events occurred and collect all possible data. However, field experiments involve high costs and only allow predictions for specific test scenarios. As addressed before in the Walsoorden field test, useful information was obtained from the failures, but it was not possible to specify whether the type of flow slide was a breaching or liquefaction, since the pressure sensors were located too far away from the failures to measure positive or negative pore pressures. Thus, field experiments make the safety assessment of flood defences and the development of measures to prevent flow slides difficult and costly. Large and small laboratory experiments are performed in controlled environments. Instrumentation is simply installed; several aspects can be studied during one experiment and experiments can be repeated one after the other. Still, large laboratory experiments involve large test facilities and it can be difficult to perform multiple tests with different boundary conditions. Numerical models, however, 
represent an alternative at a much lower cost for prediction or evaluation of the risk of a flow slide, but may not include all key processes. One of the key questions to be answered is whether a flow slide is caused by up-slope migrating breaching or by liquefaction.

In this thesis, a combination of different approaches is used to accomplish the research objectives. In Chapter 3, 4 and 5, the main effects of the embankment properties were studied with small scale experiments in a 2D flume tank, whereas the experiments for Chapter 6 were conducted in the Eurotank basin, which is $6 \mathrm{~m}$ wide, $12 \mathrm{~m}$ long, and $1.2 \mathrm{~m}$ deep.

\section{Research objectives}

- Test how the initial porosity of a sand embankment influences the flow slide type and its evolution;

- Investigation of failure mechanisms in a heterogeneous embankments;

- Analyse the relation between breach evolution and strength of the turbidity current travelling into the basin;

- Reproduction of a flow slide failure in a three-dimensional environment and its comparison of the failure observed in nature. 


\subsection{Overview of this thesis}

Chapter 2 focuses on material characterisation. The main material used in the experiments was (quartz) sand, and different tests were conducted to quantify specific material properties. This material characterisation will be used throughout the thesis and will also allow numerical modellers to parameterise numerical simulations of the experiments reported in this thesis, which could be valuable validation exercises. The laboratory programme consists of three parts. The first part is dedicated to the physical characterisation, which includes a grain-size characterisation and determination of the minimum and maximum packing density. The second part is to quantify the shear strength of the material. Since the flow slide mechanisms strongly depends on the behaviour of the material under shear, consolidated undrained triaxial tests were performed to determine the shear strength parameters. Tests were performed for two stress levels and different relative densities. The third part of Chapter 2 consists of permeability tests in order to quantify the hydraulic conductivity.

Chapter 3 analyses the influence of initial porosity during a flow slide failure. Previous successful laboratory tests reproduced in flume tanks approach the two flow-slide end-members (i.e., breaching and liquefaction) by using a very loose or very dense packing density of the sediment. However, these experiments did not simulate what happens at intermediate packing densities. In this chapter, the characteristics of the two end-member failure types are recognised. The data demonstrates the effect of porosity on breachingfailure propagation. In addition, a new type of failure, which I have called hybrid failure, is described. In these failures, a combination of the dilative and contractive behaviour is present in one single failure. These hybrid failures occur at intermediate packing densities that are more common under natural conditions. To the best of my knowledge hybrid failures have not been described in literature before.

Chapter 4 examines the influence of heterogenetic deposits on flow slide. Under natural conditions the deposits are rarely homogeneous. For instance, soil analysis from the field test in Walsoorden revealed a uniform fine sand with low clay content, and some loosely packed sand layers at certain depth, which is not coherent with the simplifications considered in most models and laboratory tests. For this, two layers of a different material were intercalated with the sand deposit. Since this study is strongly driven by the water motion and its interaction with soil surface, I chose materials with different permeability, coarse-grained sand, silt, and clay. This series of experiments was executed for a densely packed sand configuration. In a second series, different densities were tested as well for the configuration with silt inter-layering.

Chapter 5 studies the relation between breaching-failure evolution and 
resultant turbidity current. Breaches are known to generate dilute particle-laden flows called turbidity currents. While these turbidity currents have been observed and measured on the breach-failure face, they have been suggested to travel far from the source. This chapter provides coeval measurements of breaching failures and the turbidity currents that travel into the basin in front of the failure. The interaction between the turbidity current and downstream slope was investigated. Also, the influence of the breaching failure and generated turbidity current was addressed.

The previous sets of experiments were conducted in a 2D flume constrained by glass side walls. Breaching failure in an unconfined 3D embankment is investigated in Chapter 6. This experiment investigates the influence of such lateral confinement. For that purpose, an underwater flow slide was triggered in the Eurotank. To the best of my knowledge, this is the first time an experimental breach failure has been documented in an embankment without sidewalls. During the experiment, the propagation and final morphology of the failure were studied as well as the measured excess pore pressures. The results of these experiments are then compared to failures described in natural settings and the measurements performed in the confined setup used in Chapters 3-5. Results show that not only the characteristics from 2D experiments are presented in the 3D breach failure, but also the morphological aspects observed in the field.

Chapter 7 presents a synthesis of the results and conclusions of previous chapters. It also provides perspectives for future research. 

Chapter

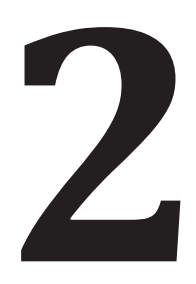

\section{Sand characterisation}

"And so castles made of sand fall in the sea, eventually."

- Jimi Hendrix (1942-1970) 


\subsection{Introduction}

This chapter characterises the quartz sand (Sibelco, BR37) that was used in the experiments presented in this thesis. The laboratory testing programme included a physical characterisation, description, and analysis of triaxial tests in order to quantify the shear strength parameters, and permeability tests to study the hydraulic conductivity. Together these characterisations cover all aspects of the sand that are relevant for the analysis of flow slides, and the results presented here will be used throughout this thesis. Furthermore, these material characterisations will aid parameterisations of any future modelling activities that may utilise the results of this thesis for validation purposes.

The behaviour of sand under external load depends mainly on its particle size and the arrangement of particles. Therefore, it is important to study the size, shape, and gradation of sand particles. The physical characterisation includes the grain-size distribution and tests to obtain the minimum and maximum porosity $\left(\eta_{\min }, \eta_{\text {max }}\right)$.

In addition, shear strength of soils is an important aspect in many geotechnical problems. Soil strength is the resistance to mass deformation based on a combination of particle rolling, sliding, and crushing. It may be reduced by the pore pressure that exists or develops during particle movement. Consequently, consolidated undrained triaxial tests were performed for two stress levels and different relative densities.

Lastly, for a given type of soil, the permeability depends primarily on the proportions of the volume of the soil that are occupied by particles and voids, and by the size distribution of the voids. Permeability tests were performed using the constant-head method for the sand at different porosities. 


\subsection{Physical characterisation}

Sand BR37 consists of $97 \%$ silica and was considered a specific density $\left(\rho_{s}\right)$ of 2.65 $\mathrm{g} / \mathrm{cm}^{3}$ (Terzaghi et al. 1996).

\subsubsection{Grain-size distribution}

The particle size distribution curve represents the distribution of particles of different sizes in the soil mass. It is considered the most basic soil identification characteristic. It can be used to determine basic particle-size distribution parameters, such as the effective size $\left(D_{10}\right)$, the coefficient of uniformity $\left(C_{u}\right)$, and the coefficient of curvature $\left(C_{c}\right)$. The effective size of a soil is the diameter through which $10 \%$ of the total soil mass has smaller size. The coefficients of uniformity and curvature are defined as:

$$
\begin{gathered}
C_{u}=\frac{D_{60}}{D_{10}} \\
C_{c}=\frac{\left(D_{30}\right)^{2}}{D_{10} D_{60}}
\end{gathered}
$$

where $D_{30}$ is the diameter through which $30 \%$ of the total soil has smaller size and $D_{60}$ is the diameter through which $60 \%$ of the total soil has smaller size.

A soil is called well graded if the grain-size distribution extends over a rather large range. In that case, the value of the uniformity coefficient is large. In accordance with the Unified Soil Classification System (USCS), a soil is referred to as well graded if $C_{u}$ is larger than about 4-6, and $C_{c}$ is between 1 and 3 (ASTM D2487-11, 2011). On the other hand, when most of the grains in a soil mass are of approximately the same size, the soil is called poorly graded and $C_{u}$ is close to 1 .

The grain size was analysed using a laser particle size (Malvern Mastersizer), which uses laser diffraction to measure the particle size. The basic principle is that small particles will scatter light at large angles and large particles will scatter light at small angles (www. malvernpanalytical.com). The scattering pattern produced by the sample is recorded and 
the distribution of particle sizes can be calculated by applying Mie scattering theory. The grain-size distribution curve of the sand BR37 is presented in Figure 2.1.

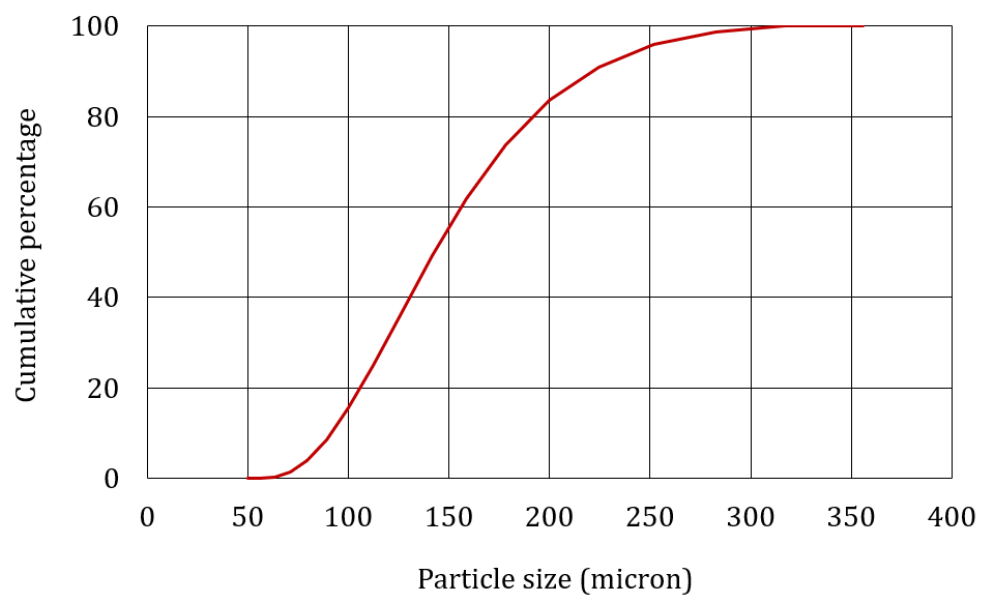

Figure 2.1: Grain-size distribution curve of the sand BR37.

The sand has a median grain size $\left(D_{50}\right)$ of $140 \mu \mathrm{m}$ and is classified as fine sand. The calculated coefficient of uniformity and coefficient of curvature are 1.76 and 0.98 , respectively (Tab. 2.1). Based on these coefficients, the sand is poorly graded.

Table 2.1: Grading characteristics of the sand BR37.

\begin{tabular}{ccccccc}
\hline \hline$D_{10}(\mu \mathrm{m})$ & $D_{30}(\mu \mathrm{m})$ & $\mathrm{D}_{50}(\mu \mathrm{m})$ & $\mathrm{D}_{60}(\mu \mathrm{m})$ & $\mathrm{D}_{90}(\mu \mathrm{m})$ & $\mathrm{C}_{\mathrm{u}}(-)$ & $\mathrm{C}_{\mathrm{c}}(-)$ \\
\hline \hline 90 & 118 & 140 & 158 & 224 & 1.76 & 0.98 \\
\hline \hline
\end{tabular}

\subsubsection{Minimum and maximum porosity}

Minimum and maximum porosities of sand BR37 were determined at the Deltares laboratory. It was used used a steel mould with a volume of $528 \mathrm{~cm}^{3}$ and a diameter of 6.7 $\mathrm{cm}$, a balance, and a bowl with an amount of sand, and a tamper (Fig. 2.2). 


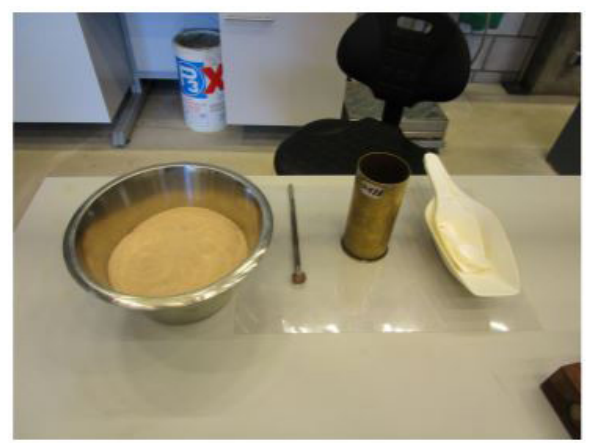

Figure 2.2: Equipment used to determine the minimum and maximum sand porosity (the balance is not in the photo).

In order to measure the maximum porosity, the sand was poured gently into the mould which was partly filled with water. The pouring was done without touching or hitting the mould to avoid any compaction. Minimum porosity was measured by pouring the sand into the mould in layers, while compacting the sand after each layer with the tamper with circular shape and $25 \mathrm{~mm}$ of diameter.

By measuring the weight of the sand in the bowl before and after filling the mould, accurate estimate could be made of the dry bulk density of the sand in the mould with the equation:

$$
\rho_{d}=\frac{M_{s}}{V}
$$

in which $\rho_{d}$ is the dry density $\left(\mathrm{g} / \mathrm{cm}^{3}\right), M_{s}$ is the sand mass in the mould $(\mathrm{g})$, and $V$ is the volume of the mould filled to the top $\left(\mathrm{cm}^{3}\right)$. With the maximum dry bulk density, $\rho_{d, \text { max }}$ it was determined the minimum void ratio, $e_{\text {min }}$, using the equation:

$$
e_{\min }=G_{s} \frac{\rho_{w}}{\rho_{d, \max }}-1
$$

where $\rho_{w}$ is the density of water $\left(\mathrm{g} / \mathrm{cm}^{3}\right)$, and $G_{s}$ is the specific gravity of the solid particles (-). For the maximum void ratio, $e_{\max }$ the maximum dry density is substituted by the minimum dry density, $\rho_{d, m i n}$. 
To calculate porosity $(\eta)$ from the void ratio $(e)$, the following expression was used:

$$
\eta=\frac{e}{1+e}
$$

Table 2.2 shows the values for the three tests used for determination of the minimum and maximum sand porosity each.

Table 2.2: Determination of the minimum (left), and maximum porosity (right).

\begin{tabular}{c|ccc|c|ccc}
\hline \hline Sample & $\mathbf{1}$ & $\mathbf{2}$ & $\mathbf{3}$ & & $\mathbf{4}$ & $\mathbf{5}$ & $\mathbf{6}$ \\
\hline \hline $\boldsymbol{M}_{s}(\mathbf{g})$ & 838.8 & 839.4 & 835.0 & $\boldsymbol{M}_{s}(\mathbf{g})$ & 675.9 & 677.1 & 676.4 \\
$\boldsymbol{V}\left(\mathbf{c m}^{3}\right)$ & 528.0 & 528.0 & 528.0 & $\boldsymbol{V}\left(\mathbf{c m}^{3}\right)$ & 528.0 & 528.0 & 528.0 \\
$\boldsymbol{\rho}_{d, \text { max }}\left(\mathrm{g} / \mathbf{c m}^{3}\right)$ & 1.59 & 1.59 & 1.58 & $\boldsymbol{\rho}_{d, \text { min }}\left(\mathbf{g} / \mathbf{c m}^{3}\right)$ & 1.28 & 1.28 & 1.28 \\
$\boldsymbol{e}_{\text {min }}(-)$ & 0.67 & 0.67 & 0.68 & $\boldsymbol{e}_{\text {max }}(-)$ & 1.07 & 1.07 & 1.07 \\
$\boldsymbol{e}_{\text {min mean }}(-)$ & & 0.67 & & $\boldsymbol{e}_{\text {max mean }}(-)$ & & 1.07 & \\
\hline \hline $\boldsymbol{\eta}_{\text {min }}(-)$ & & 0.40 & & $\boldsymbol{\eta}_{\text {max }}(-)$ & & 0.52 & \\
\hline \hline
\end{tabular}

From the mean of the three measurements, it was determined that the minimum and maximum sand porosity are 0.40 and 0.52 , respectively.

Since the method of determining minimum and maximum porosity used during these tests is not described in codes or standards, determination of minimum and maximum porosity of the sand was also done by the author at the same facilities, obtaining the same values. 


\subsection{Triaxial tests}

\subsubsection{Description}

A series of standard consolidated and undrained triaxial tests were performed at different relative densties to determine the shear strength parameters of the sand used in the experiments. The triaxial tests were conducted using an automated stress-path triaxial cell in the Deltares laboratory, manufactured by Wille BV. The main components of this apparatus include a triaxial cell, a loading frame, two electromechanical pressure pumps, and a data acquisition system. The electromechanical pressure pumps are controllers which also measure the fluid pressure and the fluid volume (both cell fluid and pore fluid). There are 2 pore pressure sensors, 2 cell pressure sensors and 1 differential pressure sensor.

In these tests, a cylindrical specimen of sand, $13.9 \mathrm{~cm}$ high was placed in a triaxial cell which can be pressurised. The samples were prepared at different porosities and sealed in a $0.25 \mathrm{~mm}$ thick rubber membrane. After the initial preparation, the specimen was saturated, isotropically consolidated and sheared by applying an increase of the axial load under constant cell pressure. The tested confining pressures $\left(\sigma_{c}{ }_{c}\right)$ were $5 \mathrm{kPa}$ and $30 \mathrm{kPa}$, according to the requirements of the experiments.

The sample in a consolidated undrained test is not allowed to drain during shearing, so the volume is assumed to be constant. This method provides data for the calculation of total and effective stresses since the pore pressure changes are measured.

\subsubsection{Procedure}

\section{Sample preparation}

The sand was put in a container with carbon dioxide for one day before the tests. The reason for this procedure is that carbon dioxide has higher water solubility than air and thus it is easy to be replaced by water in the sample saturation phase.

The samples were prepared in the triaxial cell using a mould and a thin rubber membrane, which contained a porous stone and a filter paper sheet placed on the pedestal (Fig. 2.3a). The mass of sand to be put in the mould was determined by the desired relative density using the equations: 


$$
\begin{gathered}
e=\frac{\rho_{w} \times G_{s}}{\frac{M_{S}}{V}} \\
R D(\%)=\frac{e_{\max }-e}{e_{\max }-e_{\min }} \times 100
\end{gathered}
$$

where $\rho_{w}$ is the density of water $\left(\mathrm{g} / \mathrm{cm}^{3}\right), G_{s}$ is the specific gravity of the solid particles (-), $M_{s}$ is the mass $(\mathrm{g}), V$ is the volume $\left(\mathrm{cm}^{3}\right)$, and $e_{\text {min }}$ and $e_{\text {max }}$ are the minimum and maximum void ratio, respectively.

In order to obtain very loose specimens, the samples were prepared following the water-pluviation method. This method consists of pluviating dry sand through de-aired water into the mould from a fall height of almost nil. On the other hand, the air-pluviation method was applied to achieve dense samples, complemented with small tamps by layer. The air-pluviation method is similar to the water-pluviation method except that the sand is pluviated through air rather than through de-aired water.

After the preparation of the sample, the mould was disassembled (Fig. 2.3b). Since the samples contained non-cohesive sand, a negative pressure of $6 \mathrm{kPa}$ was necessary to be applied to the samples at this stage. Otherwise, the samples would have collapsed upon the removal of the mould. In the case of low relative density samples, this negative pressure was $4 \mathrm{kPa}$, to prevent preliminary consolidation and disturbance of the sample. The dimensions of the samples were measured (Tab. 2.3), and enclosed in the triaxial cell which was filled with water (Fig. 2.3c). In order to remove the negative pressure applied before, a cell pressure of 4 or $6 \mathrm{kPa}$ was applied depending on the density. 


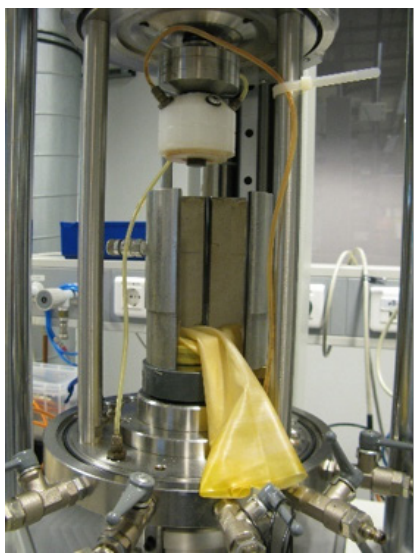

a)

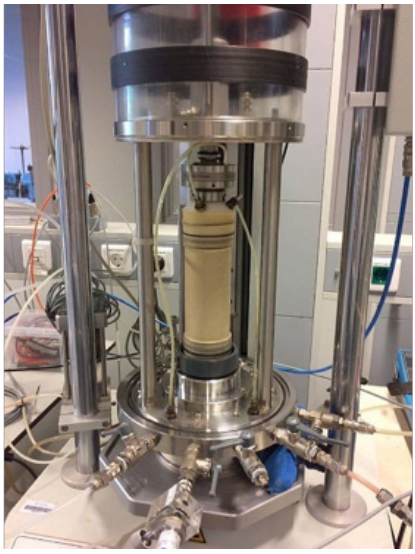

b)

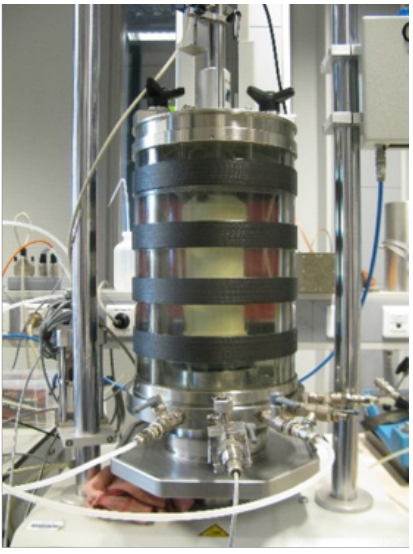

c)

Figure 2.3: a) Assembling the mould around the membrane; b) sample after the pluviation and the removal of the mould; c) placement of the triaxial chamber.

Table 2.3: Characteristics of the samples after the preparation.

\begin{tabular}{ccccccc}
\hline \hline \multirow{2}{*}{ Sample } & $\begin{array}{c}\boldsymbol{M}_{\boldsymbol{s}} \\
\mathbf{( g )}\end{array}$ & $\begin{array}{c}\boldsymbol{V} \\
\left(\mathbf{c m}^{3}\right)\end{array}$ & $\begin{array}{c}\boldsymbol{\rho}_{\boldsymbol{d}} \\
\left(\mathbf{g} / \mathbf{c m}^{3} \mathbf{)}\right.\end{array}$ & $\begin{array}{c}\boldsymbol{e} \\
(-)\end{array}$ & $\begin{array}{c}\text { RD } \\
\mathbf{( \% )}\end{array}$ & $\begin{array}{c}\boldsymbol{\eta} \\
(-)\end{array}$ \\
\hline \hline $\mathbf{1 G}$ & 571.23 & 438.70 & 1.30 & 1.035 & 8.8 & 0.51 \\
$\mathbf{1 H}$ & 601.47 & 441.89 & 1.36 & 0.95 & 30.0 & 049 \\
$\mathbf{1 I}$ & 655.00 & 449.60 & 1.46 & 0.82 & 62.5 & 0.45 \\
$\mathbf{1 D}$ & 609.50 & 441.33 & 1.36 & 0.954 & 29.0 & 0.49 \\
$\mathbf{1 E}$ & 632.90 & 447.80 & 1.41 & 0.87 & 50.0 & 0.47 \\
$\mathbf{1 F A}$ & 655.00 & 448.54 & 1.46 & 0.815 & 63.8 & 0.45 \\
\hline \hline
\end{tabular}

\section{$\underline{\text { Saturation and consolidation }}$}

For a complete saturation of the specimen, carbon dioxide $\left(\mathrm{CO}_{2}\right)$ was first percolated through the sample for approximately $20 \mathrm{~min}$. Compared to air, $\mathrm{CO}_{2}$ is more soluble in water which reduces the time and pressure required to adequately saturate the specimen (Mulilis et al., 1978). Subsequently, the specimen was flushed with de-aired water in order to completely fill the voids with water. The saturation was applied by an upward percolation 
with pressure differential of $6 \mathrm{kPa}$ for high values of relative density, and for loose packing $4 \mathrm{kPa}$, to ensure that the specimen characteristics did not modify. Percolation should be upward to facilitate the outflow of air and to prevent the creation of preferred percolation pathways. The saturation procedure was continued with a backpressure saturation phase as recommended by Black \& Lee (1973). The pressure inside the specimen (back pressure, $P_{b^{\prime}} \mathrm{kPa}$ ) was gradually increased in the range of $700 \mathrm{kPa}$ with the drainage valves opened. The purpose of this procedure is to compress the micro-bubbles of the interstitial gas that could still be present after the saturation phase. The confining pressure was increased simultaneously in such a way to maintain the effective stress (4 or $6 \mathrm{kPa}$ ) on the sample that had been established during the saturation phase. The Skempton's B-parameter was calculated to evaluate the degree of saturation:

$$
B=\frac{\Delta u}{\Delta \sigma}
$$

as the ratio of an increment of the confining pressure $\left(\Delta \sigma_{c}\right)$, under undrained conditions, and the corresponding increase in pore pressure $(\Delta u)$.

This procedure requires the drainage valves to be closed, and the pore pressures before and after the increased cell pressure are measured to determine the change in pore pressure for the change in cell pressure. It is recommended that a B value greater than, or equal to, 0.95 is achieved before the consolidation stage starts. In almost all the tests a B value higher than 0.96 was achieved, except in sample $1 \mathrm{D}$, which achieved 0.52 , because of the low back pressure applied (Tab. 2.4).

After the saturation, a consolidation stage was used to establish the desired value of effective stress, in this case $5 \mathrm{kPa}$ or $30 \mathrm{kPa}$. The objective of the consolidation stage is to allow the specimen to reach equilibrium in a drained state at the effective consolidation stress for which a strength determination is required. The pore pressure and confining pressure were maintained at the chosen values. The drainage valves were opened, and the specimen was allowed to consolidate during one hour. 
Table 2.4: Properties of the sample after saturation, and during consolidation stage.

\begin{tabular}{cccccc}
\hline \hline Test & $\begin{array}{c}\text { RD } \\
(\%)\end{array}$ & $\begin{array}{c}\text { B value } \\
(-)\end{array}$ & $\begin{array}{c}\boldsymbol{\sigma}_{3} \\
(\mathbf{k P a})\end{array}$ & $\begin{array}{c}\boldsymbol{P}_{B} \\
(\mathbf{k P a})\end{array}$ & $\begin{array}{c}\boldsymbol{\sigma}_{3}^{\prime} \\
(\mathbf{k P a})\end{array}$ \\
\hline \hline $1 \mathrm{G}$ & 8.8 & 0.994 & 705.5 & 700.3 & 5.2 \\
$1 \mathrm{H}$ & 30.0 & 0.990 & 705.5 & 700.9 & 4.6 \\
$1 \mathrm{I}$ & 62.5 & 0.998 & 705.3 & 700.3 & 5.0 \\
$1 \mathrm{D}$ & 28.9 & 0.520 & 330.9 & 302.8 & 28.1 \\
$1 \mathrm{E}$ & 48.8 & 0.960 & 529.9 & 502.2 & 27.7 \\
$1 \mathrm{FA}$ & 63.8 & 0.980 & 729.5 & 701.5 & 28.0 \\
\hline \hline
\end{tabular}

\section{Shearing}

After the consolidation, the drainage valves were closed and the samples were sheared. During shear, the cell pressure was kept constant while an axial load was applied of $0.09 \mathrm{~mm} / \mathrm{min}$ until a maximum axial displacement of $40 \mathrm{~mm}$ was reached. In this stage, it is assumed that the sample volume was constant since drainage was not allowed. An example of the final deformation is given in Figure 2.4 for sample 1FA.

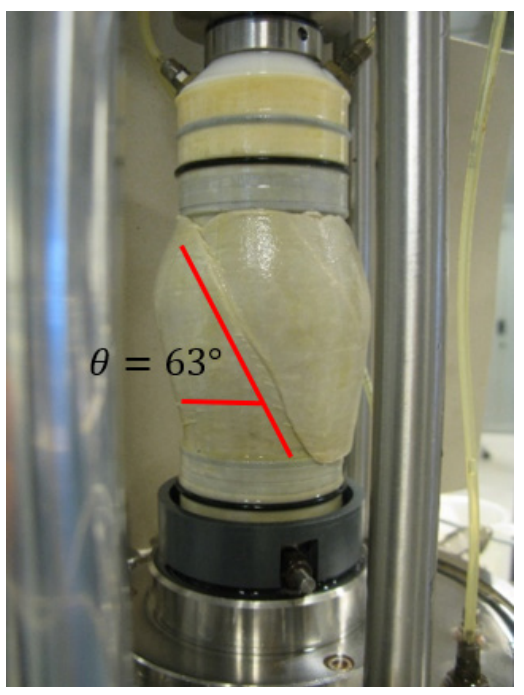

Figure 2.4: Final deformation of sample $1 \mathrm{FA}$, with $63.4 \%$ relative density and $\sigma_{c}^{\prime}=30 \mathrm{kPa}$. 


\subsubsection{Results}

In Figure 2.5, the relation between the deviator stress, $q$, and the axial strain, $\varepsilon$, for all tests is plotted. The deviator stress is defined as a difference of the major principal effective stress, $\sigma_{1}^{\prime}$, and the minor principal effective stress, $\sigma_{3}^{\prime}$ It shows the representative behaviour of the loose and dense sand for most samples. However, tests $1 \mathrm{D}$ and $1 \mathrm{H}$ with similar relative density ( $\sim 30 \%)$, which may be called loose samples, show different behaviour. The reason for that is the different effective stress applied during each test. It is evident that the relative density on its own is not sufficient to characterise a sample, since the loose sample tested at higher stress level shows higher strength.

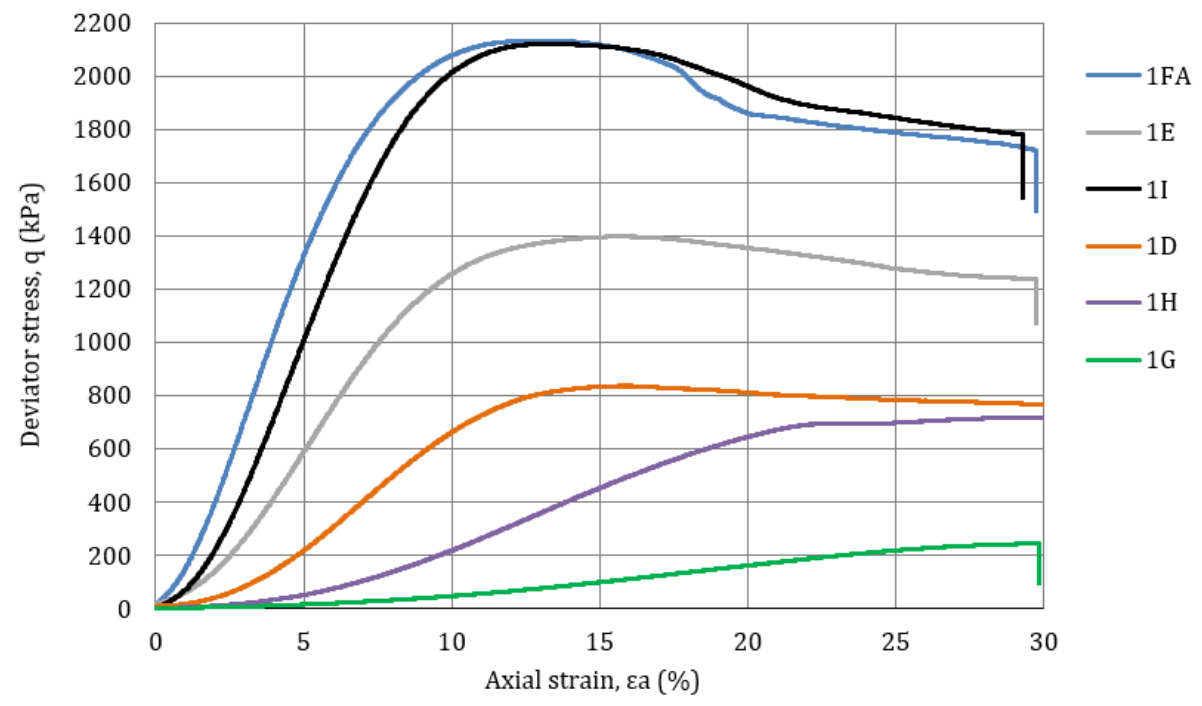

Figure 2.5: Axial strain vs. deviator stresses during the undrained triaxial tests.

Figure 2.6 shows the Mohr circles for the effective stresses in the first plott, in which the Mohr-Coulomb failure criterion (Eq. 2.9) of maximum effective deviator stresses was chosen per test (Figs. 1.4 and 1.9, Chapter 1):

$$
\tau=c+\sigma^{\prime} \tan \varphi^{\prime}
$$


where $\tau$ is the shear stress $(\mathrm{kPa}), \sigma^{\prime}$ is the normal effective stress $(\mathrm{kPa}), \varphi^{\prime}$ is the effective angle of internal friction, and $c$ is the cohesion, which was considered 0 since the soil tested was a granular soil.

The mobilized internal friction at the chosen failure criteria can be found in Table 2.5; the table shows not only the internal friction angle at peak effective deviator stresses, but also the residual value at the end of the tests calculated from the second plott in Figure 2.6 .
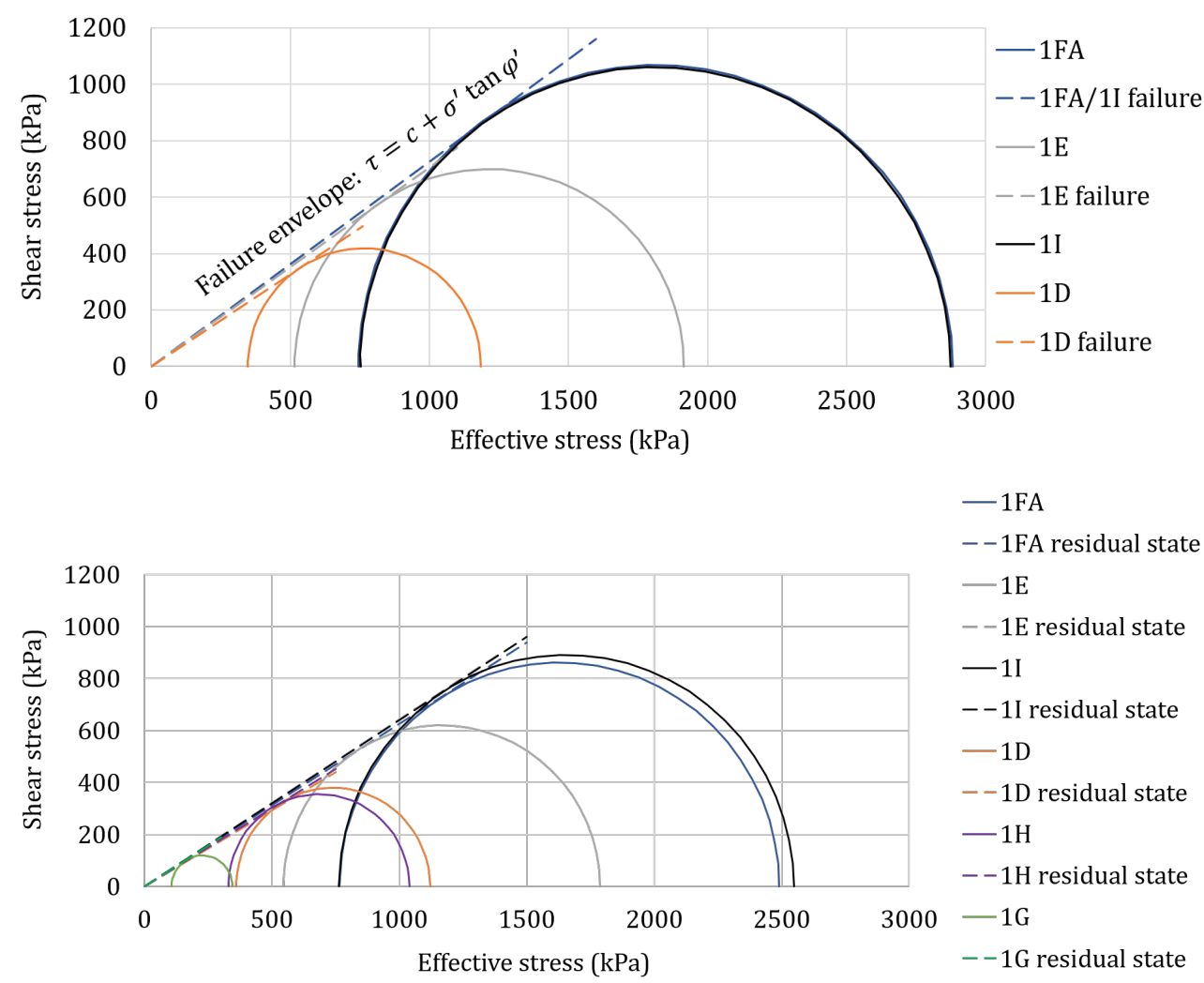

Figure 2.6: Mohr circles used for determination of the peak, and residual friction angles. 
Table 2.5: Peak, and residual friction angles after standard analysis.

\begin{tabular}{|c|c|c|c|c|c|c|c|}
\hline Test & $\begin{array}{l}\text { RD } \\
(\%)\end{array}$ & $\begin{array}{c}\sigma_{c}^{\prime} \\
(\mathbf{k P a})\end{array}$ & \multicolumn{2}{|l|}{$\begin{array}{c}q_{\max } \\
(\mathbf{k P a})\end{array}$} & $\begin{array}{c}\sigma_{1}^{\prime} \\
(\mathrm{kPa})\end{array}$ & $\begin{array}{c}\sigma_{3}^{\prime} \\
(\mathrm{kPa})\end{array}$ & $\begin{array}{c}\text { Peak friction } \\
\text { angle }\left(^{\circ}\right)\end{array}$ \\
\hline $1 \mathrm{G}$ & 8.8 & $5 \mathrm{kPa}$ & - & & & - & - \\
\hline $1 \mathrm{H}$ & 30.0 & $5 \mathrm{kPa}$ & - & & & - & - \\
\hline $1 \mathrm{I}$ & 62.5 & $5 \mathrm{kPa}$ & 2123.1 & & & 750.0 & 36.0 \\
\hline $1 \mathrm{D}$ & 28.9 & $30 \mathrm{kPa}$ & 838.0 & & & 347.1 & 33.2 \\
\hline $1 \mathrm{E}$ & 48.8 & $30 \mathrm{kPa}$ & 1399.7 & & & 515.1 & 35.2 \\
\hline $1 \mathrm{FA}$ & 63.8 & $30 \mathrm{kPa}$ & 2136.3 & & & 744.2 & 36.1 \\
\hline Test & $\begin{array}{l}\text { RD } \\
(\%)\end{array}$ & $\begin{array}{c}\sigma_{c}^{\prime} \\
(\mathrm{kPa})\end{array}$ & $\begin{array}{c}q_{u l t m} \\
(\mathrm{kPa})\end{array}$ & $\begin{array}{c}\sigma_{1}^{\prime} \\
(\mathrm{kPa})\end{array}$ & $\begin{array}{c}\sigma_{3}^{\prime} \\
(\mathbf{k P a})\end{array}$ & $\begin{array}{c}\mathbf{p}^{\prime} \\
(\mathrm{kPa})\end{array}$ & $\begin{array}{c}\text { Residual } \\
\text { friction angle } \\
\left.\text { ( }^{\circ}\right)\end{array}$ \\
\hline $1 \mathrm{G}$ & 8.8 & $5 \mathrm{kPa}$ & 239.1 & 345.9 & 106.9 & 72.4 & 31.9 \\
\hline $1 \mathrm{H}$ & 30.0 & $5 \mathrm{kPa}$ & 710.1 & 1039.7 & 329.7 & 295.33 & 31.2 \\
\hline 1I & 62.5 & $5 \mathrm{kPa}$ & 1783.5 & 2547.1 & 763.7 & 1358.14 & 32.6 \\
\hline $1 \mathrm{D}$ & 28.9 & $30 \mathrm{kPa}$ & 760.0 & 1120.3 & 360.3 & 565.8 & 30.9 \\
\hline $1 \mathrm{E}$ & 48.8 & $30 \mathrm{kPa}$ & 1240.5 & 1786.9 & 546.4 & 959.9 & 32.1 \\
\hline $1 \mathrm{FA}$ & 63.8 & $30 \mathrm{kPa}$ & 1724.4 & 2490.1 & 765.8 & 1340.6 & 32.0 \\
\hline
\end{tabular}

An additional analysis was performed to determine the critical state line. The critical state has been defined as the state at which the soil "continues to deform at constant stress and constant void ratio" (Roscoe et al., 1958). In an undrained test, the sample remains at a constant voids ratio, but the effective stress will alter to bring the sample into an ultimate state such that the particular voids ratio, at which it is compelled to remain during shear, becomes a critical voids ratio $\left(e_{c}\right)$ (Roscoe et al., 1958). In any series of undrained tests, the set of critical voids ratio points so defined can be expected to lie in or near a line on the undrained yield surface. This is obtained by plotting the void ratio and corresponding mean stress $\left(p^{\prime}\right)$. The critical state line can be estimated by fitting a best line through the data points $p^{\prime}-e$ (Fig. 2.7). The $p^{\prime}$ values used for the determination of the critical state line are included in Table 2.5 . 


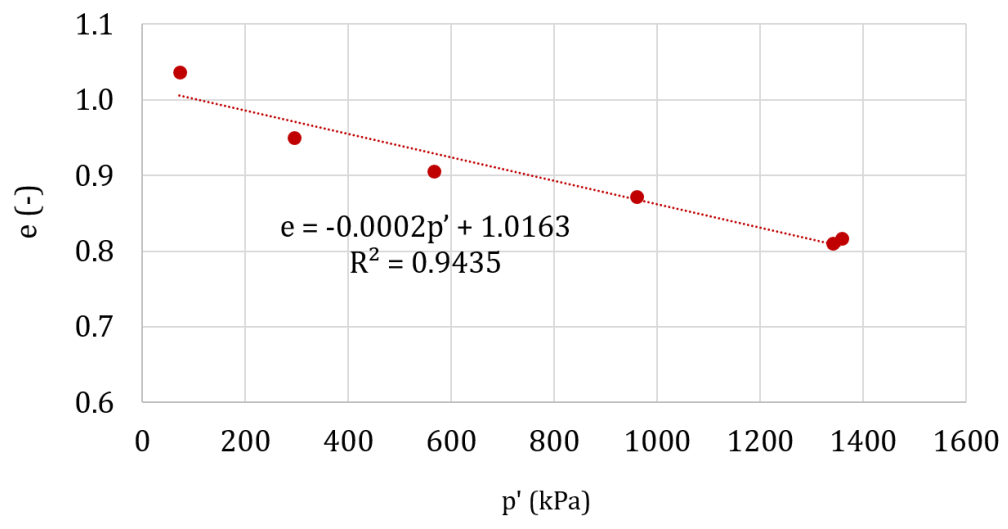

Figure 2.7: Critical state line in $p^{\prime}$-e space. 


\subsection{Permeability tests}

Unlike previous work that has relied on empirical equations, the saturated hydraulic conductivity of sand samples with different porosities was measured using a constant-head method (Reynolds et al., 2002). This procedure allows water to move through the sand under a steady-state head condition while the volume of water flowing through the sample is measured over a certain period (Terzaghi et al., 1996). The hydraulic conductivity (K, $\mathrm{cm} / \mathrm{s}$ ) was calculated using the following equation:

$$
K=\frac{Q L}{A h}
$$

where $Q$ is the water discharge $\left(\mathrm{cm}^{3} / \mathrm{s}\right), L$ is the length of the specimen (cm), $A$ is the crosssectional area of the specimen $\left(\mathrm{cm}^{2}\right)$, and $h$ is the hydraulic head difference $(\mathrm{cm})$.

The experimental setup and procedure described by Zhuang et al. (2017) was used to measure the hydraulic conductivity of sand BR37 at different porosities (Figs. 2.8 \& 2.9). A custom-built Plexiglas cell was used for the sand samples (Fig. 2.9a). The dimensions of the cell were $3 \mathrm{~cm}$ (height) by $3 \mathrm{~cm}$ (length) by $2 \mathrm{~cm}$ (width). At the bottom of the sand cell, a 5-mm hydrophilic nylon membrane was held by a stainless-steel porous plate to serve as a capillary barrier. The water reservoir at the bottom of the setup was connected to a small hanging water column, which was used to control the pressure head at the outlet. Water in the small hanging column could overflow during drainage, while extra water was added to keep the water head in the column constant during imbibition (Zhuang et al., 2017).

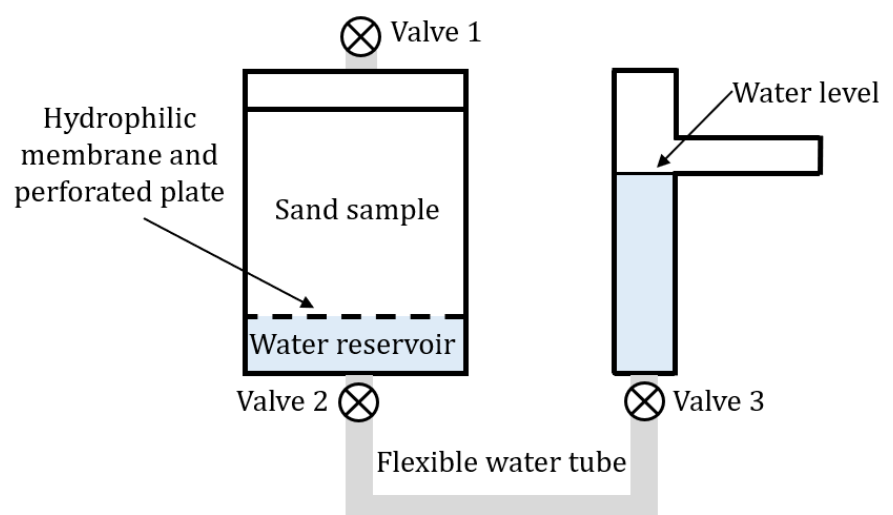

Figure 2.8: Schematic view of the experiment setup for the constant-head experiments (modified from Zhuang et al., 2017). 
Several tests were performed for different soil samples with various relative densities. The desired density of the mass of sand was calculated with the equations (2.3) and (2.4). Wet pluviation was used for sample preparation to ensure water saturation and get a uniform flow of the water through the sample during the test. The tests were performed with a duration of $1 \mathrm{~min}$, and for each porosity the test was repeated two times. The average of the measured water volume at the end of each test was used for the $Q$ calculation for each density. The parameters for each density are presented in Table 2.6.

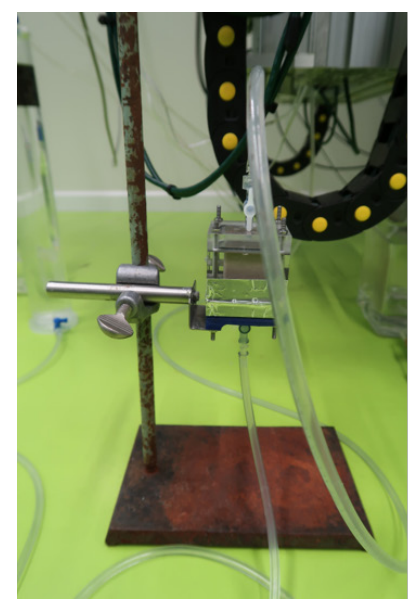

a)

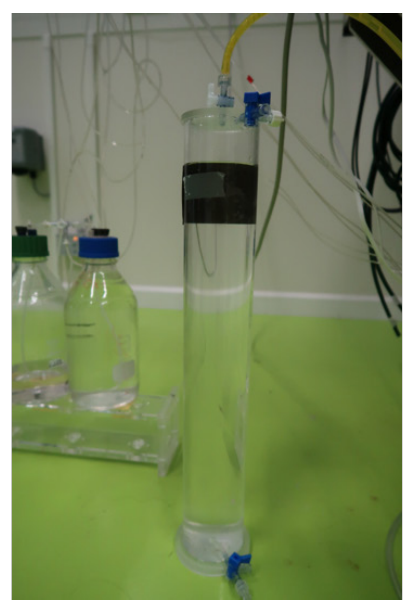

b)

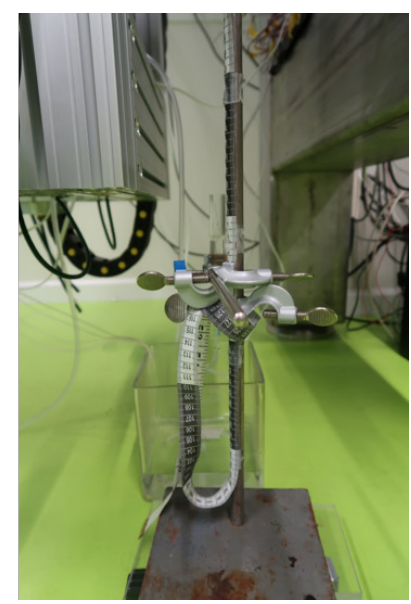

c)

Figure 2.9: Different parts of the setup: a) plexiglas cell with the sample, b) water reservoir, c) flowing water measurement.

Table 2.6: Parameters for the tests to calculate the hydraulic conductivity and permeability.

\begin{tabular}{|c|c|c|c|c|c|c|}
\hline Test & $\begin{array}{l}\text { RD } \\
(\%)\end{array}$ & $\begin{array}{c}\eta \\
(-)\end{array}$ & $\begin{array}{l}M_{s} \\
(g)\end{array}$ & $\begin{array}{c}Q \\
\left(\mathrm{~cm}^{3} / \mathrm{s}\right)\end{array}$ & $\begin{array}{c}K \\
(\mathrm{~cm} / \mathrm{s})\end{array}$ & $\begin{array}{c}k \\
\left(\mathrm{~m}^{2}\right)\end{array}$ \\
\hline Test A & 30 & 0.487 & 24.46 & 0.0817 & $5.67 \times 10^{-3}$ & $5.78 \times 10^{-12}$ \\
\hline Test B & 50 & 0.465 & 25.51 & 0.0667 & $4.63 \times 10^{-3}$ & $4.72 \times 10^{-12}$ \\
\hline Test C & 60 & 0.454 & 26.07 & 0.0650 & $4.51 \times 10^{-3}$ & $4.60 \times 10^{-12}$ \\
\hline Test D & 70 & 0.441 & 26.65 & 0.0583 & $4.05 \times 10^{-3}$ & $4.13 \times 10^{-12}$ \\
\hline Test E & 100 & 0.401 & 28.56 & 0.0433 & $3.01 \times 10^{-3}$ & $3.07 \times 10^{-12}$ \\
\hline
\end{tabular}


In order to calculate the hydraulic conductivity for any porosity value, these values were plotted in a graph and a linear trend line was defined (Fig. 2.10). With this, there is an equation for the hydraulic conductivity as a function of porosity. The $\mathrm{R}^{2}$ value of 0.9764 indicates a good fit of the trend line to the actual data.

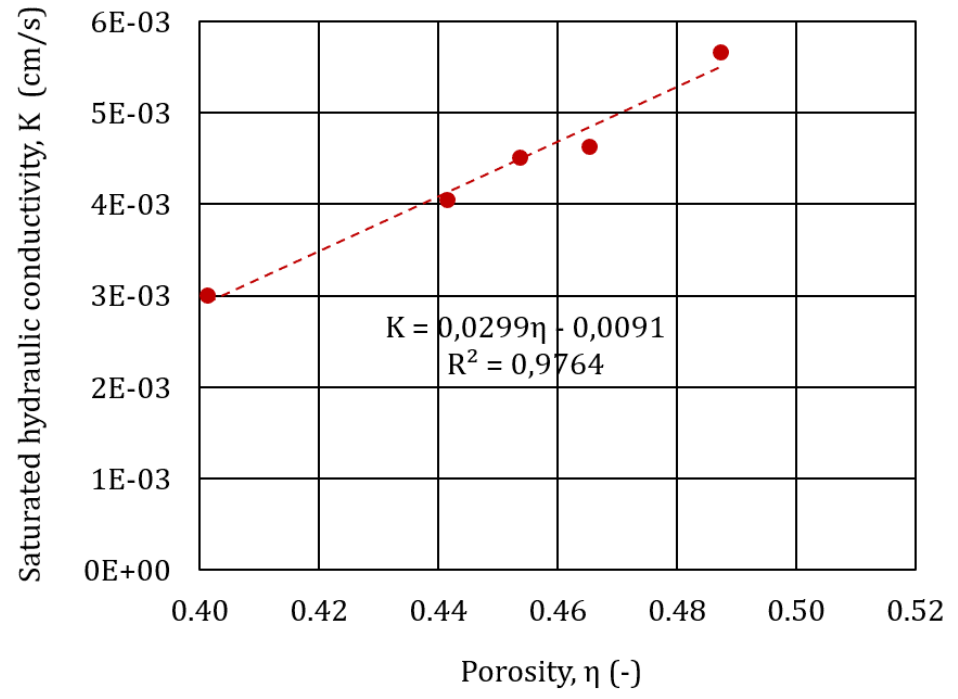

Figure 2.10: Saturated hydraulic conductivity of the sand for different porosity values.

Another property related to fluid flow through a flow slides, which is used in this thesis in Chapter 3 of this thesis, is the permeability $\left(k, \mathrm{~m}^{2}\right)$, which is the ability of fluid to flow through a porous medium (Bowles 1979). Whereas hydraulic conductivity depends on the properties of the fluid as well (saturation, viscosity, and density), permeability is an intrinsic property of a porous medium. It depends on the porosity, but also on the shape and size of the pores in the medium and their level of connectivity. Permeability can be calculated from the hydraulic conductivity through the following relation:

$$
k=K \frac{\mu}{\rho_{f} \times g}
$$

where $\mu$ is the dynamic viscosity of the fluid used to determine the hydraulic conductivity $[\mathrm{kg} /(\mathrm{m} \cdot \mathrm{s})], \rho_{f}$ is the density of the fluid $\left(\mathrm{kg} / \mathrm{m}^{3}\right)$, and $g$ the acceleration due to gravity $\left(\mathrm{m} / \mathrm{s}^{2}\right)$. 
Since the fluid used in the hydraulic conductivity tests was water, the dynamic viscosity and the density are properties of water here with values 0.001 and 1000 , respectively.

The permeability values are presented in Table 2.6. These values were plotted in a graph and a linear trend line was defined with $\mathrm{R}^{2}$ value of 0.9764 (Fig. 2.11).

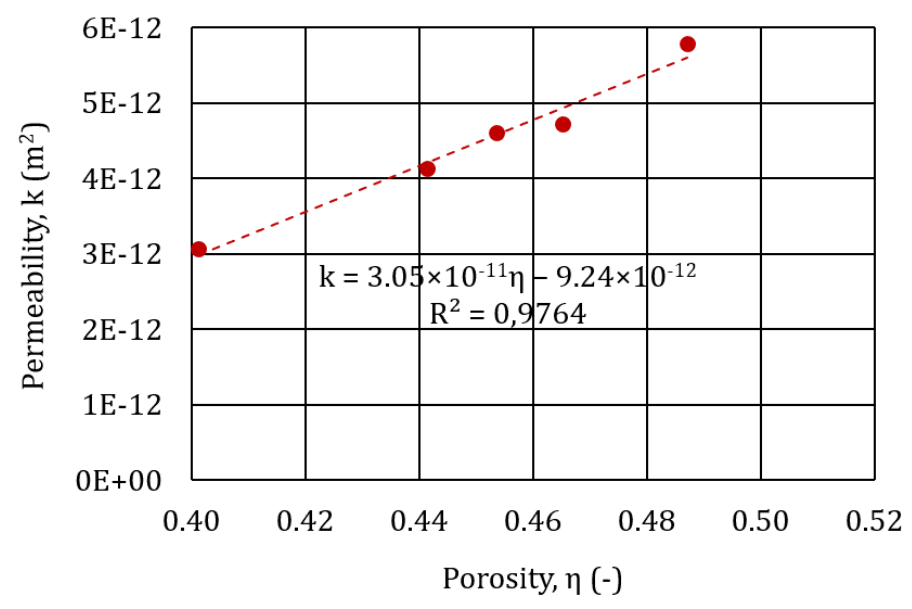

Figure 2.11: Permeability of the sand for different porosity values. 


\subsection{Summary}

The purpose of this chapter was to characterise the quartz sand that was used in the experiments presented in this thesis.

The sand consists of $97 \%$ silica with a median grain size of $140 \mu \mathrm{m}$, and it was classified as poorly graded. The minimum and maximum porosity were determined with values of 0.40 and 0.52 , respectively.

A series of standard consolidated and undrained triaxial tests were performed at different relative densities to determine the shear strength parameters. The tested confining pressures were $5 \mathrm{kPa}$ and $30 \mathrm{kPa}$. Averaging the values obtained for the tests, the sand has a peak friction angle of $35^{\circ}$, and a residual angle of $31.7^{\circ}$.

Permeability tests were also conducted to evaluate the saturated hidraulic conductivity and permeability. with values of order of $10^{-3}$ and $10^{-12}$, respectively. 


Chapter

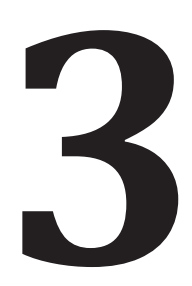

\section{Hybrid dilative-contractive behaviour in underwater flow slides}

"Every experiment proves something. If it doesn't prove what you wanted it to prove, it proves something else." 


\subsection{Introduction}

Flow slides are common features along steep channel banks in estuaries and large rivers that consist of fine sands. They are commonly distinguished as breaching (Van Rhee \& Bezuijen, 1998; Van den Berg et al., 2002; Eke et al., 2011) and liquefaction (Terzaghi, 1957; Lade, 1992; Hampton et al., 1996). The fundamental difference between them is caused by the undrained strength of granular materials, which is governed by the packing density of the sediment particles in the embankment (Duncan et al., 2014).

The first type, breaching, mostly occurs in densely packed fine sands with low permeability. Breaching is characterised by nearly vertical failure angles, slow and steady retrogressive erosion rates, and production of sustained turbidity currents (Van den Berg et al., 2002; Mastbergen \& Van den Berg, 2003; Eke et al., 2011; You et al., 2012, 2014a,b).

During the initiation of the breaching failure, deformation is related to local reorganisation of grains to more densely packed configurations (Fig. 3.1ai; Fig. 3.1bi). This initial contraction comes to a halt when the maximum packing density is reached. Further deformation can proceed only if some grains can move up and over other particles which requires an increase in bulk volume (Fig. 3.1aii; Fig. 3.1bii). This increase in volume as a result of shear deformation was discovered by Reynolds (1885) and it is called dilatancy. Dilatancy can occur rapidly only if the pore fluid can freely flow through the medium. This is termed "drained deformation" and can occur when the medium is sufficiently permeable to allow fast fluid flow, or if the failure is sub-aerial and the pores between the grains are partly filled with air. In fully drained conditions, changes in load do not cause changes in pore pressure within the soil.

Breaching occurs under partially drained conditions since the time scale for the fluid dissipation in a densely packed sand is longer than the generation of excess pore pressure. The process starts when a slope, steeper than the internal friction angle, is not stable and will start to shear. During dilatancy, the pore volume increases which is compensated by water inflow. This mechanism results in a negative pore pressure, with respect to hydrostatic pressure, and an increase of the effective stress. This reduced pore water pressure can temporarily keep the sand body stable. As water flows into the pores, due to the inward hydraulic gradient, sand particles are released one by one at the sand-water interface. This results in a steep breach face slowly regressing from its original position. The falling grains mix with water and develop a turbulent sand-water mixture, called turbidity current, flowing over and interacting with the slope surface (i.e. breach face) eventually causing erosion. This slope only fails gradually, since the negative pore pressure is released slowly by water flowing in from the ambient fluid (Van Rhee \& Bezuijen, 1998; Van den Berg et al., 2002). This local release of negative excess pore pressure results in a retarded (in 
some cases grain-by-grain) failure at the breach face (Van Rhee \& Bezuijen, 1998; Van den Berg et al., 2002; Eke et al., 2011).

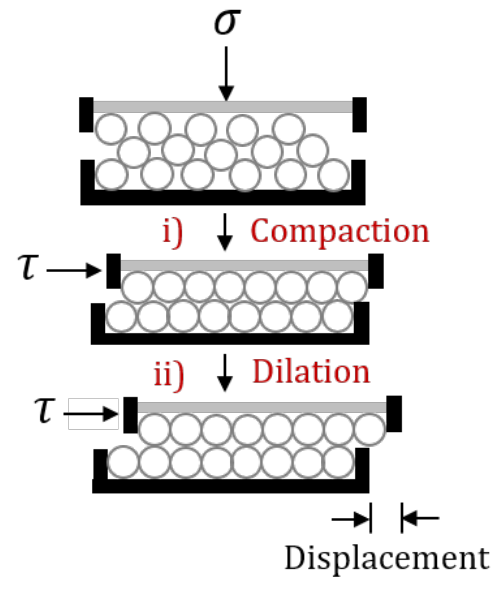

a)

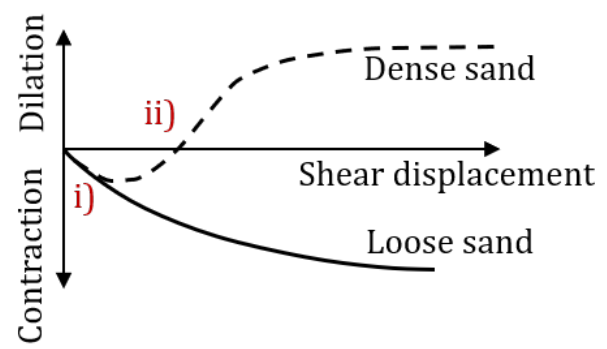

b)

Figure 3.1: a) Shear box test in a dense sand sample; b) volume change relationships during shear of a granular soil (adapted from Terzaghi et al., 1996).

In contrast, the second type of failure, liquefaction, is triggered in loose sand (Lade, 1992), and is a phenomenon in which a mass of sand on a subaqueous slope suddenly starts behaving like a viscous fluid (Silvis \& de Groot, 1995). Since the initial state is loose, there is no significant particle interlocking to overcome, and the particles tend to get closer together (Fig. 3.1bi), as the soil is disturbed. The pore pressure increases and under drained conditions the water leaves the sand deposit instantaneously.

However, if the load is rapidly applied and the water is temporarily retained in the pores (partially drained conditions), the pore pressure increases with a consequent decrease of the effective stresses. The sand deposit loses its strength and starts to behave with the consistency of a liquid. Results from flume experiments performed by Bezuijen \& Mastbergen (1988) show that the pore pressure rises from zero to values indicating almost complete liquefaction within $0.1 \mathrm{~s}$. Afterwards, the actual slide and the dissipation of pore pressures can last approximately one minute.

It becomes clear from this overview that previous research has resulted in a profound understanding of liquefaction and breaching failure mechanisms that can occur in underwater flow slides. However, previous work predominantly focussed on either 
breaching or liquefaction flow slides. No previous work has documented failures at the transition between breaching and liquefaction in intermediate packing densities despite the fact that these are more common under natural conditions.

In this chapter, the influence of the initial embankment porosity during a slope failure was studied. For the most loose, the sand deposit contracted and suddenly collapsed behaving like a fluid; the most dense maintained a vertical failure with the generation of negative excess pore pressure. Both of these behaviours are entirely in line with published end-member studies of loose and dense sand failures. A new style of hybrid failures is presented for intermediate packing densities comparable to natural conditions, where a combination of dilative and contractional behaviour is observed within a single underwater flow slide. Existing models and prediction programs of underwater flow slides need to be extended to these hybrid dilative-contractional failures for an accurate understanding and prediction of flow slides. 


\subsection{Experimental method}

\subsubsection{Experimental setup and materials}

The experiments were conducted in the Eurotank Flume Laboratory at Utrecht University. The experimental setup consists of a $4 \mathrm{~m}$ long, $0.5 \mathrm{~m}$ deep and $0.22 \mathrm{~m}$ wide rectangular flume (Fig. 3.2). The flume has a horizontal false floor of plexiglass. Sand was glued to this floor to generate roughness and friction between the floor and the flow slide. To avoid extra pressures, a plexiglass box with a permeable boundary was placed behind the soil at the back of the flume.

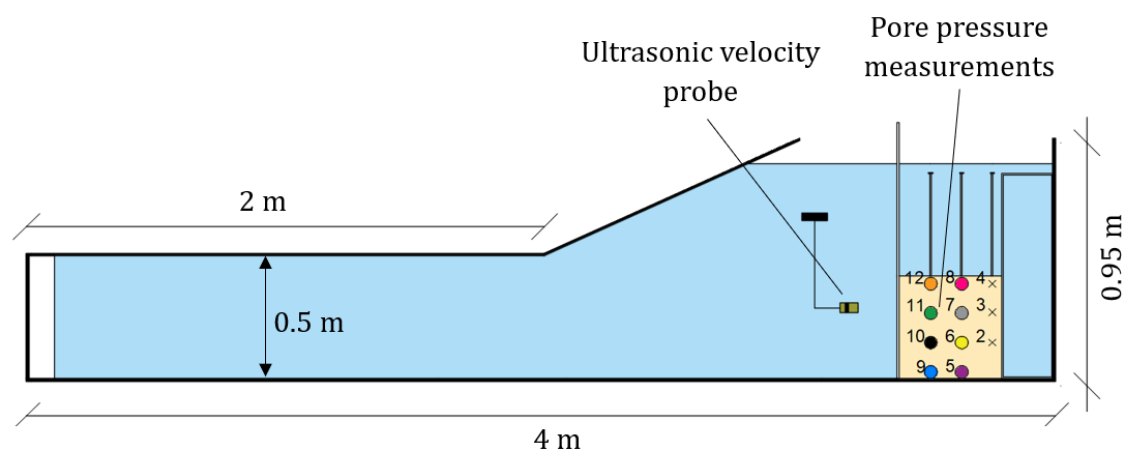

Figure 3.2: Schematic overview of the 2D experimental setup and location of the instrumentation used during the experiments.

The material used to build the sand deposit was quartz sand (Sibelco BR37). Its detailed characterisation is displayed in the previous Chapter 2. A brief review of the main properties used in this chapter is given in Table 3.1.

Table 3.1: Properties of the sand used in the experiments.

\begin{tabular}{ccccc}
\hline \hline Material & $\begin{array}{c}\boldsymbol{D}_{\text {50 }} \\
(\boldsymbol{\mu m})\end{array}$ & $\begin{array}{c}\boldsymbol{\rho}_{\boldsymbol{s}} \\
\left(\mathbf{k g} / \mathbf{m}^{3}\right)\end{array}$ & $\begin{array}{c}\boldsymbol{\eta}_{\text {min }} \\
(-)\end{array}$ & $\begin{array}{c}\boldsymbol{\eta}_{\text {max }} \\
(-)\end{array}$ \\
\hline \hline Sand BR37 & 140 & 2650 & 0.40 & 0.52 \\
\hline \hline
\end{tabular}




\subsubsection{Data acquisition}

Pore pressures and the retreat velocity of the failure face were recorded during the experiments. Pore pressures were measured with pressure transducers. The retreat velocity of the breaching front was measured with an Ultrasonic Velocity Profiler (UVP). A LabView control was used to synchronise the UVP probes and the pore pressure transducers, to ensure that the instruments started measuring at the same time. All experiments were monitored and recorded with a video camera.

\section{Pressure transducers}

To monitor the pore pressure, eleven differential pressure transducers ( $T$; Honeywell 24PCBFA6G) were used with a pressure range of $\pm 34.5 \mathrm{kPa}$. The voltage output from the transducers was recorded with a data logger of National Instruments (USN 6218). The record sampling was 200 samples per second for each transducer. A Virtual Instrument was developed in LabView to test, control and record the pore-pressure measurements during the experiments. The transducers were positioned outside the experiment to ensure that the membrane of the transducers was not damage by the sand. One port of each transducer was connected to a plastic tube with an inside diameter of $2 \mathrm{~mm}$. This diameter was adopted after several table-top tests of signal propagation with different diameters. The $2 \mathrm{~mm}$ diameter exhibited the smallest time lag for this type of experiments. The tube was filled with water, paying attention to removal of air bubbles. The opposite end of the tube was placed in the desired position within the experimental setup. The second port of each pressure tube was left in open communication with the air. All measurements were, therefore, referenced to atmospheric pressure. The transducers were calibrated by changing the water level in a small container in a table-top experiment. The calibration factor was calculated from the changes in output voltage per unit change in water pressure. Eleven different positions inside the sand body were used to record the pore pressure during the experiments. They were placed at the centre line of the flume, at $12 \mathrm{~cm}$ intervals and $2 \mathrm{~cm}$ from the bottom and the top of the sand deposit (Fig. 3.2).

\section{$\underline{U V P}$}

One Ultrasonic Velocity Profiler probe (Met-Flow UVP Duo MX; 1 MHz probe) was installed in the flume to monitor the flow slide during the experiments. The probe was placed $10 \mathrm{~cm}$ from the sand deposit to study the retreat rate of the breach face (Fig. 3.2). The retreat rate is quantified as the velocity of the breach face regression during the failure of the deposit. 


\subsubsection{Experimental procedure}

The flume was filled with fresh water up to a level of $0.85 \mathrm{~m}$ above the floor of the flume. The tubes of the transducers were filled with water and the pressure of each transducer was set to 0 at the Virtual Instrument in LabView. A removable vertical confining plate was inserted in place to constrain the sand while building the deposit. The confining plate was made of plexiglass with several $1 \mathrm{~cm}$ wide holes so porewater could escape through the permeable boundary during the building of the sand deposit. A steel mesh with a mesh size of $34 \mu \mathrm{m}$ was fixed on the inside of the confining plate to maintain the sand in place.

The sand was weighed before it was placed behind the confining plate. Initial porosity of the sand deposit was varied from 0.432 to 0.493 by following different preparation protocols. To achieve low porosities, the sand was compacted during the building of the deposits with a circular disk. The sand was compacted in layers, each of which had a thickness of 5 or $10 \mathrm{~cm}$, depending on the intended level of compaction (i.e., porosity). Two additional protocols were applied to achieve high initial porosities: one consisted of pouring the sand through the water column (wet pluviation), whereas for the second protocol the sand was fluidised by a fluidisation device at the bottom of the flume to create a low compaction. The final geometry of the sand deposits was approximately $0.40 \mathrm{~m}$ $(\mathrm{L}) \times 0.22 \mathrm{~m}(\mathrm{~W}) \times 0.40 \mathrm{~m}(\mathrm{H})$ in all experiments. It was calculated the average porosity for each experiment. The uncertainty associated to the porosity was \pm 0.005 and determined from the uncertainty in measuring the weight and volume of the sand deposits. The failure was induced by quickly removing the confining plate manually, resulting in a failure of the sand deposit. Four experiments were conducted to study the influence of the porosity on the type of failure. The initial conditions of the experiments are given in Table 3.2.

Table 3.2: Parameters of the experiments.

\begin{tabular}{ccccccc}
\hline \hline Exp. & Sample preparation & $\begin{array}{c}\boldsymbol{M}_{\boldsymbol{s}} \\
\mathbf{( \mathbf { k g } )}\end{array}$ & $\begin{array}{c}\boldsymbol{V}_{\boldsymbol{s}} \\
\left(\mathbf{m}^{\mathbf{3}} \mathbf{)}\right.\end{array}$ & $\begin{array}{c}\boldsymbol{\eta} \\
\mathbf{\pm 0 . 0 0 5} \mathbf{( - )}\end{array}$ & $\begin{array}{c}\boldsymbol{e} \\
\mathbf{( - )}\end{array}$ & $\begin{array}{c}\mathbf{R D} \\
\mathbf{( \% )}\end{array}$ \\
\hline \hline $\mathrm{A}$ & Wet pluviation + compaction & 53.0 & 0.0352 & 0.432 & 0.759 & 77.63 \\
$\mathrm{~B}$ & Wet pluviation + compaction & 50.9 & 0.0348 & 0.448 & 0.811 & 64.71 \\
$\mathrm{C}$ & Wet pluviation & 49.1 & 0.0357 & 0.481 & 0.926 & 35.88 \\
$\mathrm{D}$ & Fluidisation & 45.5 & 0.0339 & 0.493 & 0.974 & 23.96 \\
\hline \hline
\end{tabular}




\subsection{Results}

The four experiments conducted in this study showed different behaviours ranging from liquefaction to breaching, depending on the initial porosity of the sand deposits. In the following section, the results of each of these four experiments are described in detail.

\subsubsection{Experiment A (dense)}

In experiment $A$ with an initial relatity density of $\sim 78 \%$, the deposit did not collapse and maintained a steep subaqueous slope after the confining plate was removed. Sand particles were released from the sand-water interface, resulting in a slow regression of the breaching front from its original position. The falling grains mixed with the ambient water and generated a turbidity current (Fig. 3.3A). Occasionally, surficial sand layers started to slide downward until they fully disintegrated (Fig. 3.3B). Experiment A was dominated by negative excess pore pressure (Fig. 3.4a-A). These features are characteristic of breaching flow slides.

The maximum negative value was $\cong-0.55 \mathrm{kPa}$, recorded by the transducer 11 immediately after the vertical wall was removed (Fig. 3.4a-A1). During the failure of the sand deposit, the negative excess pore pressure exhibited several peaks, particularly at 15 and $50 \mathrm{~s}$. The first peak, at $\mathrm{t}=15 \mathrm{~s}$, occurred when a surficial sand layer slid down the failure face. The second peak at $t=50 \mathrm{~s}$ was recorded just before the breaching front passed the measurement location, reaching $0 \mathrm{kPa}$ afterwards which is hydrostatic pressure. The pore pressure signal from the second line of the transducers (Fig. 3.4a-A2) revealed similar trends but with a smaller magnitude. From the normalised excess pore pressure, it is observed that the pore pressure tends to zero from the top to the bottom, and the higher absolute values are at the failure surface (Fig. 3.5). The dissipation time of the excess pore pressure, measured from the start of the experiment until the excess pore pressure reached the hydrostatic pressure at $\cong 0 \mathrm{kPa}$, was approximately $90 \mathrm{~s}$ (Fig. 3.6). The average retreat rate of the breaching front was $1.6 \times 10^{-3} \mathrm{~m} / \mathrm{s}$ and constant during the experiment (Fig. 3.7). The retreat rate was calculated from the grain-by-grain failure and does not account for the surficial slides. 

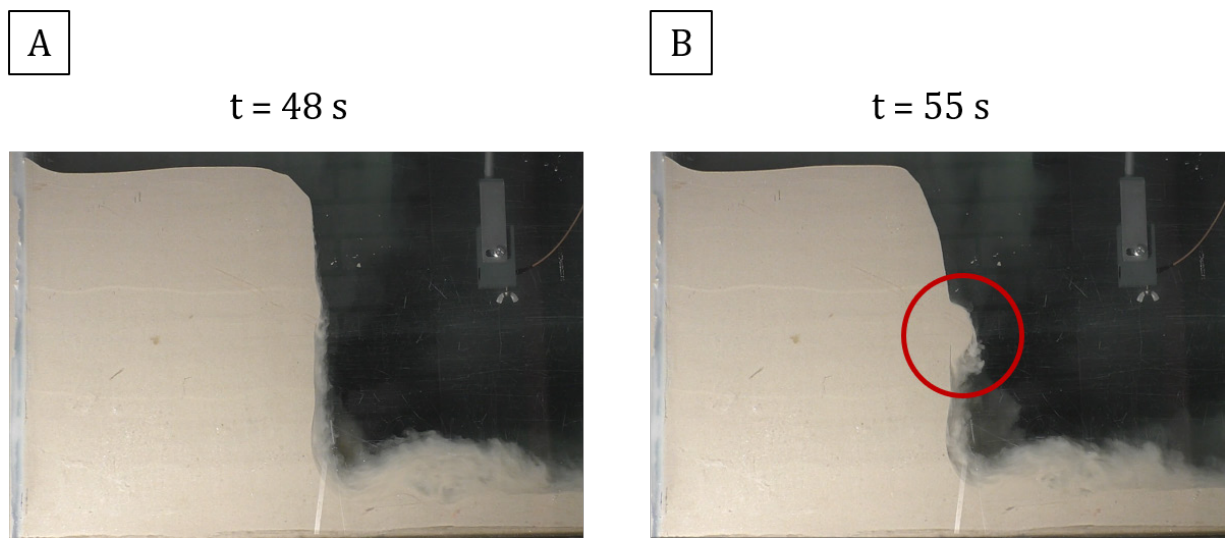

Figure 3.3: Snapshots of experiment $A$ video: (A) falling grains and generated turbidity current; (B) surficial layer sliding downward.

\subsubsection{Experiment B (medium dense)}

Experiment B had a less densely compacted sand compared to experiment A, $\mathrm{RD}=\sim 65 \%$, but also resulted in dilative breach failure (Fig. 3.4a-B). The failure of the sand column depended also on the grain-by-grain release at the failure surface and on the sliding of sand layers down the failure face, which were thicker in this experiment. Despite the difference in density, the normalised excess pore pressure had the same structures as observed in experiment A, with higher absolute values at the failure surface (Fig. 3.5). The pore pressure dissipation time was 66 s, i.e., slightly faster than in experiment A (Fig. 3.6). The excess pore pressures generated during the experiment were more negative, reaching a maximum negative value of $0.9 \mathrm{kPa}$, also registered by transducer 11 . The "peak events" registered in the experiment $B$ were more subtle than in the previous experiment but could be differentiated. Two distinct retreat rates occurred during the experiment. The first rate corresponded to the first half of the experiment and had a value of $3.6 \times 10^{-3} \mathrm{~m} / \mathrm{s}$, and during the remaining time of the experiment the erosion rate was almost the same as in experiment A with a value of $1.6 \times 10^{-3} \mathrm{~m} / \mathrm{s}$ (Fig. 3.7). 


\subsubsection{Experiment C (intermediate)}

Interestingly, experiment $\mathrm{C}$ with an initial relatity of $\sim 36 \%$ resulted in both positive and negative excess pore pressure (Fig. 3.4b-C). Transducers 5, 6, 9 and 10 recorded positive excess pore pressures whereas transducers 7 and 11 recorded negative excess pore pressures. This means that the top of the sand deposit was dilating while the bottom contracted (Fig. 3.5). I termed this hybrid dilative-contractive behaviour, to indicate that both dilative and contractive behaviour occur in a single failure at the same time. Another relevant observation was that the range of pore pressures at the beginning of the experiment is quite wide, from -1.2 to $2.0 \mathrm{kPa}$ (Fig. 3.4b-C), making these the highest pore pressure gradients recorded in any of the experiments. In the hybrid experiment the excess pore pressure decreased from bottom to top, which contrasts to breaching experiments A and B (Fig. 3.5). The dissipation time of $15 \mathrm{~s}$ is much faster than the dissipation time in the breaching experiments $\mathrm{A}$ and $\mathrm{B}$ (Fig. 3.6).

\subsubsection{Experiment D (loose)}

In contrast to the experiments mentioned before, experiment $\mathrm{D}$ with low relative density of $24 \%$ showed mainly contractive behaviour characterised by positive excess pore pressures (Fig. 3.4b-D). When the confining plate was removed, the sand deposit collapsed immediately. The maximum value for the excess pore pressure during the experiment was $1.0 \mathrm{kPa}$, registered by transducer 5 located at the bottom of the deposit. The normalised excess pore pressures indicate that the higher values were at the back and at the base of the failure. This is in contrast with experiments A and B, which had the largest excess pressures at the top and at the front of the failing surface (Fig. 3.5). The time to dissipate the positive excess pore pressure was $17 \mathrm{~s}$ and thus took almost the same time as in experiment $\mathrm{C}$ with the hybrid behaviour (Fig. 3.6). Contrary, the excess pore pressure dissipated within a sixth of the time compared to experiments A and B with densely packed sand (Fig. 3.6). 


\subsubsection{Summary of the results}

In summary, these results indicate that excess pore pressure increases with porosity, from dilative to contractional behaviour (negative to positive pore pressure, respectively) (Fig. 3.4a-A to Fig. 3.4b-D). Furthermore, in experiments A and B excess pore pressure tended to zero from top to bottom of the deposits, whereas experiments $\mathrm{C}$ and $\mathrm{D}$ showed the opposite trend, i.e., from bottom to top (Fig. 3.5). Another noteworthy aspect is the decrease of the dissipation time with the increase of the porosity, which means that the excess pore pressure needs more time to dissipate in experiments A and B with densely packed sand (Fig, 3.6). 

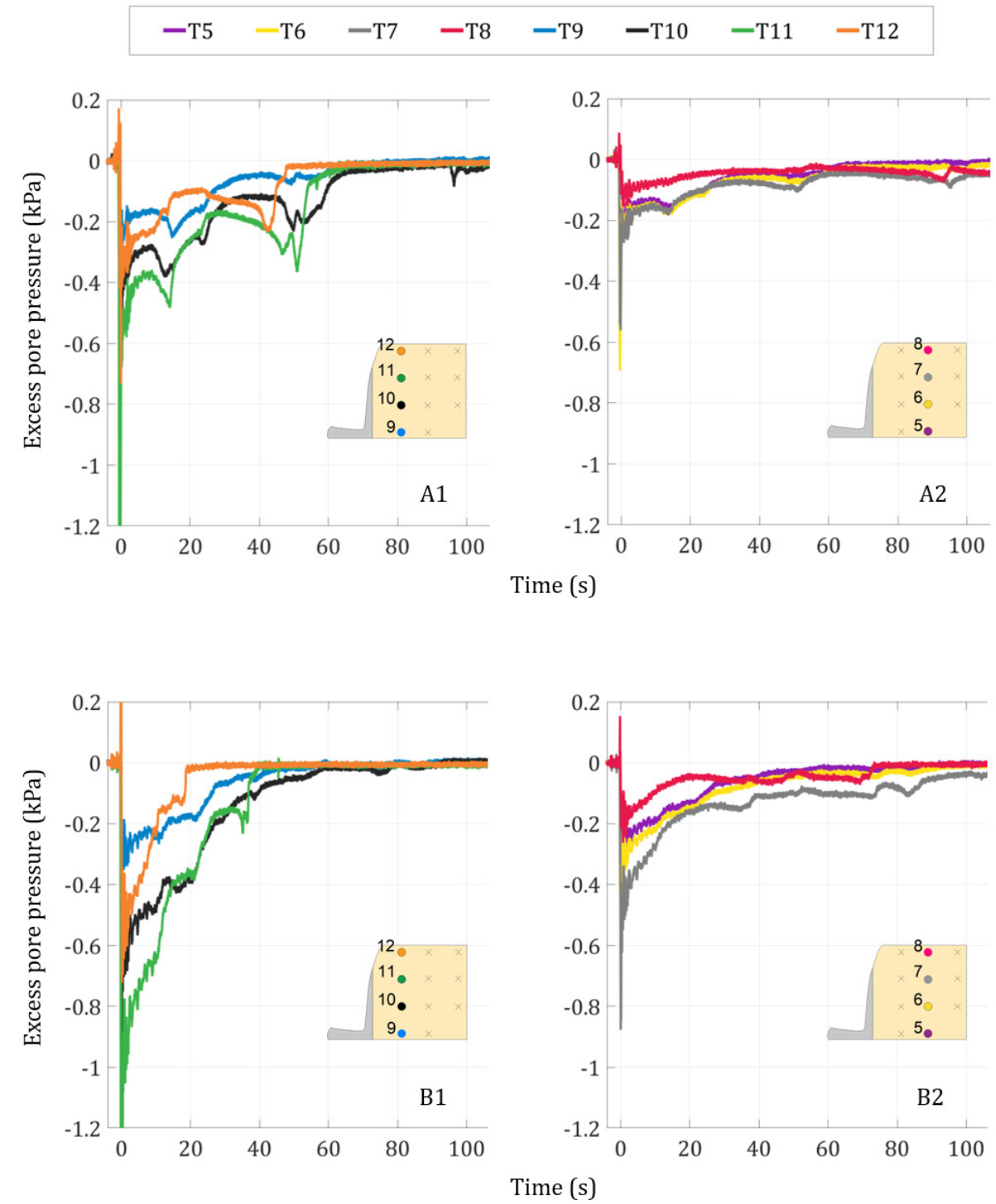

Figure 3.4a: Excess pore pressure against time for experiment $A(A 1, A 2)$ and experiment $B(B 1$, B2). 


$\begin{array}{llllllll}-\mathrm{T} 5 & -\mathrm{T} 6 & -\mathrm{T} 7 & -\mathrm{T} 8 & -\mathrm{T} 9 & -\mathrm{T} 10 & -\mathrm{T} 11 & -\mathrm{T} 12\end{array}$
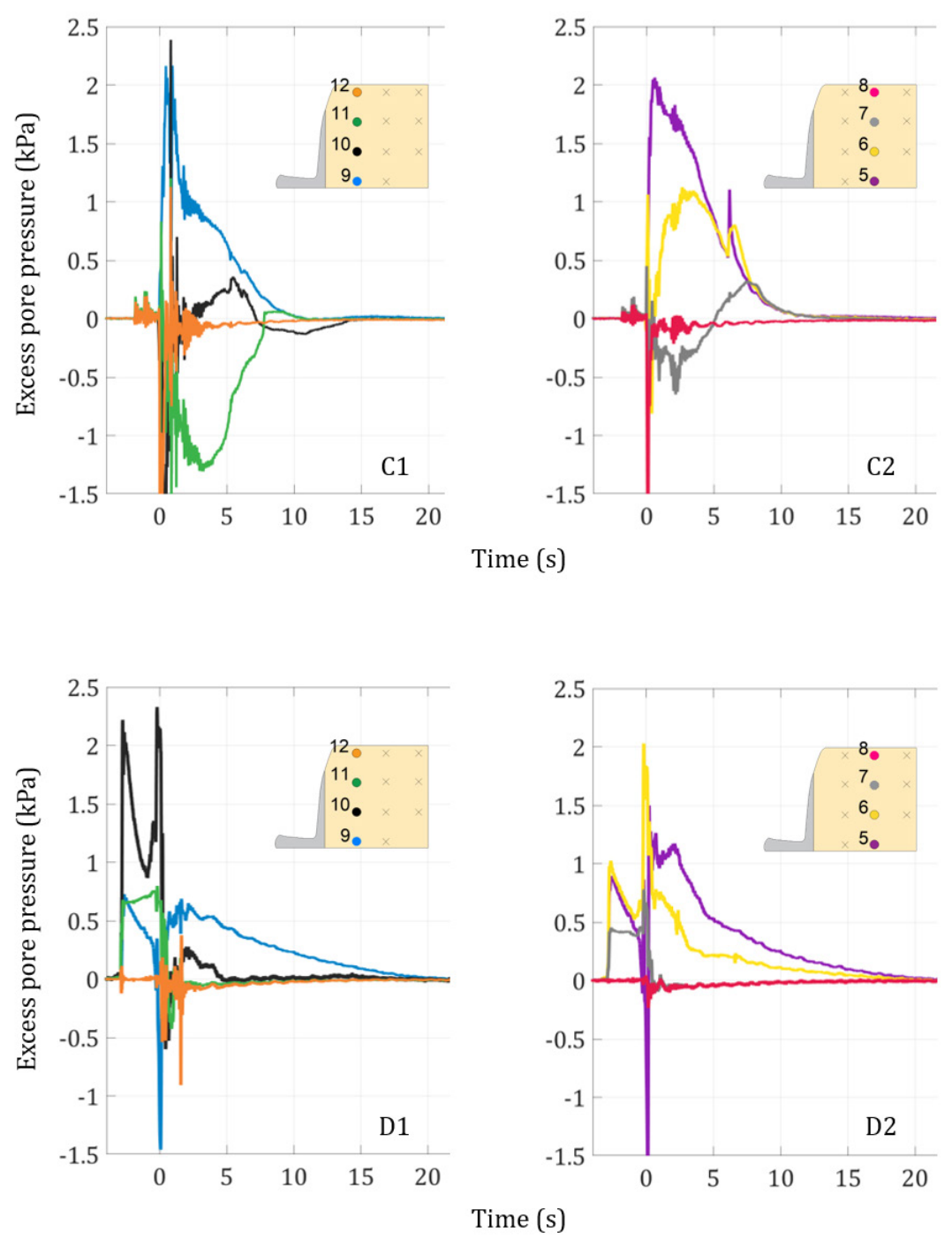

Figure 3.4b: Excess pore pressure against time for experiment $C(C 1, C 2)$ and experiment $D(D 1$, D2). 
Experiment A

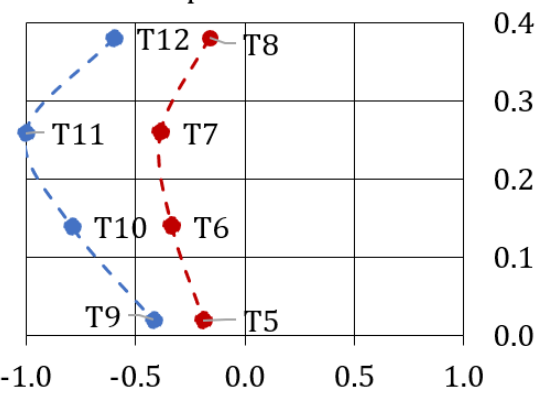

Experiment $\mathrm{C}$

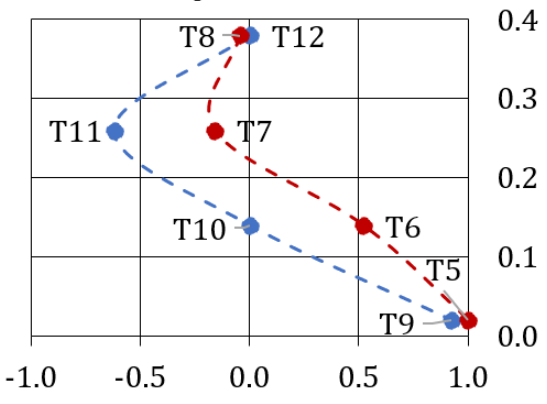

Excess pore pressure (-)
Experiment B

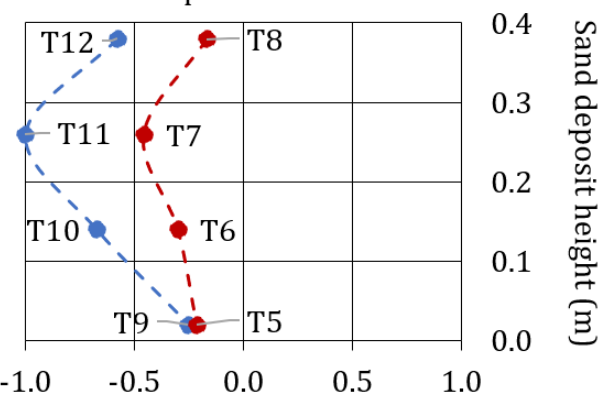

Experiment D

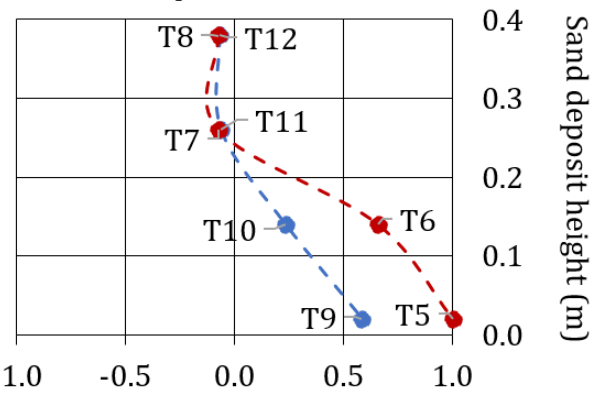

Excess pore pressure (-)

Figure 3.5: Initial excess pore pressure in different positions (cross section) of the sand deposit (normalised with the maximum excess pore pressure in each experiment) (see Figure 3.2 for positions). 


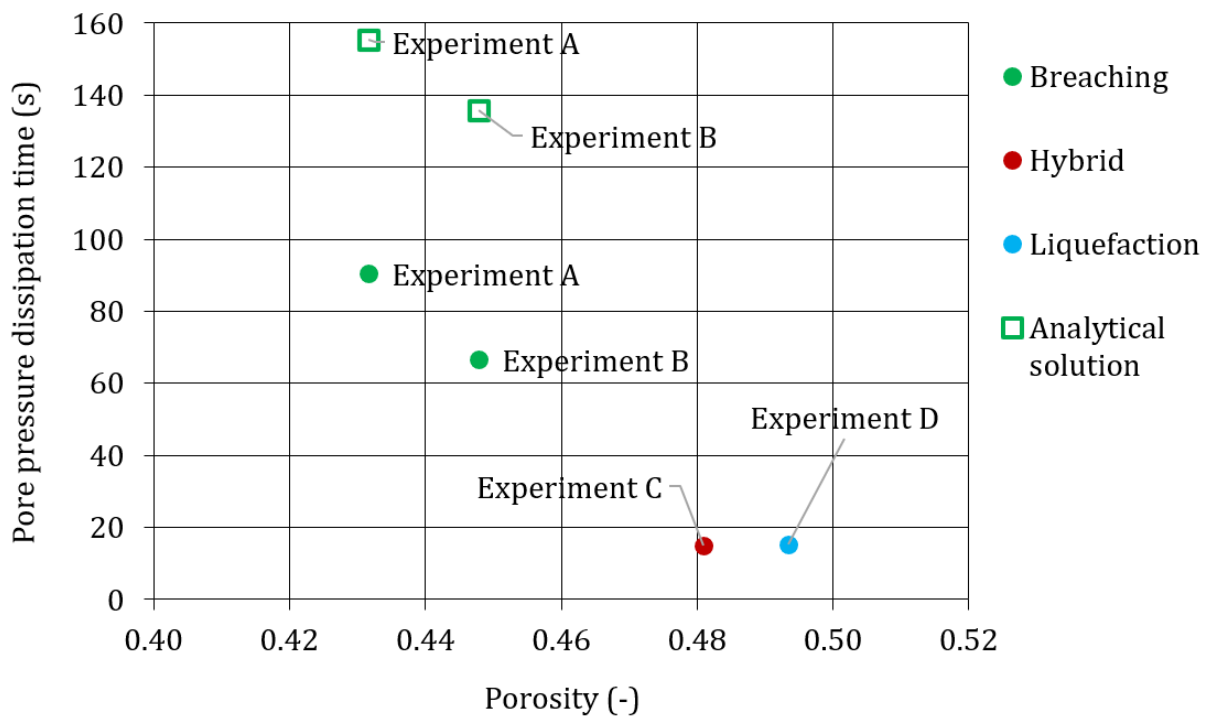

Figure 3.6: - Pore pressure dissipation time for each experiment $(\square$ analytical solution for experiments $A$ and $B$ ).

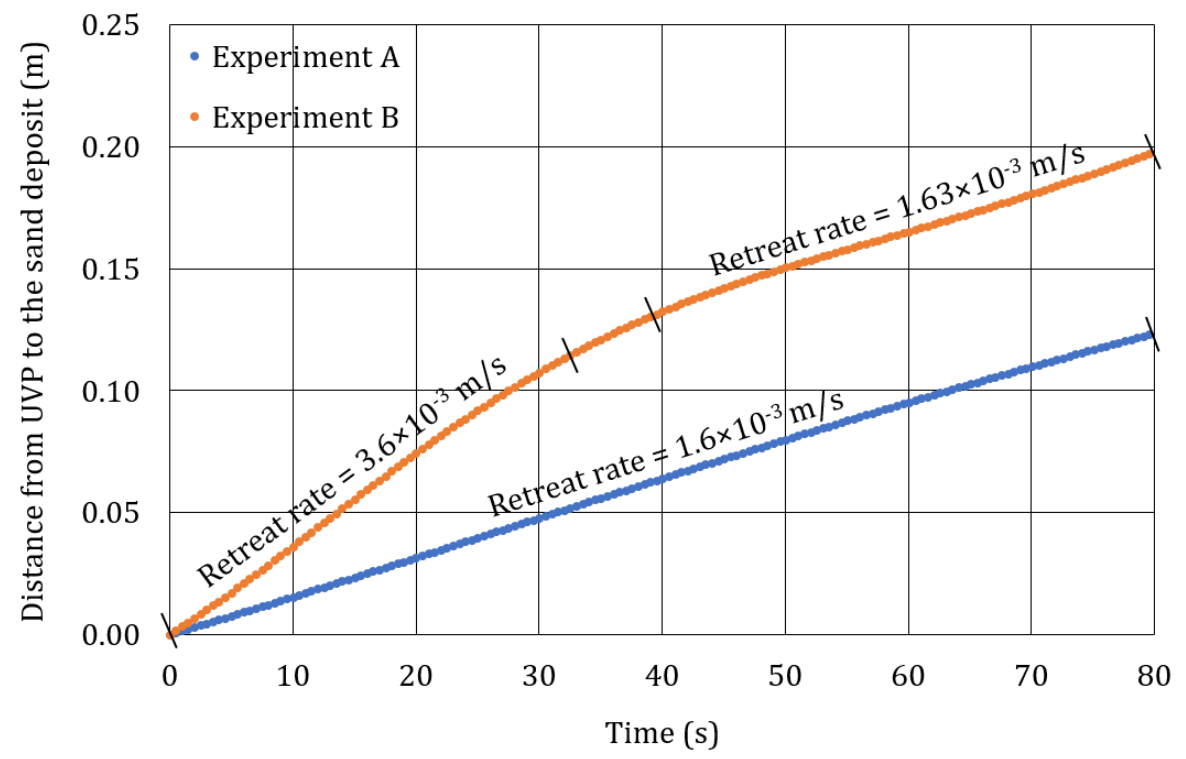

Figure 3.7: Retreat rate during breaching experiments $A$ and $B$. 


\subsection{Discussion}

\subsubsection{Influence of initial embankment porosity on breach failure evolution}

Experiments A and B were carried out with densely packed sand, and they broadly display similar characteristics in both evolution through time and spatial structure. These characteristics are indicative of breaching flow slides, and they are discussed here first.

When the vertical plate is removed, the pore pressure drops abruptly (Fig. 3.4a) and the deposit maintains a nearly vertical front. This is the result of shear dilation caused by the removal of the confining vertical plate (Casagrande, 1936; Skempton, 1954; Iverson et al., 2000; You et al., 2012, 2014a,b). A secondary pore pressure decrease occurs when the breaching front approaches the location of the transducers. Just before the breaching front passes the sensor, the pore pressure suddenly rises to hydrostatic pressure (Fig. 3.4a). This is in agreement with Van Rhee \& Bezuijen (1998) and You et al. (2012, 2014a). The dilatancy is higher near the sand-water interface (You et al., 2014b) since the grains are free to move.

Experiments A and B have almost the same spatial pore pressure structure when the excess pore pressure is normalised with the maximum excess pore pressure in each experiment (Fig. 3.5). In both experiments, the most negative excess pressures are measured near the top of the experiment, close to the failure surface by transducer 11 . The excess pressure tends to zero from this location to the bottom and towards the top of the experiment (Fig. 3.5).

During the failures in both experiments, the dominant process was grain-by-grain failure and occasionally surficial slides. These surficial slides were also first noticed by Van Rhee \& Bezuijen (1998), and later by Van den Berg et al. (2002) and You et al. (2013). They seem to occur when the turbidity current erodes the lower part of the breach face (You et al., 2013). Consequently, the upper wedge of the deposit is pending, which creates an instability leading to failure of the wedge. We can assume that surficial slides are an intrinsic property of breaching (Van den Berg et al., 2017). The magnitude of failure-surface retreat rates during experiments A and B (Fig. 3.7) are in agreement with the literature; in flume experiments, Van Rhee \& Bezuijen (1998) measured a retreat rate of $6 \mathrm{~mm} / \mathrm{s}$ for a breach height of 2.3 $\mathrm{m}$, You (2013) obtained a value of $1.4 \mathrm{~mm} / \mathrm{s}$ for a $0.30 \mathrm{~m}$ high breach, and You et al. (2014) calculated an average erosion rate of $2.5 \mathrm{~mm} / \mathrm{s}$ from $1 \mathrm{~m}$ tall breach. From field examples, Beissen et al. (2014) visually estimated a retreat rate of $13.3 \mathrm{~mm} / \mathrm{s}$ with a breach height of 6-7 $\mathrm{m}$ at Amity Point. Despite these similarities in breach characteristics, the different initial porosities between experiments $A$ and $B$ resulted in some marked differences in the retreat rate of the breach failures. 
First, there is a difference in the retreat rate of the breach front: in the first half of the experiments the failure in experiment $B$ retreats twice as fast as the failure in experiment A (Fig. 3.7). A related result to the contrasting retreat rates is the difference in time needed to dissipate the excess pore pressures, which here it is called dissipation time scale $\left(\mathrm{T}_{\text {diss }}\right)$. The dissipation timescale of experiment B is $66 \mathrm{~s}$, while pressures dissipated over $90 \mathrm{~s}$ in experiment A. Three factors need to be considered to fully explain this difference in progression rate of the breaching failures: 1) the effect of porosity on permeability, 2) the magnitudes of negative excess pore pressures, and 3) the dilation needed for grains to move freely.

Experiment B had a higher initial porosity than experiment A, which means there was a greater volume of voids in experiment $B$, and the sand grains were less interlocked. Consequently, water could flow more easily through the sand deposit in experiment B. This is confirmed by the permeability tests (Fig. 2.11; Chapter 2), which indicate that permeability is $11 \%$ higher at the initial porosity of experiment B than in experiment A. Inflow of water into breach surfaces is responsible for dissipating the excess pore pressures. Since the permeability is higher in experiment $\mathrm{B}$, water infiltrates faster and the dissipation timescale is smaller.

The second factor contributing to the faster dissipation in experiment $B$ is the excess pore pressure, which was higher during the looser experiment B compared to the denser experiment A (Fig. 3.4). Apparently, the initial packing density is inversely related to the amount of excess pore pressure generated. This is counter intuitive to the idea that more densely packed sand results in more vigorous breaches and larger excess pore pressures. Higher excess pore pressures generate larger gradients, resulting in a larger inflow of water into the breach. This leads to the faster erosion and higher retreat rates in experiment $\mathrm{B}$.

Finally, porosity controls the dissipation time directly because a larger dilatancy is needed before the packed sand can shear. The grains can only shear when the pore volume increases to a level equal to or larger than the critical porosity $\eta_{\text {crit }}$ (Fig. 3.1). A certain amount of dilatancy, $\Delta \eta$, must occur to loosen the soil from the initial porosity $\eta$ to $\eta_{\text {crit }}$. The term $\Delta \eta$ is called the dilatancy potential here, following You et al. (2014b).

The difference in porosity thus affects the permeability, the excess pore pressure, and the volume expansion needed to shear freely, and these effects combined make the breach progress faster in more loosely packed sand. These three variables are closely related to each other in the framework of Darcy-flow of the infiltrating water. We assume that the flow of pore water obeys Darcy's law so that the fluxes of water are proportional to the permeability of the deposit and the pressure gradients. This framework was successfully used by You et al. (2014b) to quantify breach evolution, and it is applied here to demonstrate that it also explains the inverse relation between porosity and dissipation time. The average 
flow rate $Q\left(\mathrm{~m}^{3} / \mathrm{s}\right)$ of water into the breach can be calculated from the dilatancy potential, volume of the initial deposit $V\left(\mathrm{~m}^{3}\right)$, and dissipation time, as follow:

$$
Q=\frac{\Delta \eta V}{T_{\text {diss }}}
$$

Darcy's law for the flow rate through a porous media can be written as:

$$
Q=-\frac{\Delta P}{\Delta x} \frac{A k}{\mu}
$$

$\Delta P$ is the pressure difference $(\mathrm{Pa})$, over length $\Delta x(\mathrm{~m}), A$ is the cross-sectional area perpendicular to flow $\left(\mathrm{m}^{2}\right), k$ the intrinsic permeability $\left(\mathrm{m}^{2}\right)$ and $\mu$ is the dynamic viscosity $(\mathrm{Pa} \cdot \mathrm{s})$. The negative sign was introduced to obtain a positive value for the flow rate when pressure decreases in $x$ direction. The $x$ direction is defined as positive into the water body standing in front of the breach face.

Combining Equations 3.1 and 3.2, the dissipation time due to Darcy flow into the breach surface can now be estimated as:

$$
T_{\text {diss }}=-\frac{\Delta x}{\Delta P} \frac{\Delta \eta \mu L}{k}
$$

where $L$ is the length of the porous medium (m), which appears from division of the sample volume, $V$, in Eq. 3.1 by the sample failure surface area, $A$, in Eq. 3.2.

The validity of the Eq. 3.3 was tested by calculating the dissipation time for experiments A and B and comparing with the values from Figure 3.6. The parameters considered for this calculation are presented in Table 3.3. $\Delta x$ was obtained from the time at which excess pore pressure peak occurs before the failure surface passed the transducer position and the measured retreat rate. Since the position of the UVP used to monitor the retreat rate is at similar height as transducer 11, the calculations were performed for this transducer in both experiments. Another reason to choose this transducer comes from the study by You et al. (2014b), which reports that the erosion rate is approximately constant 
for depths greater than $15 \mathrm{~cm}$. The definition of $\Delta P$ is not straightforward as there are many ways to quantify it from the pressure time series of Figure 3.4. In this way, it was considered the excess pore pressure relative to the peak before failure surface passes because this sets the pressure gradient driving the water inflow. The critical void ratio was calculated using the critical state line equation from Figure 2.7 in Chapter 2, substituting p' by the desired stress level. The experiments in the flume were performed at low stress level and the highest effective stress, at the base of the experiment, was $3.8 \mathrm{kPa}$. Therefore, this value was considered for p' and the critical void ratio is 1.0156 . From Figure 3.6 it can be seen the analytical solution overestimates the dissipation time by $40 \%$ and $50 \%$ in experiment $\mathrm{A}$ and B, respectively. However, such an overestimation with a factor of $<2$ is considered successful for scale analysis, which the purpose was to check whether the scales associated with hypothesised governing processes can satisfactorily account for the scales observed. In this case, we conclude that Darcy flow of water into the breach surface can, indeed, explain the time scale associated with the dissipation of the breaches at this experimental scale, reaffirming previous work that suggested to be the dominant governing process (You et al., 2014b). Moreover, there is agreement between the experiments and the Darcy perspective about the positive correlation between packing density and breach dissipation: breaches in looser sands dissipate faster because water infiltrates faster.

Table 3.3: Parameters considered for dissipation time calculation.

\begin{tabular}{|c|c|c|}
\hline & Exp. A & Exp. B \\
\hline$\eta$ & 0.432 & 0.448 \\
\hline$\eta_{\text {crit }}$ & \multicolumn{2}{|c|}{0.5039} \\
\hline$\Delta \boldsymbol{\eta}=\boldsymbol{\eta}_{c}-\boldsymbol{\eta}_{i}$ & 0.072 & 0.056 \\
\hline$\Delta x(\mathrm{~m})$ & 0.00584 & 0.006 \\
\hline$L(\mathrm{~m})$ & \multicolumn{2}{|c|}{0.4} \\
\hline$\mu(\mathrm{kg} / \mathrm{m} \cdot \mathrm{s})$ & \multicolumn{2}{|c|}{0.001} \\
\hline$k\left(\mathrm{~m}^{2}\right)$ & $3.93 \times 10^{-12}$ & $4.42 \times 10^{-12}$ \\
\hline$\Delta P(\mathrm{~Pa})$ & 274.9 & 223.0 \\
\hline
\end{tabular}




\subsubsection{The influence of intermediate and high embankment porosities on failure evolution}

The intermediate and loose packing of experiments $C$ and D prevented breach failures. The most interesting result of this investigation is related to experiment $\mathrm{C}$, which displayed hybrid dilative-contractive behaviour. This novelty will be briefly addressed after discussing the failure style for the loose experiment D.

\section{Failure in loosely packed sand}

Experiment D is an illustration of a loosely packed sand with contractive behaviour when sheared. After the removal of the vertical wall, the sand deposit responded to the instability and collapsed immediately. Since the initial state is loose, there is no significant particle interlocking to overcome (Fig. 3.1). Due to the sudden application of the shearing force, the water could not dissipate quick enough from the pores and a positive excess pore pressure was generated (Fig. 3.4b-D). Consequently, the effective stresses decrease, and, if they approximate to zero, the sand deposit may assume the rheological consistency of a liquid, i.e., liquefy. Casagrande (1936) proposed that liquefaction is not necessarily related to a zero or almost zero effective stress condition, but rather to a reduction of the effective stress large enough for the shear strength to drop substantially below the existing shear stresses in the soil mass. Whether or not liquefaction occurred in experiment $\mathrm{D}$ is difficult to prove from the measurements unequivocally, because the relative position of the grains and the shape of the deforming deposit are constantly changing after the removal of the vertical wall, which makes it extremely hard to quantify the effective stresses applied in a certain moment. The real stress path that the soil experiences in the submerged slope of experiment D is, therefore, not fully understood.

Nevertheless, some estimations of the stress conditions can be made based on the stationary initial pore pressures and deposit geometry. In the stationary condition before the failure the total stress is $11.8 \mathrm{kPa}\left(\mathrm{z} \cdot \gamma_{\mathrm{sat}}+\mathrm{z}_{\mathrm{w}} \cdot \gamma_{\mathrm{w}}=0.38 \cdot 19.34+0.45 \cdot 9.81\right)$ and the pore pressure $8.1 \mathrm{kPa}\left(\mathrm{z}_{\mathrm{t}} \cdot \gamma_{\mathrm{w}}=0.83 \cdot 9.81\right)$, which results in an effective stress of $3.42 \mathrm{kPa}$, at the elevation of the transducers at position 5 and 9 . Following the removal of the vertical plate, the sand deposit loses confinement and the grains are free to move. This reduction of stresses between the grains results in a decline of the effective stress. Since the excess pore pressures registered were in order of $0.5-1 \mathrm{kPa}$, this increases the probability of liquefaction, though the total stress was probably not reached.

The video of experiment D supports this conclusion, it is seen that the failure developed rapidly, and the granular soil behaved as a liquid material, which are two of the characteristics of a liquefaction failure. 


\section{Hybrid dilative-contractive behaviour at intermediate porosity}

From the pore pressure measurements in Figure 3.4b-C, it is observed that negative and positive excess pore pressure are generated in the same experiment. There is no intermediate behaviour between contraction and dilation; instead, dilative and contractive behaviour occur within the same failure at the same time for an intermediate porosity. From my knowledge, this failure structure has not been previously described in literature. Positive excess pore pressure was documented by the transducers at the bottom and negative excess pore pressure by the transducers at the top. This is a somewhat counter-intuitive result since the packing density is generally larger at the base due to weight of overlying grains, and loose at the top of a deposit. This would suggest that contraction is most likely to occur at the top of the deposit, and not at the base. The maximum positive excess pore pressure was $2.0 \mathrm{kPa}$, which is twice as the maximum excess pore pressure in experiment $\mathrm{D}$ with pure liquefaction. The same is observed for the maximum excess negative pore pressure, $-1.2 \mathrm{kPa}$, which is also higher than the maximum values generated in pure breaching: $55 \%$ higher than experiment $\mathrm{A}$ and $25 \%$ in experiment $\mathrm{B}$. This pore-pressure difference between the top and bottom of $3.2 \mathrm{kPa}$ is the largest gradient of all failures, and a remarkable fact is that this gradient approaches the static effective stress, $3.42 \mathrm{kPa}$ (transducers 5 and 9 at the bottom). This suggests that the entire static stress gradient from the top to the bottom of the sand deposit was balanced by the excess pore-water pressure gradient. As mentioned before for experiment B, a larger pressure gradient leads to a larger inflow of water to the sand deposit, a faster erosion rate and faster pore pressure dissipation. Consequently, the hybrid failure with the highest gradient is the fastest of all failure types with a dissipation time of 15.8 seconds (Fig. 3.6), somewhat faster even than liquefaction failure. Regarding the normalised excess pore pressure, the higher absolute values are at the back of the failure, as in experiment D (Fig. 3.5). Thus, I conclude that the hybrid failure has similarities with liquefaction and breaching flow slides. It combines these aspects to form the most dynamic flow slide in our series of experiments.

The occurrence of dilative regime on top of contractive behaviour during the same failure in experiment C can be explained with critical state theory. Casagrande (1936) introduced the critical void ratio, which is defined as the void ratio at which failure will occur at zero volume change. He also suggested that the critical void ratio decreases with increasing confining pressure. Later studies by Roscoe et al. (1958) confirmed this hypothesis based on a series of simple shear tests. They found that not only the critical void ratio can be reached from either a loose or a dense state (Fig. 3.8A), but also that it decreases with increasing confining pressure (Fig. 3.8B). The critical void ratio reached when sand is sheared at a high stress level must, therefore, be significantly less than the critical void ratio attained when the sand is sheared at a low stress level. 

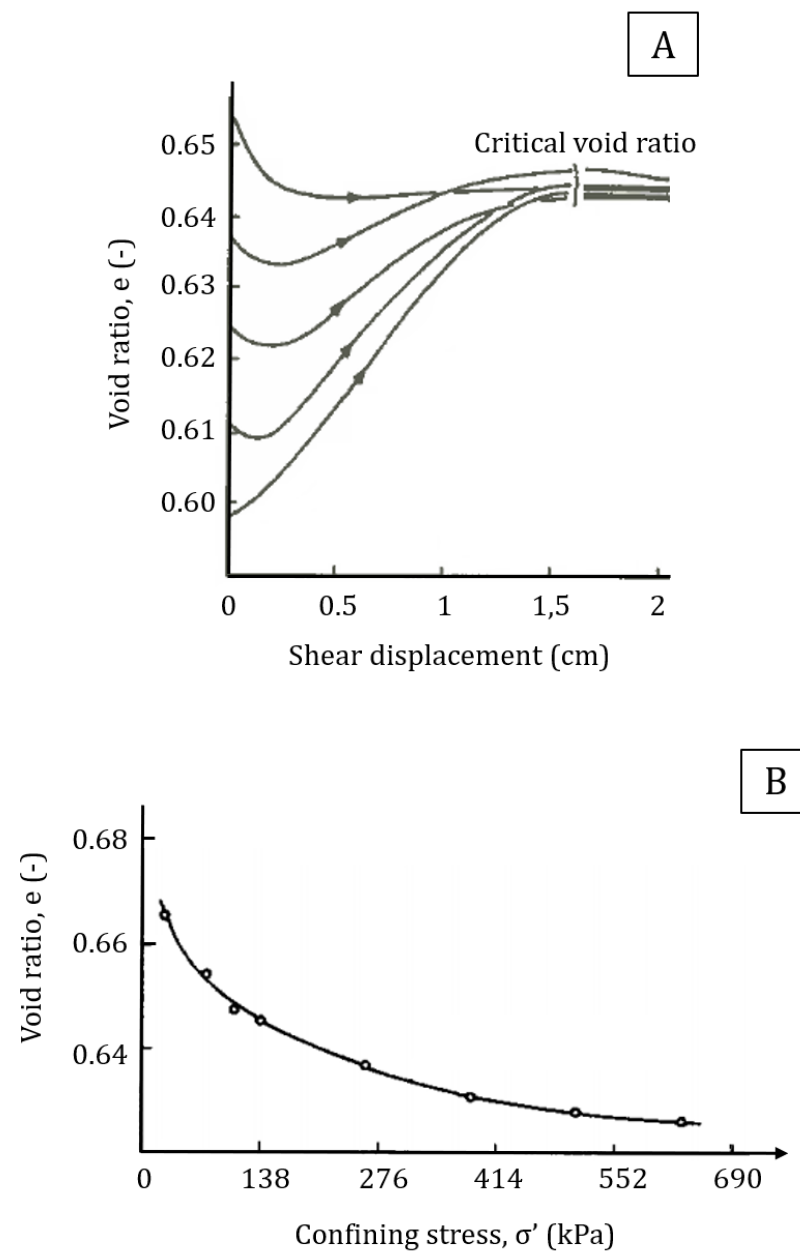

Figure 3.8: Simple shear tests on $1 \mathrm{~mm}$ steel balls with normal stress $138 \mathrm{kPa}$ : (A) void ratio and shear displacement; (B) projection of the critical state line (modified from Roscoe et al., 1958). 
Correlating this finding with the results of experiment $\mathrm{C}$, at the top of the sand deposit (very low stress level), the critical void ratio may be very high. Moreover, the critical void ratio is apparently higher than the initial void ratio, 0.926 , which was calculated after the deposit was built. When the sand is sheared following the removal of the confining wall, it tends to the critical void ratio at large deformations, which in this case needs to dilate since the critical void ratio is higher than 0.926 . This necessary expansion in volume leads to generation of negative pore pressure observed at the top of the deposit (Fig. 3.4b-C). Another result in agreement with this is the higher magnitude of negative pressures in the top of breaching experiments, which could also be due to the higher potential dilation at the top of the deposit at very low stress level.

With respect to the positive pore pressures at the bottom of the deposit, the critical void ratio is lower since it decreases with depth (with increasing stress level). In the scenario of the experiment $\mathrm{C}$, it is apparently less than 0.926 , tending to contract when sheared, and this reduction in volume causes the generation of positive pore pressure registered by the transducers at the bottom (Fig. 3.4b-C). This result indicates that liquefaction happens at greater depths. At great depth, the critical void ratio is smaller, which makes it more likely for sand to contract when sheared and to develop a larger increase in pore pressure, a defining characteristic for liquefaction. Moreover, a sand element with a larger confining pressure is probably subjected to larger deviator stresses (and shear stresses), which increases the liquefaction potential. This is in agreement with research by Castro \& Poulos (1977) who reported that "for a given soil at a given void ratio, higher values of confining pressure correspond to higher susceptibility to liquefaction". The sand B used in their study is similar to the sand used in the experiments for this thesis, and its critical state line is represented qualitatively in Figure 3.9. It illustrates the decrease of the critical void ratio, which corresponds to an increase of the critical density, with depth and confining pressure. At a depth of $0.40 \mathrm{~m}$, the liquefaction at the bottom of the hybrid failure occurred for a relative density of $36 \%$. At greater depths, with the increase of the critical density, hybrid failure is here suggested to occur at higher relative densities as well, increasing the susceptibility to liquefaction. An implication of this is the possibility that there is a limit for the breach height during a breach flow slide. If the breach surface is high enough, it will collapse at the base due to the increase of the liquefaction potential with depth.

In summary, Figure 3.9 reviews the behaviour observed in the four experiments. Besides the dilative and the contractive behaviours captured by the two end-members (breaching and liquefaction, respectively) mentioned in the literature, our study allowed to document the transition between them. For intermediate densities, the hybrid failure combines both dilative and contractive behaviour in the same failure. This is due to the initial void ratio being close to the critical void ratio, which changes with depth (with stress 
level) also changing the behaviour of the sand deposit when sheared. The hybrid failure generated the largest pore pressure gradient which resulted in the fastest failure.

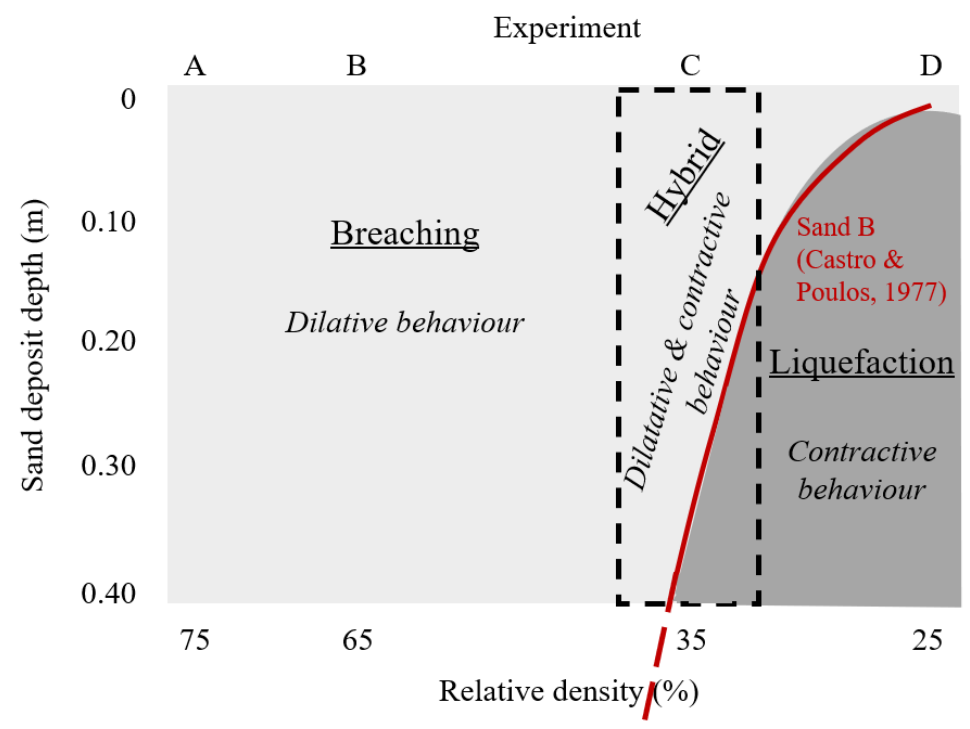

Figure 3.9: Summary of the experiments. 


\subsection{Conclusions}

Results from this chapter show that the initial packing density influences the way an underwater flow slide starts. This study provides a complete overview of underwater flow slides in fine sand material with different packing densities.

The most significant finding is the new type of failure identified for intermediate packing densities. Hybrid failure is characterised by a combination of dilative and contractive behaviour occurring at the same time. Negative excess pore pressure and dilation occurs at the top of hybrid failure, and positive excess pore pressure and contraction occurs at the bottom. This vertical superposition is explained by the decrease of the critical void ratio with increasing depth. This causes the dilatancy potential to decrease with greater depth, while at the same time increasing of the liquefaction potential. Hybrid failure generated the highest pore pressure gradients observed in any of the experiments and the dissipation time was, therefore, almost the same as in the liquefaction experiment. Hybrid failures are thus highly mobile failures and can easily be mistaken for liquefaction failures in the absence of pore pressure measurements.

Hybrid failures occur at intermediate packing densities that are more common under natural conditions than the densely packed and loosely packed conditions that have previously been the focus of comprehensive research into breaching and liquefaction endmember behaviour. Therefore, the existing models and prediction programs of underwater flow slides should now start to focus more on hybrid failures for an accurate understanding and prediction of flow slides. 


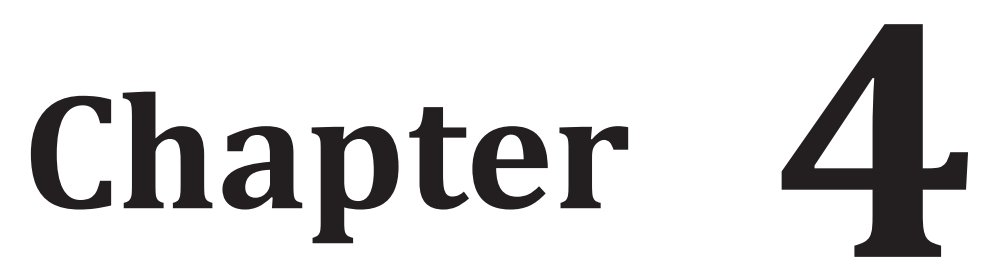

\section{The influence of embankment heterogeneity on breaching failures}

"A scientist in his laboratory is not a mere technician: he is also a child confronting natural phenomena that impress him as though they were fairy tales."

- Marie Curie (1867-1934) 


\subsection{Introduction}

Underwater embankments are rarely homogeneous in natural systems. In reality, they exhibit layering of different materials at various scales, from the km-scale of the entire embankment to the mm-scale of laminations containing sand and mud grains. These heterogeneities at the scale of the characteristic operating processes, are expected to influence the onset, evolution, and final deposits of flow slides.

The deposits of the tidal channel embankments in the Dutch province of Zeeland, which are very prone to flow slide occurrences (Widerom, 1979; Van den Ham et al., 2015; Van Dijk et al., 2019), serve as an example of the type of heterogeneities that can be encountered. The geological past of Zeeland is characterised by rapidly shifting coastlines. These changes were due to alternating sedimentation and scour caused by river flow, tidal currents, and sea-level variations (Silvis \& Groot, 1995). Figure 4.1 shows a geological profile of Zeeland to a depth of $100 \mathrm{~m}$. The upper $30 \mathrm{~m}$ of the sequence is formed by Holocene deposits consisting of tidal channel, tidal flat and lagoonal sediments that alternate with peat beds and coastal shoreface and dune deposits (Stafleu et al., 2011). Most of these consist of (medium) fine sand which, in general, is loosely packed due to high deposition rates (Silvis \& Groot, 1995). They consist of sandy tidal channel fills and clay deposited on subtidal flats. These two phases are separated by peat deposited in a regressive phase. Pleistocene deposits underlie the Holocene sequence in most of the province. Tidal channels often incise into these Pleistocene deposits at depths up to $30 \mathrm{~m}$ (Fig. 4.1). 

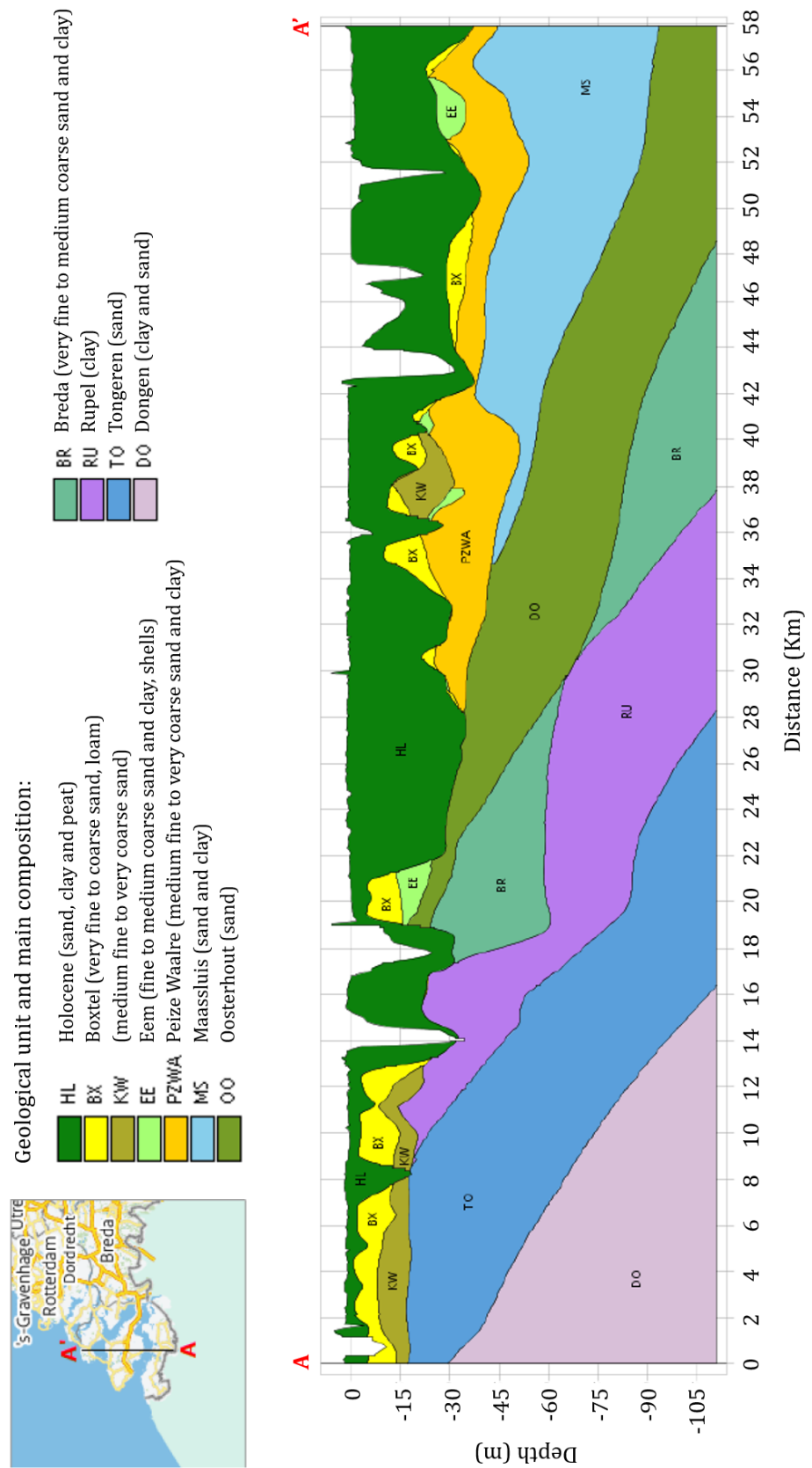

Figure 4.1: Schematic cross section A-A' through the deposits in the Province of Zeeland, showing the geological formations and their composition (Stafleu \& Gunnink, 2016). 
Besides these large-scale processes and heterogeneity, the variation in tidal currents often resulted in thin clay layers between thicker sand layers (Fig. 4.2). Figure 4.2A shows a Holocene deposit in the Neeltje Jans construction pit. These are the type of deposits in the south-west of the Netherlands where flow slides commonly occur. When we observe closer, it can be see the thin layers of clay between thick sand layers (Fig. 4.2B). Furthermore, the heterogeneity is not only documented for these two different materials, but also within the sand layers where laminations related to variations in grain size can be recognised.

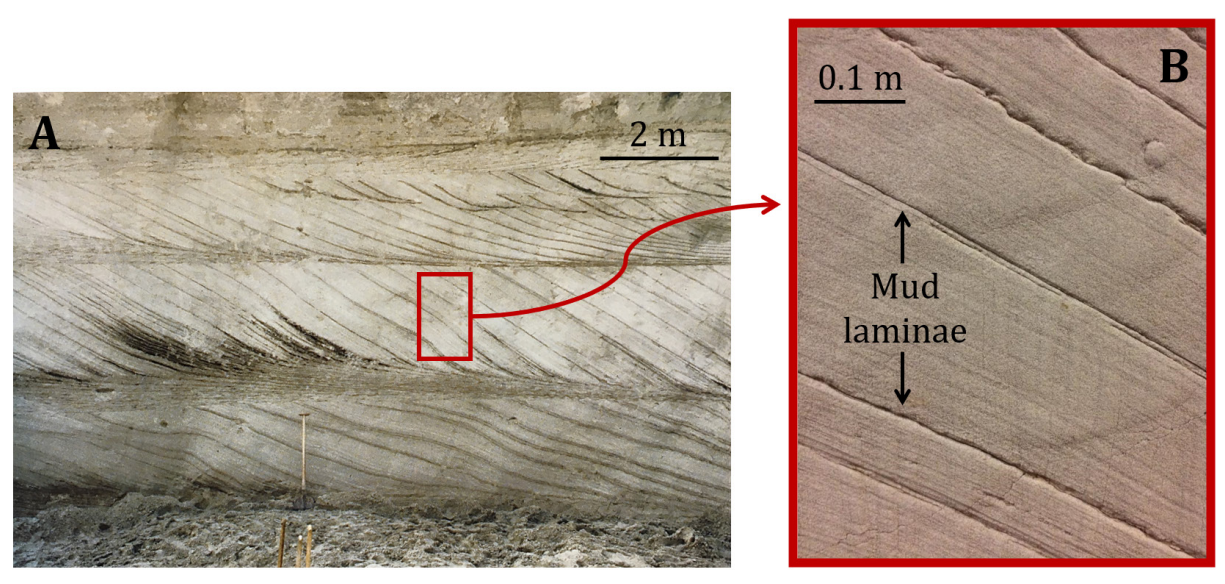

Figure 4.2: $(\boldsymbol{A})$ Lower part of the outcrop in the Neeltje Jans construction pit, 9-17 $m$ below MSL (Martinius \& Van den Berg, 2011); (B) Lacquer peel of thin-layered deposits taken in the Neeltje Jans construction pit with a variety of sand and clay laminae (collection of Utrecht University).

This heterogeneous lithology has a high impact on the groundwater flow. Figure 4.3 shows an example of 3D lithological models of tidal deposits from Walcheren and Wormer in Zeeland, which consist of alternating layers of sand and clay. Several samples were taken in order to evaluate the permeability within a $100 \times 100 \times 2$ m block. The layering of clay has a strong influence on the vertical permeability (Fig. 4.3B; Stafleu \& Gunnink, 2016). The clay layers work as a barrier to ground-water flow, and the groundwater water is confined under pressure with slow drainage. 

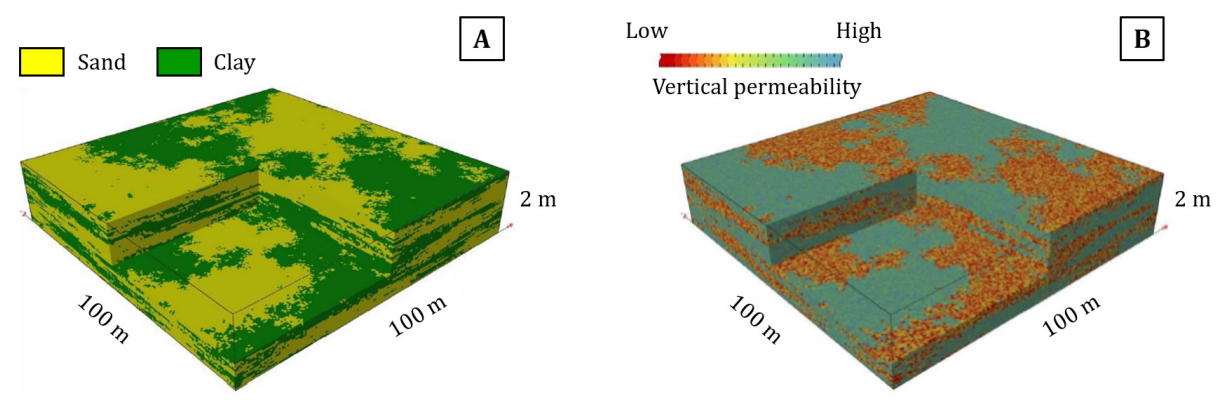

Figure 4.3: Clayey tidal deposits from Walcheren and Wormer: (A) composition, (B) permeability (Stafleu \& Gunnink, 2016).

It becomes clear from this overview that deposits that are known to be susceptible to flow slides are heterogeneous.

The experiments presented in this thesis so far were performed only with uniform sand. This approach reflects the practice common in previous experimental work, which all focused on flow slides in homogenous sands (Van Rhee \& Bezuijen 1998; Eke et al., 2011; De Groot et al., 2012; You et al., 2012, 2014a,b; Weij et al., 2016; de Jager et al., 2017). In this chapter, the experimental boundary conditions of Chapter 3 are extended to a heterogeneous context to study the influence of heterogenetic deposits on flow slides. For that purpose, two layers of a different sediment were intercalated with the sand deposit. It was chosen sediment with different grainsize and, consequently, different hydraulic conductivities, since water motion exerts a strong control on flow slides. These sediments are coarse sand, silt, and clay. Erosion modes, changes in excess pore pressure and retreat velocity of the breaching front were investigated in order to answer the questions: Is heterogeneity a primary control on flow slide evolution? Are the insights from homogenous flow slide experiments presented in literature and in this thesis in fact applicable to flow slides in heterogeneous deposits? 


\subsection{Experimental method}

\subsubsection{Experimental setup and materials}

The experiments were conducted in the same flume tank used for the experiments presented in Chapter 3 (Fig. 4.4a). Detailed information about the constitution and dimensions are presented in Chapter 3. The main constituent of the submerged deposit was the same sand that was used in the experiments of the previous chapter (Sibelco BR37; Fig. 2.1). Two $1 \mathrm{~cm}$ thick layers were intercalated with the sand deposit to study the effect of heterogeneity during a flow slide (Fig. 4.4b). The materials used as heterogeneity were either coarse sand, silt-sized crushed glass, or kaolinite clay. The grain size of the coarse sand was determined with sieves where $16.6 \%$ of the sediment was larger than $1 \mathrm{~mm}, 37.2 \%$ was between $0.5-1 \mathrm{~mm}, 24.8 \%$ in the range $0.355-0.5 \mathrm{~mm}, 10.9 \%$ between $0.25-0.355$, and $10.5 \%$ of the fraction was smaller than $0.25 \mathrm{~mm}$. Glass granules (GGR 220-S) obtained from Kuhmichel Abrasiv B.V. in the Netherlands with a median diameter of $46 \mu \mathrm{m}$ were used as silt material. Crown Kaolinite clay from Active Minerals International, with a median diameter of $0.18 \mu \mathrm{m}$ was used as clay material.

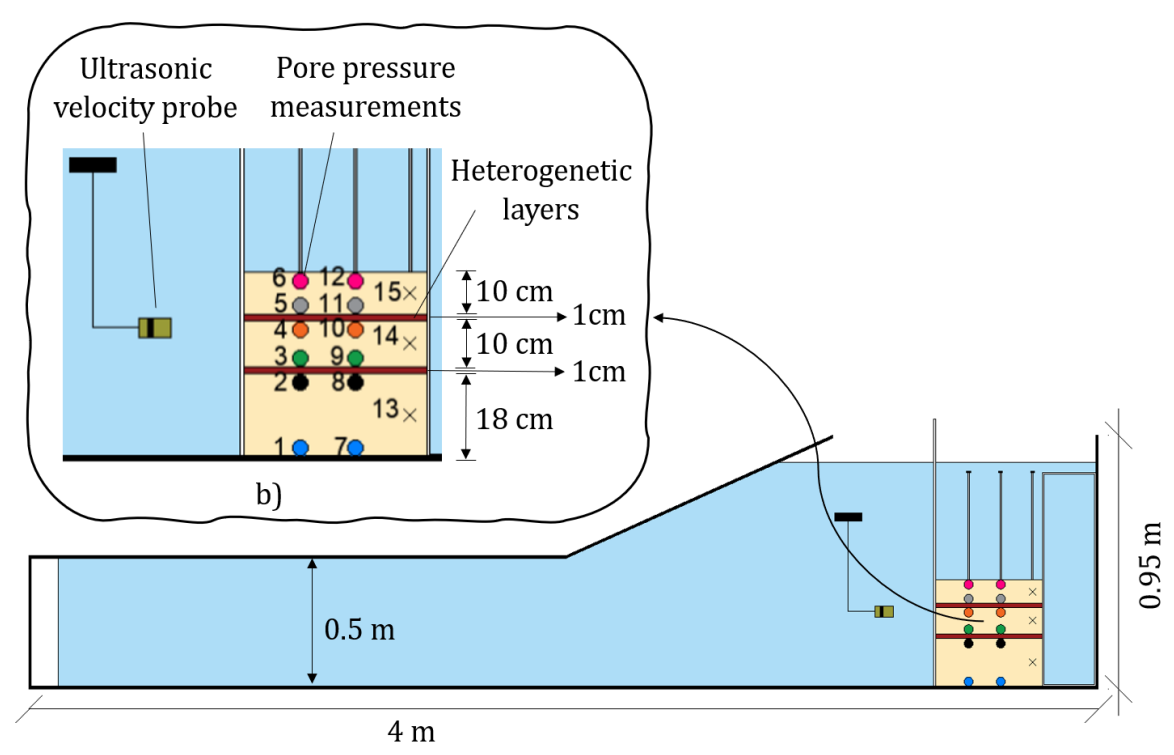

a)

Figure 4.4: Experimental design: a) schematic overview of the 2D experimental setup, b) constitution of the submerged deposit, dimension of the sediment layers, and instrumentation location. 


\subsubsection{Data acquisition}

Pore pressures and the retreat velocity of the breach face were monitored during the experiments. The pore pressures were measured with pressure transducers and the retreat velocity of the breaching front was tracked with an UVP. The pressure transducers and UVP are the same equipment used in the series of experiments presented in the previous chapter.

\section{Pressure transducers}

The same tubing system described in Chapter 3 was used to measure the pore pressure in this chapter. The only change is the number and position of the transducers. Fifteen different positions at the centre line of the flume, inside the sand deposit, were used to record the pore pressure during the experiments. Two arrays with six tubes each were located at $10 \mathrm{~cm}$ and $24 \mathrm{~cm}$ behind the confining plate. The tubes in these arrays were placed $2 \mathrm{~cm}$ from the bottom and the top of the sand layers (transducers 1-12 in Figure 4.4b). Three pressure transducer tubes were positioned at the back of the deposit in the centre of the sand layers (transducers 13-15 in Figure 4.4b).

\section{$\underline{U V P}$}

One UVP probe was installed in the flume to study the retreat rate of the failure surface (Fig. 4.4b). The probe was placed $10 \mathrm{~cm}$ from the initial breach face before failure, and $12 \mathrm{~cm}$ from the top of the sand deposit.

\subsubsection{Experimental procedure}

Two series of experiments were conducted. The type of heterogeneity was varied in the first series (experiments A-D). The packing density was varied in the second series; the heterogeneity consisted of silt in each experiment of this series (experiment C1, C2, and C3).

\section{Series 1}

Experiment $\mathrm{A}$ is a reference experiment in order to evaluate the effect of the heterogeneities in the other experiments. No heterogeneity was introduced, and the submerged deposit constituted only of sand. Experiment B was performed with layers of coarse sand, experiment $C$ with silt, and in experiment $D$ the layers were composed of clay. In each experiment, the sand and materials making up the heterogeneity were weighed before being placed behind the confining plate. The sand was compacted with a circular disc. In 
order to build the two heterogeneity layers, the material was poured through the water column after each sand layer. These layers were not mechanically compacted because this was found to disturb the thin layers too much, causing them to mix with the underlying sand. After each deposit was built, the final geometry was $0.40 \mathrm{~m}(\mathrm{~L}) \times 0.22 \mathrm{~m}(\mathrm{~W}) \times 0.40 \mathrm{~m}(\mathrm{H})$ for all the experiments, approximately. Precise dimensions for each experiment were recorded, and the average porosity was calculated from the volume and weight of the saturated deposit. The resulting average porosities of experiments A-D ranged between 0.440-0.444 (Tab. 4.1). The failure was induced by quickly removing the confining plate.

\section{$\underline{\text { Series } 2}$}

Experiment $\mathrm{C}$ was also the dense experiment with silt layers of the second series. Density was then decreased in subsequent experiments. Experiment C1 was performed with a medium-dense packing density, and each $10 \mathrm{~cm}$ layer was compacted with a circular disk. For the medium-loose and loose experiments, C2 and C3, respectively, the sand was simply poured through the water column. The difference between them is that for experiment $\mathrm{C} 3$, the sand was poured in several small amounts, which allowed the sand to settle into an even looser bed.

Table 4.1: Parameters of each experiment.

\begin{tabular}{|c|c|c|c|c|c|c|}
\hline & Experiment & $\begin{array}{c}\text { Heterogeneity } \\
\text { material }\end{array}$ & $\begin{array}{c}\text { Heterogeneity } \\
\mathrm{D}_{50}(\mu \mathrm{m})\end{array}$ & $\begin{array}{c}\eta \\
\pm 0.005(-)\end{array}$ & $\begin{array}{c}e \\
(-)\end{array}$ & $\begin{array}{l}\text { RD } \\
(\%)\end{array}$ \\
\hline \multirow{4}{*}{ 峁 } & A (reference) & - & - & 0.443 & 0.794 & 69.0 \\
\hline & B & Coarse sand & 700 & 0.444 & 0.798 & 67.9 \\
\hline & $\mathrm{C}$ & Silt & 46 & 0.440 & 0.785 & 71.2 \\
\hline & $\mathrm{D}$ & Clay & 0.18 & 0.442 & 0.792 & 69.4 \\
\hline \multirow{3}{*}{ 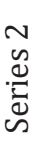 } & $\mathrm{C} 1$ & Silt & 46 & 0.460 & 0.853 & 54.3 \\
\hline & $\mathrm{C} 2$ & Silt & 46 & 0.477 & 0.912 & 39.5 \\
\hline & C3 & Silt & 46 & 0.497 & 0.989 & 20.4 \\
\hline
\end{tabular}




\subsection{Results}

\subsubsection{Experiment series 1}

The experiments of series 1 were performed in densely packed sand, and characteristics of breaching flow slides were recognised in all experiments in this series. These characteristics are: the generation of negative excess pore pressure excursions, dominant retrogression of the breach face through particle release from the sediment-water interface, occasional surficial slides, and the generation of a turbidity current (Van den Berg et al., 2002; Eke et al., 2011; You et al., 2012, 2014a,b; Chapter 3 of this thesis). These general observations were documented and discussed in detail in for experiments $\mathrm{A}$ and $\mathrm{B}$ of Chapter 3. In this section I will report only the new findings related to the presence of the heterogeneities.

\section{Erosion failure styles}

Particular failure styles were noticed in heterogenetic experiments B, C and D (Fig. 4.5). During the deposit failure in experiment $B$, the failure face rapidly ingressed at the location of the two layers with coarse sand compared to the thick fine sand layers which had a slower erosion. Fifty seconds after the experiment started, the top layer of coarse sand had an ingression of $\sim 3 \mathrm{~cm}$ (red circle in Exp. B, Fig. 4.5). On the other hand, in experiments C and $D$, there was a slower retreat of the silt and clay layers, respectively, than the layers of sand. This resulted in protrusions of the silt and clay layers which were eroded only after some time (red circles in Exp. C \& D; Fig 4.5). In case of silt in experiment C, this protrusion was $2 \mathrm{~cm}$ compared to the point with highest retrogression in the sand layer in between after $25 \mathrm{~s}$. Experiment D exhibited a similar protrusion of the clay interlayer, and additional characteristics related to the plasticity characteristic of clay, which was held together in place for some time. The $2.5 \mathrm{~cm}$ were pending in water while below the clay layer the sand was already eroded (Exp. D in Fig. 4.5). 

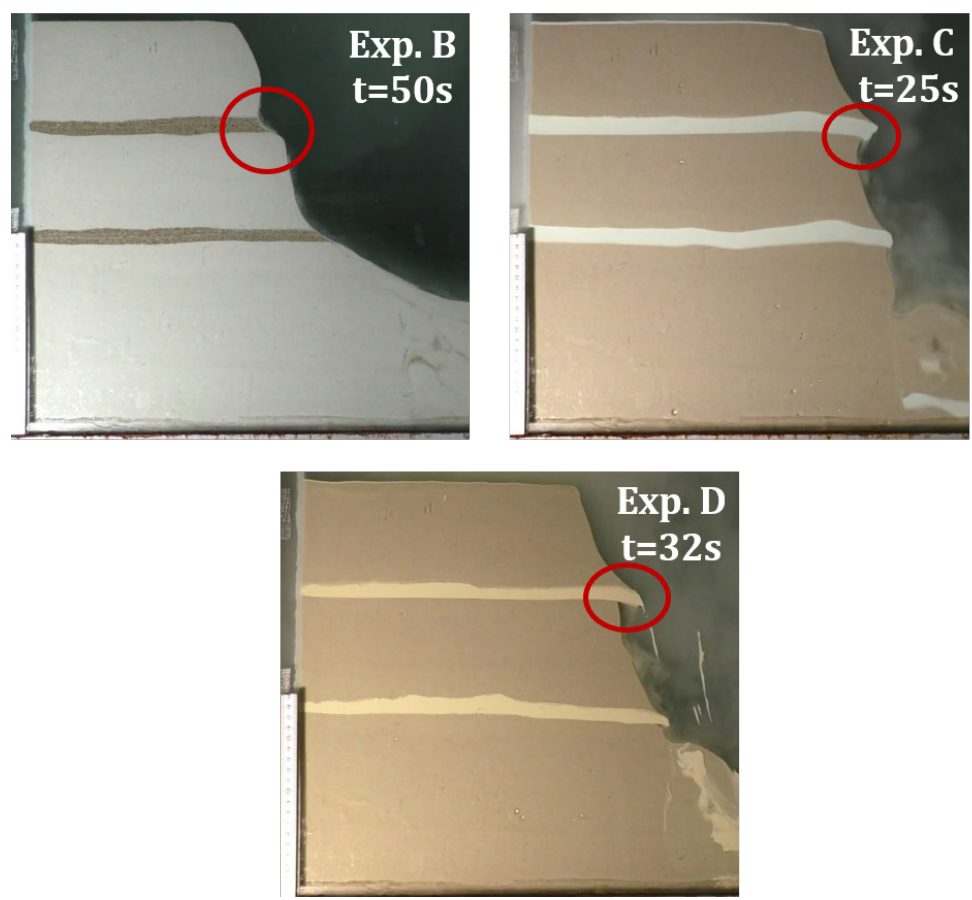

Figure 4.5: Snapshots of videos of different erosion styles for heterogenetic experiments $B, C$ and $D$. (Note that the same sand was used in experiments $B, C$, and $D$; the difference in colours is caused by different light conditions.)

\section{Pore pressure measurements}

Pore pressure measurements recorded by the transducers 1-12 are shown in Figure 4.6 for the experiments A, B, C, and D. After analysing the measurements from the transducers 13,14 , and 15 , it was concluded that these results were not relevant to study the present topic, since the changes in excess pore pressure were almost nil. For this reason, these results are not included here. The maximum excess negative pressure was recorded at the transducer location 5 in all experiments, immediately after the vertical wall was removed. Moreover, this value is more negative with the decrease of the grain size of the heterogenetic layers. It decreases from approximately $-0.6 \mathrm{kPa}$ in the reference experiment A, to $-0.9 \mathrm{kPa}$ in experiment D. A particularity is related to the peak pressures that occur just before the breaching face passes the transducer location, which are more accentuated in experiments C \& D with clay ( $-0.74 \mathrm{kPa}$ in Exp. C; $-1.1 \mathrm{kPa}$ in Exp. D, Fig. 4.6).

The pore pressure signal from the second line of the transducers 7-12 (Fig. 4.6-A2, 
$\mathrm{B} 2, \mathrm{C} 2, \mathrm{D} 2)$ has smaller magnitude than the transducers 1-6 close to the initial breach face. In some cases, this reduction is half of the magnitude at the equivalent height. Also, the magnitudes increase from experiment $A$ to $D$ in a similar way as in transducers 1-6.

\section{Normalised excess pore pressure}

From the normalised excess pore pressure plots it can be seen that the maximum negative excess pressure is located near the top of the failure, at the position of transducer 5 in all experiments (Fig. 4.7). In general, the pore pressure tends to zero from the peak in transducer 5 to the bottom of the deposit, similarly to the pressure structure observed in the dense homogenous experiments in Chapter 3 (Fig. 3.5). Experiments A and B have similar spatial pore pressure structure. The main difference is that the excess pressure is less negative in T3 above the coarse sand layer compared to T2 below the coarse sand layer. This is the opposite to the pressure change observed across the low hydraulic conductivity layers in experiments $\mathrm{C}$ and $\mathrm{D}$ (Fig. 4.7).

Experiments $\mathrm{C}$ and D show a non-uniform change of the normalised excess pore pressure along the height of the deposit, which is here called a Christmas tree effect registered by the first line of transducers (T1-6; Fig. 4.7). From the top of the deposit, the pore pressure gets more negative to the measurement location 5 . The excess pore pressure becomes markedly less negative in transducer 4 below the upper heterogenetic layer. It retains a more negative value again going downwards within the layer of fine sand to transducer 3, with another marked change to less negative values downwards across the coarse sand. From the measurement location T2, the excess pore pressure tends to zero until the bottom of the deposit.

\section{Retreat rate}

Regarding the average speed of the breaching face, two distinct rates were identified during the experiments, phase 1 and phase 2 (Fig. 4.8). Phase 1 corresponds to the first half of the experiments, during which different values were measured within the experiments. In experiment $A$, the two retreat rates for the phase 1 and $2,3.6 \times 10^{-3} \mathrm{~m} / \mathrm{s}$ and $1.5 \times 10^{-3} \mathrm{~m} / \mathrm{s}$ (Tab. 4.2), respectively, have the same values as the homogenous experiment B in Chapter 3 , which was performed at similar porosity (cf. Tables $3.2 \& 4.1$ ). In experiment B, the rapid erosion of the coarse sand layers contributed to a faster disintegration of the deposit, resulting in a higher erosion rate in phase $1,5.1 \times 10^{-3} \mathrm{~m} / \mathrm{s}$ (Tab. 4.2), $28 \%$ higher than the homogenous reference experiment $A$. Experiments $\mathrm{C}$ and $\mathrm{D}$ had similar retreat rates during the entire experiments (Fig. 4.8). These rates were intermediate: $4.2 \times 10^{-3} \mathrm{~m} / \mathrm{s}$ and $3.9 \times 10^{-3}$ $\mathrm{m} / \mathrm{s}$, respectively; so faster than the homogenous reference experiment $\mathrm{A}$, but slower than the experiment B with coarse sand. 
The retreat rates measured during phase 2 in the second half of the experiments were very close to each other in all experiments (Fig. 4.8) with an average of $1.73 \times 10^{-3} \mathrm{~m} / \mathrm{s}$ (Tab. 4.2).

\begin{tabular}{lllllllllllll}
\hline$-\mathrm{T} 1$ & $-\mathrm{T} 2$ & $-\mathrm{T} 3$ & $-\mathrm{T} 4$ & $-\mathrm{T} 5$ & $-\mathrm{T} 6$ & $-\mathrm{T} 7$ & $-\mathrm{T} 8$ & $-\mathrm{T} 9$ & $-\mathrm{T} 10$ & $-\mathrm{T} 11$ & $-\mathrm{T} 12$
\end{tabular}
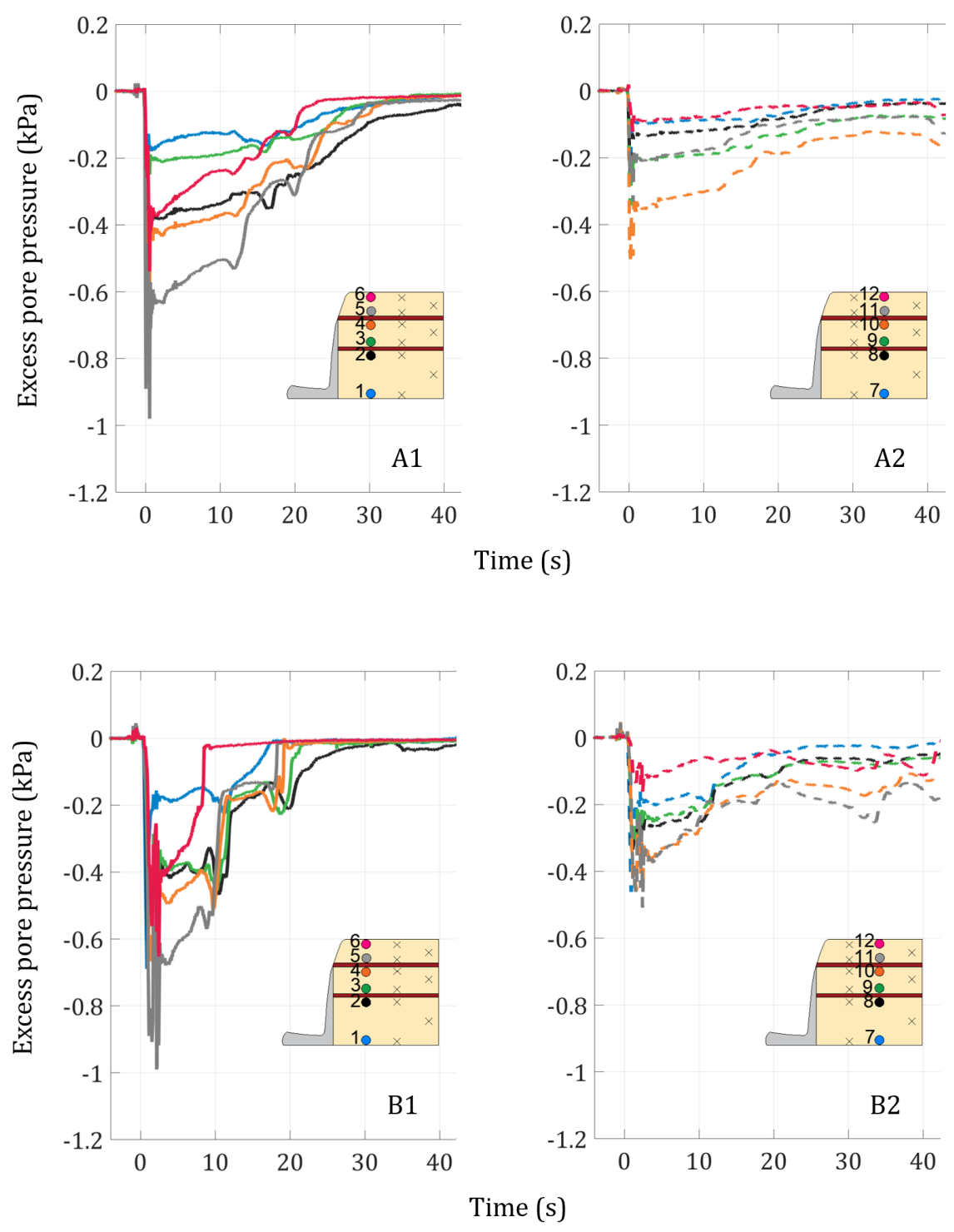


\section{$\begin{array}{llllllllllll}-\mathrm{T} 1 & -\mathrm{T} 2 & -\mathrm{T} 3 & -\mathrm{T} 4 & -\mathrm{T} 5 & -\mathrm{T} 6 & -\mathrm{T} 7 & -\mathrm{T} 8 & -\mathrm{T} 9 & -\mathrm{T} 10 & -\mathrm{T} 11 & -\mathrm{T} 12\end{array}$}
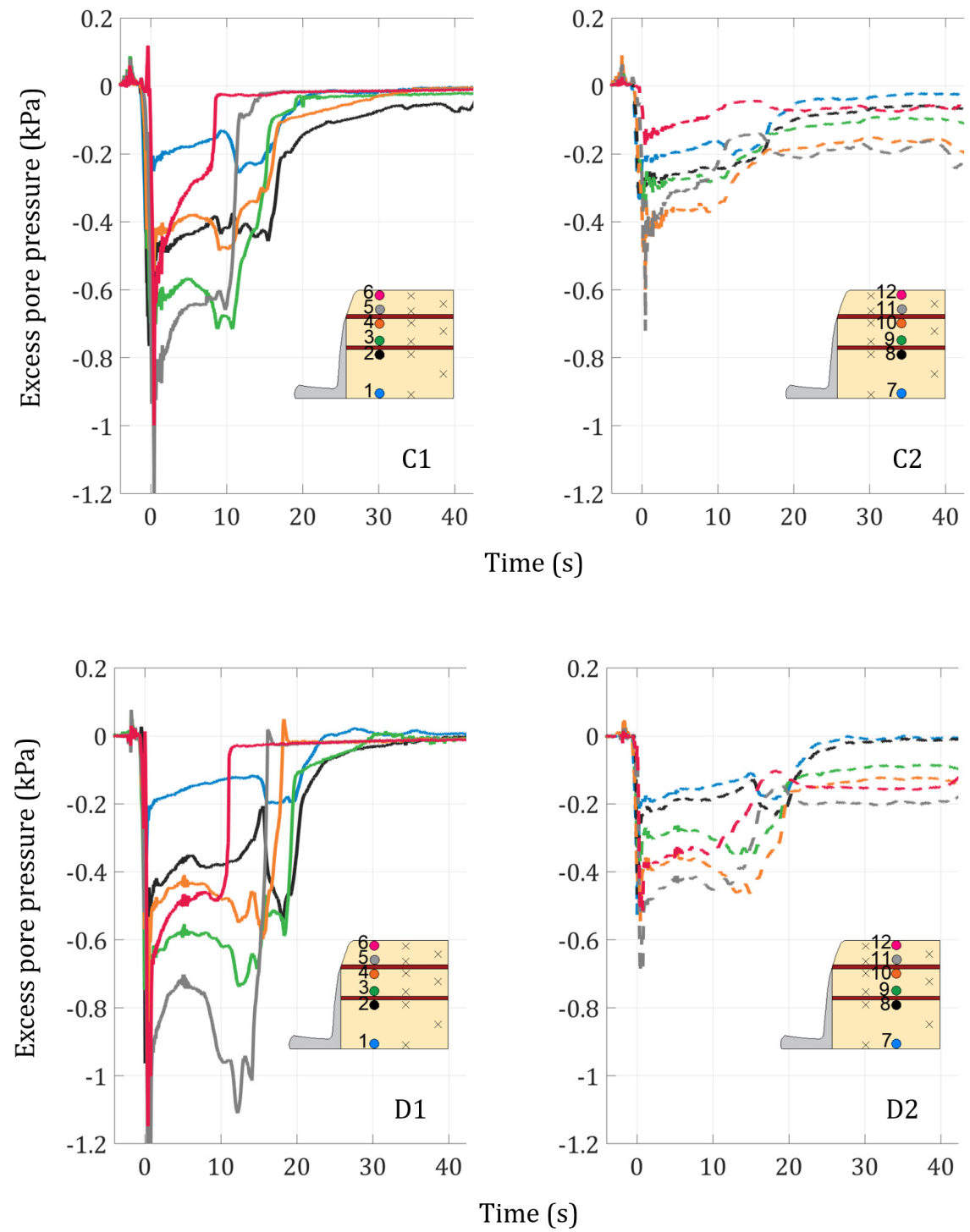

Figure 4.6: Excess pore pressure measurements for experiment $A$ ( $A 1, A 2$; previous page), experiment $B(B 1, B 2$; previous page), experiment $C(C 1, C 2)$ ), and experiment $D(D 1, D 2)$ (Transducer 1-6 solid lines, transducers 7-12 dash lines). 
Experiment A

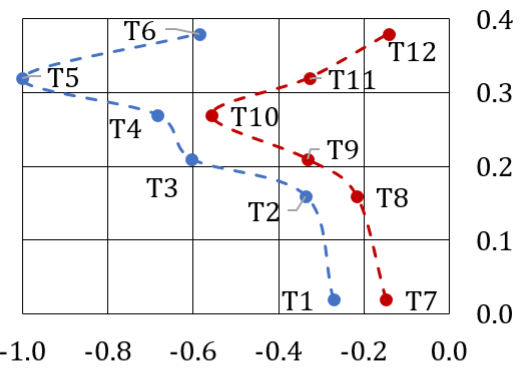

Experiment C

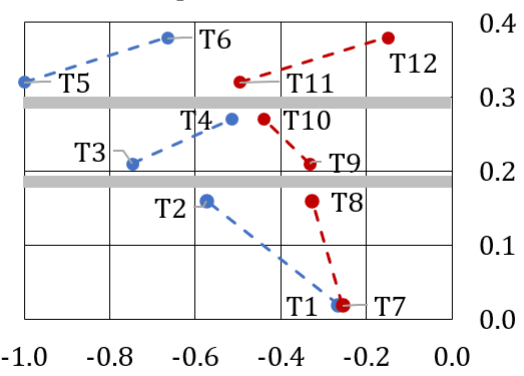

Normalised excess pore pressure (-)
Experiment B

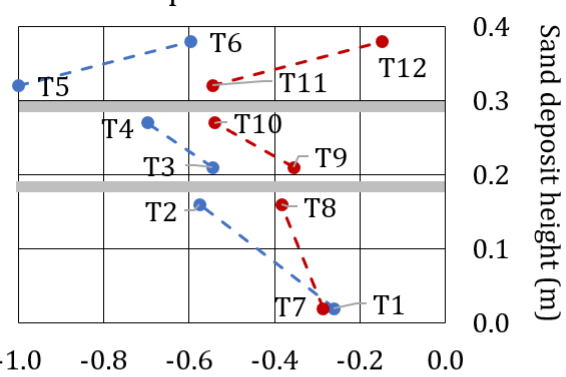

Experiment D

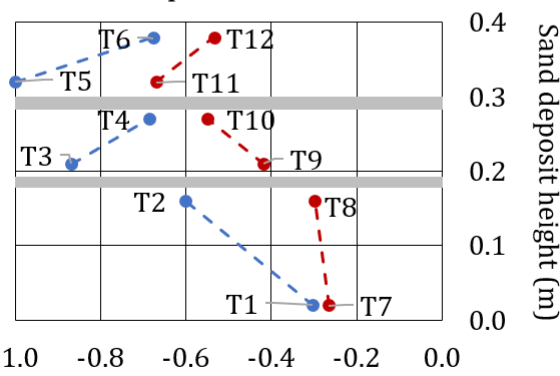

Normalised excess pore pressure $(-)$

Figure 4.7: Initial excess pore pressure in different positions (cross section) of the sand deposit (normalised with the maximum excess pore pressure in each experiment (see Figure $4.4 \mathrm{~b}$ for positions). Grey bars correspond to the heterogeneity layer positions. 


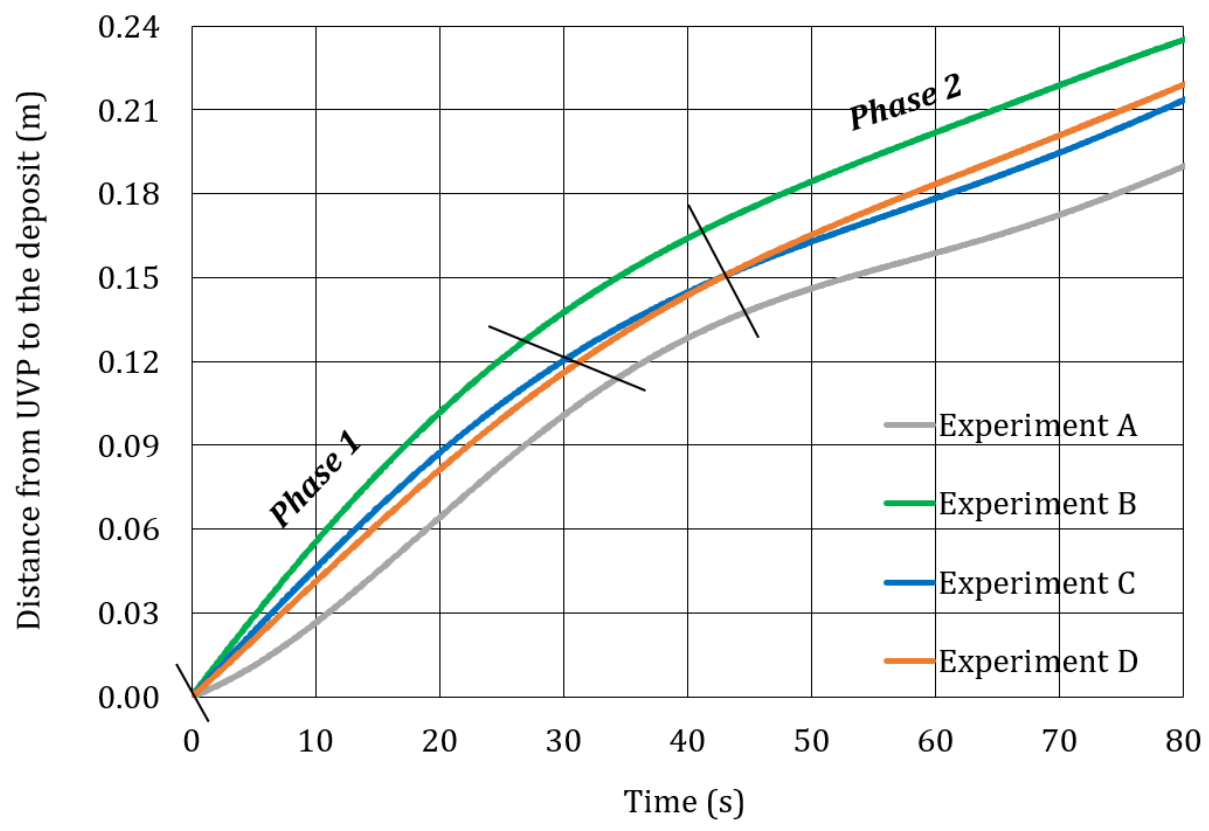

Figure 4.8: Retreat rate during the experiments.

Table 4.2: Retreat rates during the experiments for phase 1 and phase 2.

\begin{tabular}{ccc} 
& \multicolumn{2}{c}{ Retreat rate $\mathbf{\times} \mathbf{1 0}^{-3} \mathbf{( m / s )}$} \\
\hline \hline Experiment & Phase 1 & Phase 2 \\
\hline \hline A & 3.6 & 1.5 \\
B & 5.1 & 1.7 \\
C & 4.2 & 1.8 \\
D & 3.9 & 1.9 \\
\hline \hline
\end{tabular}




\subsubsection{Experiment series 2}

The experiments of series 2 are a variation of experiment $\mathrm{C}$ with silt. From this experiment, the porosity of the sand was increased in the subsequent experiments C1-3 (Tab. 4.1). The excess pore pressure measurements exhibit complex patterns of positive and negative excess pore pressures. They will be described briefly, as well as the differences when compared to the intermediate and loose experiments presented in Chapter 3.

\section{Pore pressure measurements}

Pore pressure measurements from transducers 1-12 are presented in Figure 4.9. Experiment C1 was performed in the medium-densely packed deposit with a porosity of 0.46 , and it displays breach flow slide characteristics. It mainly recorded negative excess pore pressure apart from the transducer 7 at the bottom and furthest away from the failure front, which measured a positive pressure of $\sim 0.5 \mathrm{kPa}$ (Fig. 4.9-C1). Slides with larger blocks were observed during failure compared to experiment $\mathrm{C}$ of series 1 .

Experiment $\mathrm{C} 2$ with a porosity of 0.477 had the highest positive excess pore pressure at the bottom of the deposit $(1.2 \mathrm{kPa}$ at measurement location 1 , and $1.0 \mathrm{kPa}$ at position 7; Fig. 4.9-C2). Transducer 3 and 9 recorded smaller positive excess pore pressures directly above the first layer of silt heterogeneity. All other transducers recorded negative pressure with their maximum of $0.8 \mathrm{kPa}$ by transducer 8 , which is located immediately underneath the bottom silt layer.

Experiment C3 is the loosest experiment of series 2, with an initial porosity of 0.497. In the first $5 \mathrm{~s}$ all the transducers measured positive excess pore pressure as expected accordingly to the high porosity (Fig. 4.9-C3). From $5 \mathrm{~s}$ to the end, there is a transition to negative pressures.

\section{Normalised excess pore pressure}

From the normalised excess pore pressure, in experiment $\mathrm{C} 1$ the most negative pressure was measured on the back of the failure and almost at half-height of the deposit by transducer 8 (Fig. 4.10). This is different from the dense experiment $\mathrm{C}$ in which the most negative value was measured close to the top of the failure surface by transducer 5 . A nonuniform change of the normalised excess pore pressure was registered by the transducers 7-12.

Experiment C2, with similar porosity as the hybrid failure (exp. C) in Chapter 3, also registered the maximum positive pressure at the bottom of the deposit, but in this case behind the failure surface (Fig. 4.10). From the bottom until it reaches the first silt layer, the spatial structure changes from positive to negative, which means that in a half of the deposit, 
the bottom is contracting and the top part is dilating. When crossing the first silt layer, the excess pore pressure abruptly changed from negative below to positive above the silt layer. Towards the top of the fine sand layer, the pore pressure changes again from positive to negative (Fig. 4.10). Above the top silt layer, the excess pressure tends to zero at the very top of the deposit.

The spatial structure of experiment C3 is similar to the structure of the loose experiment D in Chapter 3, which had a similar porosity (cf. Tables $3.2 \& 4.1$ ). The two of them exhibited high positive excess pore pressures at the base of the deposit, with a decrease in excess pore pressure towards the top (Fig. 4.10).

$$
\begin{array}{llllllllllllll}
-\mathrm{T} 1 & -\mathrm{T} 2 & -\mathrm{T} 3 & -\mathrm{T} 4 & -\mathrm{T} 5 & -\mathrm{T} 6 & -\mathrm{T} 7 & -\mathrm{T} 8 & -\mathrm{T} 9 & -\mathrm{T} 10 & -\mathrm{T} 11 & -\mathrm{T} 12
\end{array}
$$
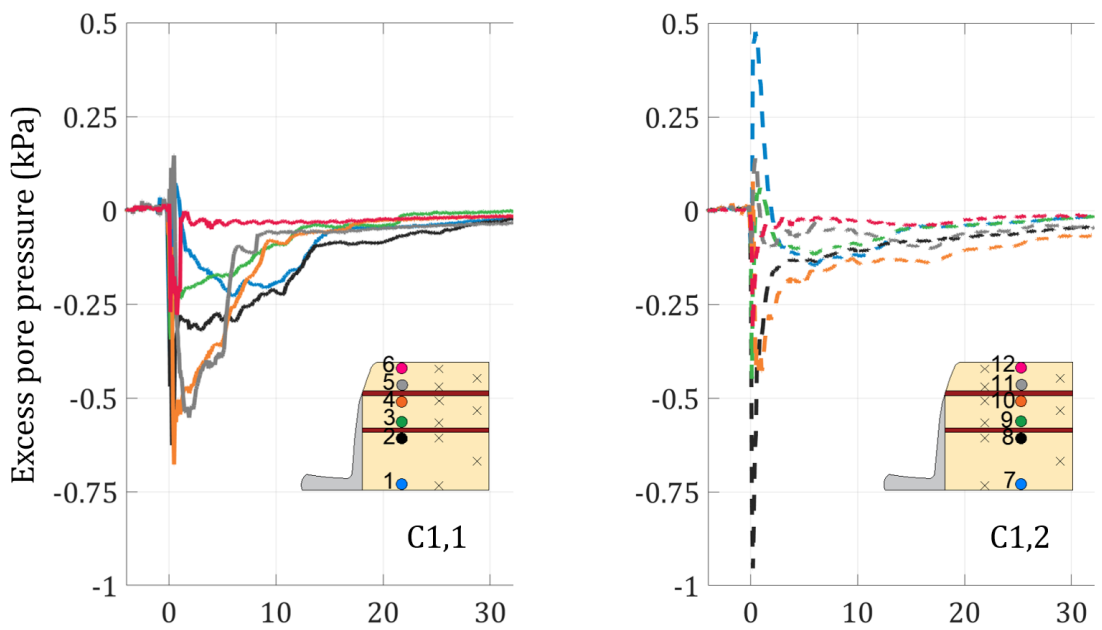

Time (s) 


\section{$\begin{array}{lllllllllllll}-\mathrm{T} 1 & -\mathrm{T} 2 & -\mathrm{T} 3 & -\mathrm{T} 4 & -\mathrm{T} 5 & -\mathrm{T} 6 & -\mathrm{T} 7 & -\mathrm{T} 8 & -\mathrm{T} 9 & -\mathrm{T} 10 & -\mathrm{T} 11 & -\mathrm{T} 12\end{array}$}
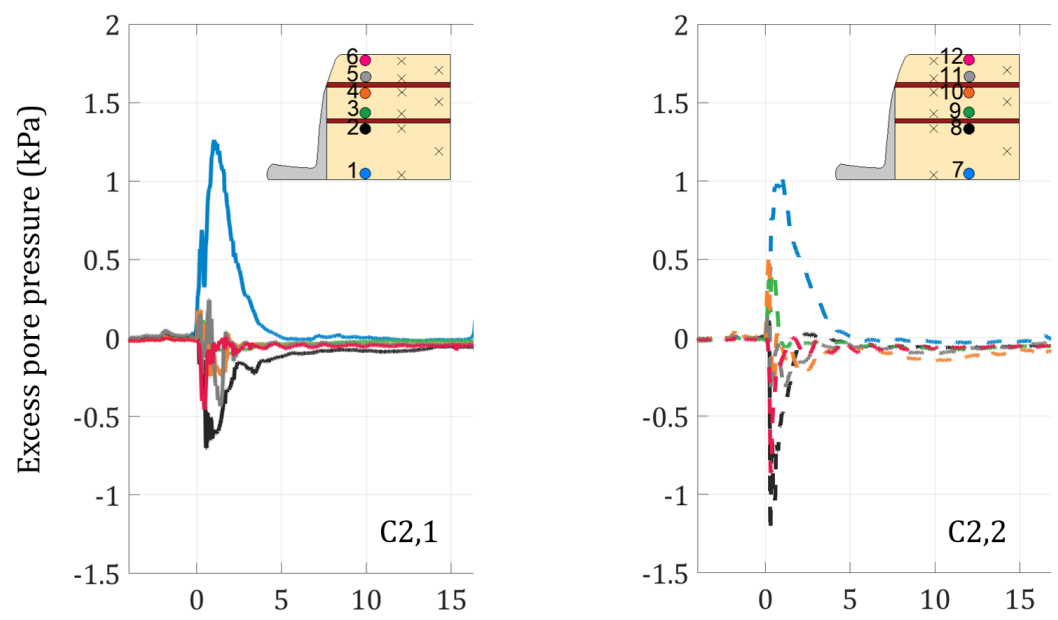

Time (s)
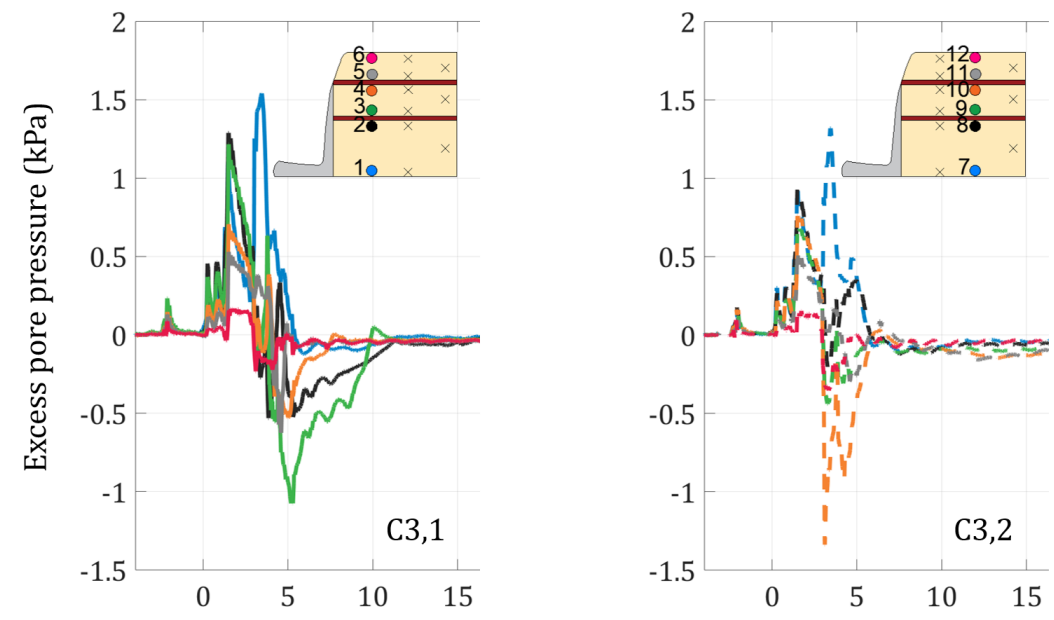

Time (s)

Figure 4.9: Excess pore pressure measurements for the experiment $C 1$ (C1,1; $C 1,2$; previous page), experiment $C 2$ (C2,1; C2,2;), and experiment $C 3(C 3,1 ; C 3,2)$ (Transducer 1-6 solid lines, transducers 7-12 dash lines). 
Experiment $\mathrm{C}$

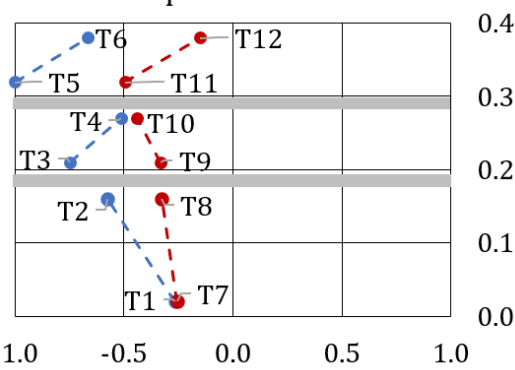

Experiment $\mathrm{C} 2$

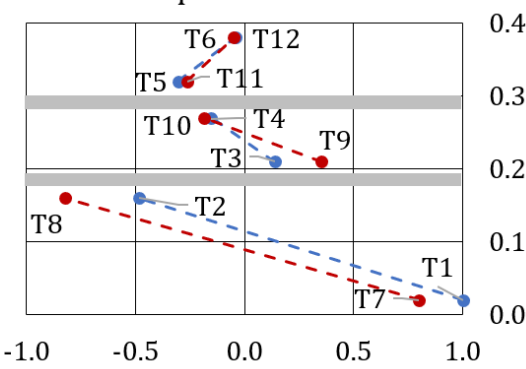

Normalised excess pore pressure $(-)$
Experiment $\mathrm{C} 1$

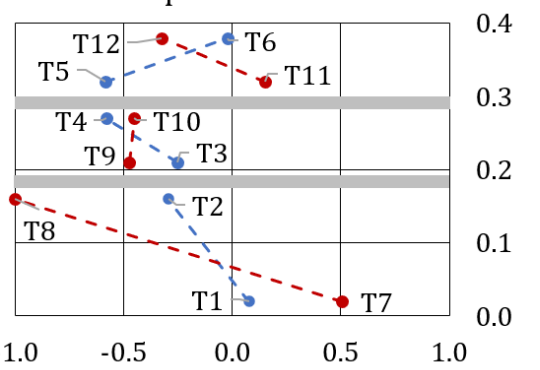

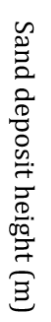

Experiment $\mathrm{C} 3$

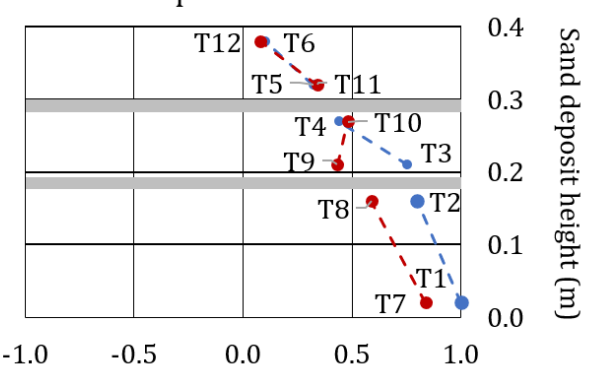

Normalised excess pore pressure $(-)$

Figure 4.10: Initial excess pore pressure in different positions (cross section) of the sand deposit (normalised with the maximum excess pore pressure in each experiment) (see Figure $4.4 \mathrm{~b}$ for positions). Grey bars correspond to the position of the heterogeneity layers. 


\subsection{Discussion}

\subsubsection{The effect of heterogeneity type on breach evolution (series 1)}

Distinct erosion processes were observed during the deposit failure in experiments $\mathrm{B}, \mathrm{C}$ and D with heterogeneous layers. This disparity is due to the different grain size of the heterogenetic material intercalated in the sand deposit. Grain size exerts a strong control over the hydraulic conductivity, which is the ease with which a specific fluid flows within a porous material. In experiment $B$, the median grain size of the coarse sand was 5 times larger than the median grain size of the fine sand. Therefore, water flowed more easily because the pore connections were larger, which resulted in a faster erosion of the coarse sand layers (Fig. 4.5, Exp. B). On the other hand, silt and clay had smaller grain size than sand, 3 and 780 times smaller, respectively. In this case, particles can pack closer together leaving smaller pore and smaller pore connections. In this scenario, it is difficult for water to flow through the deposit, which results in a slower erosion of the heterogenetic layers (Fig. 4.5, Exp. C and D).

The normalised excess pore pressure of experiments A and B had identical structure as the densely packed sand experiments A and B presented in Chapter 3. Particularly, the more negative values were located near the top of the failure surface and the excess pore pressure tended to zero from this position towards the bottom of the deposit (Fig. 4.7), which is consistent with the results reported in Chapter 3. Contrarily, the experiments with silt and clay, $\mathrm{C}$ and $\mathrm{D}$, respectively, had a non-uniform change in pore pressure along the sand deposit height (Fig. 4.7). A possible explanation might be compartmentalisation, which means that the heterogenetic layers work as a barrier to fluid flow, and the generated pore pressures are not in communication between different compartments of the submerged deposit. This could also explain why in experiment B there was no such structure. The higher hydraulic conductivity of the coarse sand heterogeneity allowed pressure communication there and prevented compartmentalization. Thus, that pressure compartmentalisation occurs where the heterogeneity has a lower hydraulic conductivity than the bulk deposit.

Now the retreat rates observed during the experiments will be discussed. Although the four experiments had similar porosity, different retreat rates were measured. This disparity can be explained by the magnitude of the excess pore pressure in the beginning of the experiments, which was $25 \%$ and $35 \%$ higher, respectively, in experiments C and D compared to the homogenous reference experiment A (Fig. 4.6). The contribution of this factor to the dissipation rate of dilative failures was already addressed in the discussion section in Chapter 3. Higher excess pore pressures generate larger pressure gradients, which 
will result in a larger inflow rate of water into the breach (Eq. 3.2). This led a faster erosion and higher retreat rates in experiments $C$ and D. The major differences in retreat rates occurred in phase 1 . During phase 2 , the retreat rates were very similar for all heterogeneity types and the homogeneous deposit. Since more than a half of sediment was eroded already in phase 1 , the deposit tends to a constant and specific retreat rate.

Besides the clear effects of the heterogeneity on breach evolution, the two centimetres of heterogenetic layers were not sufficient to modify the general behaviour of a breaching flow slide compared to those observed in Chapter 3. The main breach characteristics were still recognizable during the experiments, i.e., generation of negative excess pore pressure, dominant retrogression of the breach face through particle release from the sediment-water interface, occasional surficial slides, and the generation of a turbidity current. It can be concluded that the initial porosity is the major control on the occurrence of breach failures, whether the deposit is homogenous or heterogeneous.

\subsubsection{Heterogeneities at different sand densities (series 2)}

Despite the silt layering in the experiments of series 2 , the generated excess pore pressure is in accordance with the results obtained in Chapter 3 for different porosities. Experiment C1 was medium dense packed. Denser than experiments C and D in Chapter 3 , but looser than the experiments in series 1 in this chapter and experiment $\mathrm{A}$ and $\mathrm{B}$ from Chapter 3. Most of the generated excess pore pressures were negative (Fig. 4.9-C1), which was expected from Chapter 3 for a sand deposit with some compaction. The normalised excess pore pressure of experiment $\mathrm{C} 1$ follows the structure observed in experiments $\mathrm{A}$ and B presented in Chapter 3 for transducer 1-6. Contrary to experiment $C$, the non-uniformity appeared with the transducer 7-12 at the back of the failure (Fig. 4.10).

Experiment C2 exhibited similar type of behaviour as the hybrid failure experiment $\mathrm{C}$ in Chapter 3 since it displays both positive and negative excess pore pressure (Fig. 4.9-C2), which indicates the co-occurrence of dilative and contractional behaviour within a single failure. Due to the compartmentalisation, the change from positive excess pressures at the base of a hybrid failure to negative excess pore pressures at the top occurred within two partitions of the deposit (Fig. 4.10). The first one corresponds to the bottom layer of fine sand up to $18 \mathrm{~cm}$, within which the $10 \mathrm{~cm}$ from the bottom are contracting and the upper 8 $\mathrm{cm}$ are dilating. This is in agreement with the experiment $\mathrm{C}$ in Chapter 3. Although, in that case there was connection between the pressures in all deposit. In case of experiment $\mathrm{C} 2$, the silt layers acted as a barrier to fluid flow and the spatial structure of the pore pressures 
is referred to as a compartment of the deposit. Consequently, a second hybrid failure was stacked on top of the silt layer within the fine sand from 20 to $30 \mathrm{~cm}$ (Fig. 4.10-C2).

In accordance with the loose homogenous experiment D in Chapter 3, experiment C3 exhibited an initial positive excess pore pressure due to its high porosity and a tendency to contract (Fig. 4.9-C3).

Experiment C3 is the loosest experiment in the series, and the silt does not appear to affect the normalised excess pore pressure, perhaps because the failure is rapid, and the effect of silt is not remarkable on the pore pressure.

Despite the noticeable effects recognised in this second series of experiment, the major control on the occurrence of breaching failure, liquefaction failures, and hybrid failures remained the initial porosity. 


\subsection{Conclusions}

The aim of this chapter was to investigate the influence of a heterogeneous deposit on a flow slide. For that purpose, two series of experiments were conducted with a non-uniform sediment deposit. In the first series, two $1 \mathrm{~cm}$ layers were intercalated in the sand deposit with coarse sand, silt, and clay. These materials have different hydraulic conductivities. Similarities were observed with the results presented for the densely packed experiments A and B of Chapter 3. In this case, the two centimetres of heterogenetic material were not sufficient to modify the general behaviour of a breaching failures in a sand deposit with dimensions $0.40 \mathrm{~m}(\mathrm{~L}) \times 0.22 \mathrm{~m}(\mathrm{~W}) \times 0.40 \mathrm{~m}(\mathrm{H})$.

Secondary effects were recognised due to the different hydraulic conductivities of the heterogenetic material. Non-uniform spatial pore pressure structures (Christmas tree effect) occurred when hydraulic conductivity was smaller than sand, and ingressions into the failure surface occurred when hydraulic conductivity was larger than dominant sediment. The low hydraulic conductivity interlayers caused pressure compartmentalisation, with large pore pressure differences across the $1 \mathrm{~cm}$ interlayers. It was also noticed that the magnitude of excess pore pressures increased with the decrease of the grain size of the heterogeneity. The largest excess pore pressures were recorded in the experiments $\mathrm{C}$ and D with silt and clay, respectively. Consequently, the retreat rates during these experiments were larger than the homogenous reference experiment A, despite the lower hydraulic conductivity of the heterogeneous interlayering.

A second series of experiments repeated the dense experiment with silt layers with increased porosities. The initial porosity governed the main behaviour of the deposit failure in these experiments as well. The medium dense experiment had mainly negative pore pressure with some positive excess pressures at its base, the loosest experiment exhibited liquefaction structure with positive excess pore pressures. The intermediate experiment displayed the hybrid failure, with negative excess pressures overlying positive pressures, that has been described in Chapter 3 . Also, as in the series 1, here secondary effects were recognised due to the silt layers working as boundary. They compartmentalise and isolate the sand layers which, therefore, each work as an independent unit. This led to multiple hybrid failures being stacked on top of each other in the medium-loose porosity failure.

It is concluded here that the initial porosity is the main control on flow slide failure style, with similar failure style occurring compared to failures in homogenous deposits with similar porosity. Deposit heterogeneity does cause secondary effects such as larger excess pore pressure excursions, pressure compartmentalisation, and slightly faster retreat rates. In combination these secondary effects can give failures in heterogeneous deposits a much more complex appearance than failures in homogenous deposits. 


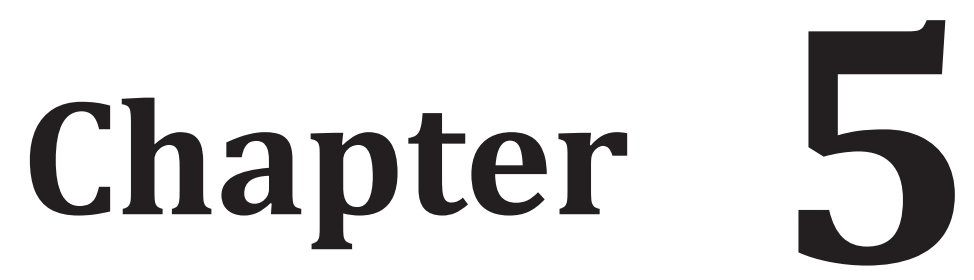

\section{Coeval measurements of breaching failures and generated turbidity currents}

"Outras vezes oiço passar o vento, E acho que só para ouvir passar o vento vale a pena ter nascido."

- Alberto Caeiro (1889-1915) Heterónimo de Fernando Pessoa 


\subsection{Introduction}

Turbidity currents are sediment-laden underflows that occur in the ocean and in lakes (Parker et al., 1986; Garcia, 1994). These currents are driven downslope by the density difference between the current and the ambient water (Middleton, 1993; Kneller et al., 1999). They are commonly initiated in deltas on continental shelves, and transport significant volumes of sediment from these deltas to deep marine environments (Simpson, 1982; Talling et al., 2015). Furthermore, turbidity currents can change the physical shape of the seafloor by eroding sediment over large areas and creating submarine canyons (Daly, 1936; Mitchell, 2014).

Turbidity currents may be caused by the direct inflow of turbid water from rivers (Lambert, 1982), by wave action that suspends sediment (Seymour, 1986), by subaqueous slumps (Dengler \& Wilde, 1987), by the discharge of mining tailings (Hay, 1987), or by dredging operations (Estourgie, 1988). Only recently it became clear that breaching may be an important source of turbidity currents in subaqueous canyons or any other subaqueous setting where sufficient fine sand can accumulate (Van den Berg et al., 2002; Mastbergen \& Van den Berg, 2003; Eke et al., 2011). The turbidity currents are generated when particles detach from the breach failure face and subsequently drag water with them while they fall under the action of gravity. When the mixture of particles and water reaches the toe of the failure face, it is deflected and flows into the basin in front of the failure as a turbidity current. The flow rate of this turbidity current is determined by the retreat rate and height of the failure surface, and by the turbulent mixing of the detached sand particles with the ambient water in front of the breach face. The characteristics and behaviour of the turbidity current that flows into the basin play a vital role in the evolution of the breach and determine the terminal of the sediment.

Critically, the interaction between the turbidity current and the slope downstream of the breach face can cause erosion or sedimentation in front of the failure. These two processes lead to two breaching regimes that were termed stable and unstable breaching by Van Rhee \& Bezuijen (1998 \& 2015; Fig. 5.1). Sedimentation in front of the breach causes the height of the breach face to decrease in time, and this is the main process during stable breaching (Fig. 5.1a). The decrease of the breach face height in turn causes a decreasing flow rate in the turbidity current, resulting in more sedimentation, and this feedback mechanism can end the breach soon after its initiation.

Secondly, the breach is called unstable when the height of the breach face increases in time due to erosion of sediment at the toe of the breach face by the turbidity (Fig. 5.1c). This increased breach height forms a positive feedback on the flow rate of the turbidity current and further enhances the erosion at the toe of the failure. Additionally, the toe- 
erosion is a source of sediment for the turbidity current on top of the sediment derived from grain-by-grain detachment from the breach face, which further increases the flow rate and erosional tendency of the turbidity current. Unstable breaching due to erosion of the toe of the failure is, therefore, generally an unfavourable effect, because the breach does not stop quickly compared to a stable breach. Furthermore, it is difficult to predict when an unstable breaching process will end. Depending on the slope of the embankment and the bypass slope of the resulting turbidity currents, it could take hours or even a day before it finishes. It is especially unstable breaching that has led to several problematic slope failures around the world. Thus, the flow rate of the turbidity current determines whether a breach is stable or unstable, and the severity of the consequences of the failure.

Another relevant flow condition is bypass, also known as auto-suspension, which is developed when the energy input of gravity acting on the suspended sediment is enough to balance the consumed energy necessary to hold the sediment in suspension (Parker, 1982; Fig. 5.1b). In practice, bypass may refer to a stage in space and time where a turbidity current passes over a bed without net sediment entrainment or deposition (Stevenson et al., 2015; Sequeiros et al., 2018). Bypassing turbidity currents form a special steady condition in between stable and unstable breaching that maintains the breach height, or marginally increases or decreases breach height depending on the upper embankment slope (Fig. 5.1b). Whether this steady case occurs in natural breaches is unknown, but unlikely because both the stable and unstable breaching regimes involve feedbacks driving breach-height away from the bypass condition.

$\underline{\text { Stable breaching }}$

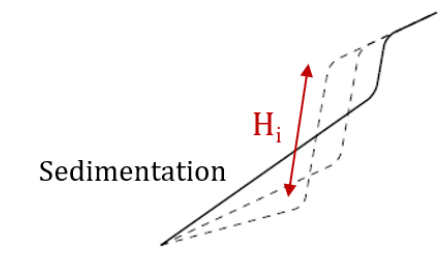

a)
Bypassing

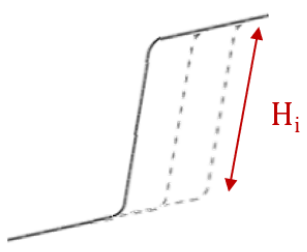

b)
Unstable breaching

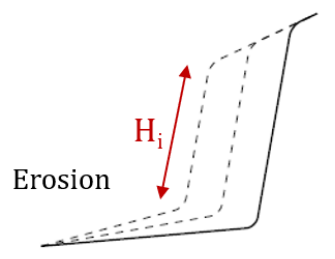

c)

Figure 5.1: Schematic illustration of the interaction between the turbidity current and the downstream slope: a) stable breaching, b) bypass, and c) unstable breaching. $H_{i}$ is the initial breach height and the solid lines correspond to the last breach face position (adapted from Weij et al., 2016). 
The behaviour of the turbidity current travelling into the basin also determines the transport distance and ultimate fate of the sediment derived from the breach face. In the Western Scheldt estuary, shoal margin collapses have occurred on average five times a year over the last decades (Van Dijk et al., 2019). A single shoal margin collapse displaced several million cubic meters within hours in Western Scheldt in 2014. The Western Scheldt provides access to various harbours along the estuary, of which the port of Antwerp (Belgium) is the largest. Shoal margin collapses in Western Scheldt estuary have implications for harbour accessibility because the displaced sediments are re-deposited into the channel and affect the width and navigation depth of shipping lanes. To guarantee the accessibility of the ports, dredging activities may have to take place in the navigation channels following flow slides. Of course, such dredging activities might themselves also cause further flow slides to occur.

The effects of shoal margin collapses and channel sedimentation on the channel dynamics of the Western Scheldt were studied by Van Dijk et al. (2019) using the numerical model Delft-3D. They concluded that the shoal margin collapses change the channel-shoal network by shallowing of the major channels and the formation of new, smaller channels on the tidal flats. Furthermore, when the disturbances caused by the local in-channel deposition are reworked along the channel and reach a seaward or landward tidal-channel junction, the bed elevation at the junction increases on average and the cross-sectional geometry of the channel junction decreases. This may inhibit the flow through the channel junction, with potential implications for channel junction stability (Van Dijk et al., 2019).

Finally, the turbidity currents generated by breach failures must have operated the same way in ancient sedimentological systems as they do in present day environments. The ubiquitous occurrence of channel bank failures and collapses of shoal margins that have been recognized in estuaries and rivers around the world in modern environments (Coleman, 1969; Laury 1971; Silvis \& De Groot, 1995; Torrey, 1995; Dunbar et al., 1999; Van den Berg et al., 2002; Beinssen et al., 2014; Van Dijk et al., 2019) suggests that this must have been a common process in ancient systems as well. However, ancient deposits of breachinduced turbidity currents are hardly recognized. The only notable exception is the work of Van den Berg et al. (2002 \& 2017) who analysed the potential depositional signature of breach failures in Belgian shallow marine deposits, fluvial deposits of sandstone in England, and Lower Jurassic, Norwegian Continental Shelf. Sedimentologists need better descriptions of the context, behaviour, and characteristics of breach-induced turbidity currents before they can confidently recognize them in ancient deposits.

Thus, knowing the characteristics of breach-induced turbidity currents and the deposits they generate is important for predicting the impact of the breach failure and the geohazard they pose to the water defences, for managing shipping lanes and estuarine channel dynamics, and for the recognition of potential breach-induced deposits in ancient systems. 
However, there is very limited integrated knowledge about breaches and their turbidity currents. On the one hand, the emerging literature on breach failure has mostly focussed on establishing quantitative understanding of breach propagation (e.g., Mastbergen \& Van den Berg, 2003; Eke et al., 2011; You et al., 2012, 2014a,b) and the turbidity current flowing down along the breach face (Van Rhee 2010; Eke et al., 2011; You et al., 2014a; Alhaddad et al., 2020). On the other hand, previous experimental studies on turbidity currents presented in literature all used an artificial mechanism, for instance a pump (Gray et al., 2005; Cartigny et al., 2013; Sequeiros et al., 2018), a constant head tank (Straub et al., 2008), a lock-gate (Felix et al., 2005), or a super-elevated suspension box (Eggenhuisen \& McCaffrey, 2012), to inject ready-made sediment-water mixtures into flumes. Contrary to those studies, this chapter presents the first experimental measurements of breaches and the related turbidity currents that flow into the basin in front of the failure. This represents a holistic analogue to natural breach-induced turbidity currents that allows us to study how the nature of the turbidity current is related to the triggering mechanism.

Specifically, here the relation between breaching failure evolution, the velocity of the generated turbidity current, and the occurrence of deposition and erosion in front of the failure was analysed. The slope of the floor in front of the failure was varied because this slope is commonly considered a primary control on turbidity current characteristics (Kneller, 2003; Stevenson et al., 2015; Pohl et al., 2020). Flow thickness, volumetric discharge, and rate of deposition were analysed in order to answer the question: How does the strength of the turbidity current relate to an evolving breaching failure? Results show that the type of failure strongly influences the characteristics of the turbidity current, more so than the slope in front of the failure. 


\subsection{Experimental method}

\subsubsection{Experimental setup and materials}

The experiments were conducted in the same $4 \mathrm{~m}$ long, $0.5 \mathrm{~m}$ deep and $0.22 \mathrm{~m}$ wide flume that was used in Chapters 3 and 4 (Fig. 5.2). The material used to build the submerged deposit was the same sand used in the experiments of the previous Chapters 3 and 4 (Sibelco BR37; Fig. 2.1).

A different deposit geometry and configuration of the flume was used in comparison to the experiments in the previous chapters. The main reason for these changes is related to the deposition observed in front of the deposit during breaching experiments A and B in Chapter 3, and experiments in Chapter 4. Those experiments resulted in stable breaching due to the accumulation of sediment in front of the breach face and consequent decrease of the breach height. Two geometrical changes were applied to promote a more vigorous turbidity current and decrease this depositional tendency. The first modification is related to the height of the initial deposit, which was increased to $0.80 \mathrm{~m}$, two times higher than the deposit height in the previous chapters. The second adjustment was that the slope of the flume floor $(\beta)$ was adjusted to $4^{\circ}$ and $8^{\circ}$ (Fig. 5.2). These modifications were expected to promote flow rate and velocity of the turbidity current, so that more sediment was transported along the flume floor, and less deposited directly in front of the failure. A reference experiment was also conducted with the flume floor on a horizontal orientation.

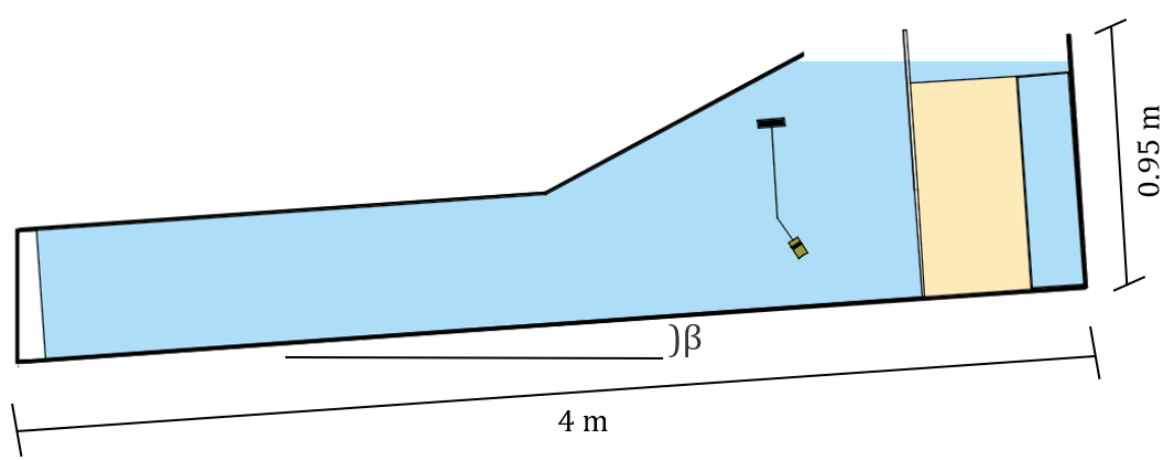

Figure 5.2: Schematic overview of the 2D experimental setup and location of the UVP probe. 


\subsubsection{Experimental procedure}

The flume was filled with fresh water up to a level of $0.85 \mathrm{~m}$ above the floor of the flume. A removable vertical plate was inserted in place to constrain the sand while building the deposit. The sand was weighted before it was placed behind the vertical plate. The sand was compacted with a circular disc after introducing layers that had a thickness of $10 \mathrm{~cm}$. After each deposit was built, the final geometry was $0.40 \mathrm{~m}(\mathrm{~L}) \times 0.22 \mathrm{~m}(\mathrm{~W}) \times 0.80 \mathrm{~m}(\mathrm{H})$. The average porosity was $0.44 \pm 0.005$ for all experiments, which was determined from the mass and volume of sediment in the deposit. Experiment $A$ is the reference experiment with a horizontal flume floor. For the subsequent experiments, the flume was adjusted to $4^{\circ}$ and $8^{\circ}$ after the deposits were built, which correspond to experiment B and C, respectively. The failure was induced by quickly removing the confining plate.

\subsubsection{UVP data acquisition and processing}

One UVP probe was installed at the centre line of the flume to monitor the velocity of the turbidity current during the experiments. The UVP probe was the same equipment used in the series of experiments presented in the previous chapters. It was installed $0.4 \mathrm{~m}$ from the sand deposit and $0.32 \mathrm{~m}$ above the bed, angled $60^{\circ}$ relative to the local bed slope (Fig. 5.2). The data acquisition settings for the UVP measurements are provided in Table 5.1.

UVP measures velocities of the suspended sediment in the direction of the beam axis. An example of the un-processed velocity data is given in Figure 5.3. This measured velocity was converted into a bed-parallel velocity component with the assumption that the bed-normal component of velocity is zero (Cartigny et al., 2013; Sequeiros et al., 2018). The coordinates were transformed from distance-to-the-probe to elevation-above-the-flumefloor. Figure 5.4A illustrates this configuration of the velocity profile measurement.

The data was subsequently processed to obtain the following characteristics of the turbidity currents: time-averaged velocity profiles, maximum velocity, flow thickness, depth-averaged velocity, volumetric discharge, and rates of deposition and erosion. The bed interface was tracked for each experiment as well as the upper boundary (top flow) between the flow and ambient water. The dashed lines delineate the limits of the turbidity current over time (Fig. 5.3); the lower dashed line traces the bed position and the upper dashed line marks the top of the flow. Where the sediment aggrades underneath the UVP probe, this results in a reduction of the distance between the UVP and the sediment bed. In some cases, this distance increases which means that some sediment was eroded from the bed. 
Table 5.1: Acquisition settings for the UVP measurements.

\begin{tabular}{ll}
\hline \hline Speed of sound in water (m/s) & 1480 \\
Measurement window (mm) & 438.82 \\
Number of channels & 277 \\
Channel width (mm) & 3.7 \\
Frequency of the ultrasound beam (MHz) & 1 \\
Number of cycles per pulse & 5 \\
Number of sound pulses per measurement & 32 \\
Minimum on-axis velocity (mm/s) & -608.6 \\
Maximum on-axis velocity (mm/s) & 603.8 \\
On-axis velocity resolution (mm/s) & 4.754 \\
Pulse repetition frequency (kHz) & 1.645 \\
\hline \hline
\end{tabular}

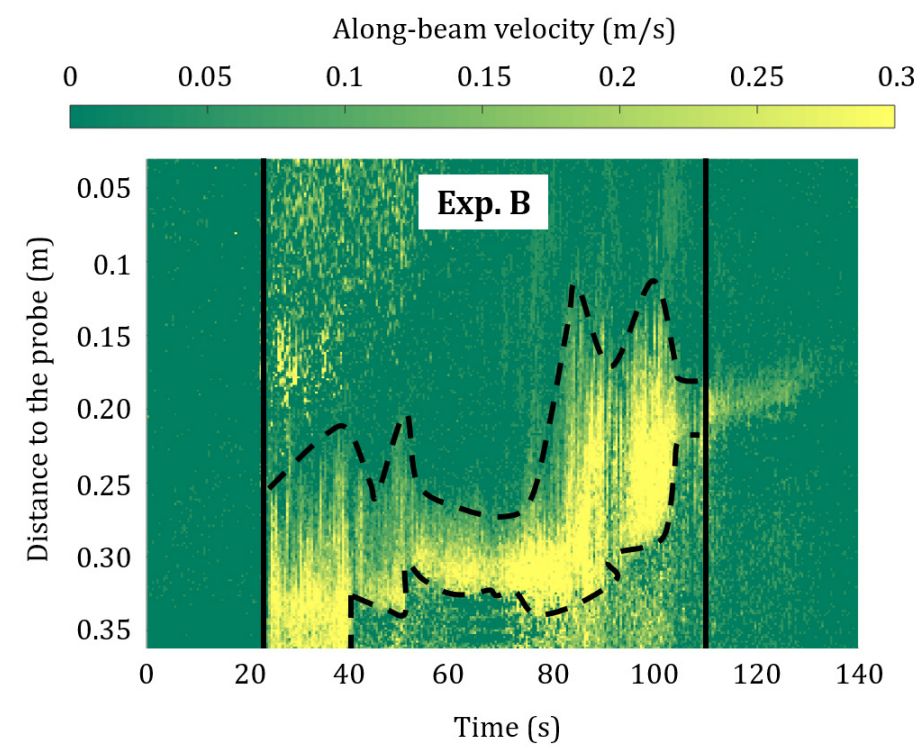

Figure 5.3: Along-beam velocity over time as measured by the UVP for experiment B. The solid vertical lines indicate the interval that was used for analysis of the velocity data. The lower dashed lines indicate the bed position and the upper dashed line indicates the top of the flow. The velocity signal below the tracked bed interface is an interference pattern and an artefact of the measurement. 


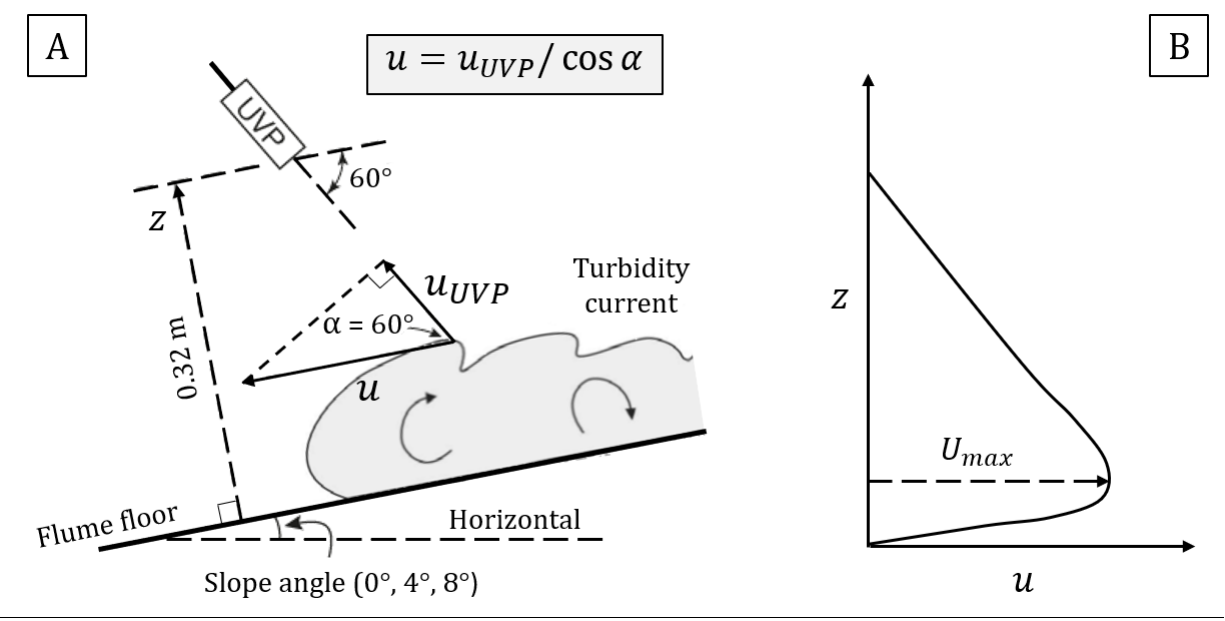

Figure 5.4: (A) UVP orientation and calculation of the bed-parallel velocity (modified from Pohl et al., 2020); (B) Illustration of a time-averaged velocity profile (modified from Launder \& Rodi, 1983).

\section{Velocity profiles}

Time-averaged profiles were calculated to obtain the flow velocities and dimensions of the turbidity currents. Figure 5.4B schematically shows a typical time-averaged velocity profile of a turbidity current. The vertical axis $(z)$ describes the distance normal to the bed, the horizontal axis $(u)$ the bed parallel velocity component, and is the maximum velocity of the flow (e.g., Launder \& Rodi, 1983; Kneller \& Buckee, 2000; Gray et al., 2005).

The flow thickness is the difference between the top flow and the bed interface.

The depth-averaged velocity was determined over the full depth of the flow, taking in account the change of bed position during the experiments. In Figure 5.3, the solid vertical lines indicate the time interval for the analysis.

The volumetric discharge was calculated by multiplying the depth-averaged velocity and the flow thickness.

The rate of deposition is the variation of the bed interface over time and was determined each second. 


\subsection{Results}

The experiments of this series were performed in densely packed sand and characteristics of breaching flow slides were recognized in all experiments. These characteristics are the generation of negative excess pore pressure (Fig. 5.5), retrogression of the breach face through particle-release from the sediment-water interface, occasional surficial slides, and the generation of a turbidity current (Van den Berg et al., 2002; Eke et al., 2011; You et al., 2012, 2014a,b; Chapter 3 of this thesis). These general observations were documented and discussed in detail in the previous chapters. In this section, only the results and new findings related to the erosion failure style and turbidity currents will be reported.

$-Z=0.02 \mathrm{~m} \quad-Z=0.21 \mathrm{~m} \quad Z=0.4 \mathrm{~m} \quad Z \mathrm{Z}=0.59 \mathrm{~m} \quad Z=0.78 \mathrm{~m}$

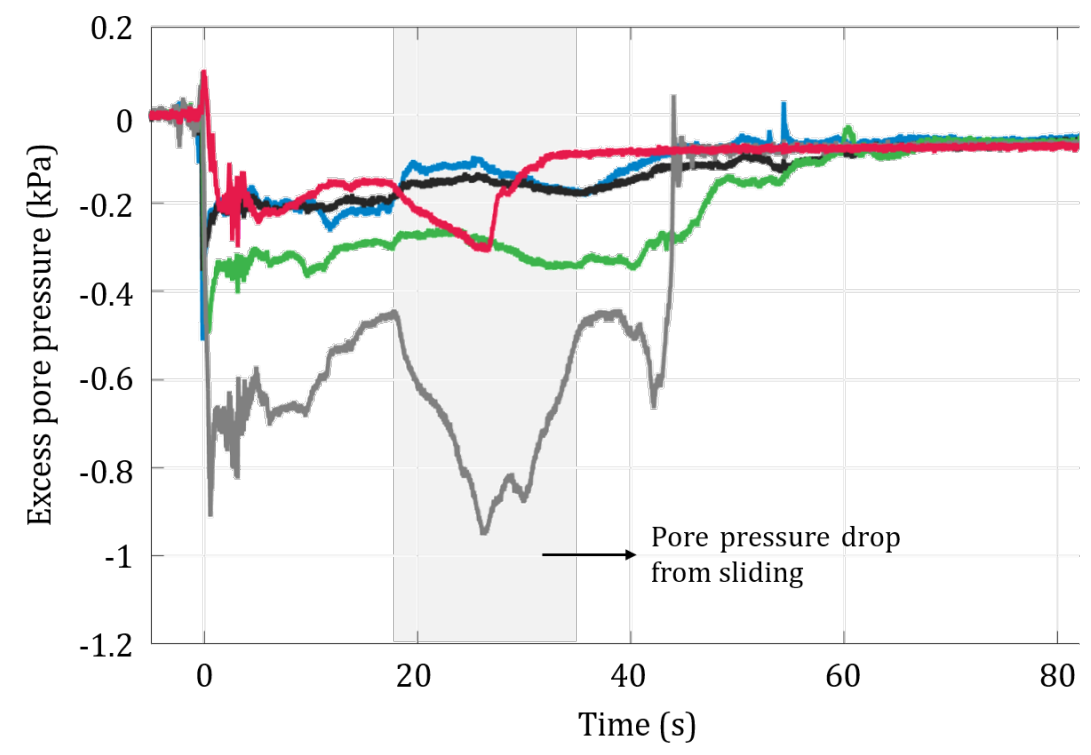

Figure 5.5: Excess pore pressure during experiment $A . Z$ is measured along the height of the sand deposit (cross section), $0.26 \mathrm{~m}$ from the initial breaching face. 


\subsubsection{Erosion failure style}

A particular failure style was observed in this series of experiments. Wedges of sand slid downward as coherent blocks (Fig. 5.6) in between phases of the grain-by-grain failure. The occurrence of these sliding wedges was not periodic and the wedges did not have the same dimensions in each experiment. They appear to occur when the turbidity current eroded the lower part of the breach face. Consequently, the upper wedge of the deposit is pending, which creates an instability leading to failure of the wedge. This failure style was also reported by You et al. (2014a), who termed it dual-mode failure to indicate the alternation between phases of grain-by-grain failure and slide-block failure. In the experiments presented here, when a wedge slid, it deformed and entrained water, and it disintegrated to becoming part of the turbidity current. This disintegration and integration of the sand wedges in the turbidity current was absolute in experiment $\mathrm{C}$, whereas in experiment $\mathrm{A}$ the sand wedges did not fully integrate with the turbidity current. In experiment B only part of the sand wedges were incorporated in the turbidity current.

Three major sliding events were observed during experiment $\mathrm{A}$, and two during experiments $\mathrm{B}$ and $\mathrm{C}$. The time corresponding to the moment when the sliding wedge reached the bottom of the failure surface is presented in Table 5.2.

Figure 5.7 shows the depositional profiles for the experiments. In all three experiments the sand started depositing and the breach height decreased in time. The sediment deposited and obstructed the breaching process at the lower part of the slope increasing the slope angle at the toe. In experiment A the sand was deposited close to the initial deposit location and with increase of the slope of the flume the sand was transported and deposited away from it. During experiment $C$ the sand was transported furthest away along the flume, exhibiting a more elongated profile (Fig. 5.7). Experiment B developed an intermediate situation between experiment $\mathrm{A}$ and $\mathrm{C}$; neither deposition close to the initial deposit as in experiment A nor so elongated as experiment $\mathrm{C}$. 

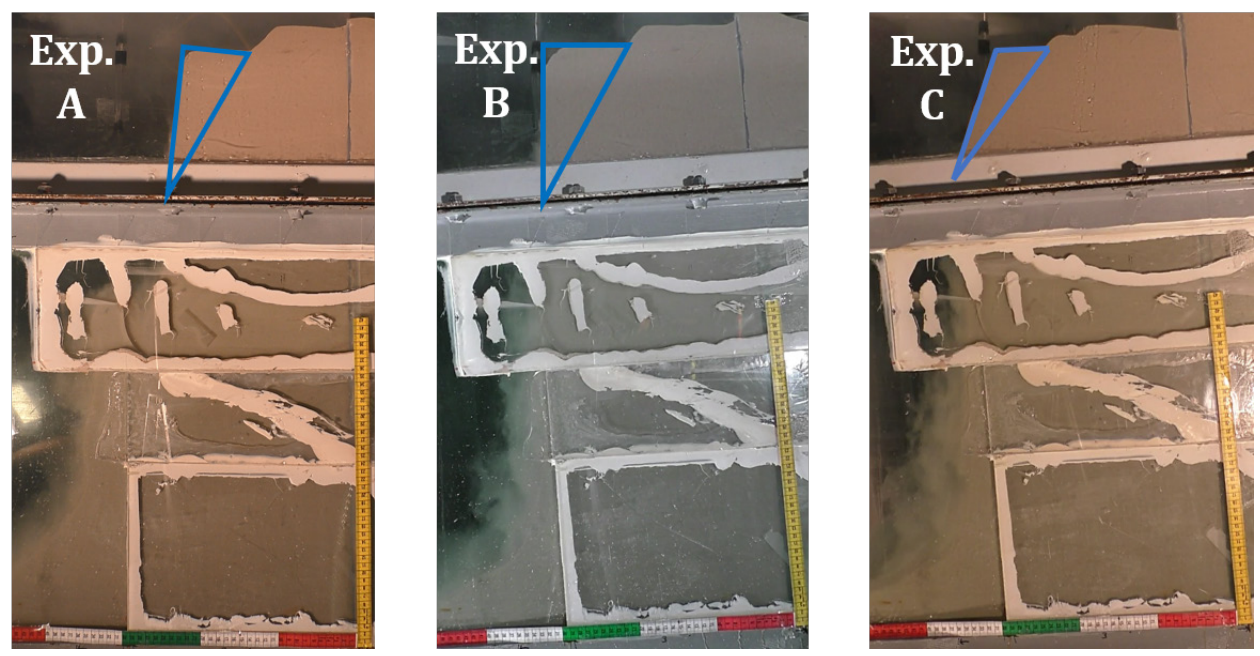

Figure 5.6: Snapshots of videos of erosion style for experiments $A, B$, and $C$ (side view of the flume). Blue triangles delineate the sliding wedges. In experiment $A$, apart from the delineated sliding wedge, another wedge is falling half height of the deposit. (Note that the same sand was used in experiments $A, B$, and $C$; the difference in colours is caused by different light conditions. White glue was used to repair a fractured glass side panel.)

Table 5.2: Timing of the sliding wedge events and the duration of the subsequent pulses in the turbidity currents.

\begin{tabular}{ccc}
\cline { 2 - 3 } & Sliding events, $\mathbf{t}_{\mathbf{i}}(\mathbf{s})$ & Pulse duration (s) \\
\hline \hline \multirow{2}{*}{ Experiment A } & 40 & 5 \\
& 50 & 5 \\
& 60 & 5 \\
\multirow{2}{*}{ Experiment B } & 55 & 13 \\
& 70 & 10 \\
\hline \multirow{2}{*}{ Experiment C } & 22 & 8 \\
& 51 & 9 \\
\hline \hline
\end{tabular}




$-\mathrm{t}=0 \mathrm{~s} \quad-\mathrm{t}=20 \mathrm{~s} \quad-\mathrm{t}=50 \mathrm{~s} \quad \mathrm{t}=70 \mathrm{~s} \quad \mathrm{t}=120 \mathrm{~s}$
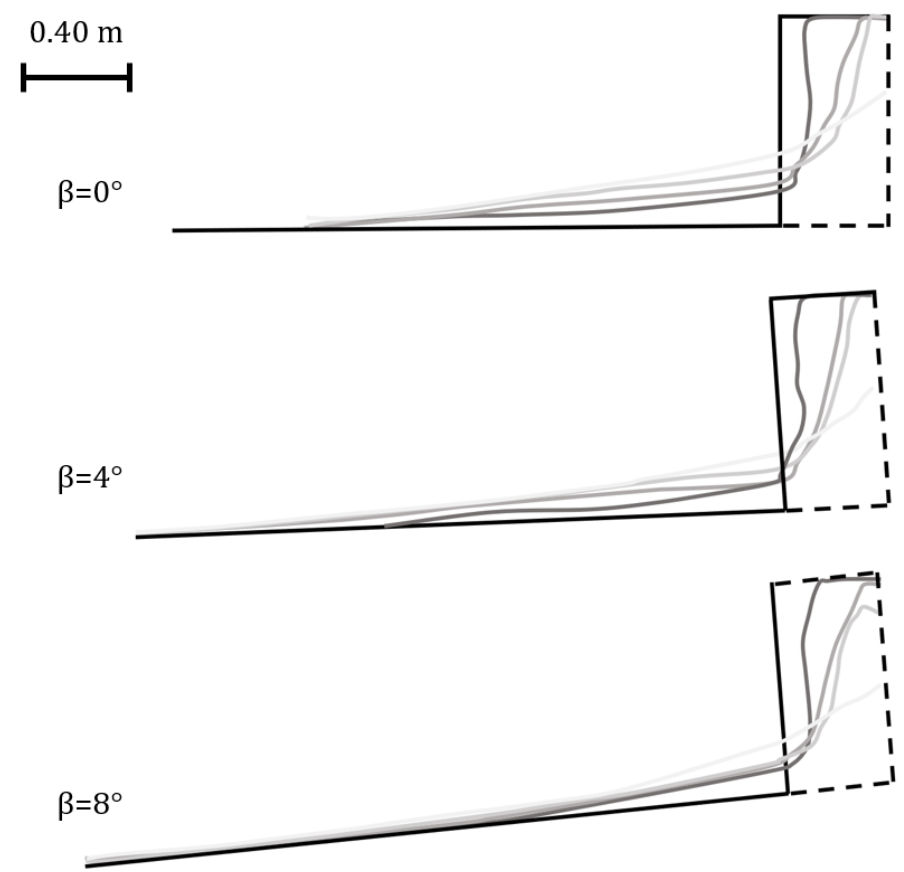

Figure 5.7: Depositional profiles for experiments $A, B$, and $C$ (side view of the flume).

\subsubsection{Turbidity current velocities into the flume}

Figure 5.8 provides the turbidity current velocity over time for the experiments. Maximum velocities in the range of $0.6 \mathrm{~m} / \mathrm{s}$ were reached during the first $15 \mathrm{~s}$ of all three experiments. After this time, these velocities decreased during the rest of experiments $A$ and C. Experiment B registered further periods of high velocities between 60 and $80 \mathrm{~s}$.

Time-averaged velocity profiles are presented in Figure 5.9. The profiles calculated for the first $15 \mathrm{~s}$ of the experiments are shown in Figure 5.9A. The maximum velocities measured in experiment A, B, and C were $0.56,0.60$, and $0.61 \mathrm{~m} / \mathrm{s}$, respectively (Fig. 5.9A). Turbidity current in experiment $C$ with slope angle of $8^{\circ}$ was faster than the turbidity currents generated in experiments $A$ and $B$ with more gentle slopes $\left(0^{\circ}\right.$ and $4^{\circ}$, respectively). The increase of the slope to $8^{\circ}$ had an increase of $8.2 \%$ on the maximum velocity. The 
maximum velocity measured in experiment $\mathrm{B}$ was almost the same as the maximum velocity in experiment $\mathrm{C}$.

Figure 5.9B displays time-averaged velocity profiles for the first sliding wedge in each experiment. The duration of the time averaging was the duration of the pulse (Tab. 5.2). The pulse duration corresponds to the time interval from when the turbidity-current flow thickness and volumetric discharge started to increase, reached the peak, and decreased afterwards. The maximum velocity of $0.58 \mathrm{~m} / \mathrm{s}$ was measured in experiment $\mathrm{B}$, with a flume tank slope of $4^{\circ}$. Next in experiment A was reached a maximum velocity of $0.29 \mathrm{~m} / \mathrm{s}$ with a horizontal flume floor, and when the flume floor had an angle of $8^{\circ}$, the maximum velocity during the sliding wedge pulse was $0.17 \mathrm{~m} / \mathrm{s}$. Correlating these velocities with the velocities measured in the beginning of the experiments (Fig. 5.9A), in experiment B it was almost reached the maximum velocity during the sliding period, and in experiment $\mathrm{C}$ a third of the velocity. In experiment $A$, the maximum velocity had a decrease of $52 \%$ during the sliding period.

\subsubsection{Correlations between turbidity-current flow-rate, and occurrence of erosion and deposition in front of the failure}

Flow thickness, volumetric discharge, and rate of deposition are presented in Figure 5.10 for each experiment. Also, the sliding wedges identified from the video records are indicated with dashed lines.

The first two sliding events in experiment A caused an increase of the volumetric discharge up to $0.016 \mathrm{~m}^{2} / \mathrm{s}$ and the flow thickness up to $0.058 \mathrm{~m}$ (Fig. 5.10, Exp. A). The sand released by these events was not transported further away, but was deposited close to the UVP, which corresponds to the peak in rate of deposition of $27 \mathrm{~mm} / \mathrm{s}$. The third sliding event at $60 \mathrm{~s}$ caused oscillation of the flow thickness and volumetric discharge. This pulsed flow eroded the bed with a rate of $-9 \mathrm{~mm} / \mathrm{s}$ which is the maximum rate of erosion measured during the entire experiment. The flow thickness and volumetric discharge reached values of $0.055 \mathrm{~m}$ and $0.012 \mathrm{~m}^{2} / \mathrm{s}$, respectively, at $62 \mathrm{~s}$ (Fig. 5.10, Exp. A). Immediately after these peak values, the sand block deposited with a rate of $22 \mathrm{~mm} / \mathrm{s}$.

In experiment $\mathrm{B}$, the first sliding wedge caused a large increase in the flow thickness and volumetric discharge after $5 \mathrm{~s}$. The flow thickness reached a value of $0.19 \mathrm{~m}$ and the volumetric discharge $0.074 \mathrm{~m}^{2} / \mathrm{s}$, which are the highest values measured during the experiment (Fig. 5.10, Exp. B). There is some deposition after this sliding event but not as pronounced as some peaks at the end of other sliding events. The second event happened at 
$70 \mathrm{~s}$ and caused also a large increase of the flow thickness and volumetric discharge at $75 \mathrm{~s}$, $0.17 \mathrm{~m}$ and $0.083 \mathrm{~m}^{2} / \mathrm{s}$, respectively. This sand rapidly deposited at $80 \mathrm{~s}$ with a rate $24 \mathrm{~mm} / \mathrm{s}$ (Fig. 5.10, Exp. B).

The first sliding event in experiment $\mathrm{C}$ caused an increase of the flow thickness and volumetric discharge, with values of $0.074 \mathrm{~m}$ and $0.019 \mathrm{~m}^{2} / \mathrm{s}$, respectively (Fig. 5.10, Exp. C). The rate of deposition oscillated between the two events until $50 \mathrm{~s}$ without a remarkable value. A peak of erosion followed by deposition was recorded after $50 \mathrm{~s}$ with values of -15 and $+22 \mathrm{~mm} / \mathrm{s}$, respectively (Fig. 5.10, Exp. C). The second event at $51 \mathrm{~s}$ was almost unnoticed, with a minor increase of the flow thickness.

Overall, we can see that the flow thickness and flux increase immediately after the occurrence of a sliding event. This correlation is clearest for experiment $\mathrm{C}$ with an $8^{\circ}$ slope angle. The rate of deposition decreases with the increase slope angle. Experiment $\mathrm{C}$ with $8^{\circ}$ has lower rate with a maximum of $\sim 22 \mathrm{~mm} / \mathrm{s}$ at $52 \mathrm{~s}$. Experiments $A$ and B have higher rates of $33 \mathrm{~mm} / \mathrm{s}$ at $18 \mathrm{~s}$ and $17 \mathrm{~s}$, respectively. This indicates that for larger slope angles there is less deposition and the sediment is transported further away.

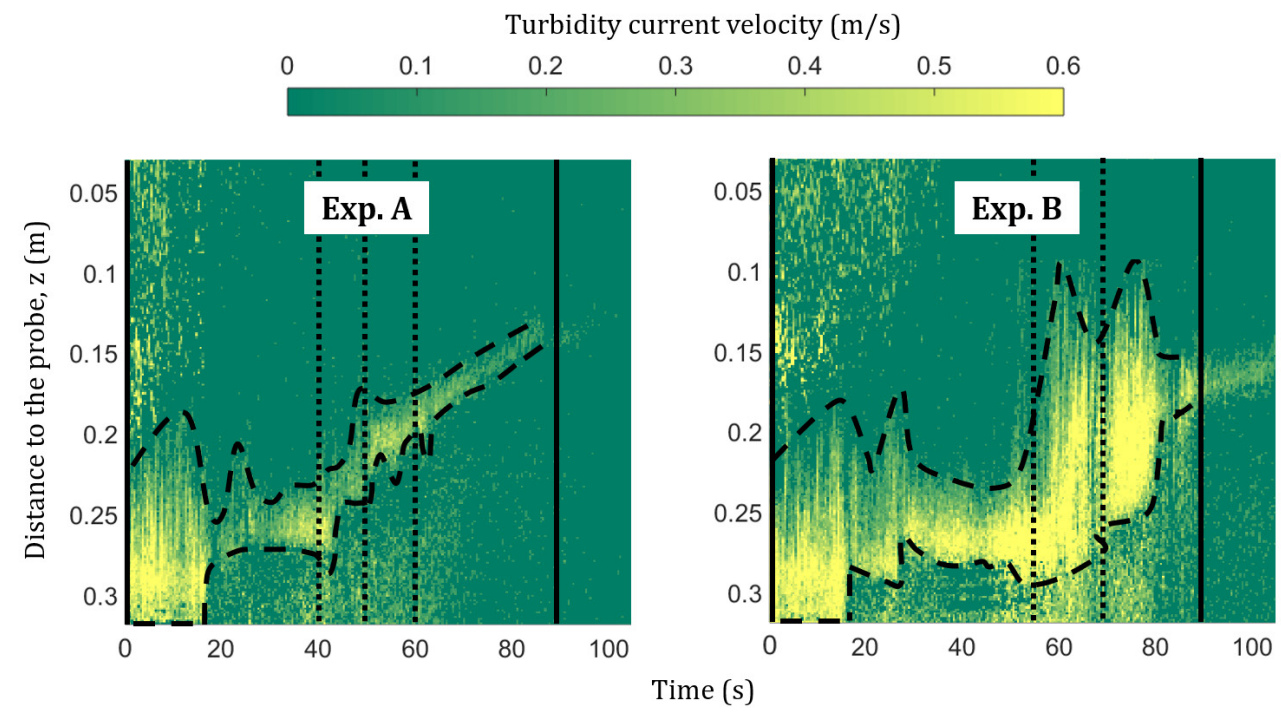




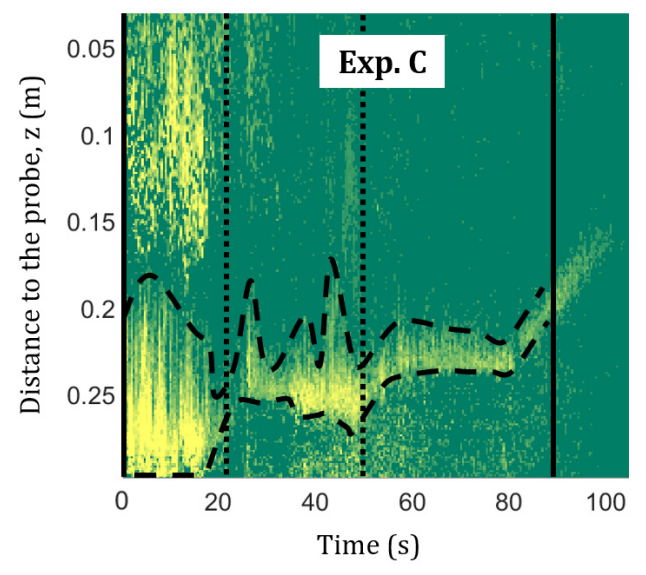

Figure 5.8: Turbidity current velocity over time for the experiments $A, B$ (previous page), and experiment $C$. The solid vertical lines indicate the interval that was used for analysis of the velocity data. The dotted vertical lines indicate the moment when the blocks reached the base of the failure surface.
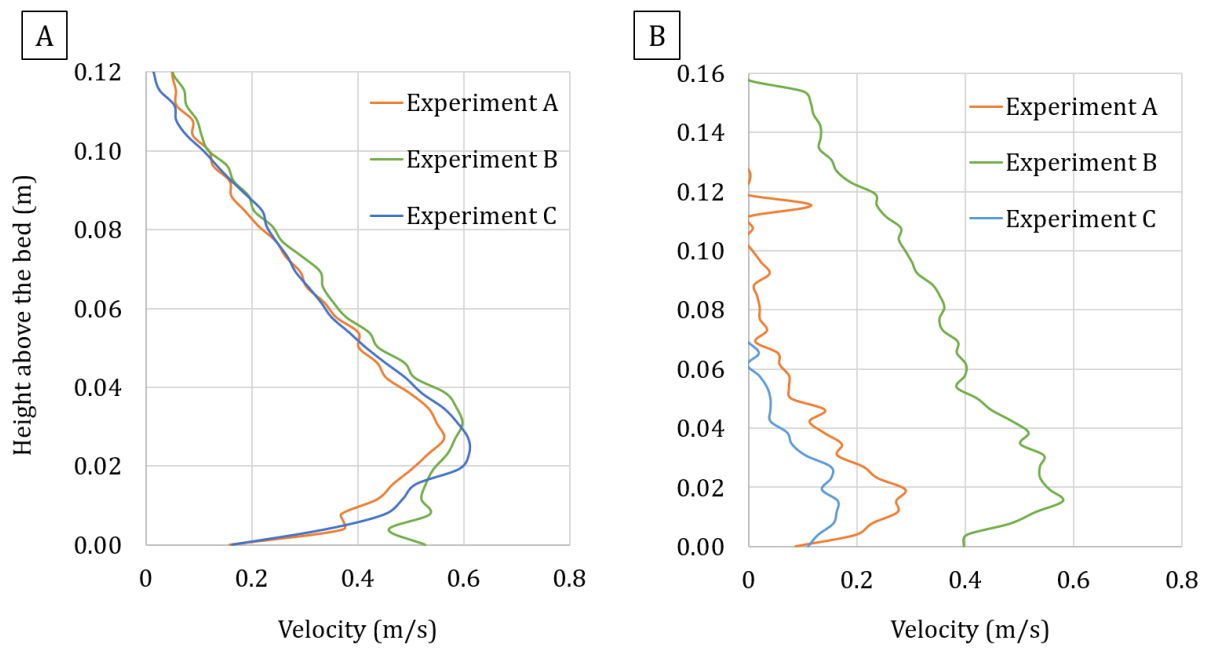

Figure 5.9: Time-averaged velocity profiles for the: (A) first $15 \mathrm{~s}$, (B) first sliding phase. 


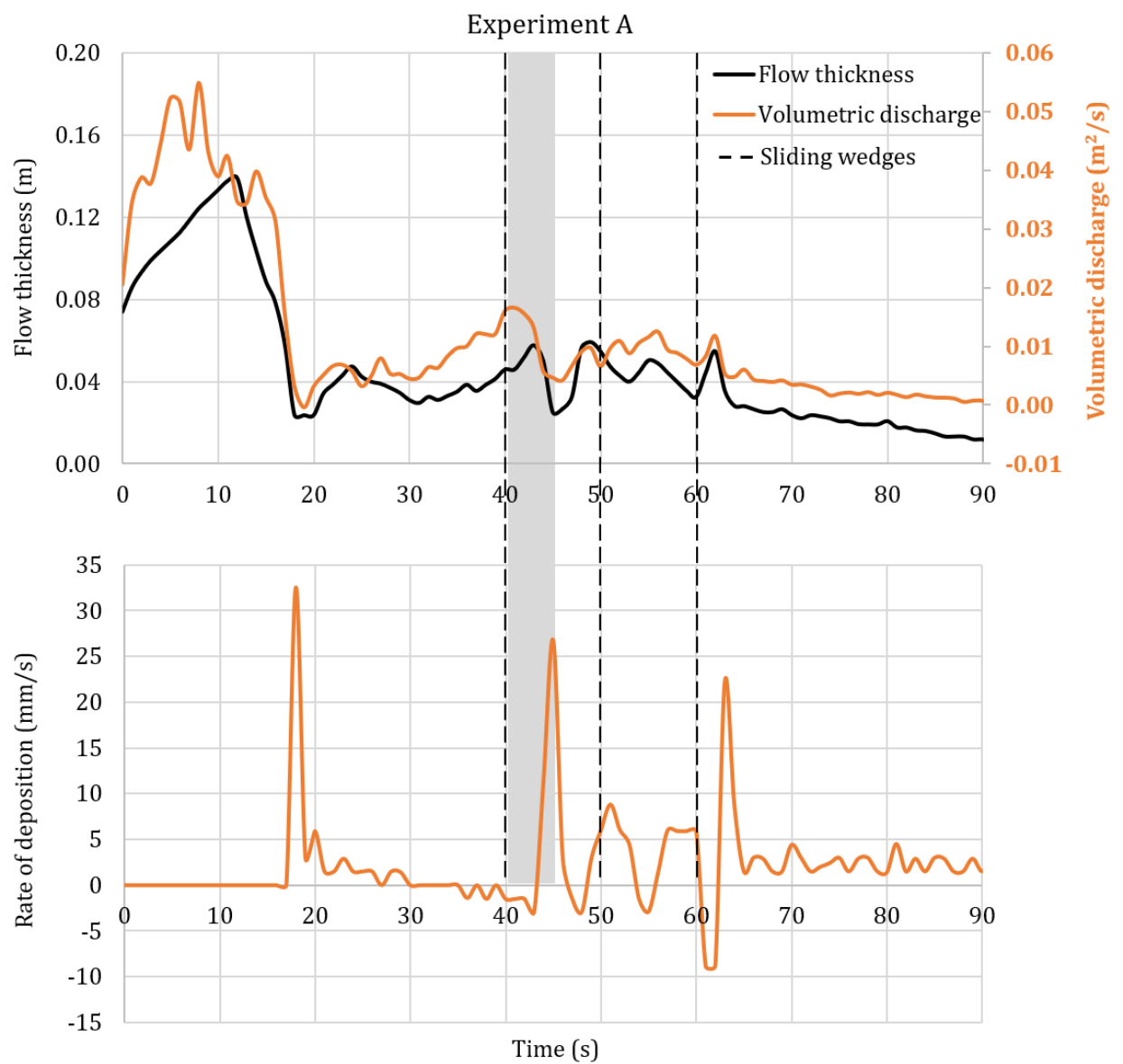




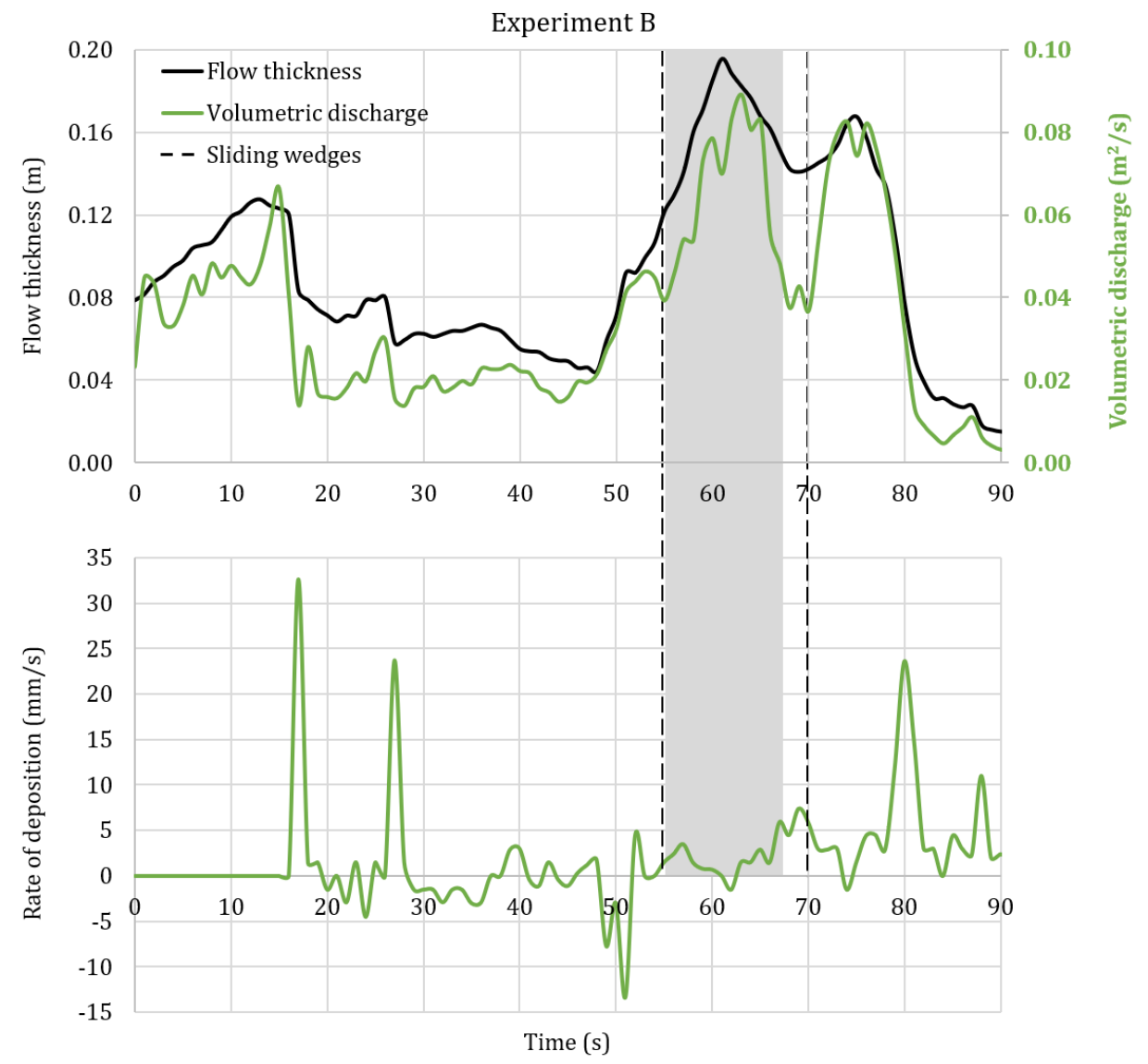




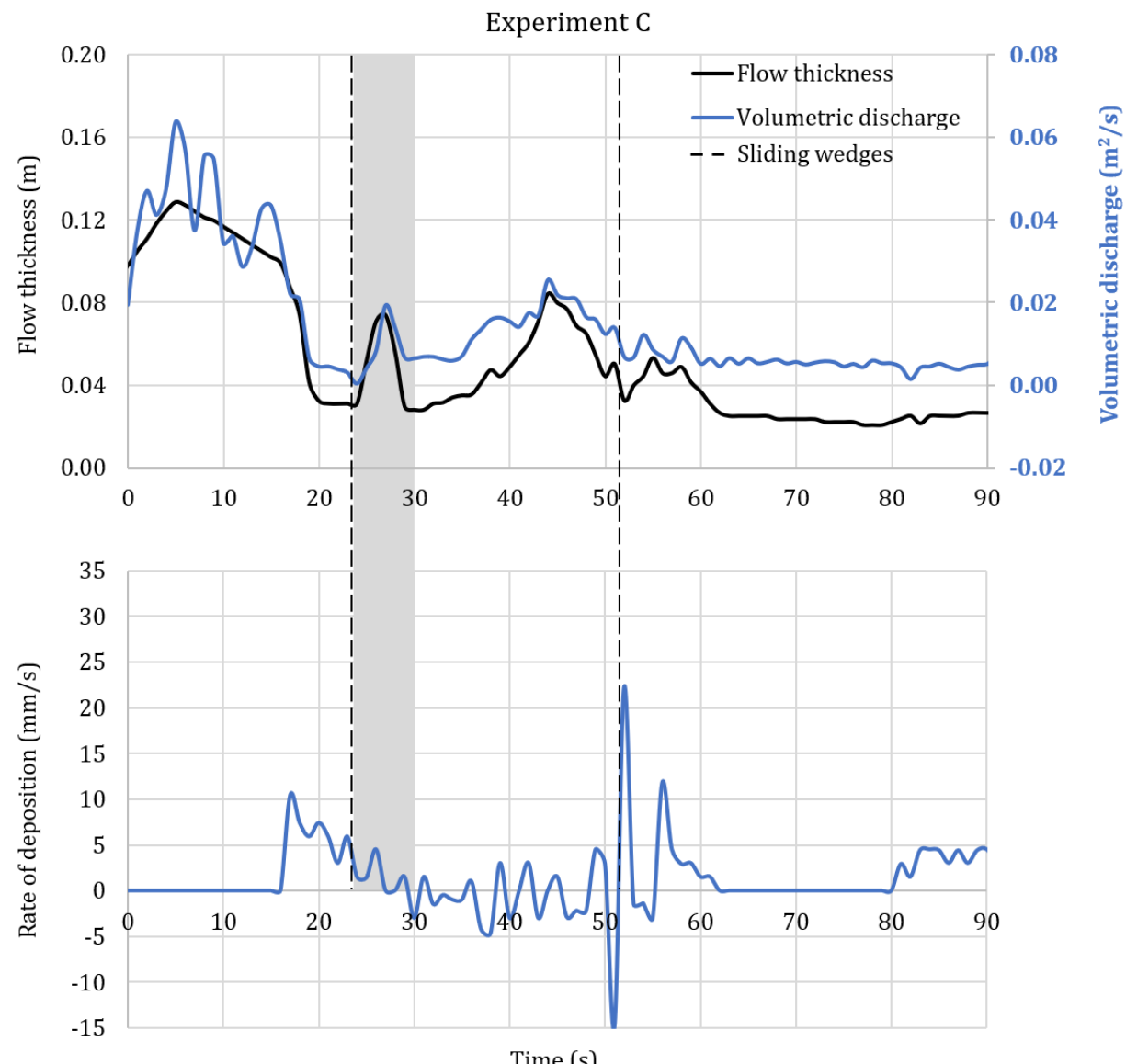

Time (s)

Figure 5.10: Flow thickness, volumetric discharge, and rate of deposition of experiments $A$ and $B$ (previous pages), and experiment $C$. The dashed vertical lines indicate the moment when the blocks reached the base of the failure surface and the grey shadow the duration of the pulse. 


\subsection{Discussion}

\subsubsection{Correlation between breach evolution, turbidity current, erosion, and deposition}

The presented results exhibit intricate correlations between breach evolution, turbidity current characteristics, and patterns of erosion and deposition on the slope in front of the failure, which can only be understood from an integrated perspective.

\section{Breach stability}

All three experiments resulted in stable breaching. The sediment started to deposit and the breach height was decreasing over time due to this accumulation of sand at the toe of the wall (Figs. 5.1 \& 5.7). The turbidity current became weak and decelerated, as the breach acted as a self-weakening process. Experimental turbidity currents reported by Eggenhuisen et al. (2019) in the same flume showed that the same sediment as used in these experiments was bypassed by turbidity currents with a maximum velocity of $1.2 \mathrm{~m} / \mathrm{s}$ with a slope flume floor of $8^{\circ}$. Pohl et al. (2020) evidenced that flows were still bypassing with a slope of $6^{\circ}$ slope. This is twice as fast as the maximum velocities measured in the beginning of the experiments in this study. An empirical study from Van Rhee (2016) shows that, for an equivalent sand, similar porosity and breach height of $0.8 \mathrm{~m}$, an inclination larger than $25 \%$ should be considered to have an unstable breaching process. In our setup conditions, this corresponds to a slope angle of $15^{\circ}$ which is almost the double of the maximum slope tested.

Another effect that tended to stabilize the breach were the sliding wedges. Most of the sand contained in the wedges was deposited immediately in front of the toe of the failure in experiments $A$ and $B$, which drastically decreased the breach height. In experiment $C$, though, the sand blocks were mixed with water at the toe of the failure surface, and incorporated into the turbidity current, which deposited the sand away from the measurement location.

\section{Turbidity current characteristics}

Time-averaged velocity profiles for the first $15 \mathrm{~s}$ illustrate that current velocity increases with slope (Fig. 5.9A; Fig. 5.10). Although, this variation is not significant with the respect to the large change in slope from $0^{\circ}$ to $4^{\circ}$, to $8^{\circ}$, where the maximum velocity is almost the same. This is likely because the breach height determines how strong the turbidity current is close to the failure, and the slope angle in front of the failure only operates as a secondary control.

Regarding the time-averaged velocity profiles for the sliding phase, the maximum 
velocity was measured in experiment B with a slope of $4^{\circ}$ (Fig. 5.9B), not in experiment $\mathrm{C}$ which had a higher slope angle. This indicates that possibly a larger wedge was formed and slid in experiment B, causing higher velocities in the turbidity current. As discussed before, the characteristics of the sliding wedges are uncertain, which leads to different timeaveraged velocity profiles for the sliding phase. It can be concluded that the time-averaged velocity profiles for the sliding phase are independent of the slope of the flume.

Besides this non-relation between the time-averaged profiles and the slope angle, the results suggest that the sliding wedges generate pulses in the turbidity current. This is illustrated as a peak in the flow thickness and volumetric discharge (Fig. 5.10). After the block of sand slides, there is an increase of the flow thickness and volumetric discharge, which later decreases when the block of sand passes (Exp. C) or deposits (Exps. A \& B).

\section{Patterns of erosion and deposition in front of the failure}

The vertical rate of deposition at the toe of the failure surface decreases with increased slope angle (Fig. 5.11). In experiments A and B, the rates were higher and the peaks more frequent than in experiment C (Fig. 5.10). This means that after the sand wedges slid in experiment $\mathrm{C}$, they diluted and incorporated the turbidity current as a sand particlewater mixture due to high inclination of the flume. When the sediment deposited, the rates were not so high because the sediment was more dispersed in the current (Fig. 5.12B). In experiments A and B, the sand wedges slid from the breach surface but were not transported further away, which is illustrated especially as the peaks of deposition at the end of the pulses (Fig. 5.12A). 

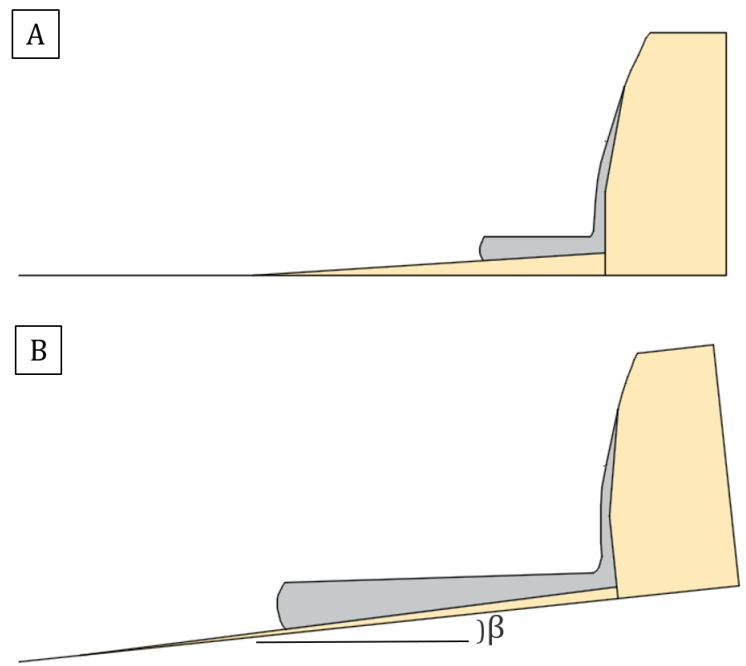

Figure 5.11: Grain-by-grain failure: (A) the sand deposited close to the breach; (B) the sand is transported further away along the flume.

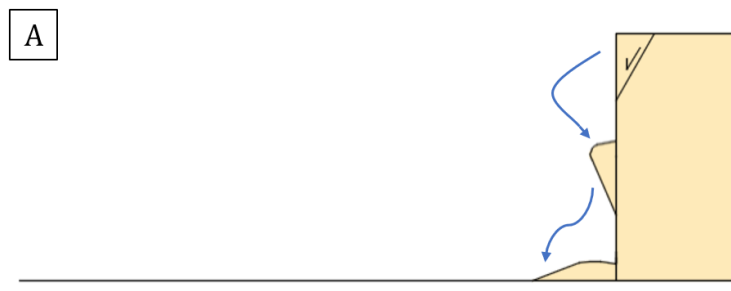

B

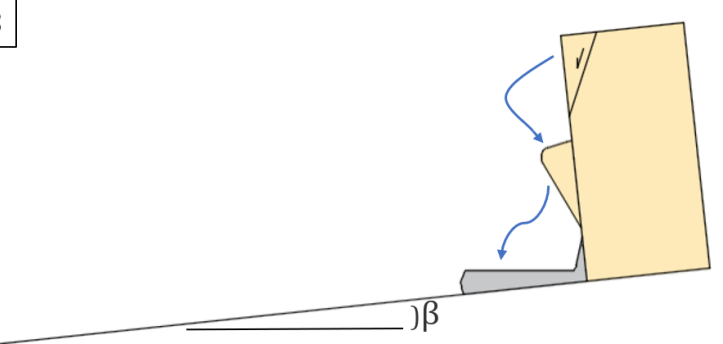

Figure 5.12: Transport of the sand wedges: (A) the sand wedge falls and deposits in front of the breach; $(B)$ the sand wedge disintegrates in water and is transported in the turbidity current. 


\subsubsection{Implications for recognising breach process influences in natural deposits}

A field example of a pulsed turbidite deposit is given in Figure 5.13. This example was encountered in deltaic deposits of Cretaceous age in southern Chile. It is viable that sliding wedges in a breach failure generated pulses in a turbidity current, which corresponds to a pattern in the turbidite deposit. Repeated pulse intervals are seen deposited incrementally layer by layer (Fig. 5.13). Other mechanisms to cause pulsed turbidite deposits are proposed by Kostaschuk et al. (2018). They attributed pulses to Rayleigh-Taylor instability generated by sinking surface lobes along the plunge line where rivers enter the receiving water body, and to interfacial waves along the underflow. Kostaschuk et al. (2018) affirm that velocity pulsing is clearly a fundamental component of continuous turbidity currents and must be incorporated into models of their behaviour.

Figure 5.14 illustrates a schematic reconstruction of the morphology directly after a breaching failure in a deltaic environment (Van den Berg et al., 2002). The process starts when a bank erosion, or a small liquefaction failure, occurs in a steep slope, initiating a breaching failure. The eroded particles suspended in water form a turbidity current which transports the particles along the tidal channel. The sands delivered downslope may build thick uniform turbidites (Van den Berg et al., 2002). If the failure has blocks of sediment sliding, the massive sand may instead be constituted of several divisions as in Figure 5.13, with each division corresponding to a pulse generated by the sliding blocks.

Besides the recognition of potential breach-induced deposits, another implication is the impact of the breach failure on shipping lanes. The depths of navigation channels can gradually decrease over time due to sedimentation (Van Dijk et al., 2018 \& 2019). Thus, the characteristics of turbidity current generated by breach failures are essential to predict the transport distance of the sediment and their deposits.

Turbidity currents represent an important sediment transport mechanism since they carry sediment from the continental shelves towards the deep sea. Therefore, the understanding of how turbidity currents are initiated, and the role that initiation processes play in influencing turbidite deposition, are vital to advance understanding of marine sedimentation. 


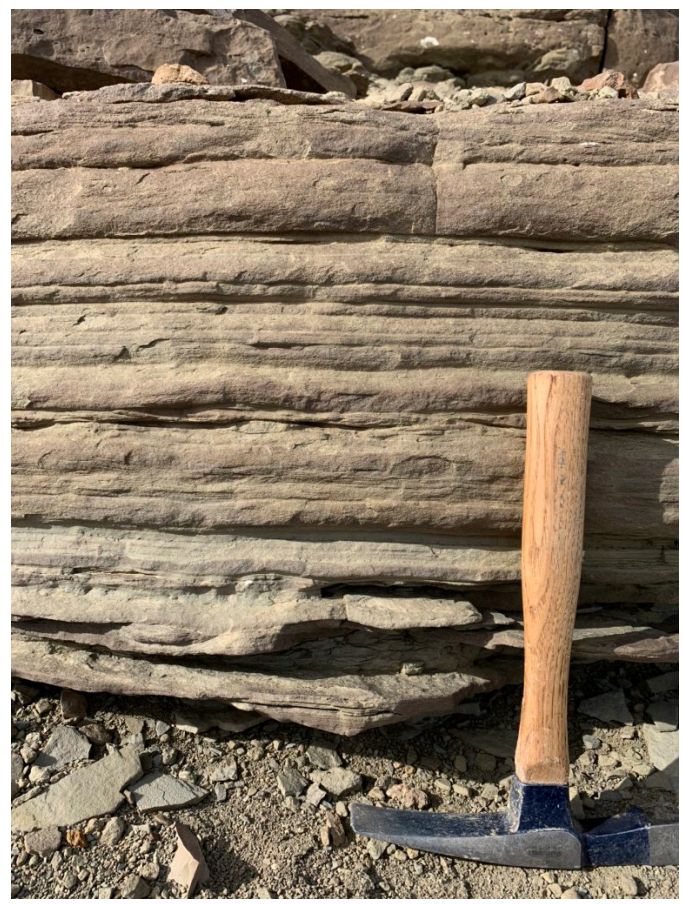

Figure 5.13: Example of a multi-pulsed turbidite deposit, possibly caused by the sliding wedges from a breaching flow slide (photo: Brian Romans).

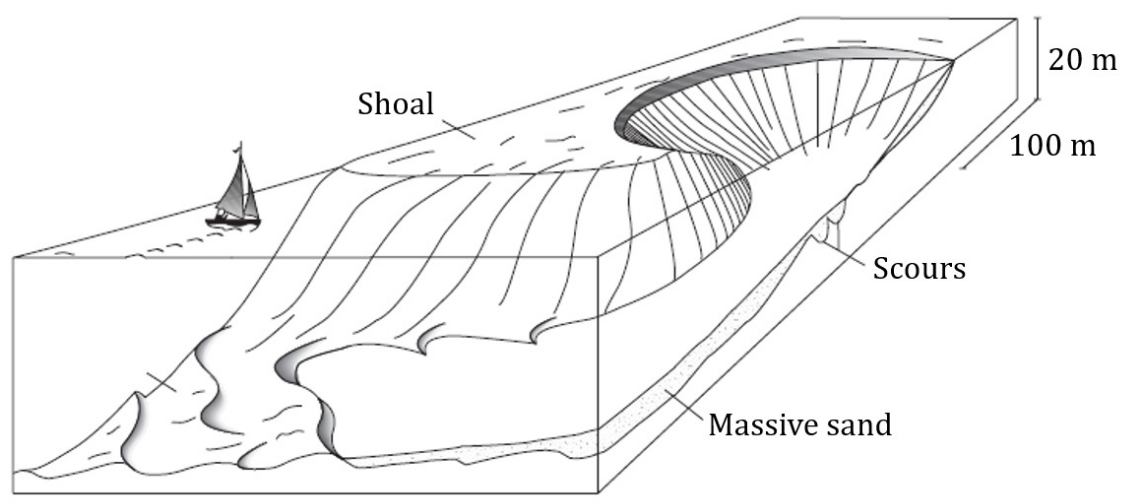

Figure 5.14: Reconstruction of morphology and deposits produced directly after a breaching failure event in a deep tidal or river channel (Van den Berg et al., 2002). 


\subsection{Conclusions}

This study presented coeval measurements of breach failures and the generated turbidity currents that flowed into the basin. The aim of this chapter was to investigate the relation between the breaching failure evolution, the strength of the generated turbidity current, and the distance the sediment is transported into the basin. For that purpose, experiments were conducted with a uniform sediment deposit with dimensions $0.40 \mathrm{~m}(\mathrm{~L})$ $\times 0.22 \mathrm{~m}(\mathrm{~W}) \times 0.80 \mathrm{~m}(\mathrm{H})$. The slope of the flume floor was adjusted to $4^{\circ}$ and $8^{\circ}$ to promote the turbidity current and have less deposition. A reference experiment was performed as well with the flume floor in a horizontal position.

With a breach height of $0.8 \mathrm{~m}$, wedges of sand slid down during the breaching failures. The sliding wedges were not periodic and had variable dimensions in each experiment. Furthermore, there was no correlation between these characteristics and the increase of the flume floor angle. Accordingly, the sliding wedges appear to be independent of the tested slope angles.

The time-averaged velocity profiles for the first $15 \mathrm{~s}$ of each turbidity current were virtually identical with only a small change in velocity with the respect to the large change in slope. Therefore, the maximum velocity is rather independent of the slope of the flume floor in the range $0^{\circ}$ to $8^{\circ}$. Apparently, the breach height was the main control of the turbidity current velocity, and the secondary control is the slope angle.

The velocity and thickness of the turbidity currents increased after a wedge of sand slid down the failure face. Regarding to the time-averaged velocity profiles for the sliding phase, there is no relation between the velocities and slope angles of the basin floor. The sliding wedges were thus the primary mechanism causing the pulses of the turbidity currents in these experiments. Sliding wedges from a breach failure are therefor likely one of the events responsible for pulsed turbidite deposits. This means that not all breach-failure generated turbidite deposits need be massive sands, as previously suggested.

Breaching flow slides are a common occurrence on continental margins and may be one of the processes by which sands are released into turbidity currents. They strongly affect the characteristics of a turbidity current and play a significant role in their evolution, influencing both morphology and stratigraphy of the deep sea. 

Chapter

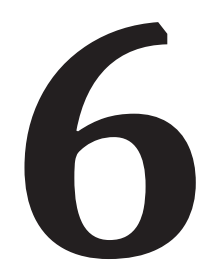

$3 D$ breaching failure
experiments

"Look deep into nature

Then you will understand everything better."

- Albert Einstein (1879-1955) 


\subsection{Introduction}

Flow slides occur at a large scale in nature but are seldom noticed when active. They initiate and propagate under water, which makes it difficult to observe them directly. Furthermore, flow slides do not occur frequently and the active phase is short lived. Much valuable insight, therefore, comes from small-scale flume tank experiments (Bezuijen \& Mastbergen, 1988; Van Rhee \& Bezuijen, 1998; Eke et al., 2011 de Groot et al., 2012; You et al., 2012, 2014a,b; Weij et al., 2016; this thesis). Occasionally, they do not remain submerged but retrogress into the subaerial embankment and become visible at the surface. In such cases, the sediment above the water level is generally moist, unsaturated sand (Mastbergen et al., 2019). Large blocks of sediment can then be seen falling and disintegrating while mixing with water (Fig. 6.1A, 6.2A). This additional sand further promotes the turbidity current generated by the subaqueous part of the breach failure (Chapter 5 ). When the failure stabilizes and terminates, the head scar has an amphitheatre shape (Fig. 6.1B, 6.2B) and there is a fan or tongue of newly deposited sand in front of the scar (Mastbergen et al., 2019).
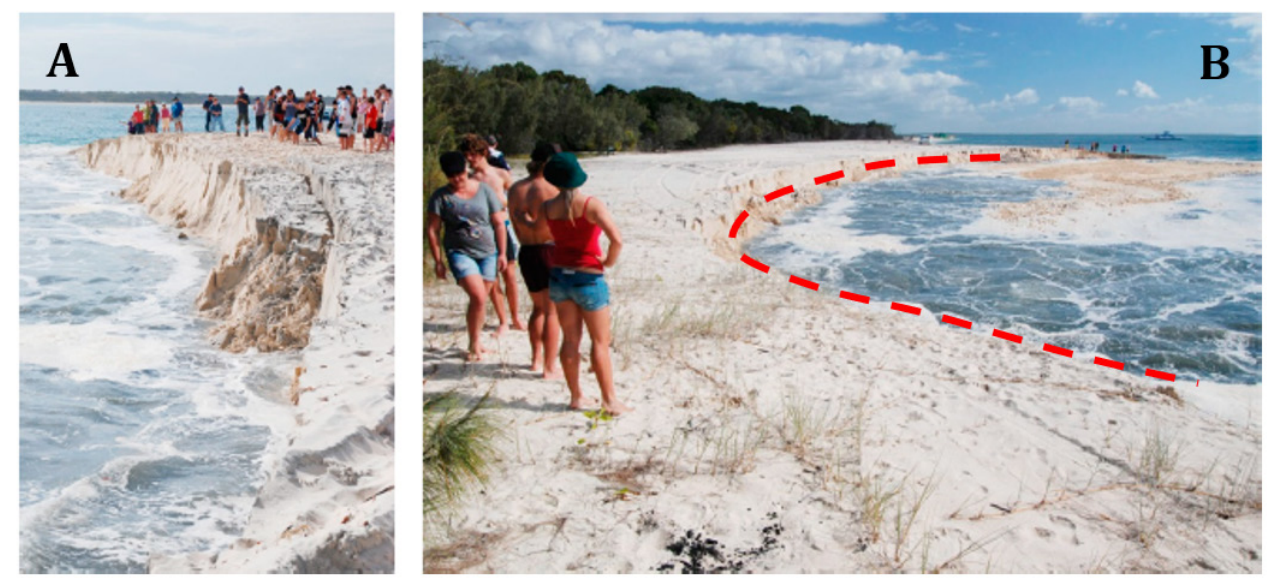

Figure 6.1: Active breach failure at Inskip Point, Queensland, Australia 2011: (A) sand blocks toppling and falling into the water; (B) view of a collapsing beach (photo: Jim Wyers, Gympie Times, in Mastbergen et al. 2019). 

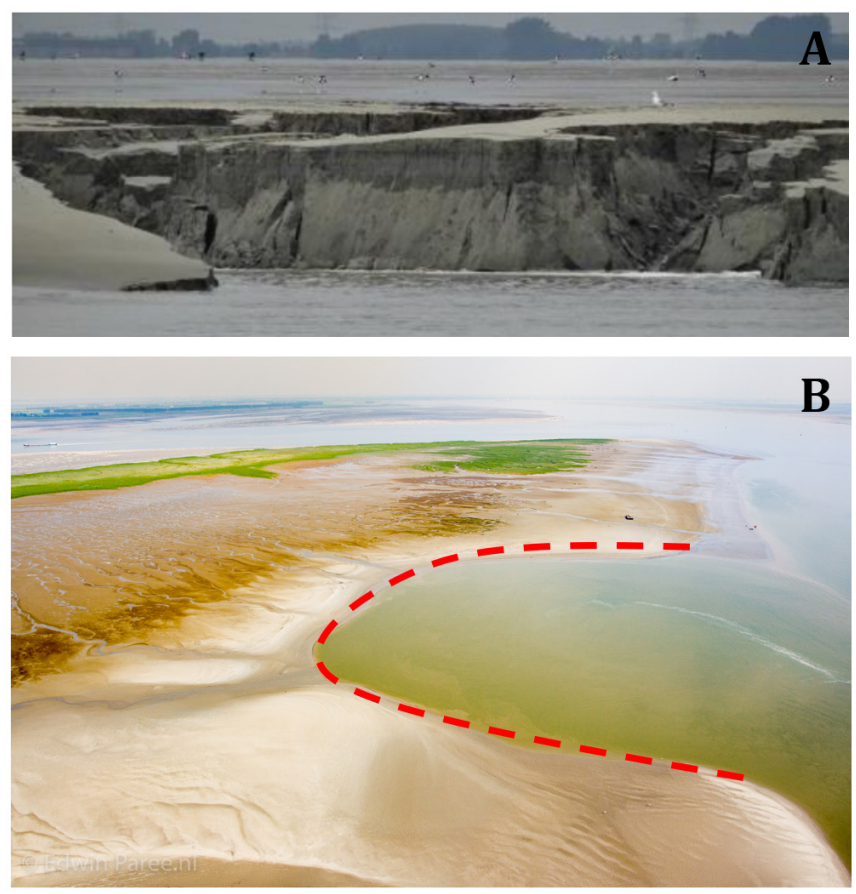

Figure 6.2: Flow slide in the tidal flat of Walsoorden in July 2014: (A) erosion of the tidal flat directly after the flow slide, $28^{\text {th }}$ of July 2014 (photo: Rijkswaterstaat); (B) Aerial view of the Walsoorden tidal flat after the collapse (Photo Copyright Edwin Paree / Rijkswaterstaat).

Koppejan et al., (1948) first published on coastal flow slides in the Netherlands, and they described typical characteristics from eye-witness reports in Zeeland at that time:

"A Zeeland flow slide is a gradual process where at intervals of a few minutes soil masses slide downward and flow out. Observation however is only possible after the disturbance has progressed to above the waterline and a steep wall has been formed here. Then at a place one or more meters landwards cracks appear about $10 \mathrm{~m}$ long, after which the soil mass in front starts to slide. In this way the slides go on, progressing about $50 \mathrm{~m}$ per hour. On the landward end of the slide the soil above and a little below the waterline may keep a very steep slope. The duration of the complete process varies from a few hours to a day." (Koppejan et al., 1948). 
These flow slides characteristics described in Zeeland seventy years ago are the same morphological characteristics observed during flow slides at the present day. Flow slides have thus been noticed to occur for a long time, but they are still not completely understood.

Previous studies of breaching flow slides, as well as the experiments presented so far in this thesis, were performed in narrow setups constrained by glass or Perspex sidewalls ("2D" flume). The benefit of this approach is that the boundary conditions are well known and a single setup can be used to perform multiple tests. In addition, it is relatively easy to install the instrumentation in the flume and to study several aspects of flow slides during one experiment. Although such tests in 2D flumes can provide valuable outcomes, some important phenomena may be distorted due to the lateral confinement. Therefore, 3D tank models are required as a next step for accurate reproduction of flow slide phenomena.

This chapter presents a breach flow slide triggered in a 3D tank. The underwater propagation of the failure, that is typically hidden from view, and the final failure morphology were investigated. The results of this experiment were compared to failures described in natural systems. In addition, the similarities with 2D flume experiments presented earlier in this thesis were investigated. 


\subsection{Experimental method}

This type of experiment has not been performed previously, and, therefore, a new experimental approach needed to be explored. The choices and adjustments resulted in one successful configuration, and one experiment is described in the results section below.

The experiment was performed in a $11 \times 1.2 \times 6 \mathrm{~m}$ (length $\times$ height $\times$ width) basin (Fig. 6.3A). The embankment was built manually with the same sand used in experiments in the previous chapters, on top of the inclined basin floor (Fig. 6.3B). The preparation of the embankment was critical and sensitive. Since after its construction it would be submerged, it had to be ensured that the angle of the embankment was smaller than the angle of repose to prevent premature erosion of the slope. The angle of the embankment after its construction was approximately $20^{\circ}$ relative to the horizontal.
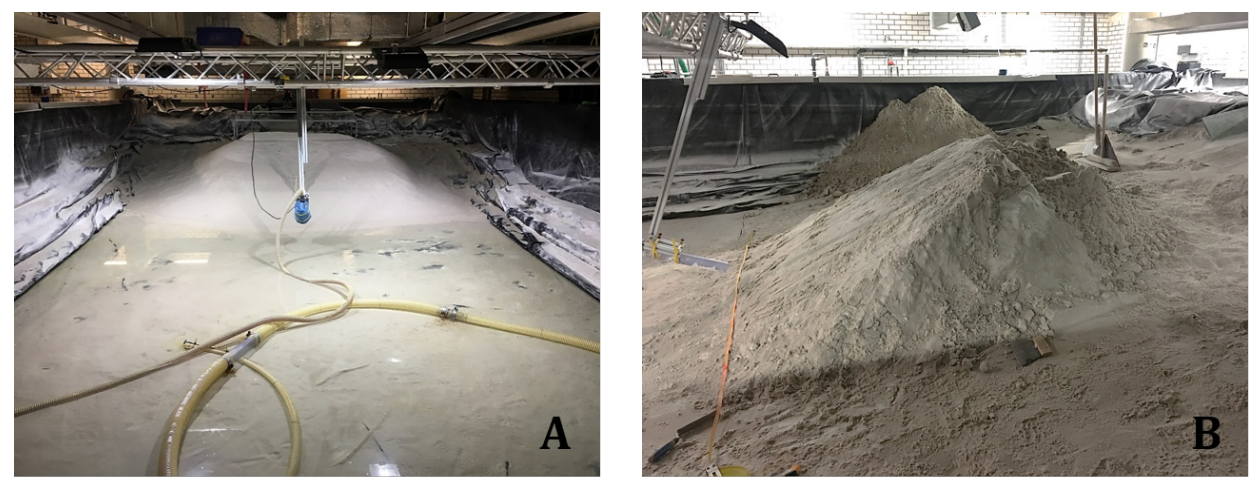

Figure 6.3: The setup: (A) basin with the final deposit from a breaching flow slide; (B) building of the embankment.

The pore pressure measurement system was installed next. Measurement positions were allocated in the central part of the embankment (Fig. 6.4A) to monitor the excess pore pressures. The pressure transducers were the same as used in the series of experiments in the previous chapters. The pore pressure system had to be adapted to this large setup, which is 27 times wider than the $2 \mathrm{D}$ flume. Another issue was to fill the tubes with water and to ensure that no air bubbles circulated in the tubes, since the equipment was above water level. The pore pressure was measured at nine different positions at the centre of the sandy embankment (Fig. 6.4B). The measurements were acquired at $4 \mathrm{~cm}$ below the sand water interface. 
After the allocation of the measurement points, the basin was scanned with a laser scanner in order to document the initial bathymetry of the experiment. From the laser scan, a Digital Elevation Model (DEM) with a horizontal grid spacing of $2 \times 2 \mathrm{~mm}$ was created (Fig. 6.5).

A pump was placed in front of the embankment to remove sand from the toe (Fig. 6.4A) and to create a breach failure. The position of the pump and its working strategy were tested and modified a few times. The excavated sand was deposited at the other side of the basin via a pipe that was connected to the pump, so that it would not influence the experiment. The water level in the basin was maintained at a constant level.
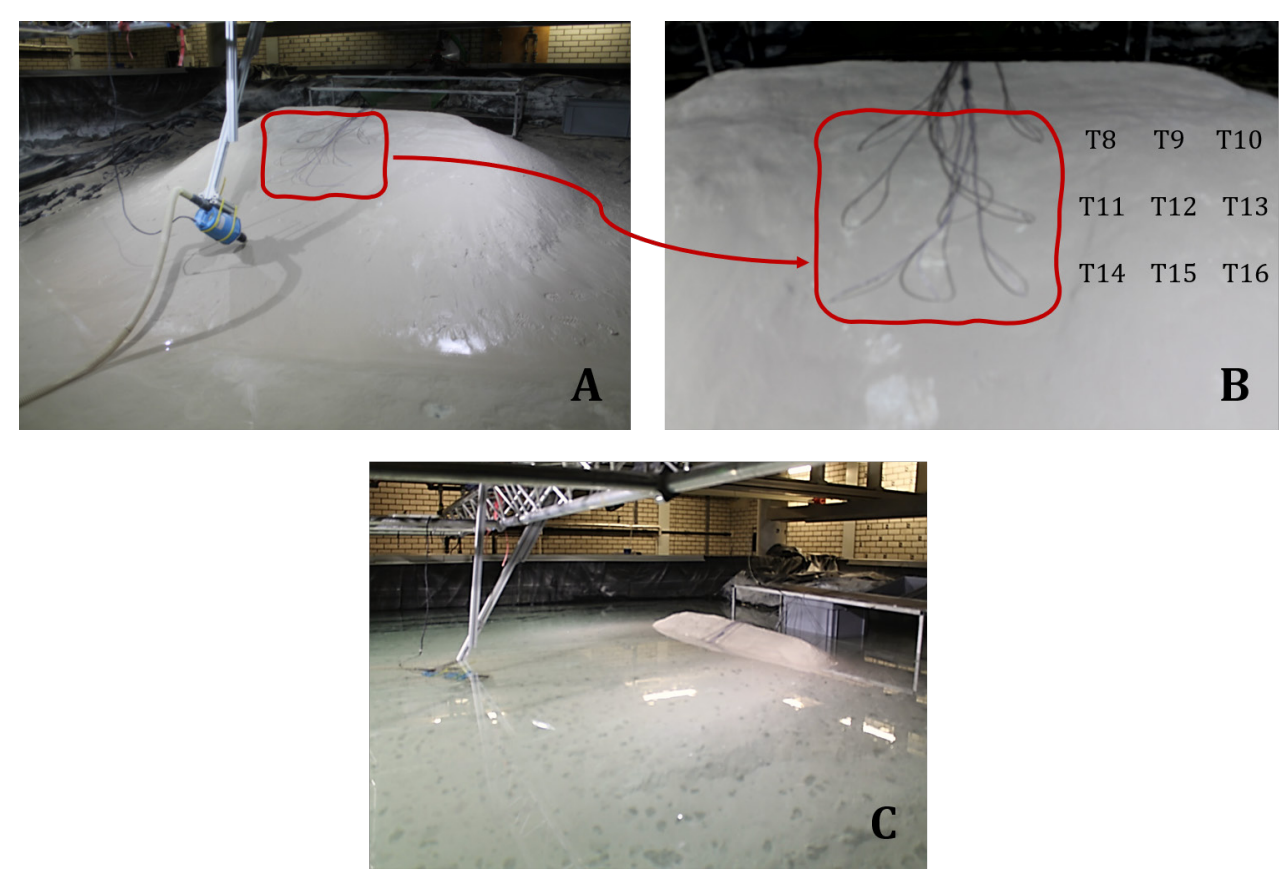

Figure 6.4: $(\boldsymbol{A}),(\boldsymbol{B})$ Pore pressure system: $(\boldsymbol{A})$ embankment with pore pressure system and pump in place, (B) transducer positions in the slope; (C) Partly submerged embankment just before the start of the experiment. 


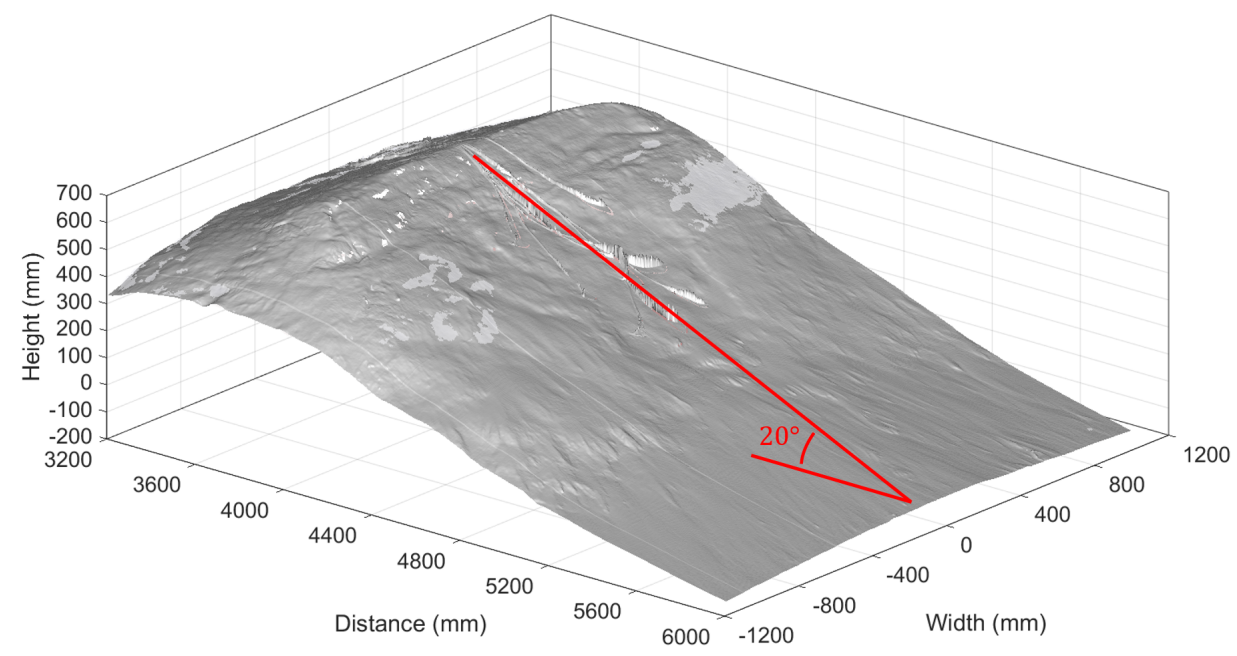

Figure 6.5: Initial bathymetry of the embankment.

After the scanning and after all the equipment had been established in place, the basin was filled with fresh water (Fig. 6.4C). After filling of the basin, two underwater video cameras (GoProHero3) were installed and turned on in front of the embankment, one at each side, and the pore pressure registration was started as well. The experiment started when the pump was turned on and started removing sand and finished when the breach had reached the subaerial part of the embankment and no more activity was noticed. The pump was moved back and forward depending on the breach evolution. This procedure had been also adopted in the Walsoorden field test described in the introduction of this thesis (Mastbergen et al., 2016). While the breach was developing and growing, the pump was turned off and moved to the back. When the breach was stabilizing, the pump was turned on again and moved forward to remove the accumulated sand. When the experiment had finished, the equipment was turned off and the basin was drained. A second scan to the basin was done to register the final bathymetry. Subtraction of the post-failure DEM from the prefailure DEM yields a map of the erosion patterns. 


\subsection{Results}

The pump was turned on and the removal of sand from the embankment started. The breach started growing until became a few centimetres high. The sand was redeposited immediately in front of the breach. For that reason, the pump was turned on and off several times to remove the accumulated sand and to maintain breach activity. The pump activity is indicated in the figures with pressure transducer timeseries in grey (Figs. 6.6, 6.7). Excess pore pressure measurements are presented in Figure 6.6 for transducers 11, 12, 14 and 15. After analysing the data and comparing them with the final morphology, it appeared that transducers 13 and 16 at the lateral side had not been conveniently positioned to measure the pore pressure. The small generated breach combined with the fact that the breach passed slightly along of those positions resulted in poor pore pressure measurements. In case of the longitudinal line with transducers 8,9 and 10, these locations were close to the water level and the sand blocks sliding from the subaerial embankment affected the measurements. For these reasons, the measurements from the transducers 8, 9, 10, 13 and 16 were not suitable and are not displayed here.

\subsubsection{Pore pressure measurements}

The pore pressure measurements indicate that a negative excess pore pressure was generated and the failure events thus are called breach events (Fig. 6.6; discussion below). In more detail, two events can be distinguished, indicated as breach event 1 at $\mathrm{t} \cong 325 \mathrm{~s}$, and breach event 2 at $\mathrm{t} \cong 470 \mathrm{~s}$. Breach event 1 occurred when the breach face approached and passed the first line of transducers, 14 and 15. Detailed information of the measurements is given in Figure 6.7A. It is seen that the pressure excursion recorded at the side of the breach (lateral pressure) by transducer 14 was smoother and lasted longer than the pressure at position 15 , located in the centre of the breach. The maximum pressure generated at lateral location 14 was $\sim-0.053 \mathrm{kPa}$, and at the central part of the breach $\sim-0.11 \mathrm{kPa}$. When the breach passed their location, the transducers were exposed to the water. Later on, transducer 15 was captured by the pump which is registered in the measurements as highamplitude noise at $\mathrm{t} \cong 460 \mathrm{~s}$, and also for transducer 14 at $\mathrm{t} \cong 650 \mathrm{~s}$ and $\mathrm{t} \cong 810 \mathrm{~s}$ (Fig. 6.6). Breach event 2 corresponds to the breach face approaching and passing of the second line of the transducers 11 and 12 (Fig. 6.6), and detailed measurements are presented in Figure 6.7B. The pressure recorded at the side of the breach (lateral pressure) by transducer 11 is also smoother and lasted longer than the pressure recorded in the centre of the breach 
by transducer 12 . In this case, the generated excess lateral pressure at transducer 11 was $\sim-0.040 \mathrm{kPa}$, and at the centre of the breach $\sim-0.13 \mathrm{kPa}$.

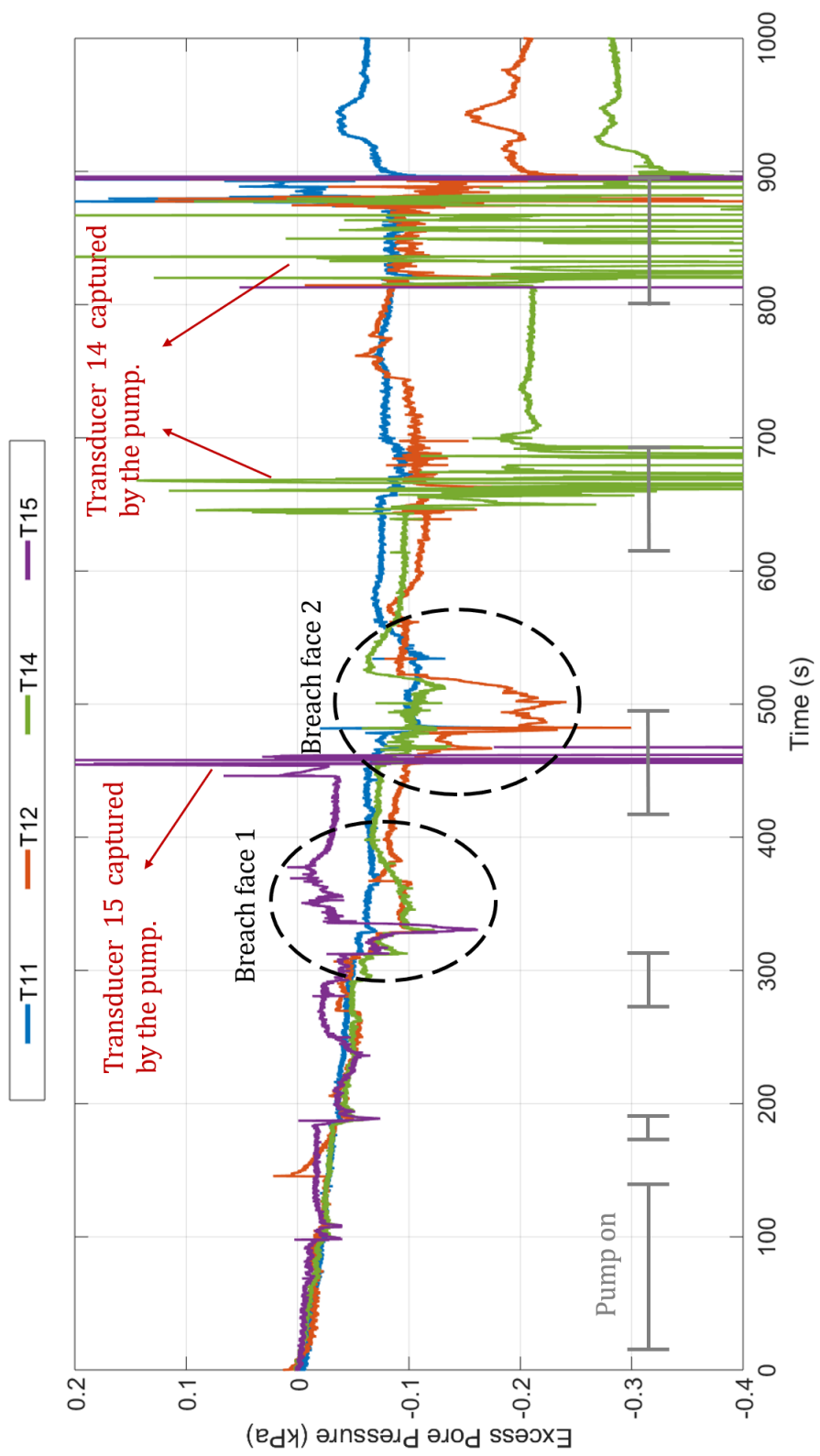

Figure 6.6: Pore pressure measurements during the breaching flow slide. 

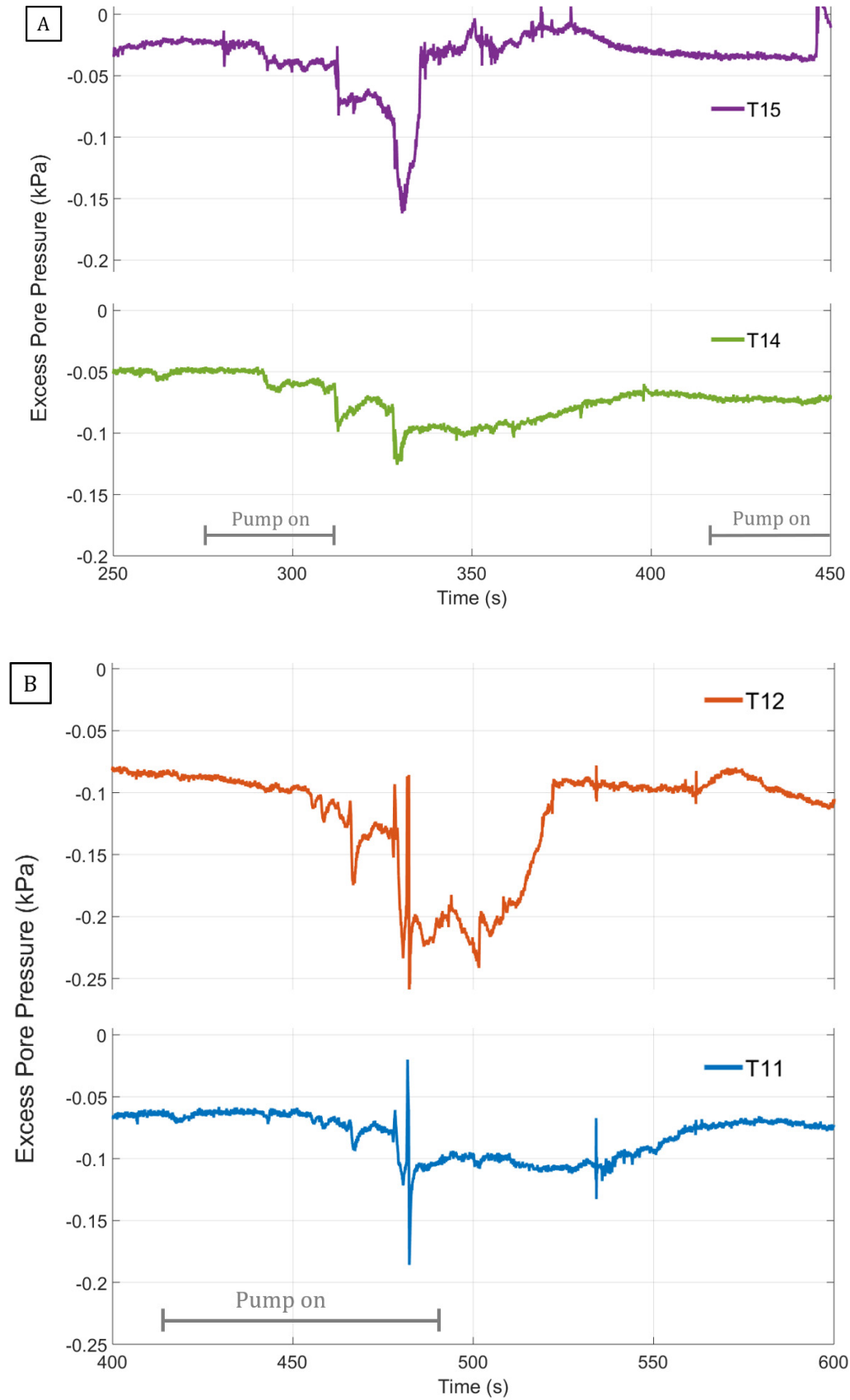

Figure 6.7: Detail of: (A) breach event 1; (B) breach event 2 from Figure 6.6. 


\subsubsection{Morphological characteristics}

When the breach reached the subaerial embankment, blocks of sand slowly dropped from the aerial part of the embankment and disintegrated in the water (Fig. 6.8). At a certain moment, the breach stabilized and no further activity was noticed. At this point, the experiment was stopped. The final deposit is shown in Figure 6.9. The morphology is like a funnel which reflects the growth of the breach towards the subaerial part of the embankment over time. At the top, the deposit exhibits an amphitheatre shape. From the final bathymetry, shown in Figure 6.10, it is seen that most of the erosion occurred in the central part of the breach with less erosion on the top and at the lateral sides, leading to the amphitheatre shape.

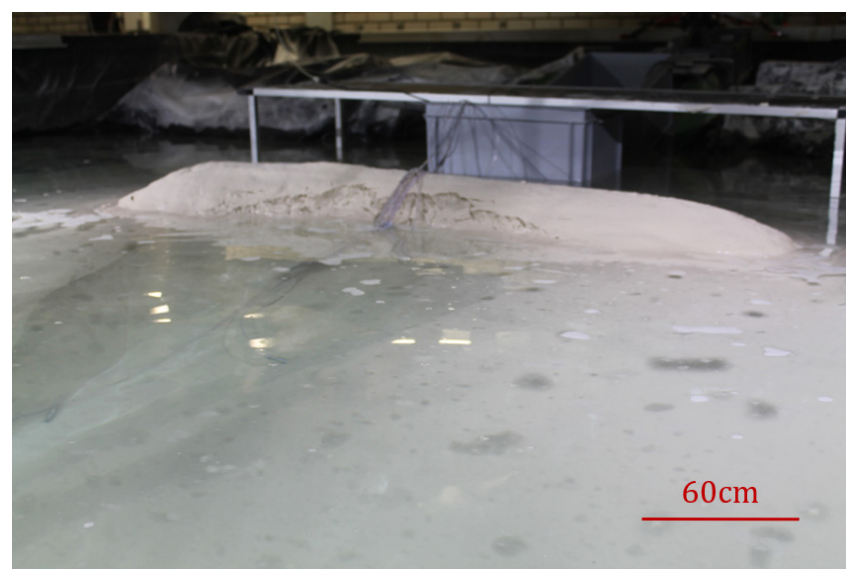

Figure 6.8: Breach reached the subaerial bank and blocks of sand started falling. 

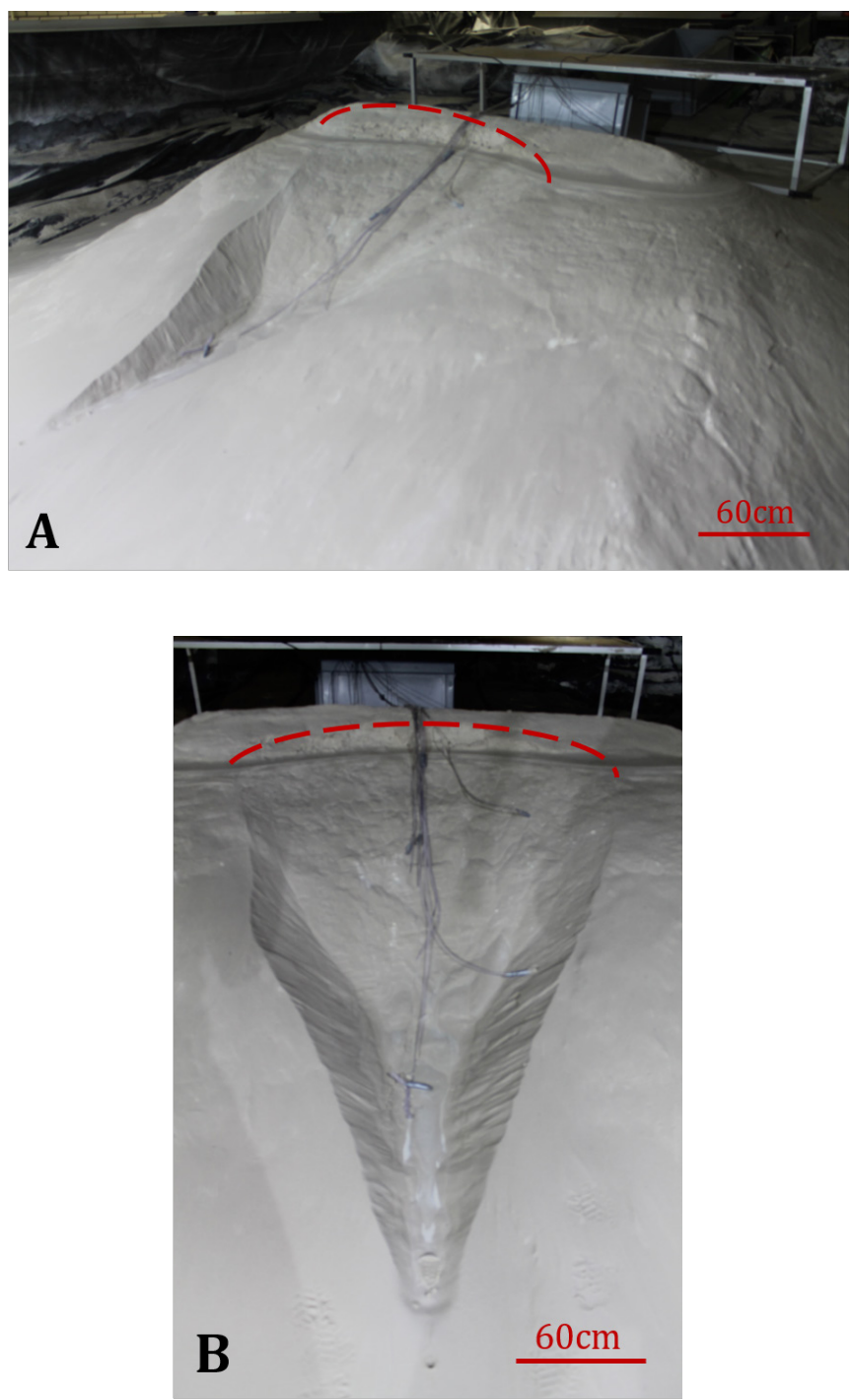

Figure 6.9: (A), (B) Final deposit after drainage of the basin with the amphitheatre-shaped breach. 


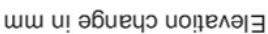
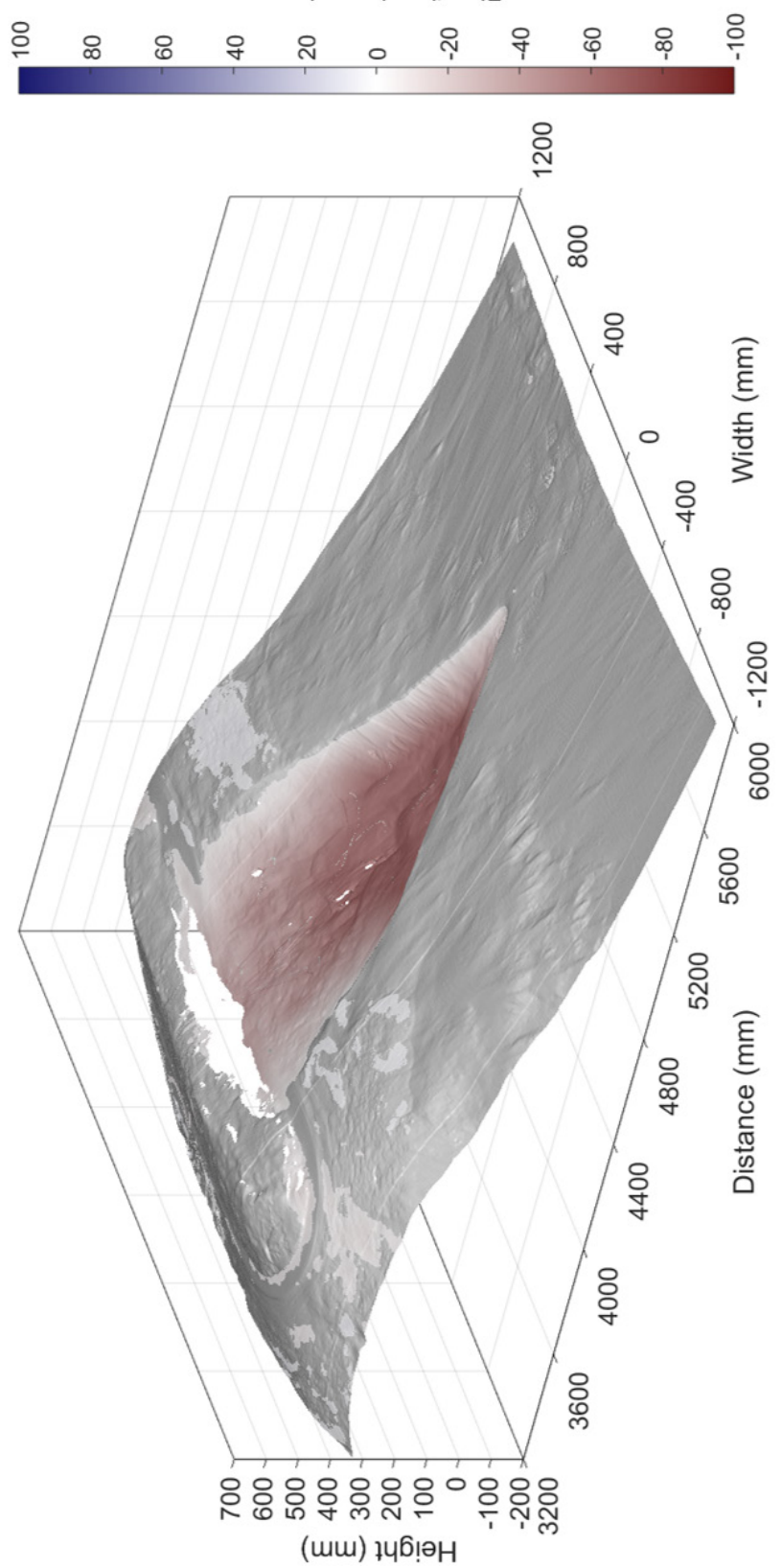

Figure 6.10: Final bathymetry and erosion patterns. 


\subsection{Discussion}

The excess pressures measured in the 2D experiments are twice as large as the central pressures in the 3D experiment. This is due to the small size of the generated breach, which was only a few centimetres high. The turbidity current generated by the falling sand grains was not strong enough to transport the grains away from the embankment (Chapter 5 of this thesis). Therefore, the sand eroded by the breach was deposited directly in front of the breach face, almost immediately after it detached from the embankment. In this case, as we saw in Chapter 5, the height of the breach face decreased in time and the failure stabilised.

Two types of pore pressure signatures can be distinguished when the breach face approached and passed the measurement locations: the excess pore pressures measured in a central position and recorded by $\mathrm{T} 12$ and $\mathrm{T} 15$, and the excess pore pressures measured in a lateral position by T11 and T14. The central pressure excursions are two times larger than the lateral pressures (Fig 6.7). Furthermore, the central pressures have the same structure as the pore pressures presented in Chapter 3 and 4 for 2D breaching experiments (Fig. 6.11). This structure is characterised by progressively more negative excess pore pressures, followed by a rapid return to hydrostatic pressure when the breach face passes the measurement location (You et al., 2012, 2014a). This demonstrates that the 2D pressures results representative for the pressures measured at the centreline of the $3 \mathrm{D}$ failure.

In Figure 6.11, though, the pressure recorded by transducer 12 does not have progressive decrease of pore pressure when the failure approaches the transducer location, which was likely caused by the pump that was working when the breach surface approached that location.

The novel results of this 3D breach experiment are the pressures measured the side of the breach, the lateral pressures, which cannot be measured during the narrowly confined 2D flume experiments. The lateral pressure excursions are smoother, last longer, and do not display the negative peak immediately before the breach face passes by, like the pressures registered at the central part of the breach. This may be because at the sides, the breach is not so strong as in central part. This is supported with the final bathymetry in Figure 6.10. It is seen that the erosion pattern was stronger in the centre than at the sides. 


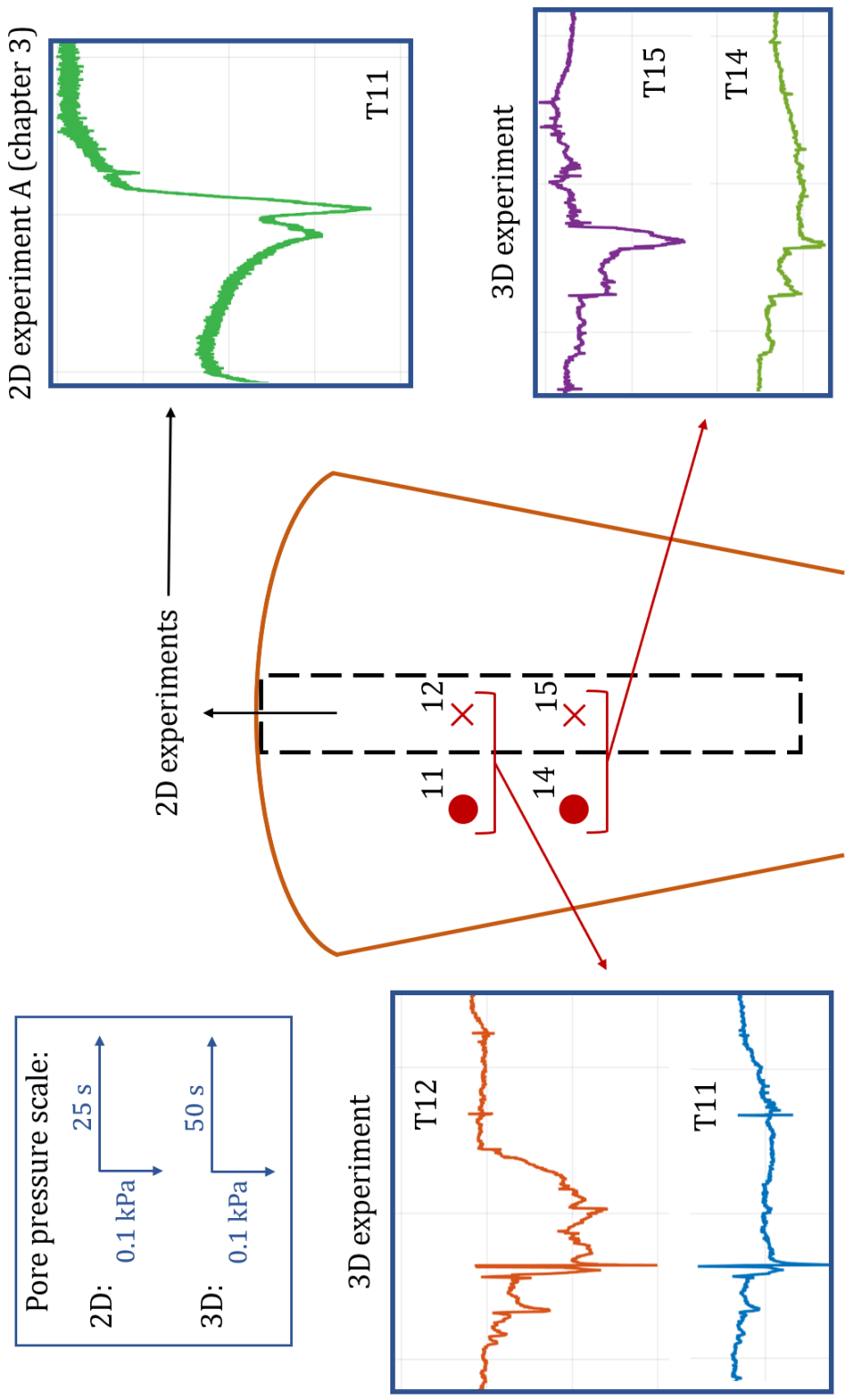

Figure 6.11: Overview of the pore pressures recorded in the $2 D$ flume experiments $A$ and $B$ in Chapter 3, and the 3D experiment. The orange line delineates the morphology of the breach (not to scale, only an illustration). 
Now it will be discussed the morphological evolution and result of the breach failure experiment, and similarities with known natural morphologies. The experiment started with an embankment with an initial slope of $20^{\circ}$. This angle is similar to the slope angle during the field test at Walsoorden (Fig. 6.12A).

Two morphological characteristics are recognized in this 3D experiment which cannot be captured in narrowly confined 2D flume experiments. The first one occurred when the breach flow slide reached the subaerial section of the embankment. Blocks of sand slowly started falling (Fig. 6.8) eroding the top of the active failure face. The second feature is related to the morphology of the final deposit, which exhibited an amphitheatre shape at the top of the embankment (Fig. 6.13A). This was also observed at Inskip Point, Australia, (Fig. 6.13B), at An Giand Province, Vietnam with the collapse of the river bank (Fig. 6.13C) and at Walsoorden with the flow slide (Fig. 6.13D). Furthermore, the concave shape is present in the bathymetry of the Walsoorden field test (Fig. 6.12B). This amphitheatre shape can be explained with the different structures of the pressure excursions measured in the central and lateral parts of the failure. Since the excess pore pressures at the sides have smaller magnitudes than the central excess pore pressures, this will result in a higher rate of progression of the central part of the breach (Chapter 3), which thus creates this concave shape. Another contribution for the concave shape is the size of the breach which is smaller at the edges, resulting in a slower progession at the edges.

Bubbles coming up to the surface (Fig. 6.8) imply that air in the sand was being released when the breach was active and growing. This aspect can also be recognised in the foam in Figure 6.1 during the active breaching failure at Inskip Point. 

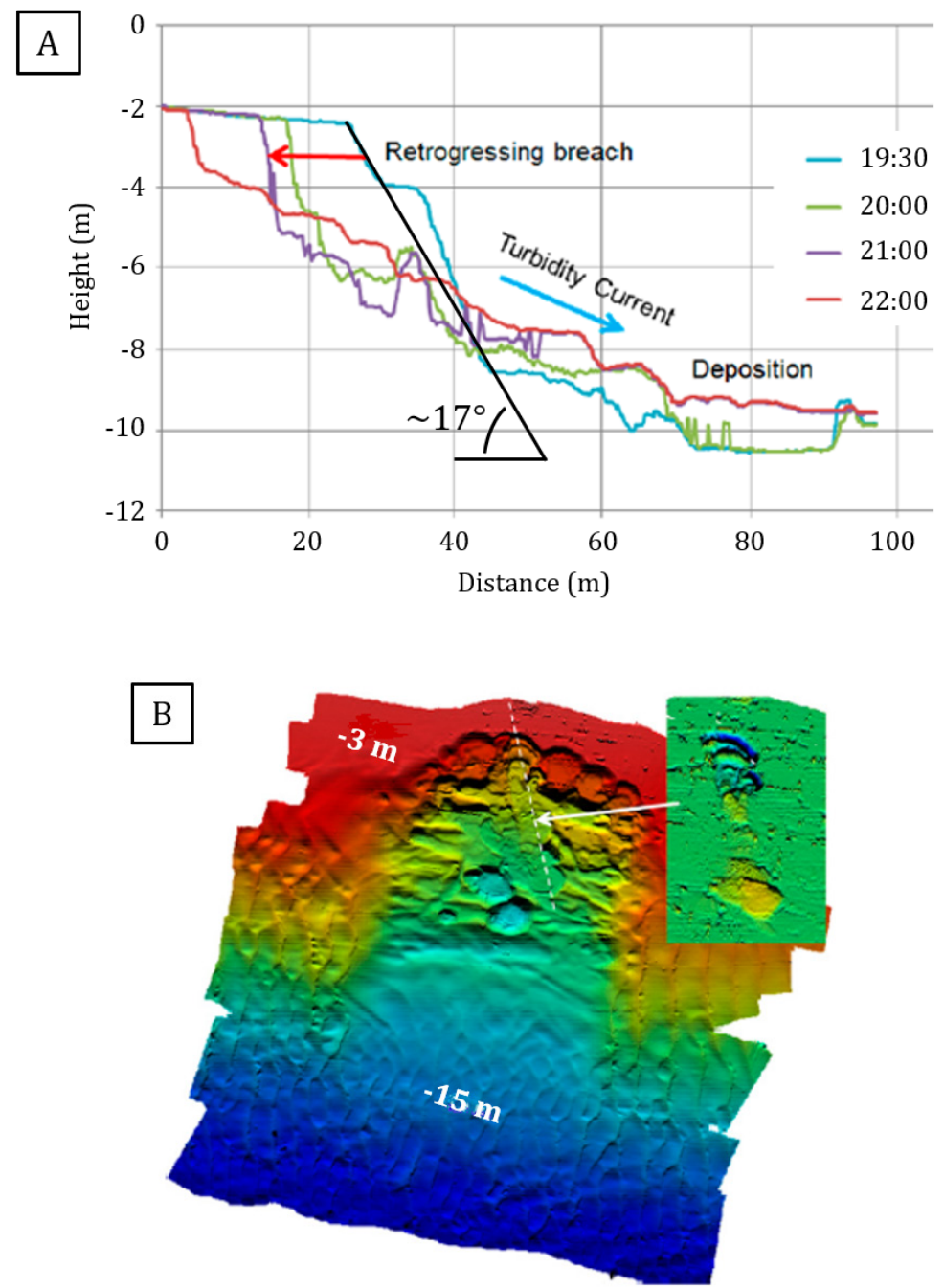

Figure 6.12: Walsoorden field test in 2014: (A) embankment geometries on 1st October 2014; (B) Bathymetry of the dredging area $(100 \times 100 \mathrm{~m})$ with small flow-slide scars (below low-water line). Differential bathymetry (blue = erosion, yellow = deposition) (Mastbergen et al., 2019). 


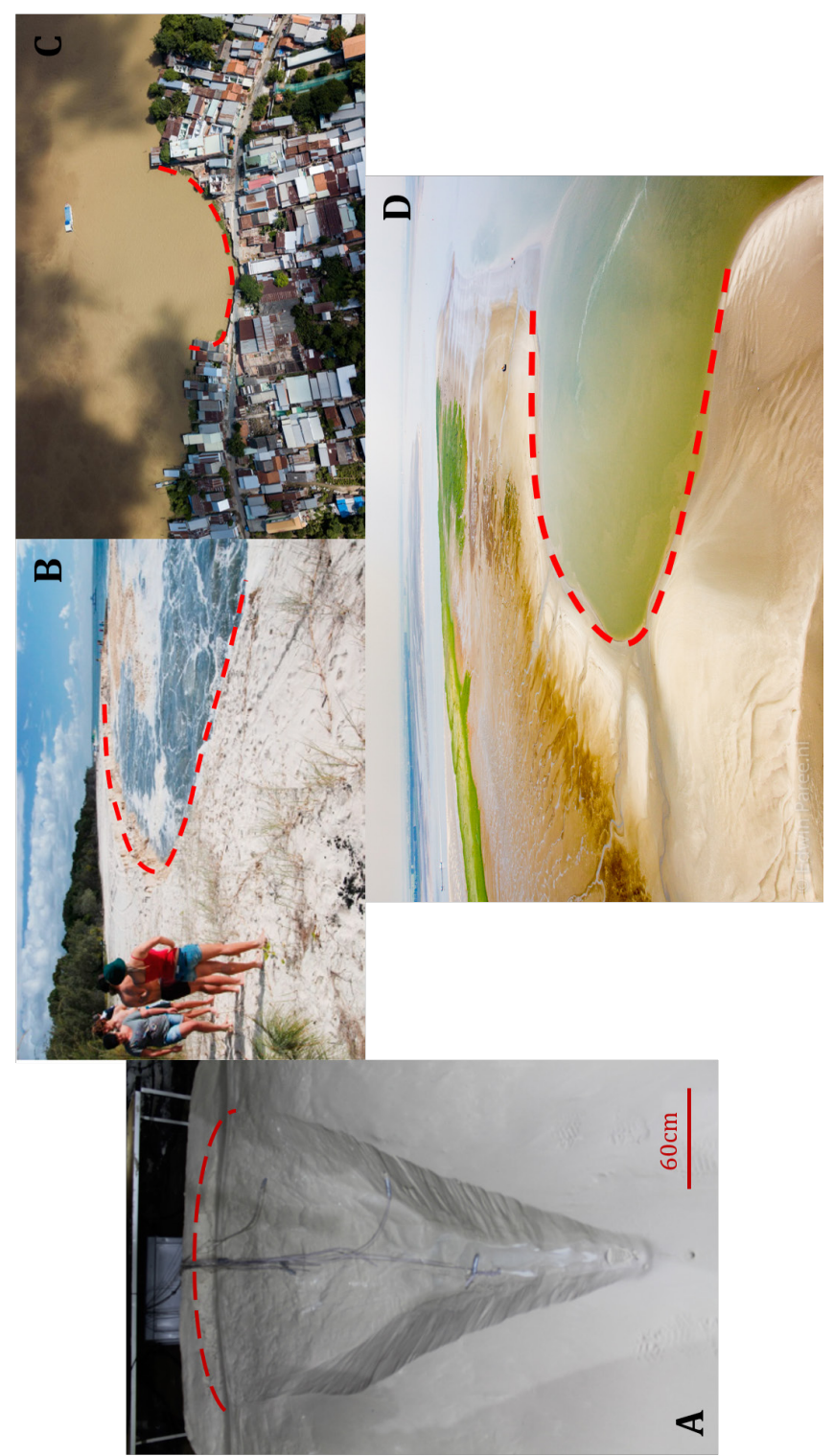

Figure 6.13: Amphitheatre shape, characteristic of a breaching flow slide, recognized in: (A) the 3D experiment, (B) breach flow slide at Inskip Point, Australia (photo: Jim Wyers, Gympie Times), (C) collapse of the river bank at An Giand Province, Vietnam (picture copyright Sim Chi Yin / Magnum Photos, all rights reserved), and (D) flow slide at Walsoorden (Photo Copyright Edwin Paree / Rijkswaterstaat). 


\subsection{Conclusions}

Breaching flow slides occur in nature at a large scale and are a 3D phenomenon. Although 2D flume experiments at small scale give us confident measurements and valuable insights, some of the characteristics may be affected by the narrow confinement of the sidewalls, or there may be scale effects that are absent in natural cases.

The purpose of this chapter was therefore to generate a breaching flow slide in a 3D environment, where the embankment continued beyond the lateral extent of the flow slide. A particular objective was to investigate if these have characteristics comparable to field examples and also if similarities exist with the 2D flume experiments presented in Chapter 3.

Despite the small size, a breaching flow slide was created in a 3D basin. Since the breach stopped quickly, a pump was used several times to reactivate it, similarly to procedures followed in field-scale experiments.

The pressures recorded at the centre of the breach were comparable to, and had the same structure, as the pressures measured in the 2D flume during experiment $\mathrm{A}$ in Chapter 3 as well as published pressure measurements in other narrow setups. A novelty here is that pressures measured at the side of the breach were documented, which could not be measured in the 2D flume. It was established that, in a 3D setup, the lateral pressure excursion is smooth when a breach approaches and passes the measurement location. The excess pressure excursions at the sides also lasted longer than in the central part of the breach. This supplies a novel explanation for the occurrence of amphitheatre-shaped morphologies because the rate of progression is faster in the centre than on the sides.

When the breach reached the subaerial bank, blocks of sand started to fall, and the final scour had an amphitheatre shape at the top of the embankment. These 3D characteristics correspond well to the field observations.

The combination of 2D and 3D experiments are an efficient way to study breaching flow slides, and the $2 \mathrm{D}$ results can be seen to be representative of the centreline of a 3D failure. 

Chapter

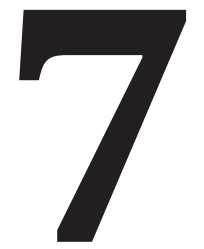

Synthesis

"Now this is not the end. It is not even the beginning of the end. But it is, perhaps, the end of the beginning."

- Winston Churchill (1874-1965) 


\subsection{Summary of the results}

The aim of this thesis was to gain a deeper understanding of flow slides (Fig. 7.1), focusing on embankment properties and their influence on the type of failure and evolution.

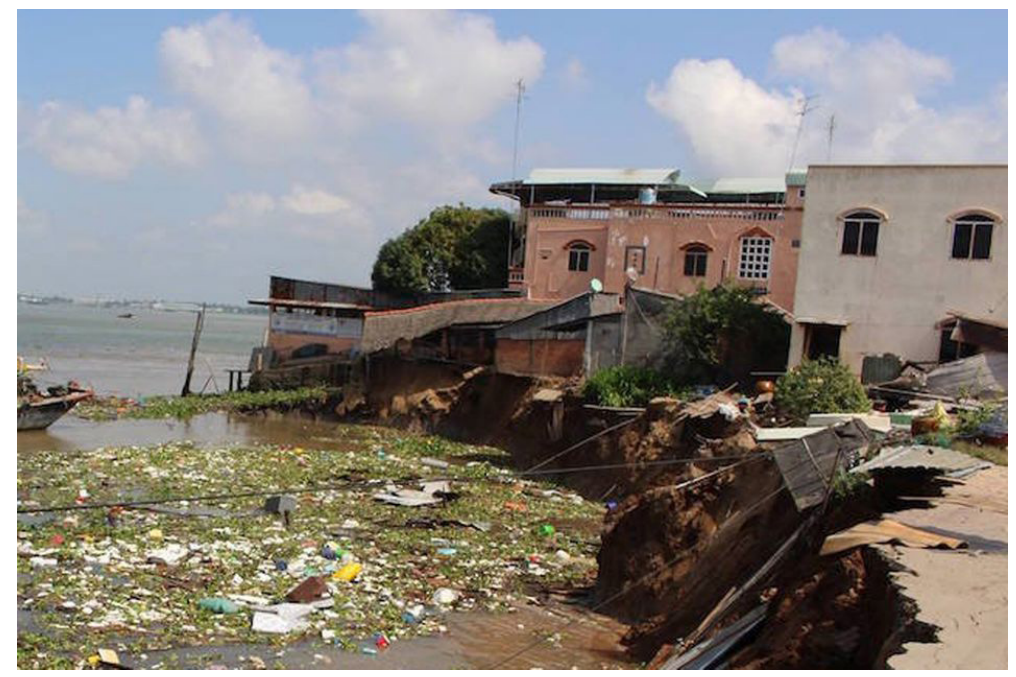

Figure 7.1: Bank collapse into Vam Nao river in An Giang, Vietnam, in April 2017 (photo via english. vietnamnet.vn).

A combination of different approaches was used in this thesis to study how flow slides depend on the embankment characteristics. In Chapter 3, 4, and 5, the main effect of the embankment properties was studied in a narrow "2D" flume tank, whereas in the experiment of Chapter 6 the sides of the wide embankment were not constrained by side walls.

The most important result from Chapter 3 is the hybrid failure, filling the gap between liquefaction and breaching. Whereas these two types of flow slide occur in loose and dense sands, respectively, the hybrid failure was identified at intermediate porosities. In the observed hybrid failures, the bottom of the deposit contracted and the top dilated, measuring positive and negative excess pore pressures, respectively. This means that the hybrid failure combines the two end-members, liquefaction and breaching, in one single failure.

Chapter 4 discussed the influence of the heterogeneity during a flow slide. Two 
1-centimetre thick layers of heterogenetic material were not sufficient to modify the general behaviour of a breaching failures in the sand deposit. The different hydraulic conductivities of the heterogenetic material caused only secondary effects on the spatial pore pressure structure. A non-uniform change of the normalised excess pore pressure along the height of the deposit (Christmas tree effect) was identified when hydraulic conductivity was smaller than sand. The silt and clay layers compartmentalised and isolated the thick sand thick layers, which each worked as an independent unit. The packing density was varied in a series with silt heterogeneity. The major control on failure style and evolution appeared to be the initial porosity, rather than the heterogeneity. Hybrid failures were also recognised in heterogeneous experiments at intermediate densities. These experiments resulted in multiple hybrid failures on top of each other in compartmentalised failures.

Chapter 3 and 4 showed that the initial porosity is the main control of a flow slide and the heterogeneity acts as a second control. Then the question arises, "what would happen in case of more and/or thicker heterogenous layers?". Certainly, in this case the role of the heterogeneity will be more dominant. Nevertheless, in a sand deposit with dimensions $0.40 \mathrm{~m}(\mathrm{~L}) \times 0.22 \mathrm{~m}(\mathrm{~W}) \times 0.40 \mathrm{~m}(\mathrm{H})$, the porosity is the main control on failure style and evolution.

Chapter 5 addressed the relation between breach evolution and strength of the turbidity current travelling into the basin. This was the first study with coeval measurements of breaching failure and generated turbidity current into the basin. The sliding wedges modified the characteristics of the turbidity current, causing pulses. When a wedge of sand slid, there was acceleration of the turbidity current and increase of the flow thickness. The sliding wedges from a breach failure are likely one of the mechanisms responsible for pulsed turbidite deposits.

The experiment in Chapter 6 was performed in a large basin. A small breaching flow slide was successfully created. Despite the small size of the event, the morphological aspects corresponded well to the field observations. Furthermore, the pore-pressure signature observed in 2D experiments when the breach face approaches and passes the measurement location was recognized here as well. The new insights in this chapter arise from the pore pressures measured at the sides of the breach, which in the narrow flume was not possible due to the confining walls. The lateral pressures are smoother and have a smaller amplitude. This explains the amphitheatre shape of observed breaches in nature, which is the result of smaller excess pressures to the side of the breach and slower progression relative to the higher excess pressures at the centreline of the breach that cause faster progression there. 


\subsection{Implications of this study for the research field}

\section{MPM-Flow project}

The combination of 2D and 3D experiments is an efficient way to study flow slides, in which case the $2 \mathrm{D}$ results are representative of the centreline of a 3D failure. Also, in the MPM-Flow project, experiments were performed in different scales. Said Alhaddad performed breaching experiments with a non-vertical initial breach height of $\sim 1.5 \mathrm{~m}$. He focused on the sand-water interface measuring the erosion rate, failure evolution, and velocity, and sediment concentration of the turbidity current travelling down the breach face. Marco Bolognin conducted field tests with SIBELCO in their sand quarries in Belgium. He acquired the bathymetry and pore pressure to monitor the slope failure.

Despite the large difference between the scale of our setups, the same phenomena and characteristics of flow slides were observed. During Said's experiments was also observed a slow retrogression of the breach face and the generation of a turbidity current and surficial slides. Moreover, for a sand deposit with an angle of $80^{\circ}$ and a minimum porosity, the retreat velocity of the breaching had an average of $2 \mathrm{~mm} / \mathrm{s}$, which is in line with the values presented in Chapter 3. In case of Marco's field tests, the final failures morphology had an amphitheatre shape also addressed in this thesis in Chapter 6. In addition, the pore pressure sensors recorded the peak of increased negative pressure when the failure surface was approaching the measurement location.

\section{Numerical modelling}

Measures to counteract flow slides are costly. Due to the severity of the consequences and costs for prevention measures, there is a need to improve existing models for prediction or estimation of the damage by flow slides. This will allow a much more refined and thus economical approach to maintenance and prevention works. The advantages of numerical analyses for solving practical problems have been recognised, and developments in software and hardware allow their application in practice with reasonable effort.

There is an increasing need for tighter integration between physical measurements and numerical simulations. An example is given below by Lisa Wobbes and me, where numerical results were compared with an experimental test (Wobbes et al., 2018; Fig. 7.2). Lisa numerically modelled static liquefaction with the double-point Material Point Method. I performed the experiment which consisted of a submerged column of loose sand with a length and height of $0.40 \mathrm{~m}$ and width of $0.22 \mathrm{~m}$. The numerical simulation of my experiment accurately captured its general evolution. However, the failure process progressed approximately 4 times faster during the MPM simulation than it was observed in 
the laboratory. Moreover, this rate-discrepancy turned out to be mesh-dependent, which is a problematic diagnostic for a numerical model.

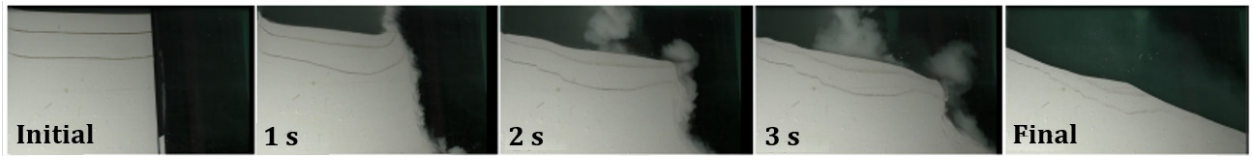

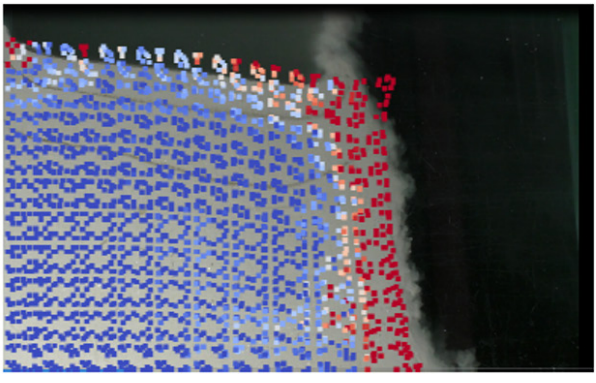

$t_{\text {exp }}=1 \mathrm{~s}, t_{\text {num }}=0.25 \mathrm{~s}$

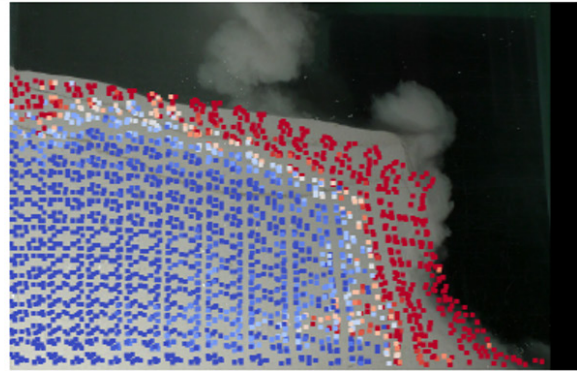

$t_{\text {exp }}=2 \mathrm{~s}, t_{\text {num }}=0.50 \mathrm{~s}$

Figure 7.2: Experimental results and a comparison with the numerical simulation; $t_{\text {exp }}$ denotes the experimental time, $t_{\text {num }}$ denotes the numerical time. The colour of the material points identifies the porosity varying from 0.49 (dark blue) to 0.52 (red) (Wobbes et al., 2018).

A numerical method should ideally be based on the physics and include models for geo- and fluid-mechanical processes of flow slides rather than only empirical relations. For instance, a more detailed integrated solution on soil-water interaction including erosion and sedimentation processes.

Following the results in this thesis, one of the key questions to be answered is whether slope failure by a flow slide is caused by breaching or liquefaction, since the initial porosity is the main control of a flow slide failure. This may be true for a section of the deposit, but in fact the porosity is not equal in the entire deposit. Natural deposits cannot be characterised by a single value of porosity. An inaccurate value can lead to underestimation of the risk that underwater flow slides pose to flood defences. That is, a wrong estimation of type of failure, breaching, liquefaction, or hybrid. Then the question arises "How does the packing density change with depth?". Site investigations are highly important to determine the profile of the natural soil deposits, to take soil samples and determine the mechanical properties of soils using laboratory tests. They aim to reduce the uncertainty of soil conditions by various combinations of field and laboratory testing. 
Another relevant aspect to investigate is whether a breach is stable or unstable. To answer this question, the characteristics of the generated turbidity current are very important. The characteristics of breach-induced turbidity currents and their deposits are important for predicting the impact of the breach failure and the geohazard they pose to the water defences. Here the technical challenge for numerical modelling is to integrate simulations of the turbidity current with simulations of the failing embankment. The characteristics of the turbidity current to study should be the velocity, how far does it travel and where does it deposit the sediment.

In order to make use of the numerical models, experimental data should be available for validation. The experiments should cover as many scenarios as possible. In this thesis, experiments were conducted with a sand deposit with different initial porosities, a deposit with different materials, and different angles in front of the deposit. In combination, previous experiments published in literature and the results presented in this thesis characterise small scale experiments in 2D flumes comprehensively. It would be worthwhile if future studies could be performed in 3D embankments, without confining side walls to have a clearer picture of what happens in natural systems. Preliminary work towards this new aim was presented in Chapter 6 of this thesis, which already yielded new insights about 3D flow slide evolution. 




\section{References}

Alhaddad, S., Labeur, R.J. \& Uijttewaal, W. 2020. Breaching Flow Slides and the Associated Turbidity Current. Journal of Marine Science and Engineering, 8(2), 67. doi. org/10.3390/jmse8020067

Altinakar, M.S., Graf, W.H., \& Hopfinger, E.J. 1996. Flow structure in turbidity currents. Journal of Hydraulic Research, 34, 713-718

ASTM D2487-11. 2011. Standard Practice for Classification of Soils for Engineering Purposes (Unified Soil Classification System), ASTM International, West Conshohocken, PA

Been, K., Conlin, B.H., Crooks, J.H.A., Fitzpatrick, S.W., Jefferies, M.G., Rogers, B.T. \& Shinde, S. 1987. Back analysis of the Nerlerk berm liquefaction slides: Discussion. Canadian Geotechnical Journal, 24, 170-179

Beinssen, K., Neil, D. \& Mastbergen, D. 2014. Field observations of retrogressive breach failures at two tidal inlets in Queensland, Australia. Australian Geomechanics, 49(3), $55-64$

Beiser, V., Dramatic Photos Show How Sand Mining Threatens a Way of Life in Southeast Asia, National Geographic, March 15, 2018, accessed September 18, 2019, https://www. nationalgeographic.com/news/2018/03/vietnam-mekong-illegal-sand-mining/

Bezuijen, A. \& Mastbergen, D.R. 1988. On the construction of sand fill dams, Part 2: soil mechanical aspects. In: Modelling soil-water structure interactions (Eds P.A. Kolkman and J. Lindenberg), pp. 363-371. Balkema, Rotterdam

Black, D. K., \& Lee, K. L. 1973. Saturating laboratory samples by back pressures. Journal Soil Mechanical and Foundation Engineering, 99(MSI), 75-93.

Bowles, J.E. 1979. Physical and Geotechnical Properties of Soil, McGraw-Hill Book Company 
Cartigny, M.J.B., Eggenhuisen, J.T., Hansen, E.W.M. \& Postma, G. 2013. Concentrationdependent flow stratification in experimental high-density turbidity currents and their relevance to turbidite facies models. Journal of Sedimentary Research, 83, 1046-1064, doi.org/10.2110/jsr.2013.71

Casagrande, A. 1936. Characteristics of cohesionless soils affecting the stability of earth fills. Journal of Boston Society of Civil Engineers, 23(1), 13-32

Castro, G. \& Poulos, S.J. 1977. Factors affecting liquefaction and cyclic mobility. Journal of Geotechnical Engineering, ASCE, 103, 501-516

Chillarige, A.R.V., Morgenstern, N.R., Robertson, P.K. \& Christian, H.A. 1997. Seabed instability due to flow liquefaction in the Fraser River delta. Canadian Geotechnical Journal, 34

Christian, H.A., Woeller, D.J., Rovertson, P.K. \& Courtney, R.C. 1997b. Site investigations to evaluate flow liquefaction slides at Sand Heads, Fraser River Delta. Canadian Geotechnical Journal, 34:384-397

Coleman, J.M. 1969. Brahmaputra River: channel processes and sedimentation. Sedimentary Geology, 3, 129-239

Coleman, S.E., Andrews, D.P. \& Webby, G.M. 2002. Overtopping breaching of non- cohesive homogeneous embankments, Journal of Hydraulic Engineering, 128, 829-838, doi: 10.1061/(ASCE)0733-9429(2002)128:9(829)

Daly, R.A. 1936. Origin of submarine canyons. American Journal of Science, s5-31, 401-420, doi.org/10.2475/ajs.s5-31.186.401

De Groot, M., Lindenberg, J., Mastbergen, D. \& Van den Ham, G. 2012. Large scale sand liquefaction flow slide tests revisited, in Eurofuge (Delft, the Netherlands) pp. 1-22

De Jager, R. R., Maghsoudloo, A., Askarinejad, A. \& Molenkamp, F. 2017. Preliminary results of instrumented laboratory flow slides. In A. Rohe, K. Soga, H. Teunissen, \& B. Zuada Coelho (Eds.), Proceedings of the 1st International Conference on the Material Point Method, 212-219. doi: 10.1016/j.proeng.2017.01.012 
Deltares.2016. Sedimentatiepatronen Plaat van Walsoorden na plaatval 22 Juli 2014, 1220094

Dengler, A. T. \& Wilde, P. 1987. Turbidity currents on steep slopes: application of an avalanche-type numeric model for ocean thermal energy conversion design. Ocean Engineering (Pergamon), 14(5), 409-433

Dunbar, J.B., Torrey, V.H. \& Wakeley, L.D. 1999. A case history of embankment failure: geological and geotechnical aspects of the Celotex levee failure, New Orleans, Louisiana, US Army Corps of Engineers Vicksburg, MS

Duncan, J. M., Wright, S. G. \& Brandon, T. L. 2014. Soil strength and slope stability, 2nd edition, John Wiley \& Sons Inc

Eggenhuisen, J.T. \& McCaffrey, W.D. 2012. Dynamic deviation of fluid pressure from hydrostatic pressure in turbidity currents. Geology, 40, 295-298, doi:10.1130/ G32627.1

Eggenhuisen, J. T., Tilston, M. C., de Leeuw, J., Pohl, F. \& Cartigny, M.J.B. 2019. Turbulent diffusion modelling of sediment in turbidity currents; an experimental validation of the Rouse approach. The Depositional Record. 1-14. doi.org/10.1002/dep2.86

Eke, E., Viparelli, E. \& Parker, G. 2011. Field-scale numerical modeling of breaching as a mechanism for generating continuous turbidity currents. Geosphere, 7(5),10631076

Estourgie, A. L. P. 1988. Theory and practice of water injection dredging. Terra et Aqua, The Hague, The Netherlands, 38, 21-28

Felix, M., Sturton, S. \& Peakall, J. 2005. Combined measurements of velocity and concentration in experimental turbidity currents. Sedimentary Geology. 179, 31-47, doi:10.1016/j. sedgeo.2005.04.008

Garcia, M. H. 1992. Turbidity currents. Encyclopedia of earth systems science. Academic Press, San Diego, Calif., 4, 399-408 
Garcia, M.H. 1994. Depositional turbidity currents laden with poorly sorted sediment. Journal of Hydraulic Engineering, 120, 1240-1263

Gray, T.E., Alexander, J. \& Leeder, M.R. 2005. Quantifying velocity and turbulence structure in depositing sustained turbidity currents across breaks in slope. Sedimentology, 52, 467-488, doi.org/10.1111/j.1365-3091.2005.00705.x

Hampton, M. A., Lee, H.J. \& Locat, J. 1996. Submarine landslides, Reviews of Geophysics, 34(1), 33-59

Hay, A. E. 1987. Turbidity currents and submarine channel formation in Rupert Inlet, British Columbia, 2. The roles of continuous and surge-type flow. Journal of Geophysical Research, 92(3), 2883-2900

Iverson, R., Reid, M., Iverson, N., LaHusen, R., Logan, M., Mann, J., \& Brien, D. 2000, Acute sensitivity of landslide rates to initial soil porosity: Science, 290, 513-516, doi:10.1126/science.290.5491.513

Jefferies, M. \& Been, K. 2006. Soil liquefaction: a critical state approach (Taylor \& Francis)

Kneller, B., Bennett, S. \& McCaffrey, W.D. 1999. Velocity structure, turbulence and fluid stresses in experimental gravity currents. Journal of Geophysical Research. 104. 5381-5391. 10.1029/1998JC900077

Kneller, B. \& Buckee, C. 2000. The structure and fluid mechanics of turbidity currents: a review of some recent studies and their geological implications. Sedimentology, 47, 62-94. doi.org/10.1046/j.1365-3091.2000.047s1 062.x

Kneller, B.C. \& McCaffrey, W.D. 2003. The interpretation of vertical sequences in turbidite beds: The Influence of Longitudinal Flow Structure. Journal of Sedimentary Research, 73, 706-713, doi.org/10.1306/031103730706

Kramer, S.L. 1988. Triggering of liquefaction flow slides in coastal soil deposits. Engineering Geology, 26, 17-31 
Koppejan, A.W.; Van Wamelen, B.M.; Weinberg, L.J.H. 1948. Coastal Flow Slides in the Dutch Province of Zeeland. In Proceedings of the 2nd International Conference on Soil Mechanics and Foundation Engineering, Rotterdam, The Netherlands, 21-30 June 1948; 13, 89-96

Kostaschuk, R., Nasr-Azadani, M., Meiburg, E., Wei, T., Chen, Z., Negretti, M.E., Best, J., Peakall, J. \& Parsons, D.R. 2018. On the causes of pulsing in continuous turbidity currents. Journal of Geophysical Research: Earth Surface. 123 (11), 2827-2843

Lade, P.V. 1992. Static instability and liquefaction of loose fine sandy slopes. Journal of Geotechnical Engineering, 118(1), 51-71

Lambert, A. 1982. Turbidity currents from the Rhine river on the bottom of Lake Constance, Wasserwirtschaft, 72(4), 1-4

Launder, B.E. \& Rodi, W. 1983. The Turbulent Wall Jet Measurements and Modelling. Annual Review of Fluid Mechanics, 15, 429-459, doi.org/10.1146/annurev. fl.15.010183.002241

Laury, R.L. 1971. Stream bank failure and rotational slump: preservation and significance in the geologic record. Geological Society of America Bulletin, 82: 1251-1266.

Martinius, A.W. \& Van den Berg, J.H. 2011. Atlas of Sedimentary Structures in Estuarine and TidallyInfluenced River Deposits of the Rhine-Meuse-Scheldt System. EAGE Publications BV, Houten

Mastbergen, D. R. \& Van den Berg, J. H. 2003. Breaching in fine sands and the generation of sustained turbidity currents in submarine canyons. Sedimentology, 50(4), 625-637

Mastbergen, D., Van den Ham, G., Cartigny, M., Koelewijn, A., De Kleine, M., Clare, M., Hizzett, J., Azpiroz, M. \& Vellinga, A. 2016. Multiple flow slide experiment in the Westerschelde Estuary, The Netherlands. In Submarine Mass Movements and Their Consequences. Adv. in Nat. and Techn. Hazards Res.; Lamarche, G., Mountjoy, J., Bull, S., Eds.; Springer: Cham, Switzerland; 41, 241-252 
Mastbergen, D., Beinssen, K. \& Nédélec, Y. 2019. Watching the Beach Steadily Disappearing: The Evolution of Understanding of Retrogressive Breach Failures. Journal of Marine Science and Engineering. 7, 368

McKenna, G.T., Luternauer, J.L. \& Kostaschuk, R.A. 1992. Large-scale mass-wasting events on the Fraser River delta front near Sand Heads. Canadian Geotechnical Journal, 29, 151-156

Meijer, K.L. \& van Os, A. G. 1976. Pore pressures near moving underwater slope. Journal of the Geotechnical Engineering Division, 102, 361-372

Middleton, G.V. 1993. Sediment deposition from turbidity currents. Annu. Rev. Earth Planet. Sci., 21, 89-114

Mitchell, N. 2014. Bedrock erosion by sedimentary flows in submarine canyons. Geosphere. 10. 892-904. 10.1130/GES01008.1

Mulilis, J.P., Townsend, F.C., \& Horz, R.C. 1978. Triaxial Testing Techniques and Sand Liquefaction. ASTM STP 654, Dyn. Geotech. Test., 265-279

Parker, G. 1982. Conditions for the ignition of catastrophically erosive turbidity currents. Marine Geology, 46, 307-327

Parker, G., \& Fukushima, Y., \& Pantin, H.M. 1986. Self-accelerating turbidity currents. Journal of Fluid Mechanics. 171, 145-181. doi: 10.1017/S0022112086001404

Pohl, F., Eggenhuisen, J.T., Cartigny, M.J.B., Tilston, M., de Leeuw, J. \& Hermidas, N. 2020. The influence of a slope break on turbidite deposits: An experimental investigation. Marine Geology. 106160. 10.1016/j.margeo.2020.106160

Reynolds, 0. 1885. On the dilatancy of media composed of rigid particles in contact. Philosophical Magazine, 5(20), 469-481

Reynolds, W.D., D.E. Elrick, E.G. Youngs, A. Amoozegar, H.W.G. Booltink, \& J. Bouma. 2002. Saturated and field-saturated water flow parameters. In: J.H. Dane and G. Topp, editors, Methods of soil analysis. Part 4. Physical methods. SSSA Book Ser. 5. SSSA, Madison, WI. 797-801. doi:10.2136/sssabookser5.4.c30 
Rijkswaterstaat. 2014. Memo: Plaatval dd '22 juli 2014' plaat van Walsoorden/Valkenisse. Middelburg

Roscoe, K. H., Schofield, A. N., \& Wroth, C. P. 1958. On the yielding of soils. Géotechnique, 8(1), 22-52. doi:10.1680/geot.1958.8.1.22

Sequeiros, O.E., Mosquera, R. \& Pedocchi, F. 2018. Internal Structure of a SelfAccelerating Turbidity Current. Journal of Geophysical Research: Oceans, doi. org/10.1029/2018JC014061

Seymour, R. J. 1986. Nearshore auto-suspending turbidity flows. Ocean Engineering Journal, $13,435-447$

Silvis, F. \& De Groot, M.D. 1995. Flow slides in the Netherlands: experience and engineering practice. Canadian Geotechnical Journal, 32, 1086-1092

Simpson, J. E. 1982. Gravity currents in the laboratory, atmosphere and ocean. Ann. Rev. Fluid Mech., 14, 213 - 234

Skempton, S.A. 1954. The pore pressure coefficients A and B. Géotechnique, 4(4), 143-147. doi:10.1680/geot.1954.4.4.143

Stafleu, J., Maljers, D., Gunnink, J., Menkovic, A. \& Busschers, F. 2011. 3D modelling of the shallow subsurface of Zeeland, the Netherlands. Netherlands Journal of Geosciences - Geologie En Mijnbouw, 90(4), 293-310. doi:10.1017/S0016774600000597

Stafleu, J. \& Gunnink, J. 2016. Hydraulische parameterisering van GeoTOP Zeeland. TNOrapport, TNO 2016 R11068

Stevenson, C.J., Jackson, C.A.-L., Hodgson, D.M., Hubbard, S.M. \& Eggenhuisen, J.T. 2015. DeepWater Sediment Bypass. Journal of Sedimentary Research, 85, 1058-1081. doi. org/10.2110/jsr.2015.63

Stoutjesdijk, T.P., De Groot, M.B. \& Lindenberg, J. 1994. Engineering Approach to Coastal Flow Slides, Proceedings of the 24th International Conference on Coastal Engineering, Kobe, Japan, 3350-3359 
Straub, K.M., Mohrig, D., McElroy, B., Buttles, J. \& Pirmez, C. 2008. Interactions between turbidity currents and topography in aggrading sinuous submarine channels: a laboratory study. Geological Society of America Bulletin, v. 120, p. 368-385. doi:10.1130/B25983.1

Stretch, D. \& Parkinson, M. 2006. The breaching of sand barriers at perched, temporary open/closed estuaries-A model study, Coastal Engineering Journal, 48, 13-30. doi: $10.1142 /$ S0578563406001295

Talling, P.J., Allin, J., Armitage, D.A., Arnott, R.W.C., Cartigny, M.J.B., Clare, M.A., Felletti, F., Covault, J. A., Girardclos, S., Hansen, E., Hill, P.R., Hiscott, R.N., Hogg, A.J., Clarke, J.H., Jobe, Z.R., Malgesini, G. \& Mozzato, A. 2015. Key future directions for research on turbidity currents and their deposits. Journal of Sedimentary Research, 85, 153 169. https://doi.org/10.2110/jsr.2015.03

Terzaghi, K. 1957. Varieties of submarine slope failures. Publication of Norwegian Geotechnical Institute, 25, 1-16

Terzaghi, K., Peck, R.B. \& Mesri, G. 1996. Soil Mechanics in Engineering Practice, $3^{\text {rd }}$ edition, John Wiley and Sons Inc.

Thomson, A.K. (Ed). 1967. The Collected Works of Thomas Welsby, II, Jacaranda Press Pty. Ltd., Brisbane

Torrey III, V., Dunbar, J. \& Peterson, R. 1988. Retrogressive failures in sand deposits of the Mississippi River. Report 1. Field investigations, laboratory Studies and analysis of the hypothesized failure mechanism, Tech. Rep. (US Army Engineer Division)

Van den Berg, J.H., Van Gelder, A. \& Mastbergen, D. R. 2002. The importance of breaching as a mechanism of subaqueous slope failure in fine sand. Sedimentology, 49, 81-95

Van den Berg, J.H., Martinius, A.W. \& Houthuys, R. 2017. Breaching-related turbidites in fluvial estuarine channels: examples from outcrop and core and implications to reservoir models. Marine and Petroleum Geology. 82: 178-205 
Van den Ham, G.A., Mastbergen, D.R., Koelewijn, A.R., Ter Brake, C.K.E. \& Zomer, W.S. 2015. Eindrapport Validatie-Experiment Zettingsvloeiing, Meten aan Zettingsvloeiing, Amersfoort: STOWA- Flood Control IJkdijk. Available online: https://www.stowa. $\mathrm{nl} /$ sites/default/files/assets/PUBLICATIES/Publicaties\%202015/STOWA\%20 2015-08.pdf

Van Dijk, W. M., Mastbergen, D. R., Van de Ham, G. A. \& Kleinhans, M. G. 2018. Location and probability of shoal margin collapses in a sandy estuary. Earth Surface Processes and Landforms, 43, 2342-2357. doi.org/10.1002/esp.4395

Van Dijk, W., Hiatt, M., van der Werf, J. \& Kleinhans, M.G. 2019. Effects of Shoal Margin Collapses on the Morphodynamics of a Sandy Estuary. Journal of Geophysical Research: Earth Surface. 124. 10.1029/2018JF004763

Van Duinen A., Bezuijen A., Van den Ham G.A. \& Hopman V. 2014 Field measurements to investigate submerged slope failures. In: Submarine mass movements and their consequences, 6th Int. Symp., Kiel. Springer, 13-21

Van Rhee, C. \& Bezuijen, A. 1998. The breaching of sand investigated in large-scale model tests, Proceedings of the International Coastal Engineering Conference. Cph. Am. Soc. Civ. Eng. 3, 2509e2519. dx.doi.org/10.1061/9780784404119.189

Van Rhee, C. 2015. Slope failure by unstable breaching. Proceedings of the Institution of Civil Engineers Maritime Engineering. Vol. 168(2) Thomas Telford Ltd, pp. 84-92

Van Rhee, C. 2016. Slope Failure by Unstable Breaching-A Sensitivity Analysis. In Proceedings of the WODCON XXI, Miami, FL, USA, 13-17

Visser P.J. 1998. Breach growth in sand-dikes. Communications on Hydraulic and Geotechnical Engineering, Rep.98-1, Fac. Civil Eng. Delft Univ.Techn., Delft, The Netherlands

Weij, D., Keetels, G.H., Goeree, J. \& Van Rhee, C. 2016. An approach to research of the breaching process, In Proceedings of the WODCON XXI, Miami, FL, USA, 13-17 June

Wilderom N.H. 1979. Resultaten van het vooroeveronderzoek langs de Zeeuwse stromen. Rijkswaterstaat, Report 75.2, Rijkswaterstaat, Vlissingen, The Netherlands 
Wobbes, E. D., Silva, J.R., Galavi, V., Eggenhuisen, J.T. \& Vuik, C. 2018. Numerical simulation and verification of static liquefaction using the Material Point Method. 4th International Symposium on Computational Geomechanics (ComGeo IV), Assisi, Italy, 2-4 May

Wobbes, E.D. 2019. Algorithmic Improvements of the Material-Point Method and Taylor Least-Squares Function Reconstruction, PhD thesis, Delft University of Technology

You, Y., Flemings, P. \& Mohrig, D. 2012. Dynamics of dilative slope failure. Geology, 40(7), 663-666

You, Y. 2013. Dynamics of dilative slope failure. PhD thesis, The University of Texas at Austin

You, Y., Flemings, P. \& Mohrig, D. 2014a. Mechanics of dual-mode dilative failure in subaqueous sediment deposits. Earth Planet. Science Letters, 397, 10-18. dx.doi.org/10.1016/j. epsl.2014.04.024

You, Y., Flemings, P., Mohrig, D., \& Germaine, J. 2014b. How heterogeneity in the shear dilation of a deposit controls the mechanics of breaching slope failure. Journal of Geophysical Research: Earth Surface, 119(11):2381-2395

Zhuang, L., Bezerra Coelho, C.R., Hassanizadeh, S. M. \& van Genuchten, M. Th. 2017. Analysis of the hysteretic hydraulic properties of unsaturated soil. Vadose Zone Journal, 16(5). doi:10.2136/vzj2016.11.0115 




\section{Summary}

Flow slides are underwater slope failures that occur in fine sandy deposits at many river and coastal locations. They occur when large amounts of sediment move down an underwater slope in a relatively short time. This can be triggered by a variety of factors including erosion by tidal flow, local changes in water pressure, or human interventions such as dredging. Flow slides can remove an entire dike or dune section, which poses a severe threat to flood defences and human life (Fig. S.1). In the Netherlands there is much research on this subject because two thirds of the country are vulnerable to flooding.

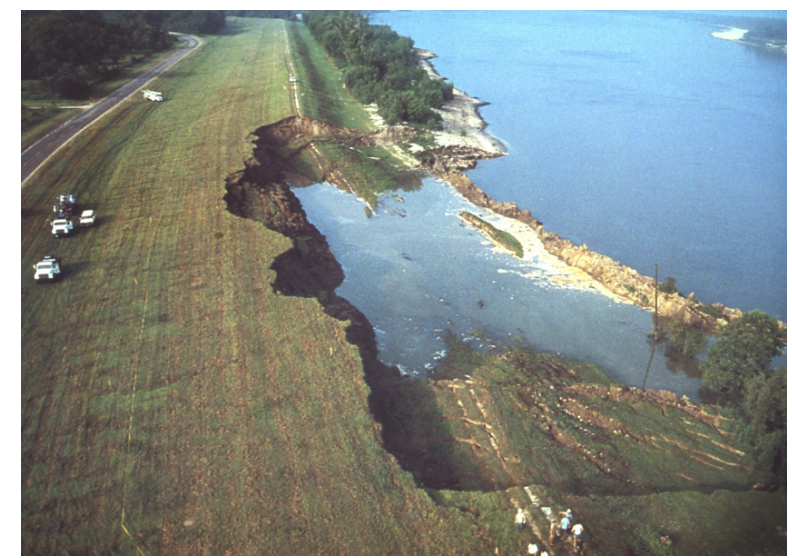

Figure S.1: Dike failure into the Mississippi River due to a flow slide in 1983 (photo: U. S. Army Corps of Engineers).

Two types of flow slides are recognised in literature: breaching and liquefaction. The occurrence of both types of failure have similar final conditions but the development and the processes of sand transport after the initial failure are quite distinct. The first type, breaching, occurs in densely packed sand and it is characterised by slow release of sand grains during dilation of the failing sediment and negative excess pore pressures. In contrast, the second type, liquefaction, is the process where a mass of soil suddenly starts behaving like a viscous fluid, so that it is able to flow out over very gentle slopes. It is triggered in loose sand and associated with contraction and positive excess pore fluid pressures. 
Despite the case histories of known flow-slide events, the processes operating during an active flow slide are not well understood. Flow slides are difficult to observe and monitor: the events start underwater and are only noticed once the failure reaches the subaerial bank. For this reason, though the final geometries of the flow slides are well known, the trigger mechanism and the actual development of the slides over time have seldom been witnessed.

This dissertation provides a deeper understanding of flow-slide processes, focusing on the properties of embankments and their influence on the type of failure. This aim was accomplished using different approaches, a 2D flume tank and the Eurotank basin, demonstrating, and quantifying the processes that contribute to the phenomenon.

The first and most important parameter studied in the 2D flume tank is the initial porosity. Previous laboratory tests reproduced in flume tanks approach the two flow-slide end-members (i.e., breaching and liquefaction) by using a very loose or very dense packing density of the sediment. However, these experiments did not simulate what happens at intermediate packing densities. Besides the characteristics of the two end-member failure types, a new type of failure, hybrid failure, is described at intermediate porosities.

The influence of heterogenetic deposits on flow slides is also addressed in this thesis. Under natural conditions the deposits are rarely homogeneous. For instance, soil analysis from a field test on the Walsoorden tidal shoal (Westerschelde, the Netherlands) revealed a uniform fine sand with low clay content, and some loosely packed sand layers at certain depth, which is not coherent with the simplifications considered in most models and laboratory tests. Since this study is strongly driven by the water motion and its interaction with soil surface, materials with different permeabilities were chosen to test the effect of heterogeneity on flow slide evolution. The results show that heterogeneity causes secondary effects such as larger pore pressure excursions, pressure compartmentalisation, and slightly faster retreat rates, with the porosity being the main control on flow slide failure style.

The last analysis carried out in the 2D flume tank concerned the relation between breaching failure evolution and strength of the turbidity current travelling into the basin. Breaching flow slides are a common occurrence on continental margins and may be one of the processes by which sands are released into turbidity currents. Results provided in this thesis show that breaching flow slides strongly affect the characteristics of a turbidity current and play a significant role in their evolution. In particular, sand wedges sliding from the breach can be recognised as pulses on the turbidity current.

Finally, this thesis provides results from a breaching failure in an unconfined 3D embankment. Although tests in 2D flumes can provide valuable outcomes, some important phenomena may be distorted due to the lateral confinement. Therefore, 3D tank models are required as a next step for accurate reproduction of flow slide phenomena. The outcomes 
show that the $2 \mathrm{D}$ results can be seen to be representative of a $3 \mathrm{D}$ failure and the $3 \mathrm{D}$ characteristics correspond well to field observations. A different pressure distribution is observed on the sides of the breach, and this difference between the centre part and the side of the breach provides a new explanation for the amphitheatre-shaped morphologies observed in nature. 



\section{Samenvatting}

Verschuivingen van onderwatertaluds komen veel voor in fijne zandafzettingen op rivier- en kustlocaties. Tijdens deze verschuivingen worden grote hoeveelheden sediment in relatief korte tijd langs een onderwaterhelling naar beneden getransporteerd. Deze verschuivingen kunnen worden veroorzaakt door verschillende factoren, waaronder erosie door getijdenstroom, lokale veranderingen in de waterdruk, of menselijke ingrepen zoals baggeren. Een enkele verschuiving kan een hele dijk- of duinsectie verwijderen, wat een ernstige bedreiging vormt voor de waterkeringen en het menselijk leven (Fig. S.1). In Nederland wordt veel onderzoek gedaan naar onderwatertaludverschuivingen omdat tweederde van het land kwetsbaar is voor overstromingen.

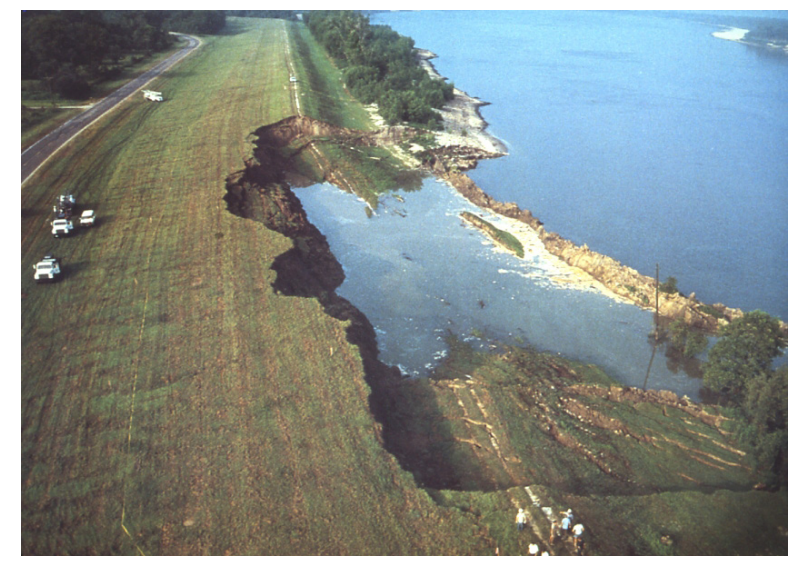

Figuur S.1: Taludverschuiving die heeft geleid tot dijkverzakking in de Mississippi in 1983 (foto: U. S. Army Corps of Enginers).

In de literatuur worden twee soorten verschuivingen herkend: bresvloeiingen en verwekingsvloeiingen. Het optreden van beide soorten verschuivingen heeft vergelijkbare eindresultaten, maar de ontwikkeling en de processen van zandtransport g zijn totaal verschillend. Het eerste type, bresvloeiing, komt voor in dicht opeengepakt zand en wordt gekenmerkt door langzame afgifte van zandkorrels tijdens dilatatie van het verschuivende sediment, gepaard met onderdruk in het poriewater. Het tweede type, verwekingsvloeiing, 
is daarentegen een proces waarbij een massa sediment zich plotseling gaat gedragen als een stroperige vloeistof, zodat deze over zeer vlakke hellingen kan stromen. Verwekingsvloeiingen vinden plaats in los zand en zijn geassocieerd met contractie gepaard met overdruk in het poriewater .

Ondanks de casuïstiek van bekende taludverschuivingen, zijn de processen die tijdens een verschuiving plaatsvinden niet goed begrepen. De verschuivingen zijn namelijk moeilijk te observeren en te volgen: de gebeurtenissen beginnen onder water en worden pas opgemerkt als ze een tijd later de oever bereikt. Om deze reden zijn, hoewel de uiteindelijke geometrieën van de verschuvingen bekend zijn, het triggermechanisme en de feitelijke ontwikkeling van de verschuvingen in de tijd zelden waargenomen.

Dit proefschrift geeft een dieper inzicht in de processen die optreden tijdens het verschuiven van onderwatertaluds, waarbij de nadruk ligt op de eigenschappen van taluds en hun invloed op het type verschuiving (bresvloeiing en verwekingsvloeiing). Dit doel werd bereikt met behulp van verschillende experimentele benaderingen in een 2D-stroomgoot en het Eurotank-bekken, waarbij de processen die bijdragen aan het fenomeen worden gedemonstreerd en gekwantificeerd.

De eerste en belangrijkste parameter die in de stroomgoot wordt bestudeerd, is de initiële porositeit. Eerdere laboratoriumtests in stroomgoten bestudeerden vervloeiingen bij een zeer losse of zeer dichte pakkingsdichtheid van het sediment. De experimenten die in dit proefschrift worden gepresenteerd simuleerden echter ook wat er gebeurt bij tussenliggende pakkingsdichtheden, die veel vaker in de natuur voorkomen. Naast de kenmerken van de twee typen bekende verschuivingen, wordt een nieuw type verschuiving, hybride verschuiving, beschreven bij intermediaire porositeiten.

De invloed van heterogene afzettingen op taludverschuivingen komt ook aan bod in dit proefschrift. Onder natuurlijke omstandigheden zijn de afzettingen zelden homogeen. Zo wedr bij een bodemanalyse voor een grootschalige veldtest op de Plaat van Walsoorden (Westerschelde, Zeeland) een fijn zand pakket aangetroffen met enkele klei laagjes en enkele losser gepakte zandlagen, wat niet strookt met de vereenvoudigingen tot een homogeen pakket die in de meeste modellen en laboratoriumtesten wordt toegepast. Omdat in deze studie wordt herkend dat de verschuivingen sterk worden bepaald door waterstroming in het verschuivende talud, is gekozen voor het toepassen van heterogeniteit doormiddel van het aanbrengen van materialen met verschillende permeabiliteit. De resultaten laten zien dat heterogeniteit het verloop van de vervloeiingen beinvloed, maar niet in die mate dat het beeld gebaseerd op de controlerende werking van de prorositeit noemenswaardig moet worden aangepast.

De laatste analyse die in de stroomgoot is uitgevoerd, is de correlatie tussen bresvloeiing en de sterkte van de troebelheidsstroom die het bekken in stroomt. 
Bresvloeiingen komen veel voor op continentale marges en kunnen een van de processen zijn waardoor zand in troebelheidsstromen ver de zee in stroomt. De resultaten in dit proefschrift laten zien dat bresvloeiingen de eigenschappen van een troebelheidsstroom sterk beïnvloeden en een belangrijke rol spelen in hun evolutie. Met name het loskomen van blokken zand is te herkennen als pulsen in troebelheidsstroom.

Ten slotte presenteert dit proefschrift de resultaten van een verschuivingstest in groter experimenteel bekken waarin de verschuiving van het talud niet door de zijwanden van de opstelling wordt beinvloed. Hoewel eerdere tests in 2D-meetgoten waardevolle resultaten hebben opgeleverd, kunnen sommige belangrijke verschijnselen worden vervormd vanwege de interactie met de zijwanden. Daarom zijn experimenten in grotere bekkens vereist als volgende stap voor een nauwkeurige reproductie van taludverschuivingen. De uitkomsten laten zien dat de stroomgootresultaten representatief zijn voor de middenlijn van de 3D-verschuiving en dat de 3D-kenmerken goed overeenkomen met veldwaarnemingen. Aan de zijkanten van de verschuivingen wordt een andere drukverdeling waar genomen, en het verschil tussen de middenlijn en de zijkant van de verschuiving geeft een nieuwe verklaring voor de karakteristieke schelpvorm van taludverschuvingen in de natuur. 



\section{Acknowledgements}

What a journey this has been, and it went so much faster than I expected it to. I remember my first days in Utrecht as if it were today. Four years flew by. Despite the initial tears and the distance from those I love, I am glad to say I have taken the right path.

At the end of this thesis, I would like to thank all the people who have contributed to my research project, for which I am sincerely grateful.

First, I want to express my gratitude to my daily supervisor Joris Eggenhuisen. During the selection process for this project, I was so nervous for the first (Skype) interview that I forgot the time zone and missed it. And later, after the presential interview, I was secretly wishing to be selected and move to the Netherlands. His enthusiasm for research was contagious and motivational for me. Our Friday meetings were a renewal of ideas and an encouragement to keep the project on track. I appreciate all his contributions of feedback and advice to make my $\mathrm{PhD}$ experience productive and stimulating.

I thank my promotor Jack Middelburg for his support during this project.

It is always comforting to have someone who speaks your mother tongue and who shares the same culture as you. I thank João Trabucho Alexandre, my co-supervisor, for listening to my despairs, for his insightful suggestions during my $\mathrm{PhD}$, and for commenting on some chapters of this thesis. Moreover, João helped me with administrative issues that a new citizen must deal with. I will always have in my mind our lunches in the Educatorium. I have learnt a lot from you about so many different topics during our meals.

A special thanks goes to Poppe de Boer for his time and effort in reading and commenting on this thesis over the last weeks before the submission.

Furthermore, I thank the members of my doctoral committee, Prof. Elisabeth Bowman, Prof. Maarten Kleinhans, Prof. David Mohrig, Prof. Wim Uijttewaal, and Prof. Phil Vardon for reading this dissertation and taking part in the defence.

My colleagues of the MPM-Flow project, Said Alhaddad, Marco Bolognin and Lisa Wobbes, are also thanked for the discussions and their constructive criticism. Lisa, my colleague and friend, it was an honour to be your paranymph. Despite our different backgrounds, we could understand each other and it was easy to work with you.

I thank Gerard Kruse for introducing me to the Deltares community and for his suggestions and advices on the soil mechanics component.

The experiments presented in this thesis had technical support from several people. Thony van der Gon Netscher helped in the first setup and ordering material. His 
assistance was essential to start the experiments. The setting and calibration of the pore pressures transducers were supported by the late Henk van der Meer, whose contribution was fundamental for most of the results in this thesis. Han Witte helped in the construction of the fluidisation device and in setting up the experiment in the big tank in Chapter 6. The pumps were against us but we finally got the experiment to work. The pressure transducers wanted a break and started giving some strange signals. Bas van Dam assisted me on solving the problem and in setting up the pore pressure measurements in the big tank. His expertise helped me in the last sprint of the experiments.

During my project, I met nice people in Deltares (Delft) who helped me in several aspects. Rob Zwaan advised me on pressure transducers and ways I could use them in my experiments. Ferry Schenkeveld made compaction technics clear to me, as well as procedures for sand characterisation tests. And Aad Oosterom and Max Zuidhoek helped me carry out triaxial tests. Thank you all!

I thank my colleagues at the Sedimentology Group in Utrecht for joining me on this journey and for showing me what geology really is. (I'm an engineer!) Jan de Leeuw, Florian Pohl, Yvonne Spychala and Mike Tilston, thanks a lot for your company and interest in my work. Thank you, Yvonne, for introducing me to the British Sedimentological Research Group community and answering my calls for help in the lab. Mike introduced me to MATLAB and showed how useful and complicated it can be. Thanks for fixing my code mistakes and explaining me all UVP (Ultrasonic Velocity Profiler) features. Florian and I shared the office in the last two years, so we were paying close attention to each other's work. Thank you for your opinions and reflections on my experiments. Your pragmatical way of answering my impasses showed me that I was complicating too much. Additionally, thank you for your comments on two chapters of this thesis. Finally, I thank Tjitske Vos for all the extra work she had dealing with the bureaucracy of my project and sending out my expenses.

When you move to other country, your flatmates are your second family. Many thanks to my Vlasstraat (ex-)flatmates, Laura Giannino, Viviana Neviani and Yulia Shcherbakova for all great times together. Your help and guidance were essential to start my new life in the Netherlands. Laura G., thank you for organising the barbeques and dinners. Also, thank you for all the nice conversations about life (some of them in Portuguese). Vivi, you are a great cook and I will never forget your delicious cakes and cookies. Thanks for all the chats during dinner after a workday and the movies we watched in the living room. Our Friday lunches at Jazzmans Café with Laura Tadé were a nice way to keep in touch and share our feelings, concerns, as well as important achievements and decisions. Thanks for always being there for me when I needed and for sharing your lives with me. Laura T., the ING (International Neighbour Group) drinks on Wednesdays were a success, which unfortunately with the progress of our $\mathrm{PhD}$ we missed more and more. I will always remember our chats 
accompanied by some beers and snacks at Tilt Café.

My family and friends in Portugal are the reason I keep going back to see them. I love spending my time with you, most of it at the table listening to your big news and sharing my own adventures.

I am deeply grateful to Carlos for all his support and positivity during my $\mathrm{PhD}$ project. You calmed me down when I was stressed out and you listened to my endless complaints and struggles. Furthermore, being at home in the middle of a pandemic while I was finishing my thesis was not easy at all. There are no words to thank you for crossing the borders and being by my side, no matter what and where. I am looking forward to seeing what life has reserved for us.

Por fim, não poderia deixar de agradecer ao meu Pai e à minha Mãe, a quem dedico esta dissertação. Agradeço o apoio incondicional em todas as etapas da minha vida, a certeza do certo nas horas mais incertas. São o exemplo de dedicação absoluta e de bons valores. Que esta dissertação seja uma conquista para mim e um motivo de orgulho para vocês. 



\section{Curriculum Vitae}

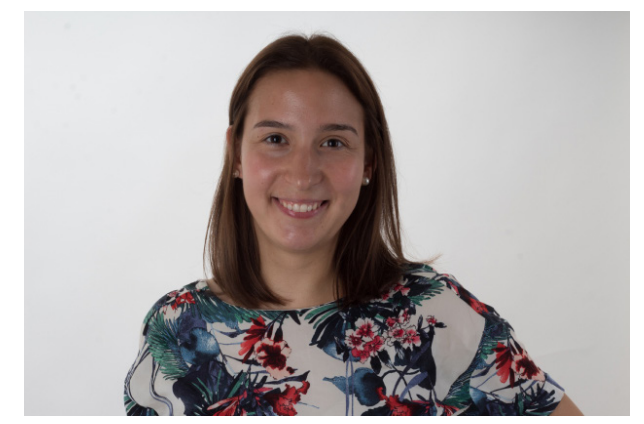

Joana Silva was born in Lisbon (Portugal) on June $24^{\text {th }}, 1989$. She grew up in Figueira da Foz and attended the Lyceum there.

After completing the secondary school in 2007, she started studying Civil Engineering at the Faculty of Sciences and Technology of the University of Coimbra. In 2015, she obtained her MSc degree and for her MSc thesis she performed numerical analysis of $1 \mathrm{G}$ tests on a reduced model of direct foundations. From June 2015 she did an internship in the area of energy certification with the duration of seven months.

Joana started her PhD at the Department of Earth Sciences at Utrecht University in February 2016. Additionally, she was teaching assistant during various courses. 



\section{List of publications}

\section{Peer reviewed conference proceedings:}

Silva, J. \& Eggenhuisen, J.T. 2019. Submarine slope failure with hybrid dilative-contractional behaviour. 2nd International Conference on Natural Hazards \& Infrastructure (ICONHIC 2019), Chania, Greece, 23-26 June

Wobbes, E. D., Silva, J., Galavi, V., Eggenhuisen, J.T. \& Vuik, C. 2018. Numerical simulation and verification of static liquefaction using the Material Point Method. 4th International Symposium on Computational Geomechanics (ComGeo IV), Assisi, Italy, 2-4 May 